\title{
Schooling despite all odds
}

Citation for published version (APA):

Yamba, B. (2017). Schooling despite all odds: evidence from Lesotho on female child careers who stayed in school. [Doctoral Thesis, Maastricht University]. Boekenplan. https://doi.org/10.26481/dis.20170622by

Document status and date:

Published: 01/01/2017

DOI:

10.26481/dis.20170622by

Document Version:

Publisher's PDF, also known as Version of record

\section{Please check the document version of this publication:}

- A submitted manuscript is the version of the article upon submission and before peer-review. There can be important differences between the submitted version and the official published version of record.

People interested in the research are advised to contact the author for the final version of the publication, or visit the DOI to the publisher's website.

- The final author version and the galley proof are versions of the publication after peer review.

- The final published version features the final layout of the paper including the volume, issue and page numbers.

Link to publication

\footnotetext{
General rights rights.

- You may freely distribute the URL identifying the publication in the public portal. please follow below link for the End User Agreement:

www.umlib.nl/taverne-license

Take down policy

If you believe that this document breaches copyright please contact us at:

repository@maastrichtuniversity.nl

providing details and we will investigate your claim.
}

Copyright and moral rights for the publications made accessible in the public portal are retained by the authors and/or other copyright owners and it is a condition of accessing publications that users recognise and abide by the legal requirements associated with these

- Users may download and print one copy of any publication from the public portal for the purpose of private study or research.

- You may not further distribute the material or use it for any profit-making activity or commercial gain

If the publication is distributed under the terms of Article $25 \mathrm{fa}$ of the Dutch Copyright Act, indicated by the "Taverne" license above, 


\section{Schooling Despite All Odds}

Evidence from Lesotho on female child carers who stayed in school

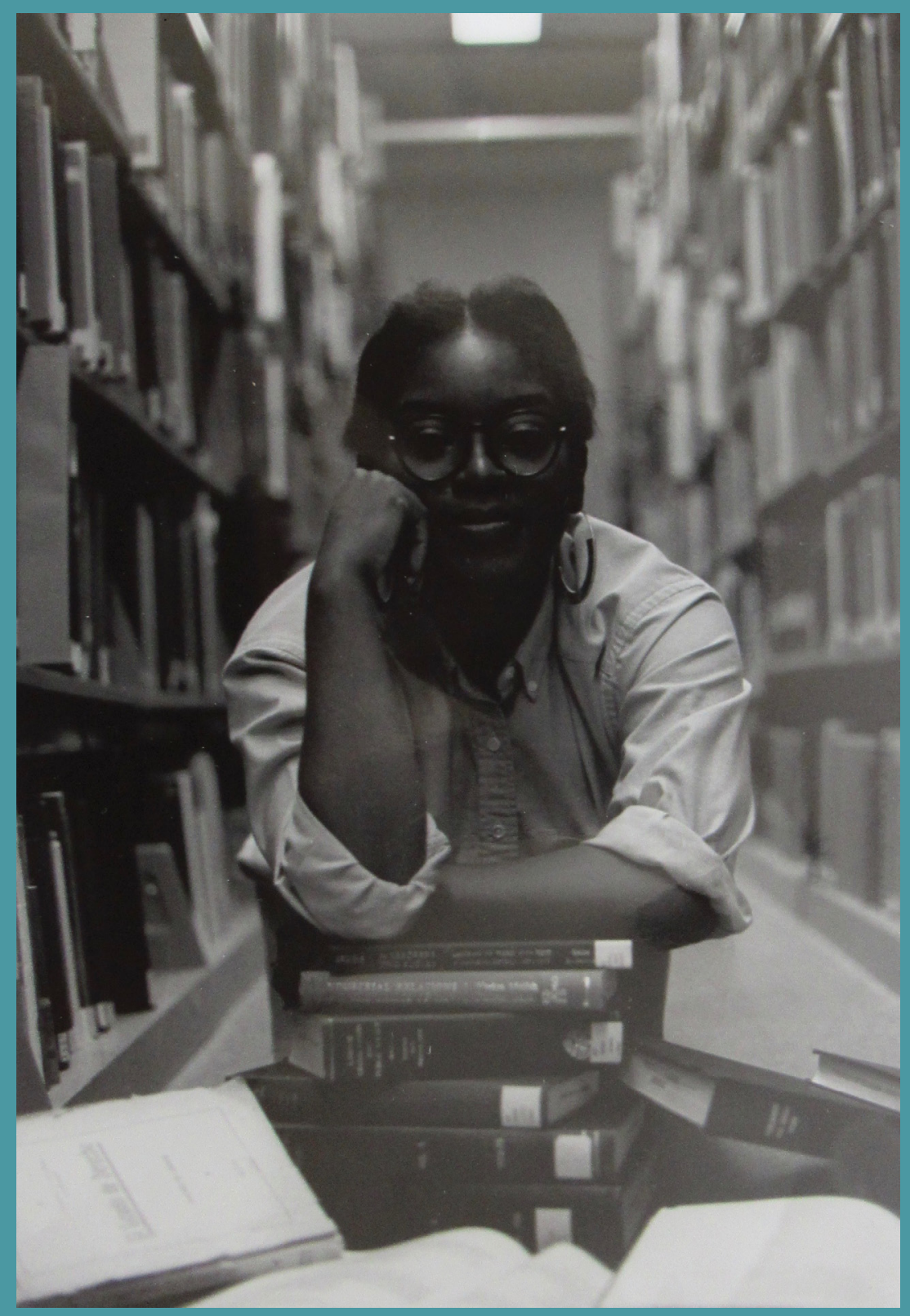

\section{Brenda Yamba}





\title{
Schooling Despite All Odds
}

\section{Evidence from Lesotho on Female Child \\ Carers who Stayed in School}

\author{
Brenda Yamba
}


(C) 2017, Brenda Yamba

Published by Boekenplan, Maastricht

www.boekenplan.nl

ISBN 9789086664221

All rights reserved. No part of this publication may be reproduced, stored in a retrieval system, or transmitted in any form, or by any means, electronic, mechanical, photocopying, recording or otherwise, without the prior permission in writing, from the author. 


\title{
SCHOOLING DESPITE ALL ODDS
}

\section{EVIDENCE FROM LESOTHO ON FEMALE CHILD CARERS WHO STAYED IN SCHOOL}

\author{
DISSERTATION
}

to obtain the degree of Doctor at Maastricht University on the authority of the Rector Magnificus,

Prof. Dr. Rianne M. Letschert

in accordance with the decision on the Board of Deans, to be defended in public

on Thursday, 22 June 2017, at 16:00

by

BRENDA YAMBA 
Supervisor:

Prof. Dr. Melissa Siegel

Co-Supervisors:

Dr. Katrin Kriz, Boston, USA

Dr. Louis Volante, Ontario, Canada

Members of the Degree Committee:

Prof. Dr. Khalid Koser (Chairman)

Prof. Dr. Lucie Cluver, University of Oxford

Dr. Morten Skovdal, University of Copenhagen

Dr. Michaella Vanore 


\section{ACKNOWLEDGEMENTS}

I dedicate my dissertation to my father, Mr. Luka Yamba and my uncle Mr. Matiya Ngalande, the two great men who connived into convincing me to pursue my $\mathrm{PhD}$. Both are in their prime years of life so the pressure was on me to complete my studies so that I could have the pleasure of presenting my book to them. I thank God that this will be possible.

I will forever be thankful to my supervisors Katrin Kriz, and Louis Volante for hand-holding me throughout my journey. They went beyond their role as supervisors and became my motivators and cheerleaders. My sincere gratitude goes to my promoter Melissa Siegel, for agreeing to join my supervisory team and provided invaluable input to my dissertation at the most critical time. To the reading committee Prof. Dr. Khalid Koser, Dr. Michaella Vanore, Prof. Dr. Lucie Cluver, and Dr. Morten Skovdal, thank you for taking the time to read my book and for the constructive feedback that helped shape the dissertation into what it finally got to be.

My heartfelt gratitude goes to Dr. Mindel van de Laar whose ability to keep track of everyone's research progress while coordinating the various aspects of GPAC, still amazes me. She was the go-to person when I needed clarity in times of selfdoubt and uncertainty. Thank you also to the rest of the Maastricht GPAC program coordinators Carlos, Guney, Charlotte, Saba and Shivani for all the help with organizing our Maastricht sessions. The chocolates sure did keep us awake.

Paulo Coelho's quote, "when you want something, all the universe conspires in helping you achieve it," worked true for me as I had a network of people that showed up at every stage of my $\mathrm{PhD}$ journey. Special appreciation goes to Chibwe Lwamba the data guru who seemed more enthusiastic about my research than I was, and was at my beck and call whenever I got stuck. I will forever be indebted to my research assistant, Mabonolo Puseletso Phori, an excellent social worker, counselor and researcher who stuck by my side during the data collection years and beyond. She became a reliable source of information on Lesotho local knowledge and culture. 
My sincere gratitude to Dr. Joe Abah, Dr. Janet Shriberg, Prof. Lorraine Sherr, Dr. Itumeleng Kimane, Dr. Thabiso Nyabanyaba, Ronnie Lovich and Prof. Linda Richter for sparing their time to help me with conceptualizing my research. Dr. Steven Kodish, introduced me to "Dedoose" and a brief breakfast meeting with him one day opened my eyes to how I could transform my data into dissertation chapters. Dr. Patrick Osewe's unrelenting support and thought-provoking questions always motivated me to soldier on.

To the GPAC cohort 2013 fellows, Clovis, Ali, Mutinta, Paul, Julia, Silvia, Camillo, Andreas, Luiz, Mohammed, Nozipho, Alexey and Jan, I couldn't have asked for a better group. Thank you for sharing this journey with me, especially the support in year one when we were all trying to figure out the dreaded 'research question.' I hope our paths cross again beyond Maastricht.

I wish I could list the names of all my work colleagues past and present, at Lesotho PEPFAR office, Pretoria Regional HIV/AIDS Program office and in Washington DC, who followed my progress with keen interest, egging me on and celebrating the milestones at every opportunity. Dr. Neway Fida unassumingly became my personal coach, motivator and reviewer. Dr. Beverly Nyberg, Gretchen Bachman, Jessica Tabler, Colette Peck, Silke Felton, Damilola Walker and Lucille Bonaventure, I will remember the brunches, lunches and dinners you arranged to find out how things were going with my studies.

Going to Lesotho for my research always felt like going back home. The support I received from the team at Lesotho Ministry of Social Development and the Ministry of Education and Training was heartwarming. Special thanks to Mme Mantsenki Mphalane and Mme Nooe for going the extra mile to help with arranging my interviews. My sincere gratitude goes to the study participants especially the child carers and their teachers for sharing their story. My wish is for their story to help make a difference in someone's life one day.

The world would be a better place with friends like the ones I have. Special thank you goes to my two life-long friends, Dr. Jackbeth Mapulanga-Hulston and Mutinta Hambayi. The former persistently pushed me to get started, while the latter walked the journey with me. Taking on such a venture with a close friend is a luxury I would recommend to anyone. We named our dissertations "The Frog" 
from the book by Brian Tracy "Eat That Frog" which gives strategies on how not to procrastinate. I must confess that there were moments when we just sat there and stared at our 'frogs'. To Edith Ng'oma, Kalongo Chitengi, Arlene Phiri, Petronella Mayeya, Bridget Muzeya, Mwape Mondoloka, Annie Sampa, Dorcas Kalonde, Yvonne Mulenga and many others I have not mentioned, thank you for celebrating this achievement with me.

Last but definitely the first, I would like to thank my wonderful family for being the motivation behind my success. Everyone understood that there were moments when I needed to be a recluse. My two precious daughters Muntanga and Esiya Muhyila, thank you for your patience and for helping out when I needed your Millennial skills. The tables turned and you gracefully assumed the role of being my support. See why I am ever so proud of you? To my beloved nieces and nephews, this is for you. What excuse are you going to give for not pursuing your dreams? My mother and my siblings, Peter, Doreen, Ivy, Mildred, Stella, Clifford, Gordon, Mubika and Lumeki, thank you for the love and support all the way. 


\section{Table of Contents}

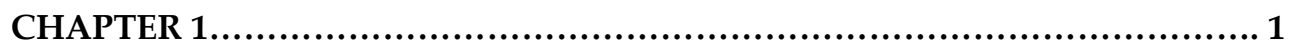

INTRODUCTION AND OVERVIEW: CHILDREN AS CAREGIVERS....................1

1.1 THE RESEARCH QUESTIONS ……………………....................................... 2

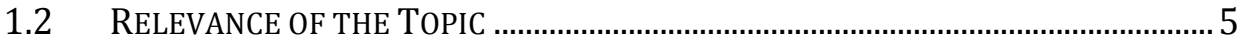

1.3 BACKGROUND INFORMATION ON LESOTHO_.......................................................... 7

1.4 RESEARCH METHODS ……….........................................................................

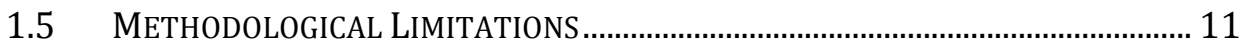

1.6 STRUCTURE OF THE DISSERTATION ................................................................ 13

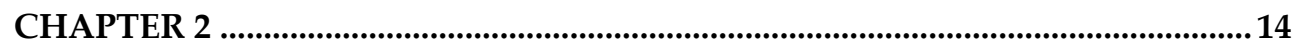

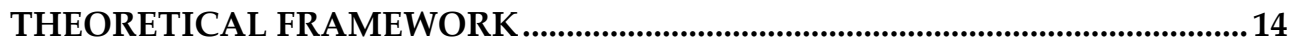

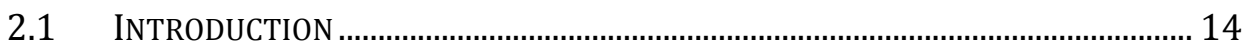

2.2 DEFINING THE CHILD CARER ………………................................................. 16

2.3 The Debate about ChILDREn's CARING Work AS ChILD LABoR................... 19

2.4 CHILD CARERS AND SCHOOL ATTENDANCE....................................................... 19

2.5 APPLYING THE SOCIOECOLOGICAL MODEL To EdUCATIONAL RESILIENCE ...... 20

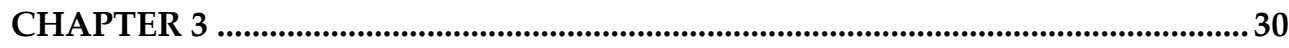

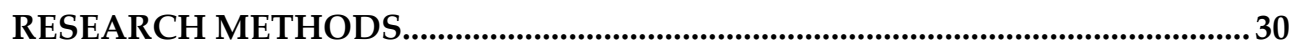

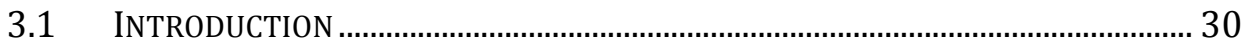

3.2 RATIONALE FOR RESEARCH APPROACH …………........................................... 31

3.3 RATIONALE FOR SITE SELECTION................................................................... 32

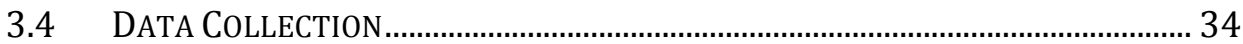

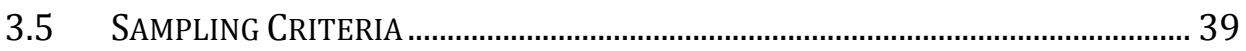

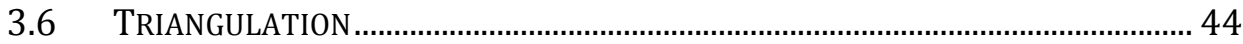

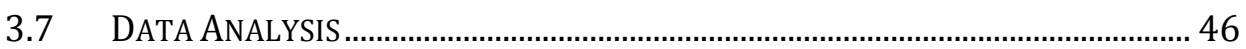

3.8 METHODOLOGICAL LIMITATIONS ........................................................................ 48

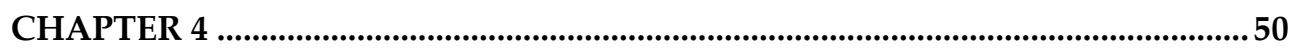

FEMALE CHILD CARERS IN LESOTHO AND RISK FACTORS .........................50

4.1 INTRODUCTION ........................................................................................... 51

4.2 PROFILE OF THE FEMALE CHILD CARERS IN THE STUDY ………....................... 51

4.3 What FACTORS CONTRIBUTED To GiRLS BEING CHILD CARERS? .................... 52

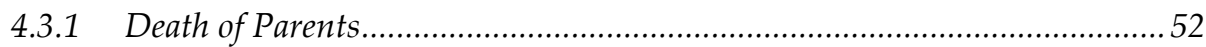

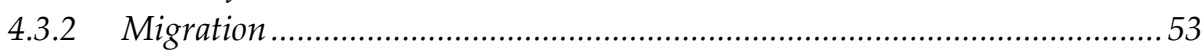

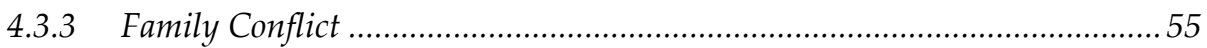

4.4 Who ChILD CARERS ARE CARING For......................................................... 55 
4.5 NATURE OF AND CHALLENGES ASSOCIATED WITH CARE...................................... 57

4.5.1 Household Domestic Chores ....................................................................... 58

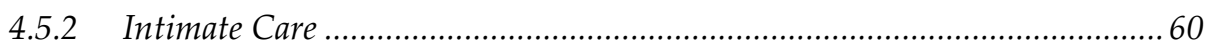

4.5.3 Parenting Younger Siblings, Including Adolescents................................. 61

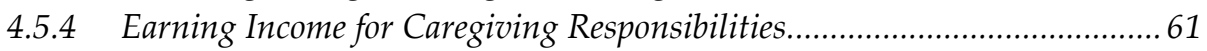

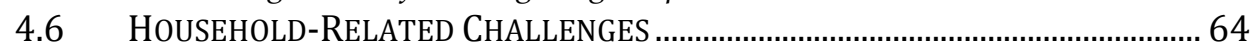

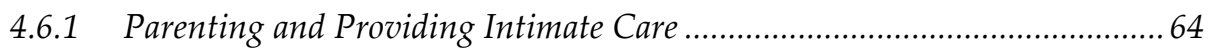

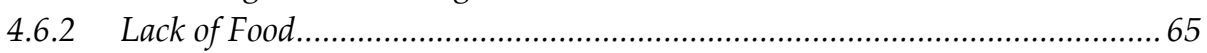

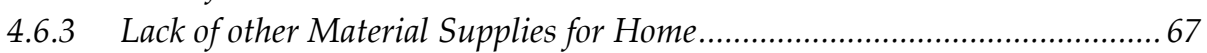

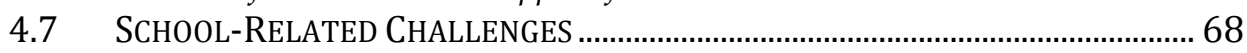

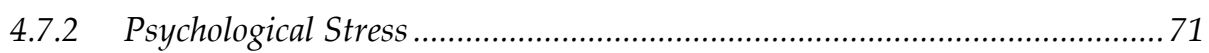

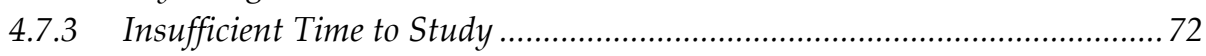

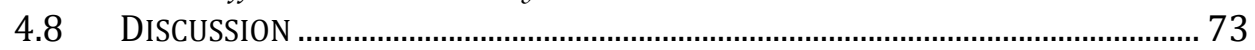

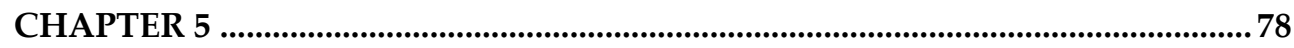

HOW CHILD CARERS' INDIVIDUAL ATTRIBUTES INFLUENCED SCHOOL

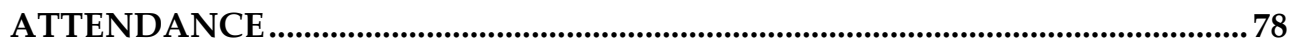

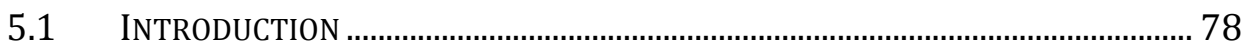

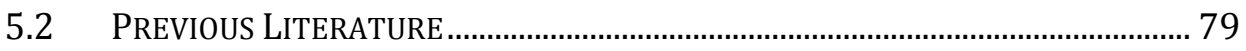

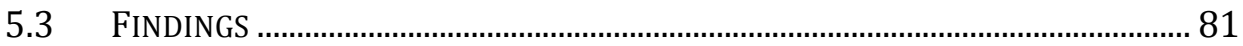

5.3.1 Embracing a Positive Vision of Better Futures and Key Milestones .............83

5.3.2 Role Models ............................................................................... 86

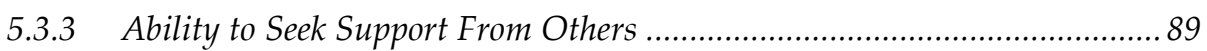

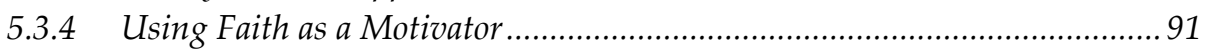

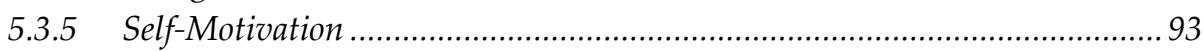

5.3.6 Employing Academic Performance as a Motivator ....................................93

5.4 INTERLINK WITHIN INDIVIDUAL DOMAIN......................................................... 94

5.5 HOW INDIVIDUAL FACTORS INTERACTED WITH OTHER SOCIOECOLOGICAL DOMAINS-FAMILY, SCHOOL, AND COMMUNITY ................................................. 94

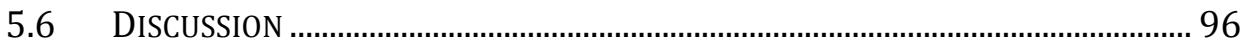

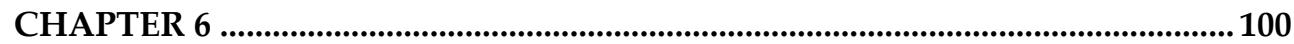

CARING SCHOOLS: PROTECTIVE AND RISK-MITIGATING SUPPORT FOR

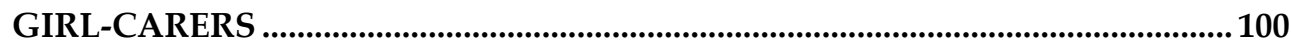

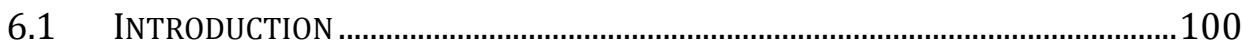

6.2 PRIOR LITERATURE ON SCHOOL FACTORS AND RESILIENCE..............................102

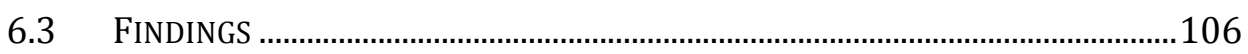

6.3.1 A School Environment Conducive to School Attendance ............................ 107

6.3.2 Teachers as a Source of Support to Child Carers ....................................... 116

6.3.3 Peers as a Source of Support to Keep Child Carers in School ..................... 122 
6.4 INTERACTION AMONGST SCHOOL FACTORS......................................................126

6.5 INTERACTION WITH OTHER SOCIOECOLOGICAL DOMAINS..................................127

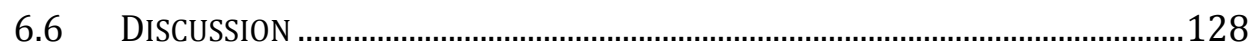

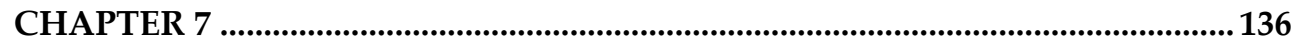

THE ROLE OF FAMILY AND COMMUNITY IN FACILITATING .....................136

CHILD CARERS' SCHOOL ATTENDANCE .....................................................136

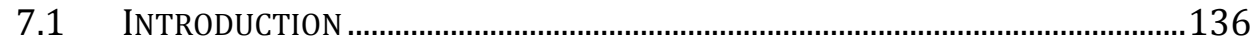

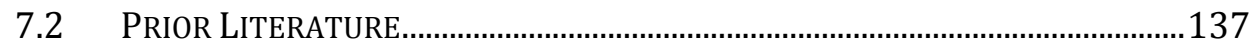

7.3 RESEARCH FINDINGS: FAMILY FACTORS.........................................................139

7.3.1 Family Members Nurturing Future Aspirations for Child Carers............. 139

7.3.3 Family Meeting Other School and Household Needs ............................... 145

7.4 RESEARCH FINDINGS: COMMUNITY FACTORS..................................................146

7.4.1 Neighbors as an Alternative Family for Child Carers............................... 147

7.4.2 Chiefs Spearheaded Provision of Care and Protection ................................ 151

7.4.3 Community Groups and Faith-based Organizations................................. 153

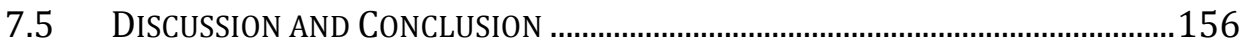

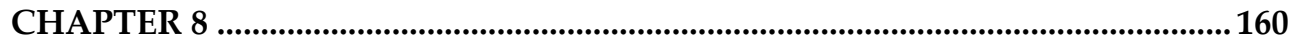

DISCUSSION AND POLICY CONSIDERATIONS..............................................160

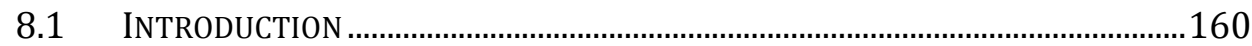

8.2 How ChiLd CARING CAUSES EduCATIONAL Risk: MisSing SCHOOL AND PSYCHOLOGICAL STRESS ..................................................................................161

8.3 A CHILD CARER'S VISION FOR A BRIGHTER FUTURE INFLUENCED SCHOOL

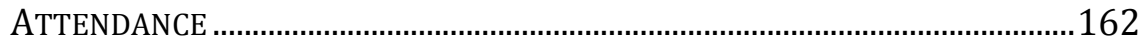

8.4 EXTERNAL FACTORS FAMILY, SCHOOL, AND COMMUNITY INFLUENCED SCHOOL

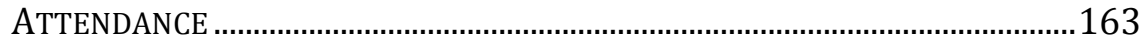

8.5 POLICY CONSIDERATIONS ....................................................................................

8.6 ACADEMIC CONTRIBUTION AND RECOMMENDATIONS FOR FUTURE

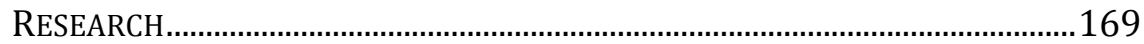

ANNEXES ……........................................................................................................... 182 


\section{List of Tables}

Table 2.1: Levels of Awareness and Response to Young Carers at the Global Level........16

Table 3.l: Orphans in Registered Secondary Schools by Type, Form, and Sex, 2014.......35

Table 3.2: Study Participants...................................................... 38

Table 3.5: Child Carer Participant Profile.......................................... 44

Table 3.6: List of Respondent Type for Triangulation ................................. 46

Table 4.2: Type of Care Recipients in the Study ....................................59

Table 4.4: Challenges and the Risk to School Attendance............................64

\section{List of Figures}

Figure 1.1. Lesotho orphanhood by age ..........................................

Figure 1.2. How HIV and AIDS affect children across the life cycle......................9

Figure 2.2 The socioecological model............................................ 22

Figure 3.3. Warm-up questions from the child carer interview guide................... 40

Figure 3.4. Quantitative items from the interview guide............................ 41

Figure 4.1. "Milly's" journey to being a child carer..................................58

Figure 4.3. Child work and urban/rural location. .......................................................64

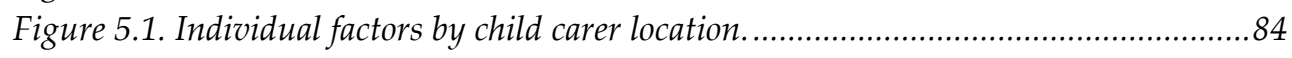

Figure 5.2. Individual factors code frequency by child location. .....................................85

Figure 5.3. Individual factors by teacher participant location............................................85

Figure 5.4. Individual factors code frequency by teacher location.....................................86

Figure 5.5. How individual factors influence school attendance. .....................................97

Figure 7.1. Child carer perspectives on family members' support.................................146

Figure 7.2. Child carer perspectives on community members' support. ..........................152

Figure 7.3. Teacher and policy maker perspectives on community support.....................152 
xii 


\section{CHAPTER 1}

\section{INTRODUCTION AND OVERVIEW: CHILDREN AS CAREGIVERS}

Also referred to as "hidden" (Becker, 2007), "excluded" (Lewin \& Akyeampong, 2009), or "invisible" (Charles, 2011) children, child carers are a recent phenomenon in academic literature. A child carer is defined as a child or young person providing primary care for a sick, disabled, or frail elderly relative in the home (Aldridge \& Becker, 1993; Robson, 2000). It is more likely that girls are the ones staying at home to care for their siblings and other younger children, as well as doing housework (Dearden \& Becker, 2004; Evans,2010; Wells, 2009). Other academic literature includes within the definition children who are heading households, or caring for their siblings (Kelly, 2000; Olsen, 1996; Robson \& Sylvester, 2007) and are engaged in housework. Children, from time immemorial, have contributed to the caregiving responsibilities in the home. However, when this stretches beyond the normal expectations of domestic chores (Robson et al., 2006) and becomes more substantial and significant (Becker, 2000), then this adult role denies children their childhood and deprives them of their rights as children (UNICEF, 2011).

In sub-Saharan Africa, the effects of the human immunodeficiency virus (HIV) and acquired immunodeficiency syndrome (AIDS) have resulted in a change in household composition, with children increasingly taking up caregiving roles. Recently, there has been a shift in caring patterns due to parental AIDS deaths, leaving grandparents increasingly taking up this role (Ardington \& Leibbrandt, 2010) and the emergence of child-headed households (Foster et al., 1997). It is within these family structures that children may be taking up caregiving roles beyond what may be considered the norm. The child carer in sub-Saharan Africa may fall under the classification of being a hidden population as their profile within the health, education, and social sectors is considered to be generally low (Thomas et al., 2003). In extreme cases, being "hidden" ultimately makes children invisible, or "forgotten," disappearing from view of other children, families, communities, and the rest of society (Moore et al., 2009; UNICEF, 2006). This limits their access to available goods, services, and support (Becker, 2007), therefore 
becoming "excluded children" who are denied their right to participate fully in society (UNICEF, 2006), including in education.

Caregiving responsibilities have been cited as one of the factors affecting regular school attendance (Lewin \& Little, 2011; Nyabanyaba, 2009; Stearns \& Glennie, 2006; UNFPA, 2012). However, some children will still attend school regularly, despite facing adverse circumstances (Cluver et al., 2012). Such children who thrive despite adversities are considered resilient (Condly, 2006; Katz, 1997).

The scope of this dissertation, therefore, is to examine perceptions of stakeholders, including in-school female child carers, teachers, policy makers, civil society organizations, and community volunteers, of conditions under which female children who are the primary carers in their households are still able to regularly attend secondary school. The focus of this study is Lesotho, a country based in Southern Africa, where the impact of HIV and AIDS has been greatest (UNAIDS 2016) and child carers have been identified as being vulnerable (Government of Lesotho, 2012; Tanga, 2013).

Lesotho policy documents, such as the Lesotho Education Sector Strategic Plan 20152015 (Government of Lesotho MOET, 2005), the National Policy on Orphans and Vulnerable Children (Government of Lesotho, 2006), and the National Strategic Plan on Vulnerable Children 2012-2017 (Government of Lesotho, 2012), acknowledge child carers as part of the vulnerable children population in need of social services. Academic literature also cites the child carer phenomenon in Lesotho, with one author attributing the rise of child-headed households to the inability of the extended family safety net to take care of orphans (Tanga, 2013). In another study exploring caregiving by young people in Lesotho, participants reported being caregivers of a sick relative, grandparents, or other relatives (Robson et al., 2006). Heading households, and being left under the care of relatives such as grandparents, were cited as reasons for poor school attendance (Nyabanyaba, 2009).

\subsection{The Research Questions}

Applying the themes identified in the literature, which I discuss below, and considering the gap in research with female child carers and schooling, I examined 
the perceptions of stakeholders on how individual, family, school, and community factors influenced female child carers regularly attending secondary school. I adopted the definition of school attendance by Lewin and Little (2011) as "regular attendance of at least $80 \%$ of the time." (p. 333). Lesotho's education system has a five-year secondary school program that runs from Form A to Form E, with an official age range of between 13 and 18 years (Classbase, 2012), although older students are not excluded from attending.

The main research question is: Why and how do some girl child carers regularly attend secondary school, despite adverse situations?

Using Urie Bronfenbrenner's socioecological model (Bronfenbrenner, 1994) as the guiding framework, the subquestions that I sought to answer in this research study were:

- What is the care-work provided by the female child carers?

- What are the challenges faced by the female child carers, and how do these pose a potential risk to school attendance?

- What individual-level factors facilitated secondary school attendance?

- What family-level factors facilitated secondary school attendance?

- What school-level factors facilitated secondary school attendance?

- What community factors facilitated secondary school attendance?

- What interaction occurs amongst individual, family, school, and community factors to facilitate secondary school attendance?

The socioecological model is a multilevel framework for explaining the interplay between personal and environmental factors or social systems (Elder, 2006; Pocock et al., 2012; Stokes, 1996). The model has been used in various academic disciplines, including education resilience, to explain the interaction between intrapersonal and external relationships in influencing positive behavior outcomes (Condly, 2006; Waxman et al., 2003).

I examined perceptions of in-school female child carers, teachers, policy makers, civil society organizations, and community volunteers, of how and why individual, family, school, and community factors influenced school attendance, and how the different factors interacted with each other to keep female child carers in school. 
(i) Individual factors were measured by looking at the following resilience factors among girl-carers who regularly attended school: (a) a sense of optimism and being hopeful for a better future (Benard, 1991; Embrace the Future, 2005), understood as whether a child reported positive future aspirations; (b) whether and how a child carer reported having role models that kept her motivated to attend school; (c) whether and how a child carer reported having sought help from family (Benard, 1991; Condly, 2006) or community members (Skovdal et al., 2009) to assist with caregiving responsibilities; and (d) whether and how a child carer reported school attendance being influenced by a child's religious background or belief (Condly, 2006; Embrace the Future, 2005).

(ii) Family factors were examined by analyzing which immediate and extended family members provided material support (such as books, uniforms, and shoes), financial support (school fees and transportation), and socioemotional support, and assisted the child carer with caregiving responsibilities (Condly, 2006; Katz, 1997; Skovdal et al., 2009).

(iii) School factors were measured by whether and how: (a) school teachers and administrators provided financial, psychosocial, and material support to child carers; (b) school peers provided financial, psychosocial, and material support for the child carers to stay in school (Donald \& Clacherty, 2005); and (c) the school environment was conducive to providing or linking (Condly, 2006) child carers to counseling services, school bursaries (Katz, 1997), and other services.

(iv) Community factors were measured by whether and how: (a) community members provided support or linked child carers to financial, material, psychosocial, and other social services, and (b) civil society organizations and faith based organizations, based in the community, provided educational support to vulnerable female children. 


\subsection{Relevance of the Topic}

Article 28 of the Convention on the Rights of the Child states that the convention places a high value on education and advocates for countries to ensure that children reach the highest level of education based on their capabilities (UNICEF, n.d). Apart from it being a fundamental child right, education contributes to poverty elimination and, ultimately, the social and economic development of a country. Development will not occur when the majority of the country's citizens do not have access to basic education (Lewin \& Akyeampong, 2009) as education is a key investment in the development of human capital (Becker, 1993). Education, whether formal or informal, plays a key role in economic development, and is "assumed to be the single most important indicator of a country's ability to achieve economic growth and development" (Wells, 2009, p. 45).

The significance of ensuring that all children have access to education has been demonstrated through global agendas, such as the UNESCO-led Education for All (EFA) movement, whose goals included eliminating gender disparities in schools for girls to have equal access to education, and ensuring that girls in difficult situations had access to free primary education (UNESCO, 2016). As a follow-up to the EFA movement, and to operationalize the new Sustainable Development Goals (SDGs), the global family adopted a new education declaration at the 2015 Incheon World Education Forum. The Education 2030 Incheon Declaration and Framework for Action (Declaration, 2015) committed to ensuring the "provision of 12 years of free, publicly funded, equitable quality primary and secondary education" (p. iv).

Despite the global acknowledgement of the critical importance of education to addressing developmental issues facing sub-Saharan Africa and other regions, progress towards universal access to education is far from being reached (Ardington \& Leibbrandt, 2010). In 2012, about 58 million children of primary school age and 63 million children of lower secondary school age were not attending school (UNESCO \& UNICEF, 2015). Sub-Saharan Africa is the region with the highest rates of children who have been excluded (UNESCO, 2017). Although barriers to attending school may seem like a generalized problem in lowincome countries, there is a need to identify vulnerable populations that may be excluded to highlight their exclusion and have an in-depth understanding of the challenges (Lewin \& Akyeampong, 2009). More significant is the need to 
understand and build on strengths, support systems (Williams \& Bryan, 2013) and other positive factors that influence those who attend school regularly despite their vulnerabilities (Benard, 1991; Garmezy, 1991). This study, therefore, sought to examine perceptions of child carers and other stakeholders to determine factors that may influence regular secondary school attendance for female child carers.

Girls were the focus of this study because girls are the most vulnerable population impacted by caregiving responsibilities and tend to drop out at higher rates (Jensen \& Nielsen, 1997; Robson et al., 2006; Stearns \& Glennie, 2006). Furthermore, the gendered nature of care work in most African societies assume women and girls to have innate nurturing traits and are therefore expected to be the primary caregivers (Evans, 2010). Although both boys and girls may be at risk of dropping out of secondary school, female students are more likely to drop out of school for family caring responsibilities, marriage, or pregnancy (Stearns \& Glennie, 2006). Attendance is expected to be inconsistent for those who combine caring responsibilities and schooling (Barnett, 2006). Despite these adversities, some child carers will still remain in school and thrive (Guo et al., 2012), and this is what this study sought to better understand.

This study will contribute to the ongoing discourse on child carers and the emerging literature on child carers in the developing world. Numerous studies have been conducted on this topic in the "Global North" (Aldridge \& Becker, 1993), but there is still little-known research focusing on child carers in subSaharan Africa, where a significant number of children have been affected by AIDS and are likely to provide care to adults (Cluver et al., 2012). In addition, the study will contribute to filling a gap in the literature on education resilience as it relates to child caring as an education risk factor in the developing world. Waxman et al. (2003) defined education resilience as success in school despite facing adverse conditions. There has been increasing work on the risk outcomes in relation to schooling (Guo et al., 2012). However, not enough has been done on education resilience in sub-Saharan Africa. Studies on education resilience (e.g., Condly, 2006; Connell et al., 1994; Johnson, 1997) have generally been conducted with a focus on minority students coming from low-income households (Waxman et al., 2003). Whether this experience is relevant to child carers in the sub-Saharan Africa setting is still unknown, hence, the importance of this study. 


\subsection{Background Information on Lesotho}

Lesotho is a landlocked country completely surrounded by its only neighbor, South Africa, and has a population estimated at about 2.1 million (The World Bank Group, 2016). It has a HIV prevalence rate estimated at $23 \%$ of $15-49$-year-olds (Lesotho Ministry of Health, 2015). The country is situated within the region most affected by HIV and AIDS and has the third highest HIV prevalence in the world after Swaziland and Botswana (UNAIDS, 2013). This has resulted in a high number of children orphaned, with about one third of all children in the country having lost one or both parents (Government of Lesotho, 2011). The proportion of orphaned children is highest among the 14-17 age group (see Figure 1.1), which is also part of the age range of children who attend secondary school. The high prevalence of potential girl-carers in the secondary school age-range makes Lesotho an important case study. The orphans are mostly cared for within a family setting and the majority live with a single parent or a grandparent (Lesotho Ministry of Health and Social Welfare, 2010). Data from the Lesotho Demographic Health Survey (LDHS) 2014 gave an estimate of 35\% as the proportion of children who did not live with their parents, and indicated that $33.9 \%$ of households in the country had fostered children under the age of 18 (Ministry of Health [Lesotho] and ICF International, 2014). It is in these settings that children often end up as caregivers.

Lesotho policy documents recognize children who play the role of caregivers as being vulnerable and therefore in need of services. For example, the Situational Analysis of Orphans and Vulnerable Children Report (Government of Lesotho, 2011) considers a child to be vulnerable when they live "without adequate adult support (e.g., in a household with chronically ill parents, a household that has experienced a recent death from chronic illness, a household headed by a grandparent, and/or a household headed by a child)" (p. 7). The Lesotho National Strategic Plan for Vulnerable Children recognizes the role of children as caregivers and the risks this responsibility poses on schooling. Figure 1.2 below highlights how being a child carer can ultimately lead to being excluded from schooling. In highlighting the plight of female child carers, the Lesotho Education Sector Strategic Plan: 2005-2015 (Government of Lesotho MOET, 2005) stated their school attendance was affected as they "look after their siblings [...] and take up additional responsibilities [including] caring for the sick" (pp. 57-58). The strategic 
plan recommended the provision of bursaries to needy children, the establishment of school-based support systems, and the implementation of well-targeted interventions to support school attendance as some of the ways of ensuring that children in adversity stay in school.

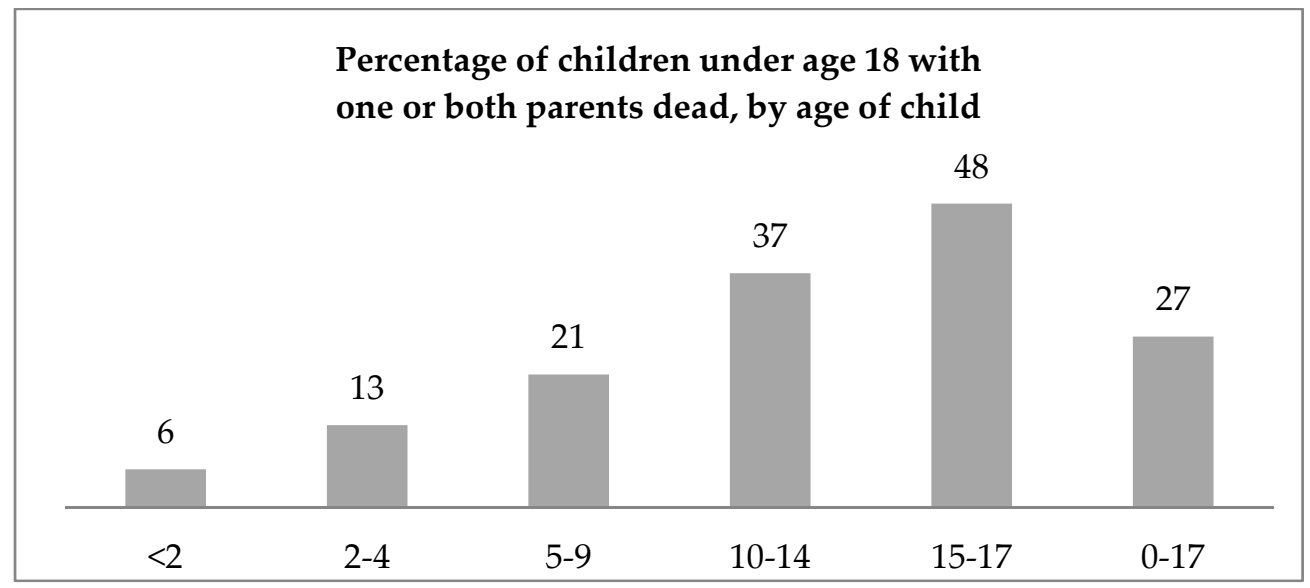

Age in Years

Figure 1.1. Lesotho orphanhood by age. Adapted from Lesotho Demographic Health Survey 2014 .

The Government of Lesotho introduced free primary education in 2000 and enacted legislation in 2010 that provided for free and compulsory seven years of schooling (Classbase, 2012). This may have led to the subsequent high primary school net attendance ratio which is estimated at $89 \%$ (UNICEF, 2015). This ratio, however, drops drastically to 33\% for secondary net attendance (UNICEF, 2015). The LDHS 2014 reported only 19\% of women and 16\% of men who have completed secondary school. In response to the declining enrollment rates, the government has been implementing a bursary program since 2001, aimed at improving access to schooling for orphans and vulnerable children. The program is, however, yet to be evaluated to assess its impact. The situation described above makes Lesotho an ideal setting to conduct this research on female child carers.

${ }^{1}$ Ministry of Health [Lesotho] and ICF International (2014). Lesotho Demographic and Health Survey. Maseru, Lesotho. 


\begin{tabular}{llll}
\hline Infants & Preschool Children & $\begin{array}{l}\text { School-age } \\
\text { Children }\end{array}$ & Adolescents \\
\hline $\begin{array}{l}\text { Exposure to } \\
\text { mother to child } \\
\text { transmission }\end{array}$ & $\begin{array}{l}\text { Loss of social } \\
\text { contact and } \\
\text { through birth and }\end{array}$ & $\begin{array}{l}\text { Becoming a } \\
\text { caregiver for } \\
\text { parents and } \\
\text { breastfeeding }\end{array}$ & $\begin{array}{l}\text { Fiblings } \\
\text { in responsibilities } \\
\text { as they assume } \\
\text { the role of }\end{array}$ \\
-Frequent & - Begin to & -Losing schooling & provider and \\
infections & experience \& & access & -Exclusion from \\
-Poor nutrition & respond to & -Increased & education \\
and growth & trauma of loss & awareness of & -Poor self esteem \\
-Emotional & -Poor nutrition & stigma & -Depression \\
deprivation & and growth & -Sexual abuse & -Sexual abuse \\
-Development & --Exposure to an & -Physical and & -Pregnancy \\
delays & abusive & verbal abuse & -STIs, including \\
-Attachment & environment & -Depression & $\begin{array}{l}\text {-Exclusion from } \\
\text { disorder }\end{array}$ \\
& -Frequent & -Increasing & formal \\
& infections & workload (child & employment \\
& & labor) & \\
\hline
\end{tabular}

Figure 1.2. How HIV and AIDS affect children across the life cycle.

\subsection{Research Methods}

This dissertation employed a qualitative research approach. I used a semistructured interview guide as the data collection tool. I chose this approach because it allowed me to purposefully sample my participants (Creswell, 2003), especially the child carers whom we do not know much about and who have been referred to as a "hidden" group of children (Becker, 2007; Moore, 2005b; Rose \& Cohen, 2010). My research sought to obtain girl-carers' views on, and experiences with, caring and schooling and stakeholders' perspectives of child carers and schooling. Semistructured interviews are, according to Barriball and While (1994), "well suited for the exploration of the perceptions and opinions of respondents regarding complex, and sometimes sensitive issues, and enable probing for more information and clarification of answers" (p. 330). Chapter 3 provides a detailed account of the research methods used. 
My dissertation is based on data from in-depth, semistructured interviews with 58 participants, comprising 28 female child carers attending secondary school, nine secondary school teachers, five policy makers, two civil society staff, and 14 members of community-based organizations. Prior to data collection, I obtained written approval from the Ministry of Education and Training and the Ministry of Social Development (MOSD), the two key ministries responsible for education and vulnerable populations, respectively. I took into account ethical considerations to ensure that the rights of all the participants were protected by explaining the purpose of the study and their rights and protection (Blumberg et al., 2011). For the interviews with children, I included other ethical considerations recommended by Noble-Carr (2006), including "informed consent, privacy and confidentiality..." (p. 5). The content of the consent form was read to the child in either English or Sesotho, ensuring that the child also understood that only pseudonyms would be used in the study.

\section{Adapted from Lesotho National Strategic Plan for Vulnerable Children².}

I transcribed the interviews verbatim and used a two-stage process for coding. Using Dedoose, a web-based computer application, I first coded the interviews, aligning them with the four domains of the socioecological model: individual, family, school, and community. This approach, known as concept-driven coding, requires that one develops codes in advance using preexisting theories or literature (Blumberg et al., 2011; Kvale \& Brinkmann, 2009). Second, I used open analysis to identify themes within these predetermined codes to identify subcodes. Blumberg et al. (2011) suggested using open analysis when the objective of the research is more focused on reading between the lines to "discover the full meaning of the source of the content" (p. 295). I further reviewed the data to identify subthemes within the key categories and other themes that did not fall within the codes that had been identified in advance. As these were not predetermined codes and were developed from reading the interviews, they are what Kvale and Brinkmann (2009) termed "data-driven" codes (p. 202).

\footnotetext{
${ }^{2}$ UNICEF adapted this diagram from Makhweya and Robbins (2003).
} 


\subsection{Methodological Limitations}

Although my study was focused on the factors that help female child carers regularly attending secondary school, the research may have been enriched by also including child carers who had dropped out in order to get their perceptions on why they thought they had dropped out. I discovered during data collection, that when girls dropped out of school, their situation changed almost immediately, as they moved out of the community to seek employment or get married. This made that population impossible for me to reach. I therefore limited my child carers sample to those that had stayed in school. Other studies that have used a similar sampling approach, with a focus on the resilient group who stayed in and succeeded in school despite adverse circumstances, include research among lowincome Chicanos (Gandara, 1995), a study on high-achieving African American youth (Williams \& Bryan, 2013), and a Kenyan study of child carers (Skovdal et al., 2009). Another limitation that my research presented is that the sample was more focused on older girls, those who were in secondary school. There may have been value in also sampling younger girl carers who had dropped out of school as they may have particular vulnerabilities worth examining.

Sampling of participants was purely purposive as my research focused on a group of children that remains under researched, especially in sub-Saharan Africa (Becker, 2007) and not much is known about them. To identify child carer participants, teachers facilitated the selection of child carers based on a set criteria that I provided to them. The teachers identified the participants based on personal knowledge of the child's situation, or in some situations, the girls self-selected. This, however may have created a selection bias in that the teachers would have identified only those girls that they perceived to have been fairing relatively well, were receiving support from the school or were in good standing with the teachers. Such selection may have influenced the responses especially on how the role the school and teachers played in supporting the child carers. In the same vein, sampling of the two study schools was purposively done by the Ministry of Education officials. There could have been a selection bias by selecting schools that may have been sympathetic to vulnerable children. This may have influenced the results of the school factors. 
Collecting data from children is more effective when traditional research methods, such as interviews, are combined with child visual and task-based techniques (Noble-Carr, 2006; Punch 2002). The limited amount of time allocated by the school authorities against the number of interviews I planned to conduct made it difficult for me to use a "resource map" (Knowledge Sharing Management, 2014) as a visual tool that would have enabled the children to map educational support structures within the family, school, and community. Additionally, time limitations may have been a barrier to children. Although I managed to develop a rapport with the child participants before the interviews, I would have preferred to spend more time building the respondents' trust in order to make them more comfortable discussing their personal issues. The time allocated for my interviews with the child carers also affected the frequency of contact with the child carers. Having only one interview with each girl may have had an impact on the depth and quality of the conversation.

Although giving the participants the option to use both English and Sesotho ensured language was not a barrier to participation, some of the meaning could have been lost in translation. The challenge of interpretation of meaning was expected; however, this can be made even more complex when cultural contexts differ and an interlingual translation is needed (van Nes et al., 2010). I provide more information on the interpretation dynamics in Chapter 3.

Finally, the study was on vulnerable children, an area of focus that I have devoted most of professional career on. It therefore follows that my position as a subject matter specialist may have had an effect on reflexivity. According to Roni Berger (2015), social standing, past experience or professional exposure may have an impact on reflexivity of the researcher. While my professional position as someone working for a donor agency may have facilitated access to some of my study participants such as the policy makers, this relationship could have influenced the information that the participants shared by either amplifying the vulnerability of the child carers in the expectation that I may influence funding, or by exaggerating the support that schools and government provides. I tried to mitigate this by diversifying my sample for triangulation. My professional knowledge and expertise may thus present a risk of bias for the study. 


\subsection{Structure of the Dissertation}

Chapter 2 provides the theoretical framework guiding the dissertation, outlining prior literature on educational resilience using the socioecological framework. The chapter starts with a review of the prior literature on child carers, the reasons for caring, the nature of care, and how this relates to school attendance and educational resilience.

Chapter 3 outlines the methods used to conduct the research and provides the rationale for the research approach and site selection. Furthermore, the chapter describes the sample and details the data collection and data analysis processes.

Chapter 4 presents the profile of the child carers in the study, describing the factors that may have caused them to be caregivers, the nature of care they provided, and who their care-recipients were. The chapter also describes the challenges faced by the child carers and how these may pose a potential risk to school attendance.

Chapter 5 discusses study participants' views on how and why individual attributes play a role in keeping female child carers attending secondary school despite the challenges they experienced due to their caregiving roles. It also highlights the collaboration between individual factors and external factors, such as family, school, and community.

Chapter 6 is an account of the perceptions of study participants of how schoolrelated factors such as the school environment, teachers, and student peers contributed to child carers being able to regularly attend secondary school.

Chapter 7, which contains two parts, first highlights study participants' perceptions of the roles that the immediate and extended family plays in influencing female child carers' school attendance. I further discuss the role of neighbors, community leaders, and community-based organizations in influencing school attendance.

Chapter 8 concludes the dissertation with a discussion, conclusion, and policy considerations. 


\section{CHAPTER 2}

\section{Theoretical Framework}

This chapter sets out the theoretical framework guiding the dissertation and outlines key issues in the literature on child carers and how these issues relate to school attendance and educational resilience in general. The chapter is presented in two parts: The first section reviews the academic literature to define child carers and looks at what distinguishes them from other children, who they care for, and how child caring relates to school success. The second part of the chapter discusses the prior academic literature on educational resilience using the socioecological framework (Bronfenbrenner, 1994).

\subsection{Introduction}

The United Nations Children's Fund (UNICEF), in its State of the World's Children Report, brings to the fore the risk of exploitation facing children who play adult roles and are deprived of their rights as children (UNICEF, 2011). The phenomenon of the child, or young carer, has captured the interest of researchers only as recently as the early 1990s. Despite acknowledging the prevalence of such children in society, developing a standard definition is still regarded as problematic (Cooklin, 2009) and controversial (Thomas et al., 2003), with still no consensus (Newman, 2002; Rose \& Cohen, 2010) and no standard criteria for labeling a child carer (Newman, 2002). The controversy stems from the lack of clarity in determining when caring ceases to be considered part of normal family roles and becomes a matter of concern (Thomas et al., 2003). This becomes even more obscure in the Global South where children and young people are expected to contribute to the household's productive work (Evans, 2010). Furthermore, the fact that children who are in this situation will not think of themselves as carers (Cooklin, 2009), or keep their caring role a secret (Thomas et al., 2003), makes it difficult to identify these children for research; thus, they remain a "hidden" group of vulnerable children. Although there has been a general call for these children to be recognized as a distinct group of vulnerable children (Becker, 2007), the variability of characteristics (Moore, 2005b) makes it unreasonable to treat them as a homogeneous group. 
Table 2.1: Levels of Awareness and Response to Young Carers at the Global Level

\begin{tabular}{|c|c|c|}
\hline Level & Characteristics & Country/Region \\
\hline Advanced & $\begin{array}{l}\text { - Widespread awareness and recognition of } \\
\text { young carers among the public, policy } \\
\text { makers and professionals } \\
\text { - Extensive and reliable research base } \\
\text { - Specific legal rights (national) } \\
\text { - Extensive codes and guidance for welfare } \\
\text { professionals and national and local } \\
\text { strategies } \\
\text { - Multiple dedicated services and } \\
\text { interventions nationwide. }\end{array}$ & UK \\
\hline Intermediate & $\begin{array}{l}\text { - Some awareness and recognition of young } \\
\text { carers among the public, policy makers } \\
\text { and professionals } \\
\text { - Small research base } \\
\text { - Partial rights in some regions } \\
\text { - Small but developing body of professional } \\
\text { guidance } \\
\text { - Some dedicated services and interventions } \\
\text { nationwide }\end{array}$ & Australia \\
\hline Preliminary & $\begin{array}{l}\text { - Little public or specialist awareness and } \\
\text { recognition of young carers } \\
\text { - Limited research base } \\
\text { - No specific legal rights } \\
\text { - Few, if any, dedicated services or } \\
\text { interventions at national or local levels }\end{array}$ & USA \\
\hline Emerging & $\begin{array}{l}\text { - Embryonic awareness of young carers as a } \\
\text { distinct social group within the } \\
\text { "vulnerable children" population }\end{array}$ & $\begin{array}{l}\text { Sub-Saharan } \\
\text { Africa }\end{array}$ \\
\hline
\end{tabular}

Note. Adapted from Becker (2007, p. 42).

The literature on child carers in sub-Saharan Africa is still emerging (Becker 2007), as illustrated in Table 2.1. The studies have been focused on children providing care for sick parents within the context of HIV and AIDS (Cluver et al., 2006; 
Robson et al., 2006). Children as carers are also mentioned in research that broadly examines the impact of AIDS on children in general, with a specific focus on orphans and vulnerable children, and HIV-positive children, or as a subgroup sample (Bray, 2009; Nyabanyaba, 2009). Robson et al. (2006) recommend further research that involves data collection from young carers within the broader context of families, and how they respond to the problems they face.

\subsection{Defining the Child Carer}

Despite the challenges presented above in defining child carers (Cooklin, 2009; Rose \& Cohen, 2010; Thomas et al., 2003), there seems to be a general consensus in the literature that the extent and nature of care determine whether a child can be considered a carer. What distinguishes child carers from other children has been described in terms of responsibilities beyond what society normally expects of a child to contribute within a household setting (Robson et al., 2006), which is more than giving a helping hand with household chores (Charles, 2011).

Children are termed carers when they are the primary or main caregiver providing care on a regular basis, and in a significant manner (Charles, 2011; Dearden \& Becker, 2002). They tend to do more domestic work and have greater (Robson et al., 2006) or excessive (Newman, 2002) responsibilities for other household members than other children. These children undertake the work that would normally be assumed by an adult (Dearden \& Becker, 2002), and they are preoccupied with providing care or thinking about the people under their care (Moore, 2005b). Taking up such responsibilities may also lead to serious negative outcomes (Becker, 2007). It therefore follows that living in a household where a family member has a debilitating condition does not always qualify a child to be called a child carer (Moore, 2005b). Cited in studies such as Robson et al. (2006) and Dearden and Becker (2002), Saul Becker's definition of child carers is more commonly found in literature:

Children and young persons under 18 who provide, or intend to provide care, assistance or support to another family member. They carry out, often on a regular basis, significant or substantial caring tasks and assume a level of responsibility, which would usually be associated with an adult. (Becker, 2000, as cited in Dearden and Becker, 2002, p. 1) 
Thomas et al. (2003) offered a more comprehensive definition incorporating the type of care that a child may provide, and the impact caregiving can have on a child:

A young carer is a child, or young person, who is in need of specific services because their life is affected by the need to provide care for a family or household member who has an illness or disability. This may include a child or young person who provides direct personal care to another person, who takes on a supportive role for the main carer, or who undertakes domestic duties as a result of the need for care. It may include a child or young person who is denied ordinary social or educational opportunities because of the other person's need for care. These needs may arise on a regular or on an occasional basis. (p. 44)

For the purpose of this study, I have defined a child carer as a young person who is 18 years or below and provides care for a sick, disabled, or frail adult in the home, or who heads a household with no adult present.

The nature of care is presented either as direct, providing intimate care to one care recipient, or indirect care, which involves a child taking over the roles of the adult who is receiving care (Siskowski, 2006). This dichotomy is, however, limiting as it makes the assumption that the care recipient will always be an adult and overlooks situations where the care recipients are younger members of the household. Robson et al. (2006) provided a more encompassing categorization of the nature of care which acknowledges other care recipients, including younger siblings, nieces, and nephews (Moore, 2005b): (a) intimate care, which applies mainly in situations where the care recipient is incapacitated and needs help with tasks such as feeding, providing treatment, and bathing; (b) general caregiving for a sick relative, such as running errands, accompanying a care recipient to the hospital, giving a care recipient food (Robson et al., 2006), and providing emotional support (Moore, 2005b); (c) carrying out domestic chores for a sick relative by themselves and maintaining the health and well-being of the general household (Moore, 2005b; Robson et al., 2006); and (d) looking after other children in the household, who may be younger siblings or cousins, or nieces and nephews. 


\section{Reasons for Children Caring}

The reasons children become carers are multifaceted and complex (Becker, 2007). Becker (2007) argued that children find themselves in this situation because there is no other alternative option. The author further contended that child caregiving happens in an environment where external services are not provided to meet the needs of family members under the care of children. Aldridge and Becker (1993) advanced the concept of socialization into care, arguing that children who became caregivers felt compelled, either emotionally or practically, to take up that role. The authors further attributed economic and other factors, such as parents' illness or disability, as triggers of child caregiving (Aldridge \& Becker, 1993). In sub-Saharan Africa, sociodemographic changes, triggered by increased AIDS-related mortality of the middle-aged population, are said to have contributed to the child carer phenomenon (Robson et al., 2006). The AIDS pandemic saw the emergence of the skip-generation households, which had children taking care of elderly grandparents (Richter \& Desmond, 2008), and child-headed households (Foster et al., 1996).

The extent or range of care is determined by the existence of support structures that help with caregiving responsibilities. These exist as paid or unpaid caring support. Professional caring services (Moore, 2005b) can be paid for, or provided by the government, community workers, or nongovernmental organizations. Informal, unpaid for support is provided by family members and friends (Siskowski, 2006) and is motivated by love, attachment, and duty (Moore, 2005b). Where external support is absent or limited, child carers may take up the responsibility of providing for both intimate and general care. Research from Africa highlights the fact that children who provide care will most likely be the ones to also find work to earn money for household expenses, including those related to caring for the sick (Robson et al., 2009).

\section{Primary Care Recipients}

Primary care recipients are categorized either as individual or multiple members of a household. Adults, especially parents (Rose \& Cohen, 2010), grandparents, or adult siblings (Robson et al., 2006; Siskowski, 2006) are the ones most often cited as individual care recipients. These would be family members with a debilitating condition such as a chronic illness, disability, mental health issue, or drug and alcohol dependency (Robson et al., 2006; Rose \& Cohen, 2010). Multiple care occurs 
where there is more than one person in the household receiving care. The household composition, in this case, would either be a combination of both adults and children or comprise of children only, as in the case of a child-headed household. The study by Robson et al. (2006), for example, found that when a child carer was looking after a sick sister, she had to take care of the sister's children as well. This research addressed this gap by working with different types of child carers, including children heading households or caring for their siblings (Kelly, 2000; Olsen, 1996; Robson \& Sylvester, 2007), or looking after disabled or frail elderly relatives in the home (Aldridge \& Becker, 1993; Robson, 2000).

\subsection{The Debate about Children's Caring Work as Child Labor}

There has been an ongoing debate about whether to classify children's caring work as child labor or not. It is not seen as an economic activity, but more relevant for socialization, and therefore is not included in calculations of work (Wells, 2009). The International Labor Organization (ILO) defines child labor as "work that deprives children of their childhood, their potential and their dignity, and that is harmful to physical and mental development" (International Labor Organization, 2017, para. 3). The definition specifically relates child labor to work that prevents children from attending school, requires them to drop out of school prematurely, or makes them try to combine schooling with long hours of work (International Labour Organization, 2017). In settings where the use of technology is low, children will work long hours in the home, therefore negating the position that domestic work is not an economic activity (Wells, 2009). My dissertation supports the ILO's position on this matter, as it follows that when housework goes beyond what is considered normal household chores, it is child labor.

\subsection{Child Carers and School Attendance}

There is a general acknowledgement in the literature on child carers that, despite experiencing adversity, some children still combine caring responsibilities with attending school, although attendance may be irregular (Cluver et al., 2012; Robson et al., 2006; Skovdal et al., 2009). The literature reviewed so far, however, presents only a scant picture of statistical data on child carers who are enrolled in school and attending regularly. Equally limited is research on child carers and school attendance within the sub-Saharan setting and, specifically, within the context of 
HIV/AIDS. Available literature has been in the broader context of orphans and vulnerable children with a focus on school access. For example, Nyabanyaba (2009) examined factors influencing access and retention for orphans and vulnerable children in Lesotho. A study by Cluver et al. (2012) is one of the few with a specific focus on young carers and access to education in the context of HIV/AIDS. This study, which measured the impact of caregiving on the education of adolescents living in sick homes in South Africa, identified children who were missing school or had dropped out in order to care for sick adults. Some of the common themes of the study included going to school hungry and the inability to concentrate while at school (Cluver et al., 2012). The study specifically targeted children who provided care in households with a sick person and did not include other types of households, such as child-headed or those with an elderly grandparent, a limitation my study addresses.

\subsection{Applying the Socioecological Model to Educational Resilience}

This dissertation was built on Urie Bronfenbrenner's socioecological model (Bronfenbrenner, 1994) as the framework for the research design. The model, illustrated in Figure 2.2, is a multilevel framework that helps explain how personal and environmental factors, or social systems, are interconnected in influencing positive behavioral outcomes (Pocock et al., 2012; Stokes, 1996)..

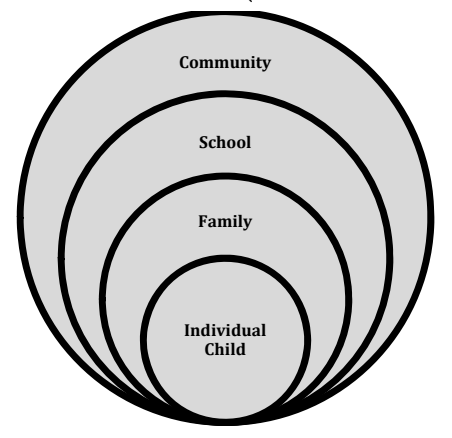

Figure 2.2. The socioecological model ${ }^{3}$.

Various academic disciplines have used the socioecological model to explain the interaction between individual and external relationships in influencing positive behavioral outcomes (Centers for Disease Control and Prevention [CDC], 2013;

${ }^{3}$ Adapted from Centers for Disease Control and Prevention (CDC). (2013, 27 December 2013). "The Socio-Ecological Model: A Framework for Prevention." Retrieved 16 January, 2014. ibid. 
Condly, 2006; Embrace the Future, 2005; Fredricks et al., 2004; Waxman et al., 2003; WHO, 2002;)

In education resilience studies, researchers have used the socioecological framework to explore factors beyond students' personality characteristics, and also examined external factors such as family, schools, and communities (Waxman et al., 2003; Williams \& Bryan, 2013). My dissertation contributes to this knowledge by exploring how individual and external factors influence the educational success of child carers who may have been at-risk of dropping out of school.

The sections that follow discuss prior literature as it relates to educational resilience from the socioecological perspective, looking at individual, family, school, and community factors - the factors I will discuss in the chapters that follow.

\section{Individual Characteristics and Resilience}

Social competence, optimism for a brighter future and spiritual or religious beliefs, are some of the individual factors known to influence education resilience in children (Embrace the Future, 2005). These individual factors will, however, need to interact with the external factors of family, school and community as "resiliency is not an attribute of any single individual" (Embrace the Future, 2005). Skovdal et al. (2009) showed that children who were coping depended on their ability to negotiate support from community members, or engaged in income-generating activities to cover school-related and other costs.

Prior literature (Benard, 1991; Johnson, 1997; McMillan \& Reed, 1994) generally agrees that resilient students possess certain individual characteristics that may lead to positive educational outcomes. Benard (1991) singled out having a sense of purpose and future as the key predictor of positive outcomes and identifies other factors that he argues make up this attribute:

Healthy expectancies, goal-directedness, success orientation, achievement, motivation, educational aspirations, persistence, hopefulness, hardiness, belief in a bright future, sense of anticipation, a sense of a compelling future, and a sense of coherence. (p. 7) 
Several other authors share the same view and agree that such children are optimistic and view things in a positive light, set long-term goals, have a sense of a positive future (Embrace the Future, 2005; McMillan \& Reed, 1994), believe in good things happening to them, and see things going their way (Scheier \& Carver, 1985). Having a vision of the future will influence one's current behaviors as long as these are associated with achieving their future goals. According to Johnson (1997), such children have a sense of purpose that makes them work towards achieving specific goals and they believe that they can change their situation. Johnson, however, looked at aspiration for a better future from a different angle and argued that academic success, which is normally considered an outcome or manifestation of resiliency, can also be a factor that enhances an individual's self-esteem, thus building the confidence needed for a child to aspire to a better future.

Role models are seen to play a significant part in influencing resilient children's optimism and vision for the future. Positive role models are people who have achieved outstanding success and motivate others to pursue similar excellence (Lockwood et al., 2002). Their presence is crucial to the development of resiliency in children (Johnson, 1997). Negative role models can also influence positive outcomes, but instead of being emulated, they would trigger avoidance and preventative strategies that children employ to avoid turning out like them. At-risk children who are resilient will most likely establish a close relationship with a known individual who gives them attention and support and may have become a role model (McMillan \& Reed, 1994). The explanation for this transition is given by Lockwood et al. (2002), who argued that optimistic or promotion-focused individuals are able to notice, recall, and be inspired by information that can contribute to reaching their aspirations of success.

Resilient children have an internal locus of control and strong self-efficacy attributes that enable them to stimulate their internal strength to cope in the midst of adversity and can lead to positive outcomes (Charles, 2011; McMillan \& Reed, 1994). These characteristics give resilient children the drive to succeed as they allow them to comprehend the situation they are in, and distinguish what is within their control (Condly, 2006). Such children will have the capacity to learn from their experience and adapt to the environment they are in (Cassen et al., 2009). However, one author, Condly (2006), cautioned about how this same intelligence 
may have negative outcomes that could leave a child "more vulnerable to emotional scarring and the internalization of stress" (p. 217).

At-risk children's involvement in formal or informal religious organizations has also been associated with developing resilience with a potential for leading to positive outcomes (Katz, 1997). Such groupings can provide a safety net for children to meaningfully participate in activities that can provide a sense of psychosocial support (McMillan \& Reed, 1994). A study by Skovdal et al. (2009) on the coping strategies of young carers in Western Kenya found that the church was a source of food and emotional support. The study further noted the role of faith as a coping strategy for the caregivers who were said to believe that God answered prayers.

Prior literature also identified social competence as one of the characteristics of a resilient child. According to Benard (1991), this entails being able to bring out positive responses such as providing support, from others. Other attributes that he noted are problem-solving skills, autonomy, and a sense of purpose. The findings in the Skovdal et al. (2009) Kenya study showed that children at risk also depended on their ability to mobilize social resources available to them, such as eliciting support from immediate and extended family members and community members.

It is worth noting that these individual factors will, however, need to interact with the external factors of family, school, and community, as resiliency goes beyond the attributes of an individual (Embrace the Future, 2005). Benard (1991) postulated the significance of the role that a caring and supportive relationship, with at least one individual, plays in influencing positive outcomes. This is corroborated in a study by Katz (1997), whose findings demonstrated how school teachers, church members, and community members all played a role in supporting the children who were taking care of ailing adults in the home.

\section{External Factors and Resilience}

There is general agreement in the literature on resilience that involvement in external formal and informal organizations can positively affect children in adverse circumstances (Condly, 2006; Fredricks et al., 2004; Katz, 1997). This involves support from immediate or extended family members (Connell et al., 1994; Skovdal et al., 2009), the school environment (Mampane \& Bouwer, 2011), as 
well as from friends, peers, and adults (Donald \& Clacherty 2005). The section that follows highlights prior literature on the external factors examined in this research.

\section{Family Factors and Resilience}

The research literature has shown that family plays a key role in building resilience among children facing adversities (Benzies \& Mychasiuk, 2009; Condly, 2006; Perez et al., 2009; Robson et al., 2006). In the context of sub-Saharan Africa, research also underscored the influence of family in providing support to children in need (Foster et al., 1996; Nyamukapa \& Gregson, 2005). Further, studies reported that traditionally, in the African setting, the extended family was expected to be the prime source of assistance to children when the family was experiencing adversity (Robson, 2006; Tanga, 2013). This traditional safety net was, however, stretched by the unprecedented increase in the number of orphans and vulnerable children due to HIV and AIDS. Although research still showed that the extended family system provides care, the level and quality of care and support have diminished (de la Porte, 2008; Foster et al., 1996; Robson et al., 2006; Tanga, 2013).

Families are considered supportive when they are able to provide protection and help a child cope by being a source of emotional and material support (Benzies \& Mychasiuk, 2009; Condly, 2006; Perez et al., 2009). The importance of such support was highlighted in a study on academic success in an at-risk Chicano population, where participants reported how scholarships, and other forms of support from family members, may have contributed to their academic achievement (Gandara, 1995). Further, literature points to the critical role of parents in building resilience among at-risk children. For example, Benzie and Mychasiuk (2009) pointed to a supportive parent-child relationship as a critical attribute for a child to overcome adversities. McMillan and Reed (1994) also supported this view and argued that children in adversity were motivated to aim towards school success when their parents had high expectations of them (McMillan \& Reed, 1994). Both authors, however, posited that support can also come from any member of the family, including siblings, grandparents, or aunts, with whom a child can create a close attachment (McMillan \& Reed, 1994, p. 138), and that what was paramount was for families to function as a close unit in facing challenges and helping at-risk children to cope (Benzie \& Mychasiuk, 2009). 


\section{School Factors and Resilience}

Prior studies have established that, as with the family environment, schools that provided care and support, and established high expectations for at-risk children, influenced their positive outcomes (Benard, 1991). A conducive school environment was one that made children feel welcome, provided a sense of safety and security, and facilitated effective participation (Cassen et al., 2009; Christiansen et al., 1997). Such schools were seen as a source of support, provided friendship, and nurtured at-risk students to believe in themselves and aspire for a better future (Christiansen et al., 1997; Skovdal et al., 2009). School-based support has been seen to provide a buffer against risk factors that a child may be experiencing in the home (Zimmerman \& Arunkumar, 1994).

Schools can therefore provide a critical space for protective factors to be developed, to foster resiliency in at-risk children (Waxman et al., 2003). Most studies have suggested school programs as the way to achieve this. For example, programs to help at-risk students develop special hobbies or interests, such as arts and sports (Christiansen et al., 2009), peer education programs, and student advisory boards (Zimmerman \& Arunkumar, 1994) have been known to help children successfully deal with life challenges. Being involved in extracurricular activities, such as school clubs and support groups addressing different risks, provides an informal form of support which can give at-risk children a sense of belonging, thereby enhancing their self-esteem and fostering a positive attitude towards engaging in school (McMillan \& Reed, 1994).

Where schools are not able to provide certain services, their personnel can facilitate referrals to organizations that provide social services (Waxman et al., 2003). This was evidenced in a South African study on teachers' ability to provide psychosocial support in schools, where teachers collaborated with other organizations to provide material support to vulnerable children (Ferreira \& Ebersohn, 2011). Schools can also organize events, such as special assemblies, and invite school guests whose messages can motivate children (Christiansen et al., 1997), which ultimately can increase resiliency and school attendance.

Studies, however, put the onus on the school authorities to build that school climate, which enables a child to participate fully (Christiansen et al., 1997; Waxman et al., 2003) in support programs that will help mitigate their risks and 
ultimately keep them attending school. In order to do so, Condly (2006) suggested that school staff needed to take a proactive approach in identifying students who may require protective interventions because being at school was not always a guarantee that the child would access development and support services. McMillan and Reed (1994) went further to suggest that teachers should seek out and personally invite at-risk children to join school programs, as many would not participate voluntarily because they feel disconnected. The Ferreira and Ebersohn (2011) study findings reported that teachers identified at-risk children by observing the children in class, or on school grounds. Taking this proactive approach requires that school staff are trained in the skills needed to identify atrisk students, and to find ways of helping them cope with their situation (Christiansen et al., 1997).

Johnson (1997) presented a dissenting view about designing school programs for at-risk children and argues that school programs are broadly designed to benefit not only at-risk students, but whoever was exposed to them. She contended that where school-based programs had a positive impact on at-risk students, individual or family factors would have to interact with each other to influence the individual resiliency factors of the at-risk student.

Educational resilience literature further highlights the unique position and the significant role that teachers and other school staff play in providing support for children who are at risk (Christiansen et al., 1997; McMillan \& Reed, 1994; SandinEsteban \& Sanchez-Marti, 2015). One critical role that teachers play is that of being a special person providing positive supportive human interactions and relationships essential to protect or compensate for children's adversities (Christiansen et al., 1997). Normally, families would be expected to provide this type of support through a network of special relationships, but in situations where at-risk children are not able to access this type of network, a relationship with one special individual can provide guidance, safety, protection, and support (Cooklin, 2009; Katz, 1997). The adult can also develop a mentoring relationship that nurtures the at-risk child by transferring knowledge and life lessons (Christiansen et al., 1997; Gandara, 1995; Katz, 1997).

Within the school setting, teachers provided special support and encouraged students facing adversities to aspire for more than what they believed they could achieve (Waxman et al., 2003). Such outstanding teachers were considered to go 
beyond their call of duty to play the additional role of being the confidant and positive role model (Benard, 1991), and demonstrated that they had high expectations for students to achieve positive outcomes (Katz, 1997; Sandin-Esteban \& Sanchez-Marti, 2015). Resiliency scholars further described a supportive teacher as one who shows kindness and compassion, provides mentorship to at-risk students, and conveys genuine support to students by listening to them and validating their feelings (Waxman et al., 2003). In addition, a supportive teacher is understanding (Zimmerman \& Arunkumar, 1994) and someone whom students could talk to about anything without feeling that they were being judged (McMillan \& Reed, 1994). Katz (1997) described this relationship as a mentoring one where an individual formed a nurturing bond and was able to "share knowledge, wisdom and lessons of life to leave a lasting imprint" (p. 7).

McMillan and Reed (1994) summed up the interpersonal qualities of a supportive teacher as one who was:

[...] Caring, having respect for them as persons and as learners, being able to get along with them, listening without being intrusive, taking them seriously, being available and understanding, helping and providing encouragement, and laughing with them. (p. 139)

Beyond the interpersonal attributes mentioned above, Waxman (2003) suggested that supportive teachers can also assist at-risk students by providing material supplies and reaching out to family members to find out what their basic needs are.

Taking into account these expectations of a supportive teacher, it is important that the skills of teachers are enhanced to provide this special attention, expect positive results, develop relationships (Christiansen et al., 1997; McMillan \& Reed, 1994), and improve education outcomes for at-risk children (Waxman et al., 2003). The training for both in-service and preservice teachers may include seminars or lectures specifically on how to work with at-risk students (McMillan \& Reed, 1994). Waxman et al. (2003) further suggested providing feedback from classroom observation and learning environment (p. 13). Nyabanyaba (2009) suggested capacitating teachers' skills to identify and support at-risk students with psychosocial support (p. 53). Ferreira and Ebersohn (2011), however, provided 
mixed arguments on this matter and argued that, by teachers choosing the teaching profession, they should already possess characteristics such as "empathy, caring and supportive dispositions" (p. 64). On the other hand, the authors contended that teachers, in most cases, did not receive formal training in social work, counseling, or psychology, and may therefore not have the needed competencies to deal with psychological issues.

Beyond teachers, resilience studies also identified peers as another source of psychological support in times of hardship (Skovdal et al., 2009). A study that reviewed lessons from research on resilient children and adolescents postulated that, for children attending school on a regular basis, positive outcomes had been associated with peer acceptance (Masten \& Coatsworth, 1998). The authors highlighted the importance of children belonging to prosocial peer groups, arguing that friends played a role in providing emotional support and were also able to influence academic achievement either positively or negatively. Another study on developmental vulnerabilities and strengths of children heading households in South Africa found peer support to be the most common source of help with schoolwork (Donald \& Clacherty, 2005).

Studies have also shown that where school factors influenced school attendance, these mostly interacted with other domains, such as family and community factors. Christiansen et al. (1997), for example, proposed a multifaceted approach in responding to the needs of vulnerable children in school and argued that where school-based programs compensated for social vulnerability, individual or family factors may also play a role in mitigating risk. The authors specifically cited parental school involvement as a factor that contributed to school success. In concurrence, Condly (2009) showed how schools might link with organizations outside the school setting to link at-risk students to access social services. The majority of the education resilience academic literature I am drawing on comes from developed countries. My dissertation adds to this discourse from the subSaharan context. 


\section{Community Factors}

The role of communities has also been highlighted in developing individual attributes, such as having hope for the future, social skills, and problem-solving skills that are characteristics of a resilient child (Benard, 1991). A supportive community is described as one whose structures and networks can help mitigate risks and provide a protective, caring, and supportive environment, and whose members have high expectations of at-risk populations (Katz, 1997). According to Grant (2011), the way in which other community members treat families will influence both the positive or negative outcomes of the family members, including young carers.

Scholars such as Benard (1991), Johnson (1997), and Benzies and Mychasiuk (2009) have suggested that the most effective protection would be to ensure that those at risk are participating in community-based programs and have access to resources and basic services. The core of this support is, according to Johnson, supportive human relationships for at-risk individuals and families. Community members can also provide mentorship to enhance resiliency amongst those at risk (Benzies \& Mychasiuk, 2009). These human relationships may be fostered through social networks that will ultimately link vulnerable individuals to mitigating services (Benard, 1991). Studies on the care and support of orphans in sub-Saharan Africa have highlighted the role of communities, suggesting that traditionally, the child was considered to belong to the community and could be disciplined and cared for by the community (Tanga, 2013, p. 180). Community groups were therefore best suited to identify those most at risk; provide social, emotional, and material support to families; and monitor their progress over time (Foster et al., 1996).

The chapters that follow will be framed around this theoretical framework and prior literature, to examine how these apply to female child carers attending secondary school in Lesotho. 


\section{CHAPTER 3}

\section{RESEARCH METHODS}

\subsection{Introduction}

This study aimed to examine factors that facilitated, or enabled, secondary school attendance of female child carers in Lesotho, and used Urie Bronfenbrenner's socioecological framework (Bronfenbrenner, 1994) to explain how personal and external factors or social systems are interconnected in influencing positive behavioral outcomes (Pocock et al., 2012; Stokes, 1996). This model has been used in various academic disciplines to explain the interaction between individual and external relationships in influencing behavior (CDC, 2013; Condly, 2005; Embrace the Future, 2005; Fredricks et al., 2004; Waxman et al., 2003; WHO, 2002). I used the framework to examine how individual and external factors influenced female school attendance in Lesotho.

These were analyzed under four domains: individual, family, school, and community.

(i) Individual factors were measured by: (a) a female child carer's sense of optimism and being hopeful for a better future (Benard, 1991; Embrace the Future, 2005), understood as whether a child reported positive future aspirations; (b) whether and how a child carer reported having role models that kept her motivated to attend school; (c) whether and how a child carer reported having sought help from family (Benard, 1991; Condly, 2006) or community members (Skovdal et al., 2009) to assist with caregiving responsibilities; and (d) whether and how a child carer reported school attendance being influenced by a child's religious background or belief (Condly, 2006; Embrace the Future, 2005).

(ii) Family factors were measured by whether and how immediate and extended family members provided material (such as books, uniforms, and shoes) and financial support (school fees and transport), 
socioemotional support, and assisted the child carer with caregiving responsibilities (Condly, 2006; Katz, 1997; Skovdal et al., 2009).

(iii) School factors were analyzed by whether and how: (a) school teachers and administrators provided financial, psychosocial, and material support to child carers; (b) school peers provided financial, psychosocial, and material support for the child carers to stay in school (Donald \& Clacherty, 2005); (c) the school environment was conducive to providing or linking (Condly, 2006) child carers to counseling services, school bursaries (Katz, 1997), and other services.

(iv) Community factors were measured by whether and how: (a) community members provided support or linked child carers to financial, material, psychosocial, and other social services, and (b) civil society organizations and faith-based organizations, based in the community, provided educational support to vulnerable female children.

These factors were assessed by how each domain influenced school attendance, and how the different domains interacted with each other to influence school access.

\subsection{Rationale for Research Approach}

Research on the phenomenon of child carers is as recent as the 1990s. This is a group of children for whom there is little research; they are also referred to as a "hidden" or "invisible" group of children (Becker, 2007; Moore, 2005b; Rose \& Cohen, 2010). Although Lesotho policy documents acknowledge child carers, school records did not capture household composition. It was therefore pertinent that we used a research approach that allowed for the specific and selective sampling of participants. Qualitative research is suitable for this type of study as it gave me the freedom to purposefully sample participants or sites best suited to answer the research question. With this approach, I was able to diversify groups of study participants. In addition to child carers attending secondary school, I also solicited the views of school teachers, government policy makers, nongovernmental organization staff, and community-based organization 
volunteers on their perceptions of potential individual, family, school, and community factors that influence secondary school attendance of the female child carer.

Since I sought to get an in-depth understanding of perceptions on the topic, I also needed to employ a research approach that would help view social phenomena in a holistic manner and allow the researcher to understand themes from the participants' own perspective (Creswell, 2003; Weiss, 1995). Using a qualitative approach also gave me the option to use a variety of tools that would help interrogate the topic at hand from different angles. For example, a semistructured interview guide helps with exploring perceptions on difficult topics and also enables probing for more information when needed. (Barriball \& While, 1994).

\subsection{Rationale for Site Selection}

Lesotho was well suited as the site for this study as national demographic data indicated a high likelihood that there would be children who were caring. The country is situated within the region most affected by HIV/AIDS, has the third highest HIV prevalence in the world after Swaziland and Botswana (UNAIDS, 2013), and a resulting high orphan prevalence of about one third of the country's children having lost one or both parents (Government of Lesotho, 2011). The orphans are mostly cared for within a family setting, with the majority living with a single parent or a grandparent (Lesotho Ministry of Health and Social Welfare, 2010). About 35\% of children in Lesotho do not live with their parents (Ministry of Health [Lesotho] and ICF International, 2014). There is a high likelihood of orphans and other children taking up caregiving responsibilities as indicated in a broadbased study on secondary school access in Lesotho, which identified child heading households and caring for the sick as critical barriers to accessing schooling (Nyabanyaba, 2009).

Furthermore, secondary school statistics showed a low 37.7\% net enrollment rate (Lesotho Bureau of Statistics, 2015) and a secondary school net enrollment rate (NER) of 32\% in 2011 (UNICEF, 2015). The Lesotho Demographic Health Survey 2014 reported that only $19 \%$ of women and $16 \%$ of men have completed secondary school (Ministry of Health [Lesotho] and ICF International, 2014). Based on the above statistics, there was a high possibility that children who were faced with 
adversity would drop out of school. It is therefore important to understand the factors that keep those who are still attending school, despite facing the risks of dropping out of school due to challenges of being a female child carer.

I conducted this research in the urban and rural areas of the city of Maseru, the capital of Lesotho. Rural/urban sites were selected to provide a varied explanation on whether location has a bearing on female child carers' school attendance. I selected Maseru purposively based on the fact that I have access to the schools, NGOs, and communities through my work as USAID's Senior Regional Advisor for orphans and vulnerable children in Southern Africa. Maseru has the highest district prevalence of $\mathrm{HIV}$ at $26.5 \%$ and third highest orphans prevalence at $31 \%$ of children having lost one or both parents (Lesotho Ministry of Health and Social Welfare, 2010). Because official reports reviewed do not provide statistical information on child carers, I used statistics of maternal, paternal, double, or "social" orphans who are in secondary school as a proxy indicator for child carers who are in school (see Table 3.1).

The Lesotho Education Statistics Report considered a child to be a social orphan when they still had parents, but were severely vulnerable due to extreme poverty and abuse (Lesotho Bureau of Statistics, 2015). Lesotho's 2014 Education Statistics Report shows that, of the 128,473 pupils enrolled in secondary school in Lesotho, $41.4 \%$ had either lost a parent by death or were social orphans, with female orphans outnumbering males. There were more orphans enrolled in the lower grades than higher grades, which could be a demonstration of orphan attrition in higher levels. In consultation with the Ministry of Education and Training (MOET), I purposively sampled two high schools, "Dengwe" Rural High School and "Kikombe" Urban High School, , one located in the rural part of the district and the other in the urban area.

At the time of data collection, "Dengwe" Rural High School had an enrolled number of 667 pupils aged between 13 and above 24 attending Form A to Form E. ${ }^{5}$ Of these, a total of 275 (213 below the age of 18) had lost either one or both parents and 38 children were considered vulnerable. The MOET data collection form

\footnotetext{
${ }^{4}$ Pseudonyms have been used for both schools to protect the identity of respondents.

${ }^{5}$ Lesotho Ministry of Education and Training, Annual Statistical Return Secondary School Form-ER42C (2015).
} 
defines a vulnerable child as "a child who is extremely poor, and or physically abused" and recommends that "only extreme cases e.g. that affect school attendance of a child" should be recorded. ${ }^{6}$ Eighty-four children were receiving scholarship support.

Table 3.1: Orphans in Registered Secondary Schools by Type, Form, and Sex, 2014

\begin{tabular}{|c|c|c|c|c|c|c|c|c|c|c|c|c|}
\hline \multirow{2}{*}{$\begin{array}{l}\text { Orphan } \\
\text {-hood } \\
\text { Type }\end{array}$} & \multicolumn{2}{|c|}{ Form A } & \multicolumn{2}{|c|}{ Form B } & \multicolumn{2}{|c|}{ Form C } & \multicolumn{2}{|c|}{ Form D } & \multicolumn{2}{|c|}{ Form E } & \multirow{2}{*}{ Total } & \multirow{2}{*}{$\%$} \\
\hline & $\mathbf{M}$ & F & $\mathbf{M}$ & F & $\mathbf{M}$ & F & $\mathbf{M}$ & F & $\mathbf{M}$ & F & & \\
\hline $\begin{array}{l}\text { Pater- } \\
\text { nal }\end{array}$ & 3031 & 4101 & 2790 & 3826 & 2067 & 2804 & 1740 & 2417 & 1465 & 1976 & 26217 & 50.5 \\
\hline $\begin{array}{l}\text { Mater- } \\
\text { nal }\end{array}$ & 1166 & 1515 & 1011 & 1320 & 769 & 1038 & 703 & 902 & 516 & 714 & 9654 & 18.6 \\
\hline Double & 1571 & 2206 & 1532 & 2037 & 1198 & 1692 & 979 & 1351 & 833 & 1156 & 14555 & 28.1 \\
\hline Social & 161 & 213 & 131 & 242 & 144 & 173 & 105 & 128 & 75 & 78 & 1450 & 2.8 \\
\hline Total & 5929 & 8035 & 5464 & 7425 & 4178 & 5707 & 3527 & 4798 & 2889 & 3924 & 51876 & 100 \\
\hline
\end{tabular}

Note. Adapted from 2014 Education Statistics Report, Lesotho Bureau of Statistics.

"Kikombe" Urban High School recorded 1,098 pupils also aged between 13 and above 24 enrolled at the school in Forms A to E. Of these, 501 (457 below 18) were paternal, maternal, or double orphans. The school recorded 388 vulnerable children and 92 received educational sponsorship. ${ }^{7}$ The schools keep records of the number of orphans by type, class, and sex and are therefore able to identify children who may be in need. Figure 1 is an example of such a form.

\subsection{Data Collection}

My study is based on data from interviewing 58 participants. I conducted 41 indepth interviews and two focus group interviews with 14 members of community based organization, and a second one with three policy makers from the Ministry Of Social Development (Refer to Table 3.2 for breakdown.)

${ }^{6}$ MO Lesotho Ministry of Education and Training, Annual Statistical Return Secondary School Form-ER42C (2015) ET Form 6 (c) Enrolment of Orphans and Vulnerable Children (OVC) by Age, Form and Sex.

${ }^{7}$ Ibid 


\section{Approvals and Ethical Considerations}

It is important when conducting qualitative studies that the researcher seeks approval of gatekeepers in order to have access to the research sites or study participants (Creswell, 2003). Prior to data collection, I obtained written approval from the Ministry of Education and Training and the Ministry of Social Development (MOSD), the two key ministries responsible for education and vulnerable populations, respectively (see Annex 2 and Annex 3 for approval letters). Although the main focus of the research was on education outcomes, it was important to notify the MOSD and also get approval because I was targeting a vulnerable population, a group under its jurisdiction. I used the letters of approval from the MOSD and MOET to gain entry into the communities where I met with the community leaders in the Area Community Councils to inform them of my research, and get verbal permission to conduct interviews in the localities. With these approvals, school principals then made arrangements to interview the child carers and the teachers.

I took into account ethical considerations to ensure that the rights of all the participants were protected by explaining the purpose of the study, and their rights and protection (Blumberg et al., 2011). For the interviews with children, I included other ethical considerations recommended by Noble-Carr (2006): "informed consent, privacy and confidentiality" (p. 5). Kvale and Brinkmann (2009) defined informed consent as follows:

Informed consent entails informing the research participants about the overall purpose of the investigation and the main features of the design, as well as of any possible risks and benefits from participation in the research project. Informed consent further involves obtaining the voluntary participation of people involved, and informing them of their right to withdraw from the study at any time. (p. 70)

The content of the consent form was read to the child in either English or Sesotho, making sure the child also understood that only pseudonyms would be used in the study and actual names would not be attached to their responses. To ensure privacy, the rural school allocated the use of the school library while the urban school set aside one office as secluded places for the interviews. To further protect the identity of the respondents, I have used pseudonyms for the schools.

Each child participant signed one consent form (Annex 4) before starting the 
interview. Before commencing the interviews with the children, the school teacher responsible for organizing the interviews signed the adult consent form (Annex 5) permitting me to interview the children. These forms, adapted from the University College Cork (2014), explain the purpose and procedures, risks and discomforts, potential benefits, protection and confidentiality, and voluntary participation.

\section{Data Collection Tools}

I employed a semistructured interview guide as the data collection tool for this study because semistructured interviews are "well suited for the exploration of the perceptions and opinions of respondents regarding complex, and sometimes sensitive, issues and enable probing for more information and clarification of answers" (Barriball \& While, 1994, p. 330). The authors further suggested using a semistructured interview guide where the sample group varied in characteristics, such as personal history, education, and profession. A semistructured format also allowed for consistency across participants and for the research to identify some prominent themes that impact resilience. It follows that with the varied nature of the sample in this research, and because I was aiming to study participants' views or experiences, the use of a semistructured interview guide was more appropriate than a standardized questionnaire.

Literature suggests that questions in a semistructured interview guide should normally be specific and presented as an outline of the research topics, with suggested probing questions that allow for a free flowing dialogue and will help the researcher solicit additional information from respondents (Blumberg et al., 2011; Kvale \& Brinkmann, 2009; May, 2001). Following this, I designed two interview guides, one to use for interviews with child carers, and the other to use with teachers, policy makers, and nongovernmental organizations. The semistructured interview guides aligned with the themes of the socioecological model, which is the theoretical framework guiding this research. 


\begin{tabular}{|c|c|c|c|}
\hline Respondents & No. & Rationale for Interview & Date of Interview \\
\hline $\begin{array}{l}\text { Female child carers } \\
\text { currently attending } \\
\text { secondary school }\end{array}$ & 28 & $\begin{array}{l}\text { To get their perspective on } \\
\text { individual, family and } \\
\text { external factors of why they } \\
\text { are in school. }\end{array}$ & $\begin{array}{l}27 \text { March } 2015 \\
6 \text { August } 2015 \\
17 \text { Nov. } 2015 \\
18 \text { Nov. } 2015 \\
20 \text { Nov. } 2015\end{array}$ \\
\hline $\begin{array}{l}\text { Secondary school } \\
\text { teachers / } \\
\text { Administrators } \\
\end{array}$ & 9 & $\begin{array}{l}\text { For triangulation and to get } \\
\text { the teacher/counselor's } \\
\text { perspective. }\end{array}$ & $\begin{array}{l}27 \text { March } 2015 \\
6 \text { August } 2015 \\
18 \text { Feb. } 2016\end{array}$ \\
\hline $\begin{array}{l}\text { Policy Makers: } \\
\text { Ministry of } \\
\text { Education and } \\
\text { Training; } \\
\text { FGI with Ministry } \\
\text { of Social } \\
\text { Development }\end{array}$ & 3 & $\begin{array}{l}\text { Triangulation. MOET is } \\
\text { custodian } \\
\text { of education policy and } \\
\text { provides school scholarships. } \\
\text { MOSD is custodian of policies } \\
\text { affecting vulnerable } \\
\text { populations and is also } \\
\text { responsible for school } \\
\text { bursaries. They will give } \\
\text { government perspective on } \\
\text { external factors influencing } \\
\text { school access. }\end{array}$ & $\begin{array}{l}28 \text { January } 2015 \\
15 \text { July } 2015\end{array}$ \\
\hline $\begin{array}{l}\text { Civil Society } \\
\text { Organization } \\
\text { providing } \\
\text { education support }\end{array}$ & 2 & $\begin{array}{l}\text { Triangulation and to get } \\
\text { views from organizations that } \\
\text { are providing education } \\
\text { support to children and } \\
\text { influencing government } \\
\text { policies. }\end{array}$ & $\begin{array}{l}15 \text { Feb. } 2016 \\
23 \text { March } 2016\end{array}$ \\
\hline $\begin{array}{l}\text { FGI with } \\
\text { Community-Based } \\
\text { Organization } \\
\text { members }\end{array}$ & 14 & $\begin{array}{l}\text { For triangulation and to get } \\
\text { views of stakeholders based } \\
\text { in the community. }\end{array}$ & 12 Dec. 2014 \\
\hline Total Respondents & 58 & & \\
\hline
\end{tabular}

The child carer interview guide (Annex 6) was structured in seven sections. The first section had warm-up questions that sought to get general information about the female child carer, such as the family composition, type of caregiving they provided, and any challenges they faced (see Figure 3.3). 
Four sections focused on the themes of the study: individual factors, family factors, school factor, and community factors, each with between two to five probing questions. The fifth section had questions to give the participant an opportunity to add on any other issues that may not fall within the four domains. The last section contained questions to collect demographic characteristics (see Figure 3.4), items which helped to categorize the population of participants and can help with further qualitative exploration (Weiss, 1995).

The interview guide for teachers, policy makers, and NGO staff had eight questions with the first three questions aimed at soliciting participants' views on child carers' general situation, such as type of caregiving responsibilities, what factors facilitated that situation, and why they were still attending school.

1. Tell me about yourself. What do you enjoy most about school?

2. Tell me about your family. Who do you live with in your house?

3. Tell me about your family members. Who takes care of them?

4. What types of responsibilities do you have for caring for other members of your family? How are you involved in caring for them?

5. Tell me how you spend your day during the week, and how you spend your Saturdays and Sundays.

6. How would you describe the amount of work related to the responsibilities you just described?

7. Tell me about the work you do to help care for your family.

8. What are the biggest challenges for you when it comes to staying in school?

Figure 3.3. Warm-up questions from the child carer interview guide.

The next four questions were tailored to the theoretical domains: individual, family, school, and community. The last question sought to determine if there were any other factors that may not have been covered in the interview.

In addition to the interview guide, I also used a focus group interview (FGI) guide to conduct two focus group interviews with members of a community-based organization and staff from a government ministry. Focus group interviews are recommended when one is soliciting different viewpoints on a topic from a group 
of experts (Blumberg et al., 2011; Kvale \& Brinkmann, 2009). The FGI guide also constituted eight questions with four soliciting views on the four theoretical domains (see Annex 7 for the list of questions).

Using a semistructured interview guide and focus group interviews, I collected data from 58 respondents, including 28 in-school female child carers, nine teachers and administrators, five senior government officials, two nongovernmental organization staff, and 14 community-based organization volunteers.

\section{Information about the child}
a. Age:
b. Form:
c. Location: Rural/Urban
d. Number of household members: Below 18
e. Number of household members attending: Above 18

i. Primary school

ii. Secondary school

iii. Tertiary education

f. Number of household members earning an income

g. Number of hours child working outside the home

h. Number of days absent in the year

Figure 3.4. Quantitative items from the interview guide. Adapted from author's compilation.

\subsection{Sampling Criteria}

School authorities guided the identification and selection of the girls based on their knowledge of the situation of the girls and from their school administrative records on children who have lost one or both parents or were social orphans. Participants were sampled on the basis of them being primary caregivers, that is, they were the ones responsible for taking care of a sick, disabled, or frail adult or sibling in the home. They also should have been heading a household comprising a child or children younger than them. The participant had to be female, aged 18 or below, and considered to be providing care on a regular basis, and in a significant manner (Dearden \& Becker, 2002). Those identified had to be regularly attending class at the two sampled secondary schools "Dengwe" Rural High School and "Kikombe" 
Urban High School ${ }^{8}$. Regular attendance was defined as attending school at least $80 \%$ of the time (Lewin \& Little, 2011).

At the rural school, the school principal requested class teachers to provide the list of girls that fit the criteria. At the urban school, the principal identified one teacher who went around the classes and worked with teachers to identify potential participants. Other children self-identified and approached the teacher offering to participate. The principals at both schools identified the teacher participants.

\section{Profile of the Female Child Carer in the Study}

The study targeted 28 females who were attending secondary school and were primary caregivers in their households. Twelve of them came from a rural school and 16 from an urban school. Of these, the majority (10) were aged 17, followed by age 18 with six participants. Three girls were aged 14, five were aged 15, and four were aged 16. The participants were drawn from all the secondary school classes, Form $\mathrm{A}$ to $\mathrm{E}$, which is an equivalent of Form 1 to 5. Lesotho's official age range for secondary school is 13 to 18 years (Classbase, 2012), although it is common to find older students as age is not a requisite for exclusion.

The largest number of participants, eight, came from Form B, followed by Form D with seven, Form A with six, and Form E with five. The least number came from Form C with two participants. Eight children indicated having received a scholarship from government or nongovernmental organizations, and 12 mentioned having been involved in some form of work to earn an income. The majority of the girl respondents are orphans, having lost one (13) or both (seven) parents. Seven girls indicated having both parents alive and one did not disclose. Fifteen were taking care of more than one individual in the household and the rest, 13, only had one care recipient. Table 3.5 illustrates the child carer profiles.

\section{School 1: "Dengwe" Rural High School.}

I conducted interviews at "Dengwe" Rural High School between March 27, 2015 and August 6, 2015. There was a lag in between interviews because of school holidays and work commitments. The first interviews on March 27, 2015 were with

\footnotetext{
${ }^{8}$ For confidentiality purposes and to protect the identity of participants, names of schools sampled are pseudonyms.
} 
six female child carers and the principal of the school. The school authorities had initially selected nine girls, but I excluded three for not meeting the child carer definition as two were living alone and one was living in a boarding house at the school. My initial approach was to sample in-school female child carers in Forms D or E. My rationale for picking the last two grades was based on the fact that Lesotho recorded a major decline in the number of enrolled students in terms of progression from Form A in 1999 to Forms D and E in 2002 and 2003 (Government of Lesotho MOET, 2005), and therefore I considered getting to this level as an indication of education success.

Upon realizing that applying these restrictions would not give me a large enough sample, I expanded the sampling frame to include all female child carers in secondary school, regardless of age and class level. This gave me a broader sample with more varied characteristics in terms of class level, type of care recipients, and other factors. I conducted the third and final in-depth interviews at the rural school on August 6, 2015 with another six female child carers. The interview guide for this set of in-depth interviews was revised to include two additional questions that would fill data gaps identified during the first round of interviews. The questions aimed to find out from the child carers' perspectives the extent of their care. Using this developmental approach, where future interview protocols are revised, is supported by (Creswell 2003), who stated that several aspects of qualitative research may be refined as the researcher learns what to ask and whom to ask.

\section{School 2: "Kikombe" Urban High School}

With the sampling experience from the first school, in addition to providing school authorities with the selection criteria, I also clarified who would not qualify. Based on this, only one candidate was excluded on the basis of living alone at home. The school principal provided the list of female child carers based on the adjusted criteria that had no limit on age or class. I conducted interviews with 16 female child carers at the school between November 15 and November 20, 2015, using the revised interview guide. I interviewed six girls on day one, followed by four and the last six on the third day. Unlike at the first school, where I conducted the interviews when children were out of class or participating in sports, the principal at the urban school suggested having the interviews during school hours with a child carer being called out of class. In both situations, the school authorities ensured that there was minimal class disruption. 
I conducted the interviews with the female child carers with the support of a research assistant, Mrs. Puseletso Phori, who played the role of translator when participants opted to use Sesotho, Lesotho's official language. Most child carers attempted to first respond in English, but would switch to Sesotho as the interview progressed and as soon as they seemed settled enough to tell their story. At this point, the research assistant would ask the questions in Sesotho using the translated interview guide. Each individual interview lasted between 25 and 45 min.

I trained the research assistant, who is a qualified social worker and has experience working with, and interviewing children, by explaining to her the objectives of my research and going through the research protocol with her. The research assistant translated the research protocol into Sesotho and we pilot tested it on an independent person, Lekhanya Lekhanya, for validation. The option of using a language other than English ensured that language did not become a participation barrier.

Barriball and While (1994) argued for the inclusion of participants who may not speak the primary language of the researcher, in this case English, if they were willing to participate and their views would add to the validity of the results. Translating the interview protocol ensured that the questions in the Sesotho interview protocol could be used in a consistent manner, an important factor for semistructured interviews. I provided the child carer respondents with a set of school supplies comprising pens, rulers, pencils, and an eraser as a gift of appreciation for participating in the interviews. In addition to the gift, I also provided a snack and a drink when I conducted the interviews after school hours. Of the three common ways of recording interviews, taking notes, audio-taping, and video-taping (Creswell, 2003), I opted to audio-tape the interviews as the most practical option for this study. I recorded my interviews using a tape recording 
Table 3.5: Child Carer Participant Profile ${ }^{9}$

\begin{tabular}{|c|c|c|c|c|c|c|c|c|c|c|}
\hline \multirow{2}{*}{$\begin{array}{l}\text { Child } \\
\text { Carer }\end{array}$} & \multirow[t]{2}{*}{ Location } & \multirow[t]{2}{*}{ Age } & \multirow[b]{2}{*}{ Class } & \multicolumn{3}{|c|}{ Care Recipient } & \multirow{2}{*}{\begin{tabular}{|l} 
Number \\
Care \\
recipient
\end{tabular}} & \multirow{2}{*}{$\begin{array}{l}\text { Scholar- } \\
\text { ship }\end{array}$} & \multirow[t]{2}{*}{ Orphan } & \multirow{2}{*}{$\begin{array}{l}\text { Earning } \\
\text { Income }\end{array}$} \\
\hline & & & & Child & $\begin{array}{c}\text { Grand } \\
\text { parent }\end{array}$ & $\begin{array}{l}\text { Other } \\
\text { adult }\end{array}$ & & & & \\
\hline Lerato & Rural & 17 & $\mathrm{D}$ & $\checkmark$ & & & 1 & Yes & Double & Yes \\
\hline Palesa & Rural & 17 & $E$ & $\checkmark$ & & & 5 & Yes & Single & Yes \\
\hline Mamea & Rural & 17 & $\mathrm{D}$ & $\checkmark$ & & & 2 & No & $\mathrm{N} / \mathrm{A}^{10}$ & No \\
\hline Limpho & Rural & 17 & $\mathrm{D}$ & $\checkmark$ & & & 2 & Yes & Double & Yes \\
\hline Tsili & Rural & 18 & $\mathrm{E}$ & $\checkmark$ & & & 2 & No & Single & No \\
\hline Mpho & Rural & 18 & $\mathrm{E}$ & $\checkmark$ & & & 1 & No & Single & Yes \\
\hline Linda & Rural & 14 & B & $\checkmark$ & $\checkmark$ & & 4 & No & Single & Yes \\
\hline Maria & Rural & 17 & $\mathrm{~B}$ & & $\checkmark$ & $\checkmark$ & 3 & Yes & Double & No \\
\hline Tina & Rural & 17 & B & $\checkmark$ & & & 1 & No & No & Yes \\
\hline Mindy & Rural & 16 & B & $\checkmark$ & $\checkmark$ & & 4 & No & Single & No \\
\hline Jessy & Rural & 18 & $\mathrm{C}$ & $\checkmark$ & & & 1 & No & Single & Yes \\
\hline Trisha & Rural & 16 & $\mathrm{C}$ & $\checkmark$ & & $\checkmark$ & 3 & No & Double & Yes \\
\hline Lisa & Urban & 15 & B & $\checkmark$ & & & 1 & Yes & Double & Yes \\
\hline Bridget & Urban & 14 & $\bar{A}$ & $\checkmark$ & & & 1 & No & Single & Yes \\
\hline Jackie & Urban & 15 & $\bar{A}$ & $\checkmark$ & & & 1 & No & No & No \\
\hline Eliza & Urban & 17 & $\mathrm{~A}$ & $\checkmark$ & & & 1 & No & No & No \\
\hline Mwaka & Urban & 14 & A & $\checkmark$ & & & 3 & Yes & No & No \\
\hline Dawn & Urban & 15 & $\bar{A}$ & $\checkmark$ & & & 2 & No & Double & Yes \\
\hline June & Urban & 15 & $\mathrm{~A}$ & $\checkmark$ & & & 1 & No & No & No \\
\hline Agnes & Urban & 15 & B & $\checkmark$ & & & 2 & No & No & No \\
\hline Bertha & Urban & 18 & B & $\checkmark$ & & & 1 & No & Double & No \\
\hline Charity & Urban & 17 & B & $\checkmark$ & & & 1 & Yes & Single & Yes \\
\hline Milly & Urban & 18 & $\bar{E}$ & $\checkmark$ & & & 2 & No & Single & No \\
\hline Kathy & Urban & 18 & $\mathrm{E}$ & $\checkmark$ & & & 1 & No & Single & No \\
\hline Joan & Urban & 16 & $\mathrm{D}$ & $\checkmark$ & & & 1 & No & Single & No \\
\hline Angela & Urban & 17 & $\mathrm{D}$ & $\checkmark$ & $\checkmark$ & & 2 & No & Single & No \\
\hline Fiona & Urban & 16 & D & $\checkmark$ & & & 1 & No & No & No \\
\hline Gina & Urban & 17 & $\mathrm{D}$ & $\checkmark$ & $\checkmark$ & $\checkmark$ & 3 & Yes & Single & No \\
\hline
\end{tabular}

\footnotetext{
${ }^{9}$ For confidentiality purposes and to protect the identity of participants, all names used are pseudonyms.
}

${ }^{10}$ Not disclosed. 
application for iPad and android phones, and used both pieces of equipment to eliminate the risk of losing data in case of equipment malfunction

Audio-taping is a proven way of capturing the interview which helps to provide a detailed record of the performance of both the interviewer and the respondent (Barriball \& While, 1994). Before the interviews, the participants consented to being tape-recorded with the understanding that the recording would be deleted once the interviews were transcribed.

\subsection{Triangulation}

In addition to interviewing the female child carers, I conducted interviews with other primary stakeholders in order to get their views on why female child carers, despite facing difficult circumstances, regularly attend school. I used this information to triangulate and validate findings of the in-school female child carers. Triangulation involves collecting and analyzing data from various sources to gain a broader perspective on the situation being investigated (Lacey, 2007). I particularly selected experts from institutions that regularly come into contact with child carers, and would therefore be key stakeholders on this phenomenon. The sources of data for this purpose included school teachers and school administrators, policy makers from two ministries responsible for education and vulnerable populations, civil society organizations, and a community-based organization (see Table 3.6).

I conducted in-depth interviews with a total of nine teachers and administrators, four from the rural school and five from the urban school. It was important to include teachers in the sample for validation and triangulation as the teachers interact with the child carers on a regular basis and were expected to provide information from past knowledge and experience, and as the adults that spent most of each weekday with the girls.

The school principals selected the teachers mainly on the basis of their involvement in supporting vulnerable children. Teacher "Teboho," for example, was the school's focal point person responsible for liaising with organizations that were interested in sponsoring vulnerable children at the school. I conducted the interviews with staff at the rural school over two days, including once when school 
was in recess, but the teachers were willing to come to the school specifically for the interviews. I had to conduct the interviews with the teachers at the urban school on the one day the school allocated to me for this process.

The purpose of the in-depth semistructured interview with the teachers was to get their views on why female child carers, despite facing difficult circumstances, regularly attend school.

I interviewed five senior government officials, four from the Ministry of Social Development and one from the Ministry of Education, in order to derive external factors that enabled girl-child carers to regularly attend secondary schooling. I opted to interview more staff at the MOSD due to the functions for which the ministry is responsible, which are relevant to my study.

Table 3.6: List of Respondent Type for Triangulation

\begin{tabular}{lll}
\hline Respondent Type & $\begin{array}{l}\text { Number of } \\
\text { Participants }\end{array}$ & Dates of Interviews \\
\hline Secondary School & 9 & 27 March 2015 \\
Teachers/Administrators & & 6 August 2015 \\
& & 18 February 2016
\end{tabular}

\begin{tabular}{lll}
\hline Policy Makers :MOET & 2 & 15 July 2015 \\
Focus Group Interview MOSD & 3 & 28 January 2015 \\
\hline Civil Society Organization & 2 & 15 February, 2016 \\
Providing Education Support & & 23 March, 2016
\end{tabular}

Focus Group Interviews with 14

12 December, 2014

Community-based

Organization Members

Total 30

Note. Source: Author's own compilation.

In particular, the functions that are most relevant are the bursaries unit responsible for issuing scholarships to vulnerable children and the social welfare directorate that issues cash grants to vulnerable households. I then conducted face-to-face interviews with a Director within the Ministry of Social Development in January 
2015, and later interviewed a policy maker at the Ministry of Education and Training.

Three policy makers from the Ministry of Social Development opted to be interviewed together, rather than individually. In order to make use of the opportunity of having three officials in the same place who were willing to offer an interview, I used the focus group interview guide for this process. According to Blumberg et al. (2011), exceptions can be made for a focus group to have a few participants, such as when discussing sensitive issues (p. 270).

I further interviewed one staff member from a national nongovernmental organization (NGO) and one staff member from an international agency, and held a focus group interview of 14 members of a community-based organization. I selected the NGO because teacher respondents mentioned it as an organization which provided education support to vulnerable children at their school.

\subsection{Data Analysis}

\section{Transcription}

The logical step following interviews is transcription. I transcribed the interviews and focus group interviews from the audio recording on the iPad and phone. It was critical that the transcriptions were recorded verbatim to avoid researcher bias, which may arise if only the summary notes are transcribed, as the researcher may only record what they find to be relevant (Lacey, 2007). Weiss (1995) also suggested transcribing "everything and use the transcripts as a set of materials to be mined" (p. 55). I then organized the data by giving each participant a pseudonym and code number separated by type of respondent.

\section{Coding}

My first round of coding was focused on individual, family, school and community factors, the four domains aligned with the socioecological framework guiding this research. As discussed in the introduction, this is a multilevel framework that explains the interplay among personal and environmental factors or social systems (Elder, 2006; Pocock et al., 2012; Stokes, 1996). This approach, known as concept driven coding, entails developing the codes in advance using preexisting theories or literature (Blumberg et al., 2011; Kvale \& Brinkmann, 2009). 
After identifying the four codes-individual factors, family factors, school factors, and community factors - from the theoretical framework, I used open analysis to identify themes within these codes. Blumberg et al. (2011) suggested using open analysis when the objective of the research is more focused on reading between the lines to "discover the full meaning of the source of the content" (p. 295). I used Microsoft Word to cut-and-paste excerpts from the interviews that fit the four key domains: individual, family, school, and community. I then reviewed the data to identify subthemes within the key categories, as well as other themes that did not fall within the codes that had been identified in advance. As these were not predetermined codes and were developed from reading the interviews, they are what Kvale and Brinkmann (2009) termed "data-driven" codes (p. 202). I included three main codes: (a) reason for caring, (b) caregiving responsibilities, and (c) challenges, in addition to the predetermined ones. The excerpts under these codes provided more information that helped answer the research question. With these additions, the total number of codes and subcodes for this study was 43 .

In order to help me standardize the coding process, I developed a code description defining the codes and indicating when they could be applied. See Annex 1, which shows the different codes that I generated and then entered into "Dedoose," a webbased computer application that is used for analyzing qualitative and mixed methods research. The use of computer packages helps simplify coding and recoding process (Lacey, 2007).

\section{Analyzing Relationship Within and Between Domains}

I employed a two-step process for analyzing the data. First, I generated reports of the data set under each code and subcode and printed them. I was then able to interrogate the excerpts to draw general conclusions about the issues being presented. For the next step, I used Dedoose to generate charts showing the subcode frequencies within each domain. Analyzing the data in this format gave me a snap-shot picture of how the study participants responded. I further generated charts to analyze the subcode frequencies under each domain against the descriptors age, location, orphanhood, child work, and type of care recipient. Presenting data using these charts gives a visual picture of the relationship between the descriptors and the subcode frequencies. 
To analyze the interplay between factors, I used Dedoose to view code cooccurrence frequency, which helped me identify the codes that I needed to review for analysis. I then generated reports of the excerpts that were common to two codes and analyzed them for any emerging themes that would explain the relationship between the codes. I also reviewed the domain codes for any salient issues that may not have been captured under two codes.

\subsection{Methodological Limitations}

The main limitation of the study is that it only covers one district in Lesotho. Although that district is representative of the problem in sub-Saharan Africa, external conditions vary across the subcontinent and the developing world, thereby affecting generalizability.

Sampling of participants was purely purposive as my research focused on a group of children that remains under researched, especially in sub-Saharan Africa (Becker, 2007) and not much is known about them. To identify child carer participants, teachers facilitated the selection of child carers based on a set criteria that I provided to them. This however may have created a selection bias in that the teachers would have identified only those that they perceived to have been fairing relatively well or were also receiving support from the school and may have influenced some of the participant responses.

The intention during the design of the study was to also interview out-of-school female children of a similar age group (14-18 years) and rural-urban locations in order to get their views on the motivation or factors that keep female child carers in school. My assumption was that, because the out of school girls would be drawn from the same geographical location, and would have most likely dropped out from the schools in the study, they would have been exposed to the same factors as the in-school girls and interviewing these girls would have benefitted the findings of the study. However, efforts to identify out-of-school female child carers through local community-based organizations were futile because girls who may have dropped out of school were said to have moved out of the area, were married, or were over age at the time and therefore did not meet the sampling criteria. Another limitation that my research presented is that the sample was more focused on older girls, those who were in secondary school. There may have been value in also 
sampling younger girl carers who had dropped out of school as they may have particular vulnerabilities worth examining.

Collecting data from children is more effective when traditional research methods, such as interviews, are combined with child visual and task-based techniques (Noble-Carr, 2006; Punch, 2002). The limited amount of time allocated by the school authorities against the number of interviews I planned to conduct made it difficult for me to use a "resource map" (Knowledge Sharing Management, 2014) as a visual tool that would have enabled the children to map educational support structures within the family, school, and community. Additionally, time limitation may have been a barrier for children. Although I managed to develop some form of rapport with the child participants before the interviews, I would have preferred to spend more time building the respondents' trust in order to make them feel more comfortable discussing their personal issues. The time allocated for my interviews with the child carers also affected the frequency of contact with the child carers. Having only one interview with each girl may have had an impact on the depth and quality of the conversation.

Although giving the participants the option to use both English and Sesotho ensured that language was not a barrier to participation, some of the meaning could have been lost in translation when Sesotho was used. The challenge of interpretation of meaning is expected but "...[is] more complicated when cultural contexts differ and interlingual translation is required" (van Nes et al., 2010, p. 314). 


\section{CHAPTER 4}

\section{FEMALE CHILD CARERS IN LESOTHO AND RISK FACTORS}

'Maria'11 is a 17-year-old girl who lives in a rural part on the outskirts of Maseru in Lesotho with her grandmother and grandfather. She takes care of the household by ensuring that there is food, water, and firewood; the house is clean; and the laundry is done. She walks for about an hour to get to her school where she attends Form B. She receives a government bursary that covers school fees and books. Her grandparents provide school supplies and school uniforms through their limited pension fund. She sometimes gets additional help with meals and school supplies from her best friend (whose parents are still alive) and immediate family. She really wishes she had parents like other children in the community.

The biggest challenge she faces, juggling school and household care, is running out of firewood in the middle of the week. Sometimes she is unable to finish her homework during the week because of all the chores she has to do. She spends a lot of her day fetching water and firewood. She combats her challenge by taking advantage of the weekends. She says:

"[On Friday] I gather firewood for the evening...on Saturday, I gather enough for the week... I cook...fetch water...clean...go to the river to do some washing...[and finally] start preparing supper. [On Sunday] I cook, then [go] to school to study. When I am done, I go back home to get some water... [and] prepare supper."

What motivates her, despite the challenges she faces, is her dream of one day becoming a teacher. She states that her biggest motivation to stay in school is to provide a better life for her grandparents. In five years she sees herself studying at a university and ensuring that all of her grandparents' needs are met, as she will be making money, and they are the ones who are helping her study.

\footnotetext{
${ }^{11}$ For confidentiality purposes and to protect the identity of study participants, names of all participants are pseudonyms.
} 


\subsection{Introduction}

The main focus of this study was to examine the factors that kept female child carers attending secondary school despite facing adversities of being a caregiver. In order to do so, it was essential that the study also understood how the challenges of caregiving could potentially present as risks to school attendance. These results can also inform policy so that governments can take active steps that can mitigate the unique cadre of challenges that child carers face.

Table 4.4 illustrates how challenges that study participants reported could create risks to attending school. I used Casen, Feinstein, and Graham's (2008) definition of risk factors as the "variables that signal an increased chance of poor outcomes" (p. 73). Subsequent chapters then discuss how individual, family, school, and community factors play a role in mitigating some of these risks to keep child carers in school. A similar approach to understanding resiliency was used in a study that looked at the coping strategies of child carers in Western Kenya, who are caring for ailing or aging guardians. The study showed that the extent to which children were able to cope was influenced by their ability to negotiate and access community support, and the ability of the community to share resources (Skovdal et al., 2009).

This section first provides a description of the female child carer by discussing the factors that contributed to them becoming child carers, presenting who the care recipients are, and what the nature of care is. This is followed by a discussion of the challenges which are presented as household-related factors and school-related factors. It concludes with a discussion about how psychological factors, financial constraints, parenting responsibilities, missing school, and time constraints as challenges may pose a risk to girl-carers' school attendance.

\subsection{Profile of the Female Child Carers in the Study}

The study targeted 28 girls who were attending secondary school in one rural and one urban school in Maseru and who were providing care in their households. The majority (20) of the girl interviewees were orphans who had lost one or both parents. Seven girls were categorized as social orphans, with both parents alive, and one did not disclose. Fourteen girls were providing multiple care (to more 
than one individual), which was equal to the number of those providing care to one individual in the household. Individual care recipients were siblings, grandparents, and nieces or nephews. Multiple care households comprised a combination of siblings alone, siblings and nieces/nephews, grandparents, grandparents, and siblings.

\subsection{What Factors Contributed to Girls Being Child Carers?}

This section discusses the reasons advanced by study participants as to why the girls in Lesotho took up caregiving responsibilities. Study participants cited death, migration, poverty, and family conflict as the probable reasons why they ended up in this situation as child carers. The AIDS pandemic may have been an underlying reason behind much of the death in Lesotho. The UNAIDS report estimated that about 73,000 children had been orphaned as a result of AIDS (UNAIDS, 2015). According to Becker (2007), the reasons why children become carers are multifaceted and complex. He argued that they find themselves in that situation because there is no alternative option. The author further contended that child caregiving is a result of services not being available to address the needs of those that the children end up caring for, summarizing as follows:

Their caregiving is an outcome of the interplay between demands for, and availability of, informal care within any family, community or society; a lack of available or affordable health and social care provision, particularly home-based care for people with care and supervision needs; and the lack of recognition and support available to meet the parenting needs of ill or disabled parents. (p. 34)

\subsubsection{Death of Parents}

The majority $(70 \%)$ of the child carers in the study had lost one or both parents, and some experienced family death for the second time when a relative who had assumed their guardianship also died. In the following excerpt, "Lerato," aged 17, a double orphan attending Form D at the rural school, described the multiple deaths she and her sister had experienced: “We don't have parents, we are double orphans, so I am the one who is left with [my sister]. We lived with our grandmother and grandfather but they died a long time ago, so now it's just the 
two of us." Similarly, 'Lisa,' aged 15, also a double orphan in Form B at the urban school, described her experience and said, "After my mother's death, we went to stay with my grandmother, my mother's mother. She also passed on in 2002 and we lived with her children whom I refer to as my brothers."

The quotes demonstrated how death of a parent or guardian usually resulted in some shift in family structure, or relocation of family members-factors that were said to have resulted in girls taking up the caregiving role. See Figure 4.1 illustrating how death and migration led to one girl becoming a child carer.

\subsubsection{Migration}

Study participants identified migration of parents and siblings to South Africa as a key-contributing factor that led to the girls becoming child carers. The International Organization for Migration defines migration as "the movement of a person or group of persons, either across an international border, or within a state" (International Organization for Migration, 2016, para. 19). The most common type of migration from Lesotho to South Africa is, according to Elkan (1980), temporary or circular economic migration, that is, where the persons move for short periods and return home periodically. The author described this migration from Lesotho and South Africa's other neighboring countries Botswana and Swaziland as historical, and migration was therefore not a surprising finding of my study. Participants mentioned how people migrated with the expectation of finding jobs and supporting their families back home. The unexpected finding, however, was the common pattern of movement by women following the death of a husband. The widow almost immediately left the country to go to "Gauteng," in reference to the Gauteng Province of South Africa. Migration of mothers seemed to have had a significant impact on the girls becoming caregivers. Some interviewees alluded to siblings who also emigrated, leaving their children under the care of the female child carers. The findings showed that those that migrated travelled without their families. Elkan proposed that people migrated without their families because "there would be nowhere to stay" (p. 585).

"Mpho," a single orphan aged 18 and caregiver of a sibling, described the reason for her mother's emigration as follows: "[My mother] left this year because I am going to write my external [examination] and my sibling is also going to write her 
examination. She did not have any means to pay our school fees, so she decided to leave and try to find something that will help her."

Another child carer, "Gina," aged 17, who was attending Form D at the urban school and was the caregiver of her grandmother and siblings, also described how the migration of her mother to South Africa prompted her move to live with her grandmother, who ultimately became her care recipient. "I used to live with both my parents [...] but, when I was in Grade 5, my father died and, after his funeral, my mother left for Gauteng. I then moved here to Maseru to live with my grandmother."

Participants also made reference to internal migration among child carers or older relatives as another factor that put girls in a caregiving position. Internal migration among child carers happened when they relocated to other towns to live with relatives, sometimes with the expectation that they would look after them, but other times the child was brought in so that she could take care of the family. For example, 16-year-old "Trisha," a double orphan who had been living with her grandmother, moved to look after her young cousins whose mother had migrated to South Africa. "I have been staying with my grandmother until I had to do my Form A, when I moved [here] to stay with my aunt's children. My aunt has always been away." This quote also highlighted another type of internal migration where children relocated in order to attend a good secondary school.

Essentially, the primary reason for the relocation would be to access education, but the caregiving aspect presented itself depending on where the child stayed. The case of 17-year-old "Charity," a single orphan and caregiver of a 9-year-old niece, for example, showed how she relocated for the purpose of schooling, but also found herself taking up the caregiver role. She described her situation as follows: "My father is deceased. [...] So, when I got to secondary level, I came to high school and that is how I ended up living [here]. My mother is not here, she has gone to work. I live with my sister's child."

These findings concurred with the results of another study conducted amongst young carers in Lesotho, where children migrated to live with other relatives, in most cases a grandmother (Robson, Ansell, \& Huber, 2006). Relocating to attend a 
good school was also a finding in a study on academic success among low-income Mexican Americans who had achieved high academic success (Gandara, 1995).

Internal rural to urban migration of adults occurred mainly amongst surviving parents and siblings who moved to the city in search of work, leaving the child carers in charge of the household. Quite clearly, the push factor was poverty. Most child carer respondents explained that the parents or siblings migrated so that they would be able to provide for them and pay their school fees.

\subsubsection{Family Conflict}

Study participants highlighted family conflict as another factor that put female child carers in the situation they were in. Poor treatment of the child carers by their stepmothers and sisters-in-law was mentioned as the reason why the children opted to move to live alone, or move to another household where they became the caregiver. For example, "Tina," aged 17, described how family conflict made her move from living with her father to opting to live with a grandmother whom she had to take care of. She said, "I had to leave because we were not in a good relationship with my stepmother so I went to live with my grandmother. She lived alone." It is most likely that the child opted to live in a household where she felt loved, even if she had to provide care.

One respondent also mentioned how an aunt who had fostered two sisters had asked them to move out of the house as she was not able to take care of them due to financial problems. What is clear from the above is that poverty and death were the underlying factors which placed the child carers in this caregiving situation. The study also found that poverty was the driving force for the external migration of the child carers' adult family members, and also a contributing factor that made children relocate internally.

\subsection{Who Child Carers Are Caring For}

Primary care recipients are categorized either as individual or multiple members of a household. Adults, especially parents (Rose \& Cohen, 2010), grandparents, or adult siblings (Robson et al., 2006; Siskowski, 2006) are those most often cited as individual care recipients. These would be family members with a debilitating condition such as chronic illness, disability, mental health, or drug and alcohol 
dependency (Robson et al., 2006; Rose \& Cohen, 2010). Multiple care occurs where there is more than one person in the household receiving care. Household composition, in this case, would either be a combination of both adults and children or comprising children only, as in the case of a child-headed household.

2009: Milly's father died.

Death

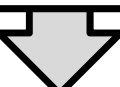

Mother moved to South Africa in search of work. 'Milly' living with grandmother, brother and sister.

Migration

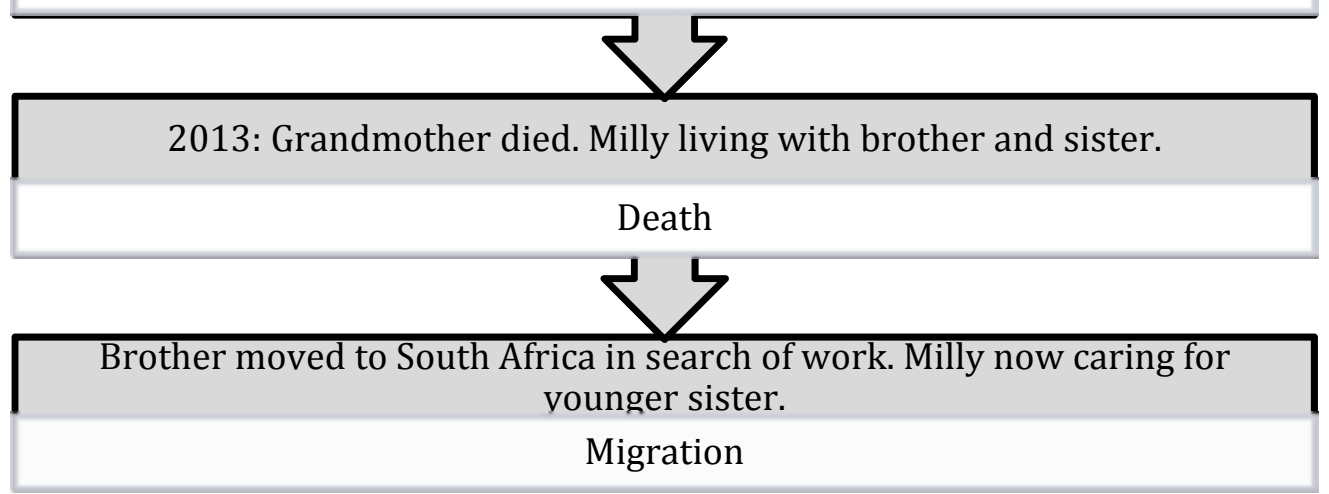

Figure 4.1. "Milly's" journey to being a child carer demonstrated how multiple family deaths and external migration of family members led to her being a child carer. Source: Author's compilation based on participant interview.

Study participants reported that child carers provided care to both individual and multiple members of households. Individual members comprised a younger sibling, a grandparent, or a niece or nephew. Multiple care households were mostly close relatives comprising a combination of siblings alone, siblings and nieces/nephews, grandparents, grandparents, and siblings. In my sample, it was more common to find children heading households with no adult presence $(87 \%$ urban; $69 \%$ rural), as shown in Table 4.2 . 


\subsection{Nature of and Challenges Associated with Care}

Nature of care is presented either as direct, providing intimate care to one care recipient, or indirect care, which involves a child taking over the roles of the adult who is receiving care (Siskowski, 2006). This dichotomy is, however, limiting as it makes the assumption that the care recipient will always be an adult and overlooks situations where the care recipients are younger members of the household. Robson et al. (2006) provided a more encompassing categorization listed below, which acknowledges other care recipients, including younger siblings, nieces, and nephews (Moore, 2005b) and can be applied to the nature of care provided by the children in the study.

(i) Carrying out domestic chores for a sick relative themselves and maintaining the health and well-being of the general household (Moore, 2005; Robson et al., 2006).

(ii) Looking after other children in the household, who may be younger siblings, cousins, or nieces and nephews.

(iii) Providing intimate care, which applies mainly in situations where the care recipient is incapacitated and needs help with tasks such as feeding, providing treatment, and bathing (Moore, 2005; Robson et al., 2006).

(iv) General caregiving for a sick relative, such as running errands, accompanying care recipient to the hospital, giving care recipient food (Robson, 2006), and providing emotional support (Moore, 2005b).

All of the participants in the study acknowledged that some secondary schoolgoing girls were providing care at home and articulated the caring responsibilities that the children had. For example, when asked who takes care of the home, "Linda," aged 14, in Form B at the rural school and caregiver of a grandmother and three siblings, had this to say about who was responsible for the household:

I am the one who makes sure that everything is there, the house is clean, there is food and things are in order. I do washing, I make sure there is firewood, I wash dishes, I sweep because I realize that such work seems to be too much for my siblings because they are still children. I also fetch water. 
Table 4.2: Type of Care Recipients in the Study

\begin{tabular}{llll}
\hline \multicolumn{1}{c}{ Care Recipient } & $\begin{array}{c}\text { \# Carer } \\
\text { Rural }\end{array}$ & $\begin{array}{c}\text { \# Carer } \\
\text { Urban }\end{array}$ & $\begin{array}{l}\text { Combined } \\
\text { Urban/Rural }\end{array}$ \\
\hline Grandparents & 1 & 0 & 1 \\
\hline Grandparents \& other Children & 2 & 2 & 4 \\
\hline One Sibling S & 4 & 9 & 13 \\
\hline Multiple Siblings & 2 & 2 & 4 \\
\hline Multiple $\quad 2$ & 2 & 4 \\
Nieces/Nephews & & & 28 \\
\hline One Niece/Nephew or Cousin & 1 & 1 & 28 \\
\hline Total & 12 & 16 & 2 \\
\hline
\end{tabular}

Note. Source: Author's compilation based on interviews

Another child carer from the rural school, "Dawn," a double orphan aged 15 in Form A and caregiver of a niece and sibling, described how she put the needs of her care-recipients before hers. She said, "[I go to bed hungry] but I would go and beg, especially for the children so that at least they have something to eat. [...] I put them first because I can cope."

Teacher "Kojane," from the rural school, acknowledged the responsibility of the child carers and stated the following:

They take the role of the mothers actually; they are the ones who mostly care for the families than boys, because they are going to take care of the siblings if they are there. In case of those who stay with the very old people, or the disabled people, they are the ones who take care and make sure that there is everything to ensure that there is food [and] everything that is needed at home.

\subsubsection{Household Domestic Chores}

Study participants cited sweeping, cooking, washing clothes, and heating water for bathing as the common household chores that child carers performed. In rural settings, the caregivers had to add another layer of work in order to carry out these chores. The task of cooking, for example, required that the girls went out to collect 
firewood, the fuel commonly used for cooking and heating water. Some households reported having electricity or gas, but the former would be reserved for lighting purposes only, while gas was sparingly used, as they had to purchase it. The child carer participants also reported fetching water from a common tap within the village as part of the household duties. Furthermore, the responsibility of finding food fell on the child carers, who would ask neighbors, pick wild vegetables, or find work where they were paid either in cash or in kind. As "Tina," aged 17 in Form B at the rural school and caregiver of a sibling, said, "What challenges me the most is having to go around asking for food when I don't have it, especially asking for vegetables."

Keeping the house and surrounding areas clean came up as an important domestic task that the child carers performed. Some children reported having to clean more than one house, or a separate room from the main house, where other family members lived. Most girls talked about having to wake up very early in the morning, sometimes as early as 03:00 a.m. in order to leave their homes clean and perform other household chores before going to school. "Mindy" aged 16, a single orphan in Form B and caregiver of four family members, described the chores she needed to undertake before going to school. She said, "I wake up early to sweep and cook, but if it's during the plowing season I won't be able to cook because I have to go and weed and sometimes harvest."

Getting their care recipients ready for school came up as another important task that the girls were responsible for. In the excerpt below, teacher "Mapula," from the rural school, described how this responsibility affected their schooling:

Sometimes they even come to school late because they have to prepare the siblings. They prepare themselves to go to school, they prepare the siblings to go to school, and it's really hectic.

Some child carer interviewees reported having been involved in other laborintensive work, such as working in the fields and plastering homes. The more labor-intensive tasks were usually carried out on the one day of the weekend when they did not have to go to school for compulsory study the whole morning. 


\subsubsection{Intimate Care}

Intimate care applies mainly in situations where the care recipient is incapacitated and needs help with tasks such as feeding, providing treatment, and bathing (Moore, 2005; Robson et al., 2006). Although this definition is limited to care recipients who are incapacitated as a result of illness or disability, this study also identified children who are not able to take care of themselves as recipients of intimate care. Intimate care in this case will include bathing, feeding, and looking after care recipients when they are sick. The study participants reported intimate care recipients as grandparents, younger siblings, and nieces and nephews. Grandparents who were both frail and sick relied on the child carers to prepare food and bathe them. Seventeen-year-old "Gina" explained how she was involved in providing intimate care while still trying to attend school:

What challenges me the most is when my grandmother is sick because I know that I have to rush home after school to check on her and the children as well; at the same time I have to clean the house, cook and do washing. If I have to do all these things after school, I feel so burdened and I can't, it is not easy.

Similarly, "Linda," aged 14 and caregiver of siblings and her grandmother, explained why she had to provide intimate care: "My grandmother is sick now, she cannot do anything. She has painful feet and knees. She is bed-ridden so I am the one who helps her."

Study participants also indicated how the female child carers provided intimate care to their younger family members by performing chores such as bathing them, getting them ready for school, and caring for them when they were sick. For example, 18-year-old "Mpho," a single orphan attending Form E at the rural school and caregiver of a sibling, illustrated in the following quote how reliant younger care recipients were on their caregivers, and also how child carers strove to stay in school despite their responsibilities: "I take care of my sibling even when she is sick. I would go to school and ask for permission [to miss school] and take her to the clinic." 


\subsubsection{Parenting Younger Siblings, Including Adolescents}

The responsibilities of the child carers looking after younger children went beyond the household chores and providing intimate care to include assuming other parenting roles. Participants described the child carers' obligations such as having to deal with behavioral issues presented by their care recipients. 'June,' a 15-yearold caregiver, had this to say: "[Being a child carer] is not good at all because you think of many things like what my sister could have done in my absence because she can be very mischievous at times."

A policy maker participant described the child carers' various parenting responsibilities in the following quote: "They will also be ensuring that the siblings get education if they are supposed to be going to school, making sure they attend the classes as routine, making sure that from classes they are doing their homework, making sure that the house is in good order."

\subsubsection{Earning Income for Caregiving Responsibilities}

Overall, the number of child carers who said they engaged in some form of income-generating activity was $45 \%$. The difference became more significant when data was analysed by location, with more children $(69 \%)$ from the rural school having indicated that they earned income compared to only $19 \%$ from the urban area (see Figure 4.3). Most (71\%) of the double orphans and $41 \%$ of the single orphans were involved in some form of income generating activity, such as working in people's homes or gardens, and selling fruit. Only one third of the child carers, whose parents were still alive, reported having been involved in some form of work.

Participants mentioned working in people's homes performing domestic chores, such as washing clothes or fetching water, and working in the fields in exchange for food or money, as the common types of piece work. The children also mentioned fruit-selling as another common income generating venture, although this was said to happen seasonally. 'Mpho' had this to say in regards to how she earned income:"There is a lady next door whom I relate with very well. I sometimes help her do house chores after which she would give me some money." 
Offering a child carer an opportunity to work was considered a form of support to the child. Respondents discussed how teachers and neighbors offered child carers tasks to perform at home in order to earn money. The role of teachers and neighbours is described in detail in Chapters 5 and 6, which discuss school and community factors.

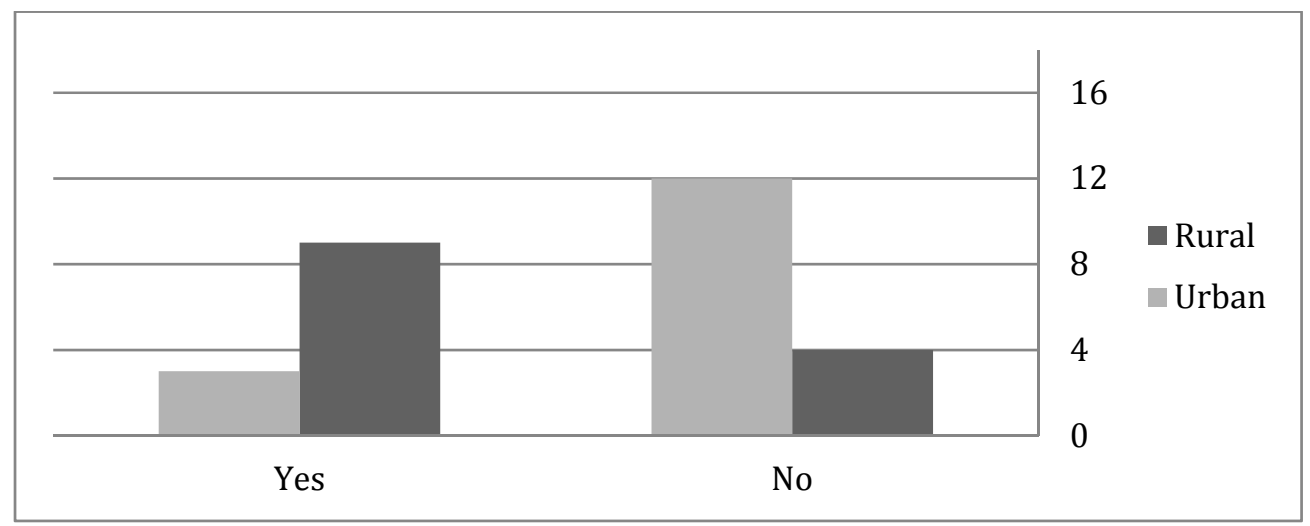

Figure 4.3. Child work and urban/rural location. Source: Author's compilation from interviews.

\section{Challenges}

I have categorized the challenges that the participants discussed into two areas: household-related challenges and school-related challenges. This chapter focuses on the challenges, and how these may be a potential risk to school attendance. Subsequent chapters will then address the individual, family, school, and community factors as they related to keeping female child carers in school.

Most study participants acknowledged that the mere fact that children were playing adult caregiving roles in a household was a major challenge in itself. Being the one that everyone in the household looked up to when the family faced problems, the one who had to think about how to provide for the family, and the realization that they were the ones to play the adult role were specifically mentioned as general sources of worry. "Dawn," aged 15, a double orphan and caregiver of two young relatives, opened up about the challenges of being a caregiver. She stated, "It is painful to be a child caring for other children because I am still a child and need a parent to support me, and I also need time to play." 
Table 4.4: Challenges and the Risk to School Attendance

\begin{tabular}{|c|c|}
\hline Challenge & Risk to School Attendance \\
\hline \multirow[t]{4}{*}{ Parenting Roles } & Worrying about care recipients \\
\hline & Lack of concentration due to worry \\
\hline & Missing school to care \\
\hline & Insufficient time for school work \\
\hline \multirow[t]{3}{*}{ Insufficient Food } & Missing school to work or look for food \\
\hline & Worrying about no food at home \\
\hline & Lack of concentration \\
\hline \multirow[t]{3}{*}{ Safety and Security } & $\begin{array}{l}\text { Stay with siblings at home to ensure safety and } \\
\text { security }\end{array}$ \\
\hline & Guard household property during the day \\
\hline & Worrying about safety and security of property \\
\hline \multirow[t]{3}{*}{ Illness } & Worry about ill care recipient \\
\hline & Missing school to provide care \\
\hline & Lack of concentration \\
\hline \multirow[t]{2}{*}{ Missing School } & Poor academic performance \\
\hline & Losing hope of completing school \\
\hline \multirow[t]{3}{*}{ Lack of Finances to Pay Fees } & Missing school \\
\hline & Expelled from school \\
\hline & Losing hope of completing school \\
\hline \multirow[t]{3}{*}{ Insufficient Time to Study } & Not completing school work \\
\hline & Fatigue from caregiving responsibilities \\
\hline & Poor academic performance \\
\hline
\end{tabular}

Note. Source: Author's own compilation.

Similarly, "Trisha," aged 16, also a double orphan taking care of three young family members, bemoaned the problems she had to face as a child carer:

What challenges me the most is when these children keep telling me that they have run out of something. I always worry about where to find things because I am also a child, and they can also see that there is no adult in the family. 


\subsection{Household-Related Challenges}

The study findings showed that children expressed a lot of stress and anxiety brought about as a result of their caregiving responsibilities. These challenges, if not mitigated, may cause a risk to the female child carers' regular school attendance. Interviewees cited parenting and providing intimate care, insufficient food, lack of other material supplies for home, and safety and security as the main challenges that female child carers faced at home.

\subsubsection{Parenting and Providing Intimate Care}

Taking up adult responsibilities in the family required that the child carers also assumed the role of being a parent to the younger children under their care. Respondents talked about the challenges of child carers not only having to deal with the problems that other children in their households encountered, such as relationship issues, but also worried about their own "parent-child" relationship with the care recipients. The excerpts below illustrated this. "Mpho," aged 18, caregiver of a teenage sibling, lamented how the sister's moods troubled her:

Sometimes she would wake up moody, not talking to me and if I try to talk to her, she would shout at me. [...] Sometimes when I try to wake her up in the morning she would refuse [to get up] and yell at me, telling me that I wake her up too early and she cannot wake up that early. This troubles me a lot because sometimes she would refuse to wake up.

Child carers also demonstrated a lack of knowledge about recognizing or addressing psychosocial issues that their care recipients may be facing. For example, "Jackie," aged 15, attending Form A at the urban school, described how she dealt with what could have been a manifestation of psychological problems:

My sister also talks in her sleep. That worries and scares me a lot [...] When she talks, I wake her up so that we can pray and then go back to sleep again.

The findings showed that child carers' responsibilities for their care recipients extended beyond the home as they also took up other adult roles, such as attending parent meetings for their younger relatives. Participants also described 
how the girls constantly worried about the well-being of their family members, even when they were away from home. 14-year-old "Mwaka," taking care of three young relatives, illustrated this in her quote: "[I worry] when one of the children tells me that there is a parents' meeting [at school]. I always feel confused because I would not know as to who would go and represent the child [and] since I would be in school, I do not have a chance to go." Another child carer, "Charity," a single orphan aged 17 and caregiver of a young relative, also described her fears related to being a caregiver:

[I worry] because like I indicated that I live with a sick child, I always find it hard to stop thinking about her when I am at school. Wondering if she had made it to [her parents' home], if she found her parents, whether she would have to walk back [home] or how she would cope the whole day until I get back home.

The excerpts above showed how child carers experienced a lot of anxiety and the internal conflict of not knowing how to carry out the adult responsibilities outside of the home, as well as having to deal with making a choice between being in school or executing parental duties.

\subsubsection{Lack of Food}

Almost all study participants discussed how running out of food, or not having sufficient food, was a major challenge which brought about great anxiety and stress. The child carers expressed concern about not being able to provide for their care recipients, as well as having to look for food and the food preparation process.

The staple food of the Basotho people is "papa," a thick maize meal porridge that is eaten mainly with vegetables, or "moroho," as it is locally known, as the accompaniment. The respondents commonly stated that the child carers went to school "on an empty stomach" because they did not have either the maize meal or the vegetables. Although the child carers who were enrolled at the rural school reported receiving a meal at school, they still expressed their constant worry that their care recipients who were left at home had nothing to eat. "Palesa," aged 17, attending Form $\mathrm{E}$ at the rural school and taking care of five young family members, expressed this problem in the excerpt below: 
Hey, it causes a lot of stress because like now I'm being in school and I know that when I left home, there was no food for the child, so it troubles me each time I think about the fact that she is at home and has not eaten anything. [...] I am at school and left without any food, I didn't have anything to eat. That affects me and my performance at school.

Unlike the rural school, the urban school did not offer school meals, something that some girls and teacher interviewees considered to be a challenge for children who did not have sufficient food at home. This was identified as a problem by "Angela," a single orphan, aged 17, and a caregiver of her grandfather and a sibling, who said: "We don't have a school feeding program here, so sometimes I leave home without food and I don't like that."

The child carers typically acquired food from various sources. The majority of the carers relied on support from family members who either gave them food, or gave them money to buy the food. Respondents discussed how challenging it was to rely on migrating family members for money, as the funds came through inconsistently and were not always sufficient to get them enough food to last until the next remittance. One respondent stated that the "month seems longer" when they run out of money. Another described how the mother only bought maize meal, leaving the responsibility of finding the vegetables and other foodstuffs to the child. Finding the vegetables was mentioned as a big challenge because of how often this had to be done, and, in most cases, the child carer had to ask neighbors and friends. In the quote below, "Angela," aged 17, described how the lack of food became a major concern:

Sometimes, during the course of the month, you will find that we struggle to get food, especially vegetables...so as the person who does everything, I become puzzled as to what I will do for us to get some food and other things like washing powder... I get worried.

Although it may seem that school lunches provided a way out of this problem, the girls still worried about the care recipients that remained at home with no food. This revealed the interconnectedness between the physical stress of hunger and the psychological stress associated with leaving those under their care at home. 
Respondents from the rural area mentioned challenges related to growing food. Not having land ownership meant the family did not have the option of growing their own food to supplement other sources. Owning land, however, was not always the solution, as not having the means, time, or capacity to work on the fields was noted as a worrying factor for the child carers. Efforts to circumvent this challenge sometimes created other problems. For example, one child carer entered into an arrangement in which others offered to till the land if she would prepare food for them before they went to the field. However, she had to wake up as early as 03:00 a.m. in order to do so before going to school. This also demonstrates how girl-carers could be exposed to exploitation.

Participants mentioned how food preparation also added to the challenges that the child carers faced. The task required that the girls went out to collect firewood, the fuel commonly used for cooking and heating water. Some child carers reported having electricity or gas in their homes, but these would be used sparingly or, in the case of electricity, would be reserved for lighting purposes only as they did not have money to buy electricity units. Furthermore, cooking was also mentioned as one of the main household chores that hindered their ability to do school work at home. The time factor is discussed below under the section on school-related challenges.

\subsubsection{Lack of other Material Supplies for Home}

Similar to the challenges the child carers faced in providing food for their care recipients, participants also mentioned how the girls worried about having other supplies such as washing soap, shoe polish, paraffin, electricity units, sanitary pads, and clothes for their care recipients and for themselves. 'Kathy,' a single orphan, aged 18, and caregiver of a sibling, discussed how not having sufficient funds created a problem for them.

Sometimes, you will find that the money that my mother sent is not enough for us to get all of our needs; so, during the month, I become stressed because things just finish and I wouldn't know what to do. That stresses me a lot. 


\subsubsection{Safety and Security}

A major challenge discussed by most child carer participants was security in the home. They reported living in fear because of people who came to "knock on the doors" at night. Having doors that did not close or lock properly left the child carers feeling vulnerable to intruders. "Tina," aged 17, a double orphan and caregiver of her sibling, described her fears by saying:

Sometimes, we find that people knock at our door, especially at night. We have two doors and the one does not lock well, so they would be knocking at that door and even on windows. Sometimes, we just hear someone is trying to push the door open.

Living with an adult in the house was considered a security precaution, but only during the day because at night adults who were frail or sick were not considered a deterrent. The child carer respondents reported how keeping the family safe was therefore their responsibility. Some children living in child-headed households raised concerns about the safety of their household effects when they were at school during the day. As "Trisha," aged 16 and caregiver of three nieces and nephews, stated: "If there was an adult in the family, there would always be someone at home who would make sure that our things are safe while we are at school."

The child carers brought up another issue that arose from not having an adult at home during the day when they were in school. They suspected that this disadvantaged them from receiving external support when registration for services was being conducted, as there would be no one to represent them during the day.

\subsection{School-Related Challenges}

The study identified three main school-related challenges that may have created a risk to school attendance. Participants cited missing school, psychological stress, and insufficient time for schoolwork as the main challenges. These factors are discussed in the section below. 


\subsubsection{Missing School}

When asked to describe situations in which the child carers missed school, almost all of the child carer respondents acknowledged that they did miss school, with the majority citing caregiving responsibilities as one of the reasons for doing so. Children with multiple care recipients cited missing school as a challenge more frequently than those with only one dependent. This was not surprising as the more people one had to look after, the more likely it was that the extent of care increased. The participants specifically mentioned their own and their care recipients' illness, running errands, nonpayment of school fees, and lack of basic material needs as factors that made them miss school. Teacher respondents mentioned using school absenteeism as an indicator of vulnerability that prompted a further enquiry on the child's situation. The children pointed out that missing school was a source of worry because they considered education to be the gateway out of their adversity.

\section{Missing School Due to Illness}

Most teacher and child carer study participants cited illness of either the child carer or their care recipient as a reason for missing school. The excerpts below describe situations in which illness of a care recipient, or that of the child carer herself, became a barrier to attending school. The citations also showed how child carers' responsibility went beyond providing intimate care at home as they also had to accompany younger children under their care to access medical services. "Mpho," in the following quote, explained how taking care of a sick family member led to her missing school. She said: "I miss school when there are serious issues that force me to be absent, like when my sister is sick and I have to take her to the clinic. Those are some of the reasons why I may be absent from school."

In the same vein, "Gina" described how she handled both her own illness and that of her care recipients: "[I miss school] when I am sick, but if I go to the clinic and come back on time, I go straight to school. I also miss school if one of the children is sick and I have to take them to the clinic."

The responsibility of caring for the care recipient who is sick included taking them to the clinic or hospital. Although accessing primary health care services at the local level was not considered to present much of a problem, as the service was 
free, participants reported the need for money to pay medical fees at a referral hospital. They also raised, as a challenge, having to worry about how to meet other health-related costs, such as the cost of transportation and buying medication.

\section{Missing School to Run Errands}

Child carer participants mentioned running errands as a reason for missing school. These errands were activities that would ordinarily be the responsibility of an adult in the household. For example, one child talked about how she missed school in order to go and deposit her school fees at the bank. Another child, "Trisha," a double orphan, aged 16 and caregiver of three young relatives, missed school when she had to be at home to wait for someone bringing household items from an aunt who had migrated to South Africa. "I will have to wait for the person delivering the items so I have to wait the whole day. Other times I leave very late and realize that I cannot make it to school because it's already late."

\section{Missing School Due to a Lack of School Fees}

Respondents highlighted not paying school fees as a major challenge and a reason for missing school. Children who did not pay school fees were expelled until they were able to pay. Being sent away from school was a source of distress for the child carers as stated by "Jessy," a single orphan aged 18 in Form C at the rural school and caregiver of a sibling:

Last year I could not come to school because [my mother] said I should stay home so that my sister can be the one that goes to school, but then she realized that I was not happy with the decision. I was hurt because I realized that I was not going to complete my studies.

Although participants identified child carers who were receiving scholarships, they also described the challenges of getting them. Not every child carer was able to benefit from the availability of government or other scholarships. Participants described the difficulties they encountered in obtaining scholarships mainly because they did not know where to go for help, needed transportation money to get to various offices, and, when they did apply for scholarships, they were told that they did not meet the eligibility criteria. One child carer participant stated that she could not get a scholarship because her mother was still alive, able-bodied, and could work, and only those living with grandparents could be sponsored. Some 
participants mentioned the inability to submit necessary documentation as a major barrier to accessing scholarships. This was attributed to surviving family members' unwillingness to provide documents, such as a parent's death certificate or passport. It was not clear from the explanations given what the motive for not complying was. One child carer described how her paternal grandmother did not want to release her deceased father's passport because she was not recognized as part of the family. Teacher "Kakoma," at the urban school, expressed a similar sentiment and attributed this reluctance to the fact that some of the relatives wanted to keep the girls as helpers at home, rather than take them through school. He said:

Actually, you find that the families are not good at all, I am sorry to say, because you find that, at times, there is a certain pupil who needs to be helped and we need certain documents for this kid to get sponsorship, they will refuse to give you the documents.

\section{Missing School Due to a Lack of Material Needs}

Several respondents spoke about how they missed school because their uniform was dirty or they did not have sanitary pads. For example, "Tina," aged 17 from the rural school, lamented how she missed school "when I am sick or sometimes when I don't have pads, I stay at home." Tardiness was described as an indicator of vulnerability, as this was more an indication of not having soap at home, or not having the time to wash. As "Bertha," aged 18, a double orphan in Form B at the urban school, stated: "And sometimes we end up missing school because our uniforms would be dirty."

\subsubsection{Psychological Stress}

Respondents discussed how worrying while at school affected the child carers' concentration in class. The child carers worried more about issues at home than what was going on in school. The social-emotional health and general well-being of their care recipients was their main source of worry. Child participants specifically mentioned worrying when a family member was sick, or when there was no food at home. "Lerato," aged 17, caregiver of a sibling, expressed how her attention at school was affected by worrying: "Sometimes my sister would be sick, so when she is sick, when I am in class, I cannot concentrate because I keep 
thinking about her and how she's doing." In the same vein, "Joan," aged 16, a single orphan in Form D at the rural school and caregiver of a sister, had this to say:

It is stressful because sometimes I would have left my brother with no food and when I think about that or when my friends offer me food, I just feel bad because I don't know how he is doing or whether he has eaten or not.

A few respondents alluded to the child carers worrying generally about the fact that they had this responsibility of caring. For example, the quote by "Limpho," aged 17, a double orphan and caregiver of two younger relatives, illustrates this when she said, "I cannot concentrate while at school because I keep on thinking of the problems I have."

\subsubsection{Insufficient Time to Study}

According to several study participants, child carers worried that they did not have sufficient time at home to combine house chores with school work. The long distance from school exacerbated the already limited amount of time, as most child carers returned home late from school. The demands of caregiving necessitated the girls to prioritize house chores over schoolwork, thus affecting their ability to complete their school assignments. "Lerato," aged 17, illustrated this in the quote below:

What troubles me the most is that sometimes I would be given homework and I don't have a chance to do it because I have to cook, so we will be using a candle for lighting, so as I would be cleaning and cooking after school and that by the time I am trying to study, the candle is gone so it doesn't give me a chance to do my homework.

Most child carers explained how they had to wake up very early in the morning in order to find time to perform house chores before going to school. "Mindy," aged 16, discussed the chores she needed to complete before she went to school every morning: "[From Monday to Friday], in the morning when I wake up I heat water for my brothers, then we bathe. After bathing, I leave them with food to eat if we have food at home." 
Authorities from the sampled schools recognized that some of the children's home environments were not suitable for studying; therefore, they instituted compulsory study time one day of the weekend. Teacher participants attributed the students' improved school performance to this measure. Despite this program having academic benefits, some teacher interviewees found it to be limiting the amount of time the children could spend on caregiving responsibilities. For example, teacher "Kabelo" explained how the extra study day affected the children:

Some of them still struggle to make ends meet because the school policy does not allow them enough time to do piece work. Every child must be here at 06:50 and leave at 16:30 [or] 18:00 so it means they forfeit any piecework that they could do between 17:00 and 18:00. There is [also] compulsory study every Sunday. They only have Saturday, which is not enough because they have to do washing and cleaning so they do not get enough time to find piece jobs.

\subsection{Discussion}

The study findings clearly demonstrate that being a child carer comes with responsibilities and challenges that are a source of worry and pose significant risk to the educational success of child carers. Lack of food, material support, and finances were identified as challenges that caused a risk to female child carers' school attendance. Child carer respondents identified themselves as caregivers, a role that they described as a major challenge in itself.

\section{Psychological Stress}

The risks discussed by study participants draw attention to the fact that the female child carers experienced significant psychological stress as a result of being caregivers. This finding parallels the argument that caring can also be a traumatic experience (Robson et al., 2006), which could even lead to depression (Thomas et al., 2003). The key point to note from my study is that even though child carers devised coping strategies to ensure that they were able to attend school, the pressure of caring weighed heavily on their minds even while at school. Ultimately, this stress and anxiety may pose a risk to school attendance, and may, according to Moore (2005), also have an impact on their school success. 
Cluver, Kganakga, Lane, and Operario (2012) described school as a place of refuge and coping from being a young caregiver. The findings of this study, however, revealed that for some children, although being at school relieved them from physically providing care, their absence from home actually became a source of concern as the child carer continued to worry about the persons they had left behind. This finding supports previous studies in Wales (Thomas et al., 2003), South Africa (Cluver et al., 2012), and Australia (Moore, 2005b), where child carers were reported to have experienced disrupted attention (Cluver et al., 2012) related to having to cope with worrying about the well-being of those under their care.

\section{Financial Stress}

Not having sufficient food and other material items at home put the child carers at risk of not attending school regularly or even dropping out of school altogether. Although the child carers in the study indicated that they worked after school hours or during weekends, having to fend for the family in this manner put them at risk of missing or dropping out of school altogether. This corroborates other research findings that children who were earning income for their households had to suspend school for periods of time in order to meet caregiving demands (Skovdal et al., 2009), and a Lesotho study that reported children taking turns to attend school to earn an income (Nyabanyaba, 2009, p. 49).

It is most likely that the girl-carers had to make choices about how they needed to spend the limited financial resources they had available, and food would be the obvious priority for the family, which may have required them to forego other items. Thus, lack of other supplies such as sanitary pads and soap to wash their uniform presented a challenge for the child carers to the extent that they even missed school. Other Lesotho studies also showed that lacking basic school supplies (Tanga, 2013) and having a worn-out uniform (Nyabanyaba, 2009) affected school enrollment, attendance, and success. Similar findings from a Tanzania study showed that children's access to schooling was affected when they lacked school uniform (Evans, 2005). Providing sanitary pads to vulnerable children was reported as a way of improving school attendance, concurring with a study which argued that a lack of sanitary pads may lead to girls missing school (Kirk \& Sommer, 2006). Other scholars gave a contradictory view, showing that menstruation had very little impact on school attendance (Grant et al., 2013; Oster \& Thornton, 2011). 


\section{Parenting}

The challenges of parenting and providing intimate care to their family members highlighted the internal conflict that child carers experienced when having to deal with the expectation of playing the adult role, while recognizing that they were still children. The role of parenting younger family members brought about anxiety among the child carers who did not have the parenting skills to manage younger family members, especially teenagers. Further conflict arose where the parenting role was expected of them beyond the home to other places such as school. Child carers were expected to fulfill the parenting responsibility beyond the home, such as attending parent meetings to represent their young relatives. The child carers were presented with a situation where they had to make a choice between meeting some of their parenting obligations and going to school. Other studies have, however, also reported positive outcomes of caregiving, such as learning skills (Skovdal et al., 2009) and having a sense of closeness as a family (Thomas et al., 2003).

\section{Missing School}

Although findings showed that child carers were able to attend school, despite facing adversities, the study also suggested that they had to go to great lengths in order to do so. As evidenced in other studies (Cluver et al., 2012; Moore, 2005; Robson, 2006), child carers missed school for both noncaring and caregiving responsibilities. Missing school affected their schoolwork, something that was considered a barrier to getting the education needed to achieve their future goals. The demands of caregiving affected the quality of learning and negatively affected their academic performance (Robson, 2006; Siskowski, 2006). Missing school was usually never intentional and, if anything, child carers made every effort to attend school despite the various challenges with which they were confronted. This finding converges with existing research, which found that truancy amongst young carers was not a major issue as they wanted to go to school and were affected when circumstances forced them to stay away (Thomas et al., 2003, p. 40). Similarly, Moore (2005) showed that children not only missed school, but also reported frequently presenting late or having to leave school early in order to provide care.

There were exceptions, however, to how much child carers could combine schooling with caregiving. The illness of a relative was one of the instances when 
they felt that they needed to stay at home to look after the family member or take them to a health facility to access medical services. Going to school when there was a sick person at home had an emotional effect on the child carer as they still worried about their care recipient, and the costs associated with seeking health services. These findings align with the suggestion by Cluver et al. (2012) that the decision to miss school was usually presented as a 'forced choice,' with carers of a sick person pressurized by an internal sense of moral obligation to take care of them over going to school. The Robson (2006) study in Tanzania also showed that providing care to a sick family member appeared to be the main reason for irregular school attendance.

\section{Time Constraints}

Respondents showed how time limitation was a factor in both caring responsibilities and schoolwork. The child carers seemed to be constantly juggling to find ways to fit in both, and sometimes one thing had to suffer to ensure that something else was achieved. In most cases, children prioritized their care responsibilities over school. This finding is similar to that of Moore (2005), who found that young carers gave primary importance to their caring responsibilities over the amount of time allocated for schoolwork. Thomas et al. (2003) also found that carers struggled to keep up with both schoolwork and study, and had to find ways of catching up with missed work. Contrary to the Thomas et al. and Moore findings that child carers prioritized caregiving over school work, my study also found that sometimes the children placed primary importance on schooling. When children prioritized school, the caregiving responsibilities suffered.

\section{Conclusion}

Although this study categorized the challenges the child carer faced into two broad areas, problems experienced at home and those experienced at school, the findings show how they are interconnected. The child carers worried about the challenges they faced at home, even while at school. This constant worry about the challenges is bound to increase their risk of dropping out of school in order to provide care on a full-time basis, protect their property, and find means of providing for the care recipients. This may also impact the quality of their learning experience. The children will most likely be fatigued from having to wake up very early to complete household chores before going to school, which may affect concentration, leading to poor school performance and ultimately dropping out. Although 
attending school provides some relief from the problems child carers face at home, school attendance without support that addresses the other challenges alone is not sufficient to ensure educational success. School attendance will need to be coupled with support that reduces psychosocial vulnerability. 


\section{CHAPTER 5}

\section{HOW CHILD CARERS' INDIVIDUAL ATTRIBUTES INFLUENCED SCHOOL ATTENDANCE}

Tina* is 17 years old and lives in Lokalia* with her sister. She runs the household and occasionally gets help with food from her aunt. It is her father, who works and lives in Maseru, who takes care of them financially. He pays her fees to go to school located a 10 to 15 minute walk from their family home, where both she and her sister go to school. She gets along with her sister. "I really enjoy staying with my sister," she says.

She does most of the work in the home. "I clean, I cook [...] and fetch water," she explains. She also requests help from the neighbors when her and the sister are in need. She weeds people's gardens in order to obtain some extra income for vegetables and other needs.

She struggles with finding food sometimes and states that "what challenges [her] the most is having to go around asking for food when [they] don't have it, especially asking for vegetables." There is also the challenge of dealing with potential criminals who often knock on their door and windows at night.

Tina dislikes having to cope with these challenges, and uses that as motivation to stay in school. "I want to change this life that I am living now... Every morning when I wake up, I tell myself that I should go to school to study...because I realize that our family is struggling," she says. However, her biggest motivation is her enjoyment of learning, and her desires to one day become a teacher. She aspires to be like her teacher, who is the most important person at the school to her. She says, "[My teacher] is the person who helps [me] when [I have] problems and when [I am] troubled."

\subsection{Introduction}

This chapter discusses the perceptions of female child carers and other study participants on how individual attributes, such as having a vision for the future, play a role in keeping female child carers attending secondary school, despite the difficulties associated with being a caregiver. Individual factors form part of Urie Bronfenbrenner's socioecological model (Bronfenbrenner, 1994), the framework on which I have based my study. This model has been applied in various disciplines, including education resilience, to examine how personality traits and external factors interact to influence education resiliency (Condly, 2006; Fredricks et al., 
2004; Garmezy, 1991; Williams \& Bryan, 2013). Education resilience has been defined as success in school despite facing adverse conditions (Waxman et al., 2003). This chapter begins by reviewing literature that discusses individual factors and the link to students' resilience and school attendance. I then present the findings of the different individual attributes of female child carers in the study as they relate to school attendance.

I found that study participants pointed to child carers having a vision for a better life in the future as the key individual attribute that motivated female child carers to continue attending school. The child carers' future aspirations to change their difficult situation, and to be able to provide better quality care for their relatives, were reported to have driven their vision. Participants reported that having role models, belief in a higher power, and good academic performance molded the child carers' vision. Study participants highlighted self-motivation and having the social skills to seek support as other personality traits that may have influenced child carers' schooling. This is followed by findings from the analysis of the interaction between individual and external domains of family, school, and community and how this relates to regular school attendance. The chapter ends with a discussion.

\subsection{Previous Literature}

Prior academic literature (Benard, 1991; Johnson, 1997; McMillan \& Reed, 1994) generally agrees that resilient students possess certain individual characteristics that may lead to positive education outcomes. Benard (1991) singled out having a sense of purpose and future as the key predictor of positive outcomes and identified other factors that he argued make up this attribute:

Healthy expectancies, goal-directedness, success orientation, achievement, motivation, educational aspirations, persistence, hopefulness, hardiness, belief in a bright future, sense of anticipation, a sense of a compelling future, and a sense of coherence. (p. 7)

Several other authors have shared the same view and agreed that such children are optimistic and view things in a positive light, set long-term goals, have a sense of a positive future (Embrace the Future, 2005; McMillan \& Reed, 1994), and believe in 
good things happening to them and things going their way (Scheier \& Carver, 1985). Having a vision for the future will influence one's current behaviors as long as they are associated with achieving their future goals. According to Johnson (1997), such children have a sense of purpose that makes them work towards achieving specific goals, and they believe that they can change their situation. She, however, looked at aspiration for a better future from a different angle and argued that academic success, which is normally considered an outcome or manifestation of resiliency, can also be a factor that enhances an individual's self-esteem, thus building the confidence needed for one to aspire to a better future.

Role models are considered to play a significant part in influencing resilient children's optimism and vision for the future. Positive role models are people who have achieved outstanding success and motivate others to pursue similar excellence (Lockwood et al., 2002). Their presence is crucial to the development of resiliency in children (Johnson, 1997). Negative role models can also influence positive outcomes, but instead of being emulated, they would trigger avoidance and preventative strategies that individuals employ to avoid turning out like them. At-risk children who are resilient will most likely establish a close relationship with a known individual who gives them attention and support and who may have become a role model (McMillan \& Reed, 1994). The explanation for this transition is given by Lockwood et al. (2002), who argued that optimistic or promotion-focused individuals are able to notice, recall, and be inspired by information that can contribute to reaching their aspirations of success.

Resilient children have an internal locus of control and strong self-efficacy attributes that enable them to stimulate their internal strength to cope in the midst of adversity and can lead to positive outcomes (Charles, 2011; McMillan \& Reed, 1994). These characteristics give resilient children the drive to succeed as they allow them to comprehend the situation they are in, and distinguish what is within their control (Condly, 2006). Such children will have the capacity to learn from their experience and adapt to their environment (Cassen et al., 2009). Condly (2006), however, cautioned about how this same intelligence may have negative outcomes that could leave a child "more vulnerable to emotional scarring and the internalization of stress" (p. 217). 
At-risk children's involvement in formal or informal religious organizations has also been associated with developing resilience, with the potential for leading to positive outcomes (Katz, 1997). Such groupings can provide a safety net for children to meaningfully participate in activities that can provide a sense of psychosocial support (McMillan \& Reed, 1994). A study by Skovdal et al. (2009) on the coping strategies of young carers in Western Kenya found that the church was a source of food and emotional support. The study further noted the role of faith as a coping strategy for the caregivers who were said to believe that God answered prayers.

Literature identified social competence as one of the characteristics of a resilient child. According to Benard (1991), this entails the ability to elicit positive responses from others, such as providing support. Other attributes that he noted were problem-solving skills, autonomy, and a sense of purpose. The findings in the Skovdal et al. (2009) Kenya study showed that children at risk also depended on their ability to mobilize social resources available to them, such as eliciting support from immediate and extended family members and community members.

It is worth noting that these individual factors will, however, need to interact with the external factors of family, school, and community, as resiliency goes beyond the attributes of an individual (Embrace the Future, 2005). Benard (1991) postulated the significance of the role that a caring and supportive relationship with at least one individual plays in influencing positive outcomes. This was corroborated in a study by Katz (1997), whose findings demonstrated how schoolteachers, church members, and community members all played a role in supporting the children who were taking care of ailing adults in the home.

\subsection{Findings}

This section presents the findings of how key individual factors (vision, role models, seeking support, faith, and self-motivation) positively affected female child carers' secondary school attendance. The child carers viewed school attendance as the prerequisite to obtaining an education, perceived as a conduit to them achieving a future they envisioned. The girls' vision was influenced by the desire to get out of the situation they were in and live a better life, where they could also provide better quality care for their current and future care recipients. 
Their vision was also to reciprocate care to family members who were supporting them and to bring back those that had migrated in search of work.

Study participants most frequently mentioned vision as a factor that influenced school attendance for female child carers. Most study participants reported having a vision for the future, and having the ability to seek support as the key individual factors that influenced child carers' school attendance. Role models and religious belief were noted as attributes that influenced child carers' vision and, ultimately, their desire to stay in school. Study participants cited religious belief as a trait that gave the child carers the ability to cope with their situation and hope for a better future. See Figure 5.1 illustrating the number of child carers who reported how individual factors played a role in keeping them in school. The chart shows that most (26 of the 28 ) child carer participants pointed to having a vision as a key factor.

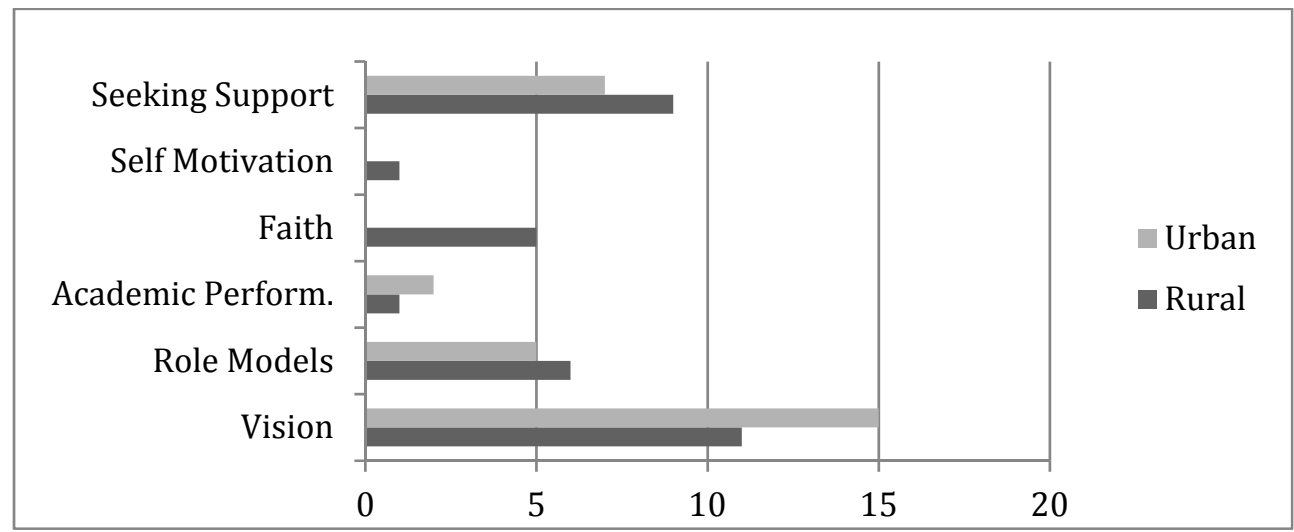

Figure 5.1. Individual factors by child carer location. Source: Author's own compilation from study interviews.

From the teacher's perspective, however, the ability to seek support and being selfmotivated scored highest for a number of teachers citing individual factors (see Figure 5.3). When analyzed by code frequency, however, self-motivation reduced to below half of seeking support code frequency (see Figure 5.4). Further, the study demonstrated that there was an interaction between individual factors and family, school, and community attributes that may have influenced school attendance. Figure 5.2 shows similar results when analyzed by code frequency. 


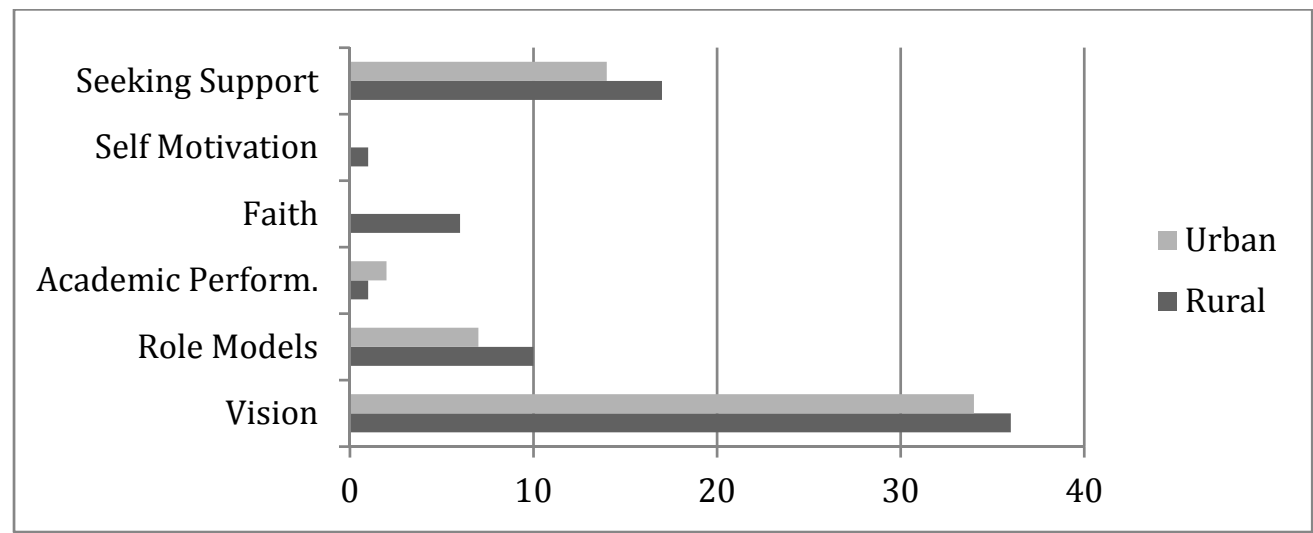

Figure 5.2. Individual factors code frequency by child location. Source: Author's own compilation from study interviews.

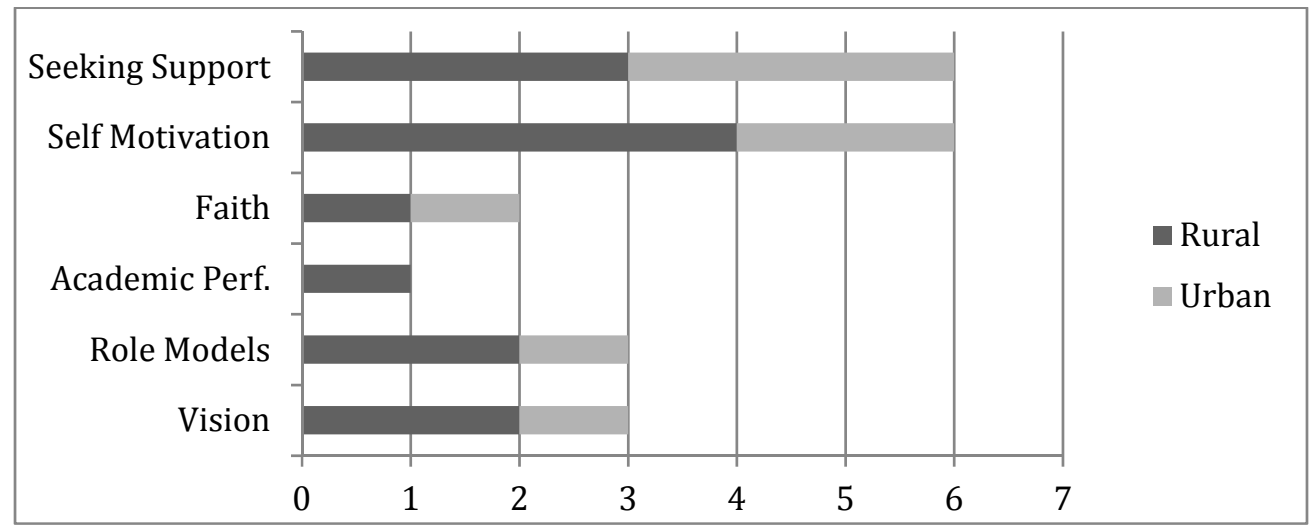

Figure 5.3. Individual factors by teacher participant location. Source: Author's own compilation from study interviews.

\subsubsection{Embracing a Positive Vision of Better Futures and Key Milestones}

I applied the vision code when a participant made reference to future aspirations for education attainment, career, or lifestyle. The vision code frequency ranked highest within the individual factors domain, even when analyzed by rural/urban location (see Figure 5.2) or child carer age. Almost all child carer respondents described how they envisioned a better life in the future, articulated career plans 
with a clear pathway to the type of job they desired, and indicated how they planned to take care of their families.

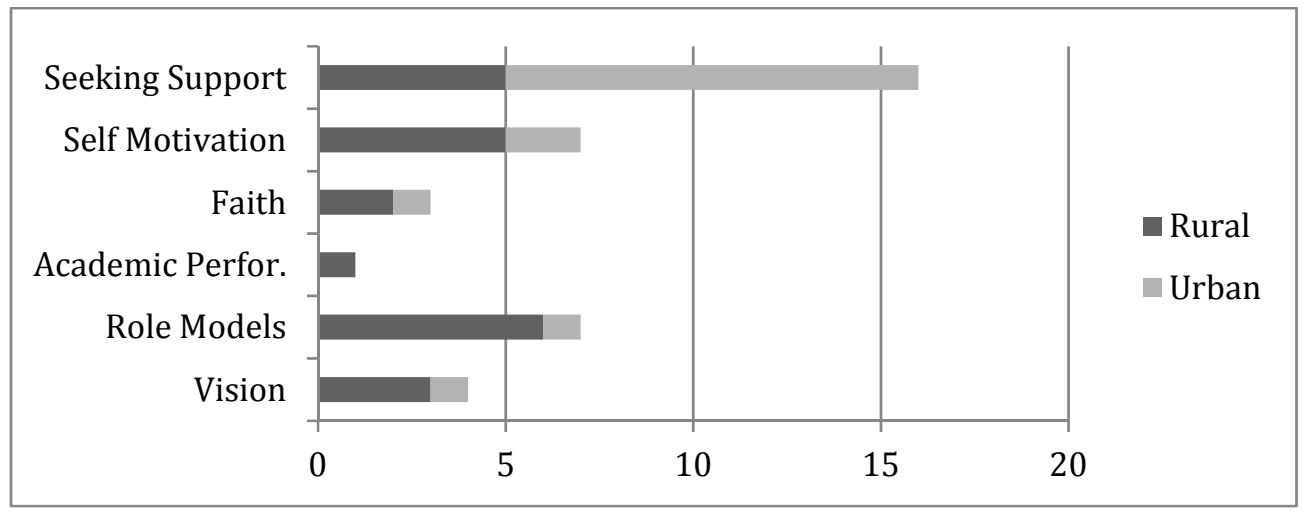

Figure 5.4. Individual factors code frequency by teacher location. Source: Author's own compilation from study interviews.

This desire for an improved way of life was mentioned as a major motivation for school attendance. "Tina" aged 17, who is in Form B at the rural school and takes care of her sibling, expressed her vision as follows:

I want to change this life that I am living now. I don't like what I am living at all. Every morning I wake up, I tell myself that I should go to school to study hard so that I can pass my subject because I realize that our family is struggling [...] I want to be a teacher, so I think I will be living a good life in five years' time with my sister. I want to change the kind of life that we are living.

Similarly, "Trisha," aged 16 and in Form C at the rural school, and caregiver of a niece, expressed her desire to change her life in future as follows:

I have realized that the kind of life that we are living now is not the same kind of life that one lives when they are educated. It is not good, as I compare us with other children who would leave home having eaten bread and tea...I always tell myself that I will go to school and study hard because I want to have a brighter future. 
Tina's quote shows that the child carers interviewed viewed a good education as a way to escape the dire situation they were in and move toward a brighter future. Most of them demonstrated this by articulating the type of life they envisioned for themselves, including the type of job they intended to have. The respondents depicted these ambitions by describing their pathways from school, starting with early career paths and high expectations of finding good jobs. The child carers viewed passing school examinations as a key milestone in the pathway to attaining their ultimate aspirations, and linked attending school to good examination performance. "Mpho," aged 18, who is in Form E at the rural school and takes care of two siblings, expressed the relationship between attending school and attaining her vision for the future:

What makes me keep on coming to school is that I intend to pass my Form E well because if I do not pass well, it is going to be difficult for me to get admitted to tertiary schools so I want to work hard because I know that I will have good chances and be admitted, thereafter I will be able to change the situation that I am in.

\section{Vision of Care Reciprocity}

The future caring responsibility code was applied when respondents mentioned providing care in the future. A number of child carers alluded to a future where their role as caregivers still continued, but they saw themselves providing this care under different circumstances and in an improved environment. Child carer participants envisioned a future that still included those they were currently caring for, despite having plans to start their own families. This desire to provide quality care in the future was mentioned as a factor that motivated child carers to continue attending school, which was seen as a precursor to leading a good life and ultimately having the ability to provide better quality care. Interestingly, the child carer participants did not make any reference to weaning off those under their care, even for those whose siblings were together with them in high school. Caregiving was therefore perceived as a continuous responsibility.

For those children who received support from extended families, being able to reciprocate this support was mentioned as a motivating factor to attend school. As described below under the section on family support, there was a general indication that those providing material, financial, or emotional support may have 
been in a vulnerable situation themselves, and were therefore making sacrifices to ensure that the caregivers continued attending school. "Lerato," aged 17, a double orphan in Form D at the rural school and caregiver of a sibling, explained her vision for reciprocating care like this: "I see myself as a teacher. I see my life better than it is now and I will be helping other people and some of those who are helping me now. I will be living well, by the way!" "Maria," aged 17, a double orphan in Form B at the rural school and caregiver of her grandparents, expressed her vision for reciprocating care like this: "I see myself studying at a university and helping my grandparents and making sure that I get all their needs because I will be having money, because they are the ones who are helping me study."

As part of reciprocating care, some child carers also expressed a desire to normalize their family composition by bringing back the adult that had left the household and migrated in search of employment. The respondents considered themselves the solution to this predicament and attending school was seen as a way to make this possible. In the following excerpt, "Mpho," aged 18, describes how one respondent envisioned a future living with a parent that had left the country for economic reasons:

If I manage to [get a good job], my mum will be able to stay at home, take care of her house and I will be supporting her with everything that she needs because she raised me well until death separated her from her husband. She became so poor that she decided to do something because she wanted us to attend school.

\subsubsection{Role Models}

The positive role model code was applied when participants described a known or unknown individual whom a child caregiver looked up to for inspiration and whom they aspired to be like and wanted to emulate. Family members, teachers, and school peers who seemed to have been living a successful life fell under this category of role models. Others were persons who shared a similar background as child carers, but had overcome adversities and obtained a future that the child carers envisioned for themselves. Child carers considered such role models to be a source of encouragement and emotional support to the extent that they also influenced their career choices. 
Study participants also identified negative role models that influenced their attendance. They mentioned a negative role model whose attributes triggered avoidance strategies that Lockwood et al. (2002) described. The negative role model code was applied when participants reported reasons why a female child carer should not emulate an individual. The child carer participants reported how negative role models influenced their school attendance because they used them as an example of whom or what not to become in the future. For example, the following quote from "Agnes," aged 15, a Form B student at the urban school who has a sister working in a factory, said she had decided to stay in school so that she would not end up as a factory worker and leave her children behind. "She always tells me that I should attend school and work hard because if I don't, I'll become a factory worker and leave my children like she did."

\section{Familial Role Models}

Study participants singled out immediate and distant relatives as role models that child carers aspired to emulate. Role models were those family members whom child carers perceived to have accomplished great achievements and were living a successful life. Having what was considered a good job was the measure of success study participants used. They were able to link success of family members to educational success, hence, their motivation to continue attending school. The following quote is an example of this linkage. Being part of an educated family provided a pool of role models to look up to for motivation. "Charity," aged 17, a single orphan in Form B at the rural school, identified several role models in her family: "I have educated people in my family, so I want to look like them [...] my grandmother's child is a primary school teacher, the other one is a soldier. I want to achieve what they have achieved."

Child carer participants looked up to those relatives who were said to have overcome adversities similar to those faced by the child carers and were now successful. Such family members played a dual role of being a role model, as well as motivating the child carer to continue attending school. For instance, "Kathy," aged 18, a single orphan in Form $\mathrm{E}$ at the urban school and caregiver of a sibling, stated that she had a relative who had a difficult childhood like her but was now working. "I have [an] aunt who was struggling just like I do but persevered, she is the one who motivates me and encourages me to work even harder. She is now a teacher." Similarly, "Fiona," aged 16, who attends the urban school in Form D and 
is the caregiver of a sibling, said: "I have made a vow to myself that I will attend school and be like my brother. He is a teacher."

\section{School Role Models}

Within the school setting, study participants identified teachers as individuals whom child carers aspired to emulate in terms of career choice. Some child carers mentioned a teacher by name, while others talked about the teaching profession in general. Interestingly, although child carers described personal attributes, such as kindness, that made the teacher their individual of choice as the most important person in the school, they did not refer to those characteristics when discussing the issue of role models. The child carers instead focused on emulating the teacher as a person whose job was good enough to change one's way of living. The child carer's vision of success was having a good job, and having a good education was the prerequisite to achieving that goal. "Limpho," aged 17, a double orphan in Form D and caregiver of a sibling and niece, expressed this vision to be educated and be like her teacher: "I enjoy seeing other people like my teachers...because I believe that one day I will be like them. I want to be educated so that I can be like Mrs. X."

One of the policy makers I interviewed corroborated the idea of the importance of role models to female child carers' educational success: "These children still have role models, so, as they go to school they look up to someone. Each time they see that particular person they feel inspired and wish to be like them."

The teacher participants reported how the schools organized school events where they invited school alumni to motivate the learners. According to the teachers, the child carers may have looked up to these alumni as role models, as stated by "Kojane," a teacher at the rural school in the quote below:

Here at school sometimes we hold sessions [where] we call motivational speakers, people from outside, they come here [to] talk to [our students]. Sometimes we call our ex-students for them to talk to [our current students] and tell them that I [was here], from Form A to E, [...] then here I am working somewhere. They play a big role actually. You see they are being motivated by such things. 
Teacher participants reported that teachers were trained to motivate their students and also described how they played a role in building the children's skills to identify role models. Teacher "Kojane," in the excerpt below, further explained how teachers at the rural school motivated the students: "We always say to them, whatever you see in someone, whatever you like about somebody is exactly what you are going to be in future if you try very hard to work at school. So that motivation keeps them to this [level]."

\section{Community Role Models}

Participants made general reference to "people" outside of the school or family setting whom they looked up to as role models. Although it was not clear from all the responses whether these individuals were from the communities or villages where the child carers lived, I decided to categorize them as such with the assumption that the catchment area where child carers lived would be the most likely place outside of the school setting where any interaction with other role models would happen. "Palesa," aged 17, a single orphan in Form E at the rural school and caregiver of a sibling and niece, explained how she sought motivation from people that she considered successful:

I look at other people like when I have problems. I sit around people who motivate me; like I met someone who was at university, they had just completed their studies. She always told me that at least I had someone who cared for me; they didn't have anyone and relied on other people in order to survive. When [she] told me her life history, I knew I could achieve something in life.

A teacher at the rural school, teacher "Kojane," mentioned the educated community members as people that child carers looked up to for motivation and said: "And in their villages there are some people who are very educated so some of these people are their role models."

\subsubsection{Ability to Seek Support From Others}

Study participants discussed how various stakeholders such as teachers, neighbors, and family members provided some form of help to child carers. However, what was not always apparent was whether this support was solicited 
by the child carers, or whether it was offered by the people who were willing to help. In order to address this obscurity, I only applied the seeking support code when a participant reported that it was the child carer that asked for help from others. More than half (57\%) of the child carers and $66 \%$ of the teachers mentioned seeking support as influencing school attendance. Seeking support was among the codes that were mentioned most frequently among child carers, even when analyzed by rural/urban location, age, orphanhood, and number of care recipients.

Some of the strategies used by child carers to seek support involved telling another person about their problems, asking for help, and going to someone else's house for temporary reprieve. Child carers cited family members, neighbors, and teachers as the people from whom they sought support. As discussed in Chapter 3, although seeking help could be seen as the first resort for support when faced with a difficult situation, the child carers also presented this as a challenge and expressed frustration at the fact that the responsibility of finding solutions rested on them and not on an adult. They considered asking for help an embarrassment, which could be the reason that some children opted to ask to work and be paid in cash or kind. "Charity," aged 17, a single orphan in Form B at the rural school and a caregiver of a 9-year-old niece, expressed this frustration and lamented, "Sometimes I feel embarrassed to ask for food, especially if I see that I would have to ask for the whole week."

Study participants mentioned food and money as the items child carers asked for the most from other people. "Joan," aged 16, a single orphan in Form D at the urban school and caregiver of a sibling, stated how sometimes, these requests were made with the promise of returning or paying them back when their situation improved, or when they received remittances from their relatives working away from home. "Sometimes you find that we don't have vegetables and I have to go and find them. I go to my neighbors, but sometimes I ask for money and tell them that I would pay them back when we receive ours."

Other child carers were reported to have sought piece work from neighbors in order to be paid in cash or in kind. A few child carers indicated seeking support from other family members, or neighbors, to help with parenting responsibilities. For example, "Agnes," aged 15 in Form B and caregiver of two brothers, describes in the excerpt below how she asked a neighbor to help with homework support for 
her siblings. She said: "Sometimes, if my brothers have been given homework that I find too difficult, I ask her [neighbor] and she would help them."

The girls reported how sometimes asking for help required that the child carer leave the house to find a relative or neighbor who could assist. Where support was not always available, the child carer had to move from one house to another. "Tina" aged 17, explained how child carers went to other people's homes in search of help: "We go to our neighbors and if they don't have enough to share, we go to our grandmother's house." In the following excerpt, "Trisha," aged 16, a double orphan caring for three young relatives and attending Form $C$ at the rural school, corroborated this by explaining how she had to leave home to go to ask for help: "Yes, we get help from my grand uncle. So if we don't have things like maize, we usually go to his place and he helps us." The whole process of looking for help by moving from one house to another could add an extra burden on the caring responsibilities.

These quotes illustrate the availability of a social support structure that helped mitigate some of the problems the child carers faced which would have been a potential risk to school attendance. Being able to solicit support, and receive it, helped reduce the risk of the child carer missing school to find means of securing food and other material needs.

\subsubsection{Using Faith as a Motivator}

Formal or informal religious organizations have been known to help young carers to cope under difficult circumstances (Skovdal et al., 2009). The faith code was applied when respondents described how being involved in religious activities through prayer and receiving emotional support from a religious person were sources of motivation. The code was not applied when respondents only mentioned going to church without linking it to any form of support.

Almost all the child participants from the rural school reported belonging to a church and attending church service regularly on Sundays. This was, however, not the case for the urban child carers; although they acknowledged being a member of a church, they were not involved in church activities because they were expected to be at school on Sunday for compulsory study. Those who reported having 
received some form of support from church perceived it more as a source of spiritual motivation than a place to receive financial or material support to help them attend school. In addition, the participants perceived the counseling and motivational talks that the church provided as a source of hope for a better future. "Gina," aged 17, a single orphan in Form D at the urban school and caregiver of siblings, a cousin, and a grandmother, explained in the following excerpt how she gets motivated by going to church: "[I go to church] because I get encouraged by what the priest says, that we should trust in God because He will help us through all our problems. I enjoy going to church."

Similarly, "Maria" aged 17, a double orphan in Form B at the rural school who takes care of her grandparents, expressed the motivation she gets from going to church as follows: "[At church], we are also told to pray to God and trust in Him because we will succeed in life."

Study participants reported how the school played a role in providing spiritual counseling to the child carers. This was done either on a one-to-one basis between teacher and learner or during school-wide events, such as school assemblies. Teacher "Mapula" from the rural school explained how teachers are involved in spiritual counseling in the excerpt below:

What we always tell [the students is] that there is nothing like prayer. [When] you pray, God provides because God gives you even some things you haven't asked [for]. You ask, he will give you at the right time, don't cease [to] pray. I think that's one of things that keeps the [child carers] going.

Similarly, teacher "Kabelo" from the urban school described how their school included religious motivation in school-wide activities: "We just make sure that the assembly goes well. Every week three students lead the assembly: one reads the Bible, the second one encourages and the third prays. So, in a way, they still gain spiritually." The quotes by the child carers and the teachers all illustrated how religiosity and having hope for the future are connected. 


\subsubsection{Self-Motivation}

The self-motivation code was applied when participants referred to a child carer who was self-motivated, had inner drive, or was determined to keep attending school. Teachers, policy makers, and nongovernmental organizations described these attributes in the child carers who continued attending school, despite living in adversity. A policy maker I interviewed described children who were driven:

You must have inner self-motivation as a child, and must know your goal that you want to reach at the end of the day. I think that it is what keeps the child going despite all challenges and hardships.

Being self-motivated was associated with school performance. Teacher "Gillian" from the urban school described child carers as being determined, based on the fact that the children were performing as well academically as the learners who were noncarers. "They are determined because when you look at their Form E performance, it shows that they are committed to their education. They pass well like other children." Surprisingly though, only one child participant, "Tina," aged 17 , alluded to this attribute by describing the inner dialogue she engaged in to motivate herself to go to school, and linked attending school to positive outcomes that would change the family situation. "Every morning I wake up, tell myself that I should go to school to study hard so that I can pass my subject because I realise that our family is struggling." The quotes illustrated that self-motivated children are goal-oriented with a passion to learn.

\section{Employing Academic Performance as a Motivator}

The academic performance code was applied when participants mentioned educational performance as the reason for child carers attending school. A few participants who linked academic performance to the child carers' continued school attendance specifically noted how school progression to senior high school, Forms D and E, gave them the impetus to continue going to school in the midst of facing adversity. The education system in Lesotho requires one to pass end-of-year examiniations in order to be promoted to the next class. The citations below illustrate how perseverance itself was perceived to be a motivating factor. For example, "Mindy," aged 16, a single orphan in Form B at the rural school and caregiver of her grandmother and three siblings, described how academic 
performance inspired her to stay in school despite her caregiving responsibilities: "[I continue to attend school] because I have realised that my performance is good and it doesn't really show that I live with my grandmother only."

This was corroborated by a policy maker I interviewed, who attributed level of education to a child carer's continued school attendance and stated the following: "Because of the level of education they are at, it is not easy for [a student] to decide to drop out, especially looking at the fact that they are very close to going to a university or tertiary level."

\subsection{Interlink within Individual Domain}

The findings showed that there was an interlink between the various factors within the individual domain that ultimately influenced school attendance. Figure 5.5 illustrates the intradomain interactions.

The individual attributes of academic performance, having role models, faith, and self-motivation are linked with the vision attribute, illustrating how each of those may have influenced a child carer's vision for a brighter future. The relationship between vision and academic performance was bidirectional, as having a vision for a better future was also seen as a motivation to perform well in school.

The role model attribute is interlinked with vision and academic performance. Positive role models were said to have influenced the child carers' vision and hope for the future, and also encouraged children to excel academically.

\subsection{How Individual Factors Interacted with Other Socioecological Domains- Family, School, and Community}

\section{Individual Factors and Family}

The study findings show interrelations between the family factors and the individual attributes of vision, academic performance, and role models. Financial support, family situation, and family role models were noted as motivating elements for child carers' vision for a brighter future, which ultimately was a driver of school attendance. 


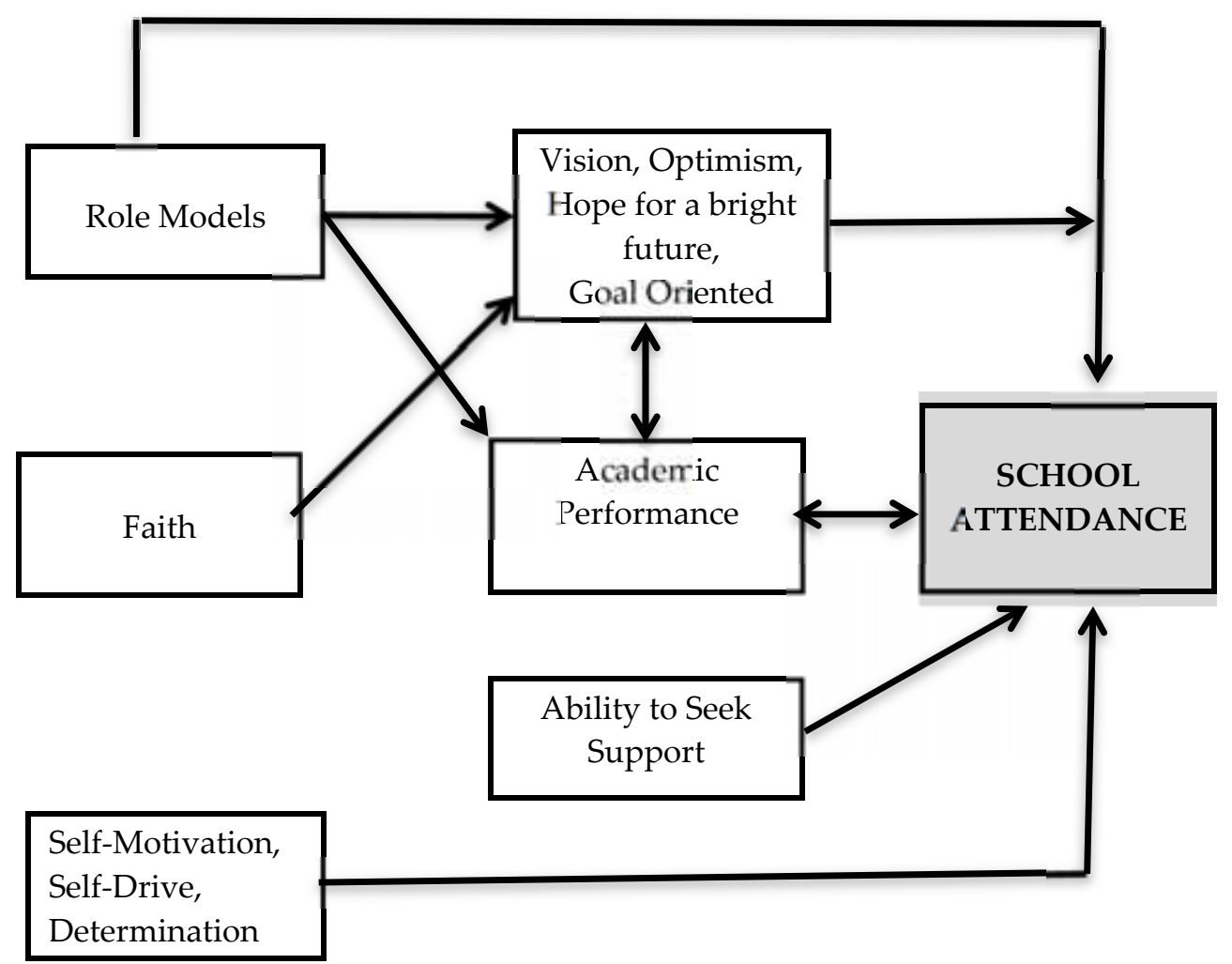

Figure 5.5. How individual factors influence school attendance. Source: Researcher's own diagram based on research findings.

Child carers felt indebted to family members who paid their school fees and linked their future aspirations to reciprocating this support. The quote below is from "Lisa," aged 15 in Form B and caregiver of a sibling, describing how she hoped to take care of those who were providing for her: "One other thing that makes me work even harder is [that] I always remember my brothers because they hustle to help us. I always pray to God that I may have a bright future so that I can help them."

The child carer's desire to remove the family from poverty and to provide better care for their care recipients in the future influenced the link between the family situation and vision. Family members who were considered to be role models influenced the links to vision and academic performance. 


\section{Individual Factors and School}

The findings show an interaction between school and four individual factors (vision, role models, academic performance, and faith). This linkage highlights the significance of the teacher and child-carer relationship, as the school teacher was associated with all the four attributes, while school peers were only linked to the academic performance attribute. Child carers considered teachers to be their role models, who also influenced their vision for a brighter future and academic performance. The findings also showed how teachers played a role in influencing the child carer's religious belief by providing individual counseling or through school organized events, such as assemblies.

\section{Individual Factors and Community}

The relationship between individual factors and community occurred with the factors role models and faith. These linkages did not come out as strongly as with other domains. The link with community role models happened when child carers identified people within the community whom they considered to be successful and worth emulating. The church was seen as playing a key role in influencing female child carers' spiritual belief that gave them hope for a better future.

\subsection{Discussion}

\section{Having a Vision}

The findings established that having a vision for a better life in the future was a key factor that motivated female child carers to continue attending school. Participants perceived a relationship between attending school and achieving their future goals as they considered school attendance as the first step on the pathway to a brighter future. Having a vision for the future also required that the children had the social competence to see themselves beyond their current situation and plan for the future. This is in concurrence with literature that identified working towards specific goals as an attribute found in resilient children (Benard, 1991; Genevieve, 1997). The child carers exhibited this quality by first acknowledging that the situation they were in was dire, then articulating a clear vision of the type of life they wanted to live in the future, and finally defining the pathway to getting there, including the resources and support system needed to achieve that goal. They linked school attendance to achieving good results for good career prospects, which would ultimately give them a better life. People who allow themselves to 
maintain such hopes and dreams of a future beyond their adverse situation draw on what Tara Yosso theorized as their "aspirational capital" (Yosso, 2005).

The study findings showed that the child carers' aspirations to provide better quality care for their dependents influenced their vision for a better future. This was a novel finding. Their plans to reciprocate care to those that were supporting them in one way or another reflect a sense of intergenerational indebtedness. Interestingly, from the child carer's perspective, reciprocation of care was still perceived as one sided, with the child carer continuing to support the family member in the future, without expecting anything in return. None of the respondents alluded to any expectation of reversed roles where current care recipients, including those that were in school, took up the caring role in the future. The desire to continue providing care was also triggered by the need to normalize family composition, either by bringing back the adults that had migrated, or by the child carers starting their own families.

\section{Emulating Positive and Avoiding Negative Role Models}

The findings showed that the female child carer's school attendance was most likely inspired by both positive and negative role models whom they were able to identify within the school, family or community setting. Having the ability to notice, recall, and be inspired by information that contributes to reaching one's aspirations of success is an attribute of optimistic or promotion-focused individuals (Lockwood et al., 2002). The study findings show that this skill can also be taught or nurtured as demonstrated by teacher participants who reported having provided motivational talks that taught child carers to identify positive elements in individuals as role models. Although the majority of respondents discussed positive role models, some child carers also described how negative role models influenced school attendance. Negative role models trigger avoidance and preventative strategies that individuals employ to avoid turning out like people who have not achieved desirable outcomes (Lockwood et al., 2002). In this study, female child carers considered attending school as a strategy to avoid failing. They saw failure as something that would hinder achieving their goals for the future.

\section{Seeking Support}

My study findings showed that female child carers exhibited traits of resiliency by taking a proactive approach to addressing their problems (Christiansen et al., 
1997). Their ability to solicit support from family members, school, and neighbors to meet their school and home needs helped reduce their risk of missing school to find means of finding food. This finding also aligns with Benard's (1991) view that social competence (i.e., the ability to elicit positive responses, such as providing support, from others) is one of the traits of a resilient child. Similarly, my study findings resonate with the Evans (2005) Tanzania study, and Skovdal et al. (2009) Kenya study, which showed that children at risk also depended on their ability to mobilize social resources available to them, such as eliciting support from immediate and extended family members and community members. Having the ability to maneuver through social institutions, such as schools and communities, is what Yosso (2005) termed "navigational capital." The study also showed that the children counted on the support from their networks within the school and communities to seek help. Yosso defined peer support and other social networks as social capital.

\section{Self-Motivation}

The self-motivation attribute was recognized more frequently by other participants, rather than the child carers themselves. Teachers, policy makers, and nongovernmental stakeholders identified self-motivation as a factor that influenced school attendance more frequently than the child carers did. The teacher respondents used child carers' school performance as an indication of selfmotivation. Although children did not describe themselves as being selfmotivated, it was clear from how they described other attributes, such as their optimism for a brighter future, that there was an inner motivation that pushed them to continue attending school.

\section{Using Faith as a Motivator}

Findings of a study in Western Kenya by Skovdal et al. (2009) showed that child carers expressed their hope in a better future through their spiritual belief that God would provide solutions to their problems. My study had similar findings, where the role that faith played in child carers' motivation was cited in the context of it being a source of spiritual and emotional support, factors that gave them a sense of hope for a brighter future. Participating in church teachings and prayers gave them hope in dealing with the problems they were facing, and influenced their aspirations for a better future. The children also cited the church as a place where they received counseling and emotional support needed to deal with the problems 
experienced. This aligns with Katz (1997), who associated involvement in religious organizations with developing resilience leading to positive outcomes.

\section{Academic Performance}

Participants perceived academic performance and school progression as motivators to continued school attendance. This finding resonates with the view advanced by Johnson (1997) that academic success, although normally regarded as an outcome or indicator of resiliency, can also help build an individual's selfesteem and confidence, attributes necessary for one to work towards achieving a better future.

\section{Conclusion}

The study showed that the female child carers exhibited individual traits of resilient individuals. Having a vision for a better life in the future was perceived to be the most prominent factor that motivated the child carers to beat the odds. The findings show that intradomain and interdomain factors played a role in influencing female child carers' school attendance. Being able to identify role models contributed to female child carers' school attendance to the extent that they were able to identify individuals within different settings who influenced their desire to have a successful life in the future. This ability to notice and be inspired by information that contributes to reaching one's aspirations of success is a characteristic found in optimistic or promotion-focused individuals (Lockwood et al., 2002). The study found that this is a skill that can be enhanced in others. The interaction with external factors, especially with school teachers, comes into play to enhance these skills, enabling female child carers to identify role models among family members, within the school setting and in the community at large. Religion also played a role in providing hope for the future. The role of religious background contributed to the extent that child carers believed that God would help them through their difficult situation, giving them hope for a better future and therefore influencing their setting future goals. Faith alone did not directly influence school attendance. 


\title{
CHAPTER 6
}

\section{CARING SCHOOLS: PROTECTIVE AND RISK- MITIGATING SUPPORT FOR GIRL-CARERS}

\begin{abstract}
"Jessy"12" is an 18-year-old girl who lives in a one-room hut in a rural village near Maseru with her 15-year-old sister. Her father died, and her mother lives and works in Maseru City in order to support the family and pay school fees. She walks 45 minutes to get to school, enjoys netball, and plans on studying accounting in the future. She takes initiatives to make ends meet; such as participating in work for food programs in the summer, and selling dried peaches during the winter.
\end{abstract}

Her greatest challenge is when she has to go to the field. She says: "We don't have cattle...so there are people who will be plowing for us... Last year we planted our field through the "Halfed" system.13"

What challenges her is waking up as early as 03.00 a.m.in order to have time to cook and deliver the food; which is her form of payment to the people ploughing. She has to prepare for school and final exams. She also struggles because sometimes their mother can only afford maize meal, and they have to find food to go with the meal. "We struggle to get vegetables," she says. There is the added challenge of burglars due to the high crime in her village. She explains that "whenever it was night time [they] became scared that someone would knock at our door."

School is her means for escaping these challenges. Her friend is the most important person to her at school, and when she is there, she forgets about her troubles. Her mother encourages her most, and always tells her that education will make them succeed. Her teachers, aunt and community help by buying dried peaches, and providing clothes and vegetables, respectively.

\subsection{Introduction}

The story above depicting the life of "Jessy" is an illustration of the situation of most of the girls in the study, where despite going through adversities, they are

12 To ensure confidentiality of study participants, all names used here are pseudonyms.

${ }^{13}$ A partnership where each party comes with what they have to offer (e.g., land or cattle for ploughing, labor, etc.). 
still able to attend secondary school. Schools are places where children tend to spend a lot of time and are therefore suitable sites for interventions to support children who may be at risk due to various environmental stressors (Condly, 2006). As discussed in Chapter 4, girls who are caregivers face challenges that may put them at risk of dropping out of school, including psychological issues, missing school, time constraints, lack of food and other materials, and lack of finances for fees and other school requirements. As my study has also shown, despite experiencing such adversities, some children show resiliency by being able to combine caregiving with regularly attending school (Cluver et al., 2012; Robson et al., 2006; Skovdal et al., 2009). This raises the question as to why and how such girls still beat the odds and manage to do so.

This study drew on an educational resilience theoretical framework which is influenced by resilience studies from a mental health perspective (Waxman et al., 2003). According to Condly (2006), resilience is defined as the ability to survive and thrive in spite of obstacles or adverse circumstances. It does not, however, imply being immune to vulnerability, but rather is associated with school success and is broadly defined as those students who "...succeed in school despite the presence of adverse conditions" (Waxman et al., 2003, p. 1). For the purpose of this study, success in school was defined as regular school attendance.

This chapter therefore discusses the study participants' perceptions of how schoolrelated factors such as school environment, teachers, and student peers contribute to child carers' ability to regularly attend school. Using Urie Bronfenbrenner's socioecological model (Bronfenbrenner, 1994) as the framework to explain how various factors are interconnected to influence educational resiliency (Condly, 2006; Embrace the Future, 2005; Fredricks et al., 2004), my study findings showed that teachers and peers played a critical role in providing a conducive school environment that supplied the protective and risk-mitigating support necessary to keep female child carers attending school. For example, interviewees mentioned that teachers paid school fees and provided uniforms for child carers to attend school. The study also found that there was interplay between school factors and other nonschool domains, such as the community, to ensure that girl-carers continued attending school. For example, community members approached school authorities to inform them of the plight of the girl-carers as a way of soliciting help to keep girl-carers in school. 
The chapter is organized to start with a description of prior literature on school factors vis-à-vis educational resiliency. I then present the findings starting with a discussion on how being in a conducive school environment provided a protective and mitigating space for child carers to keep attending school. I further present the findings on the role of teachers, and the role of peers in supporting child carers' school attendance. This is followed by a discussion on the interplay between school factors and other domains, including family and community. The chapter ends with a discussion and conclusion section.

\subsection{Prior Literature on School Factors and Resilience}

Prior studies have established that, as with the family environment, schools that provided care and support and established high expectations for at-risk children influenced their positive outcomes (Benard, 1991). The author estimated the success rate of such children who experienced multiple risks and were in a caring school climate at between $50-80 \%$. Other scholars considered a conducive school environment as one that made children feel welcome, provided a sense of safety and security, and facilitated effective participation (Cassen et al., 1997; Christiansen et al., 1997). Such schools were seen to be a source of support, provided friendship, and nurtured at-risk students to believe in themselves and aspire for a better future (Christiansen et al., 1997; Skovdal et al., 2009). Schoolbased support has been seen to provide a buffer against risky factors that a child may be experiencing in the home (Zimmerman \& Arunkumar, 1994).

Schools can therefore provide a critical space for protective factors to be developed in order to foster resiliency in at-risk children (Waxman et al., 2003). Most studies suggest having school programs as the way of achieving this. For example, programs to help at-risk students develop special hobbies or interests, such as arts and sports (Christiansen et al., 2009), peer education programs, and student advisory boards (Zimmerman \& Arunkumar, 1994), have been known to help children successfully deal with life challenges. Being involved in extracurricular activities, such as school clubs and support groups addressing different risks, provides an informal form of support which can give at-risk children a sense of belonging and enhance their self-esteem, thus fostering a positive attitude towards engaging in school (McMillan \& Reed, 1994). 
Where schools are not able to provide certain services, their personnel can facilitate referrals to organizations that provide social services (Waxman et al., 2003). This was evidenced in a South Africa study on teachers' ability to provide psychosocial support in schools, where teachers collaborated with other organizations to provide material support to vulnerable children (Ferreira \& Ebersohn, 2011). Schools can also organize events, such as special assemblies, and invite school guests whose messages can motivate children (Christiansen et al., 1997), which ultimately can increase resiliency and school attendance.

However, studies have put the onus on the school authorities to build that school climate, which enables a child to participate fully (Christiansen et al., 1997; Waxman et al., 2003) in support programs that will help mitigate their risks and ultimately keep them attending school. In order to do so, Condly (2006) suggested that school staff needed to take a proactive approach to identify students who may require protective interventions because being at school was not always a guarantee that the child would access development and support services. McMillan and Reed (1994) went further to suggest that teachers should seek out and personally invite at-risk children to join school programs, as many would not participate voluntarily because they feel disconnected. The Ferreira and Ebersohn (2011) study findings reported that teachers identified at-risk children by observing the children in class or on school grounds. Taking this proactive approach requires that school staff is trained in the skills needed to identify at-risk students and to find ways of helping them cope with their situation (Christiansen et al., 1997). A South Africa study that offered a similar recommendation found that most schools did not have staff with a specific mandate to provide counseling (Bhana et al., 2006).

Johnson (1997) presented a dissenting view about designing school programs for at-risk children and argued that school programs are broadly designed to benefit not only at-risk students, but whoever was exposed to them. She contended that where school-based programs had a positive impact on at-risk students, individual or family factors would have to interact with each other to influence the individual resiliency factors of the at-risk student.

Educational resiliency literature further highlighted the unique and significant role that teachers and other school staff played in providing support for children who 
were at risk (Christiansen et al., 1997; McMillan \& Reed, 1994; Sandin-Esteban \& Sanchez-Marti, 2015). One critical role that teachers play is that of being a special person providing positive, supportive human interactions and relationships essential to protect or compensate for children's adversities (Christiansen et al., 1997). Normally, families would be expected to provide this type of support through a network of special relationships, but in situations where at-risk children are not able to access this type of network, a relationship with one special individual can provide guidance, safety, protection, and support (Cooklin, 2009; Katz, 1997). The adult can also develop a mentoring relationship that nurtures the at-risk child by transferring knowledge and life lessons (Christiansen et al., 1997; Gandara, 1995; Katz, 1997).

Within the school setting, teachers provided special support and encouraged students facing adversities to aspire for more than what they believed they could achieve (Waxman et al., 2003). Such outstanding teachers were considered to go beyond their call of duty to play the additional role of being the confidant and positive role model (Benard, 1991), and demonstrated that they had high expectations for students to achieve positive outcomes (Katz, 1997; Sandin-Esteban \& Sanchez-Marti, 2015). Resiliency scholars further described a supportive teacher as one who showed kindness and compassion, provided mentorship to at-risk students, and conveyed genuine support to them by listening to them and validating their feelings (Waxman et al., 2003). A supportive teacher was also described as being understanding (Zimmerman \& Arunkumar, 1994) and a person with whom students could talk about anything without feeling that they were being judged (McMillan \& Reed, 1994). Katz (1997) described this relationship as a mentoring one where an individual formed a nurturing bond and was able to "share knowledge, wisdom and lessons of life to leave a lasting imprint" (p. 7).

McMillan and Reed (1994) summed up the interpersonal qualities of a supportive teacher as one who was:

[...] caring, having respect for them as persons and as learners, being able to get along with them, listening without being intrusive, taking them seriously, being available and understanding, helping and providing encouragement, and laughing with them. (p. 139) 
Beyond the interpersonal attributes mentioned above, Waxman (2003) suggested that supportive teachers can also assist at-risk students by providing material supplies and reaching out to family members to find out what their basic needs are.

Taking into account these expectations of a supportive teacher, it is important that the skills of teachers are enhanced to provide this special attention, expect positive results, develop relationships (Christiansen et al., 1997; McMillan \& Reed, 1994), and improve education outcomes of at-risk children (Waxman et al., 2003). The training for both in-service and preservice teachers may include seminars or lectures specifically on how to work with at-risk students (McMillan \& Reed, 1994). Waxman et al. (2003) further suggested providing feedback from classroom observation and the learning environment. (p. 13). Nyabanyaba (2009) suggested capacitating teachers' skills to identify and support at-risk students with psychosocial support (p. 53). Ferreira and Ebersohn (2011), however, provided mixed arguments on this matter, and argued that by teachers choosing the teaching profession, they should already possess characteristics such as "empathy, caring and supportive dispositions" (p. 64). On the other hand, the authors contended that, in most cases, teachers did not receive formal training in social work, counseling, or psychology, and may therefore not have the needed competences to deal with psychological issues.

Beyond teachers, resilience studies also identified peers as another source of psychological support in times of hardship (Skovdal et al., 2009). A study that reviewed lessons from research on resilient children and adolescents postulated that for children attending school on a regular basis, positive outcomes had been associated with peer acceptance (Masten \& Coatsworth, 1998). The authors highlighted the importance of children belonging to prosocial peer groups, arguing that friends played a role in providing emotional support and were also able to influence academic achievement either positively or negatively. Another study on developmental vulnerabilities and strengths of children heading households in South Africa found peer support to be the most common source of help with schoolwork (Donald \& Clacherty, 2005).

Studies have also shown that where school factors influenced school attendance, these mostly interacted with other domains, such as family and community factors. 
Christiansen et al. (1997), for example, proposed a multifaceted approach in responding to the needs of vulnerable children in school and argued that, where school-based programs compensated for social vulnerability, individual or family factors may also play a role in mitigating the impact on at-risk children. The authors specifically cited parental school involvement as a factor that contributed to school success. In concurrence, Condly (2009) also showed how schools might link with organizations outside the school setting to link at-risk students to access social services.

Based on the cited literature, protective school factors included having a conducive school environment that provided a sense of security and safety, was a source of support, provided friendships, facilitated effective participation, and nurtured atrisk students to aspire for a better future. Also within the school space, teachers and peers played a key role in providing financial, material, and psychological support to at-risk children. My study aimed at building on this literature and explored whether these protective factors applied to female child carers vis-à-vis regularly attending secondary school. I discuss the findings in the sections that follow.

\subsection{Findings}

The Lesotho Education Sector Strategic Plan: 2005-2015 (Government of Lesotho MOET, 2005) recognizes family care as a critical factor affecting girls' school attendance as they "look after their siblings [...] and take up additional responsibilities [including] caring for the sick" (pp. 57-58). The strategic plan recommends the provision of bursaries to needy children, establishment of schoolbased support systems, and implementation of well-targeted interventions to support school attendance as some of the ways of ensuring that children in adversity stayed in school. The document does not, however, go further to suggest specific interventions for these recommendations.

This section presents the findings of how school-related factors positively influenced female child carers' secondary school attendance. The study found that a supportive and caring school environment, flexibility with school policies, a school feeding program, and connections to support services motivated children to stay in school despite their adversities. Second, teachers and other school 
authorities played a major role in creating this protective climate within the school and provided or linked to supportive services, especially mentorship, school fees, and food support, that helped mitigate the child carers' risks to school attendance. Furthermore, study participants also cited school peers as a group that provided material, emotional, and schoolwork support. Getting this support was said to have motivated child carers to stay in school.

\subsubsection{A School Environment Conducive to School Attendance}

Study participants described the school setting as "a place of refuge from the worries of caregiving." Waivers on some school policies, such as late payment of fees, school lunch, extracurricular activities, and nondiscrimination, are factors that respondents mentioned that made the school climate conducive enough to be a pull factor for school attendance. The study found that some programs, although designed to reach all students, had positive unintended outcomes for those facing adversity. For example, the unanticipated benefits of the school feeding program, which catered to all students, were that this one meal at school not only motivated girl-carers to attend school, but allowed them to take some food home to their care recipients. The role of teachers in contributing to this enabling environment and providing support to child carers is discussed further in this chapter.

The sampled schools were reported to have been using the Ministry of Education reporting form as a way of identifying children who were either orphaned or vulnerable. This form captured enrollment numbers of orphans and vulnerable children by age, form, and sex. The data collection form defines a vulnerable child as "a child who is extremely poor and or physically abused" and recommends that "only extreme cases e.g. that affect school attendance of a child" should be recorded. ${ }^{14}$ Thus, from the onset of enrollment, the schools were aware of a child's vulnerability. Respondents indicated that further details of the vulnerable child's situation became evident through the interaction that staff and students had with them. Sometimes, children themselves approached teachers, while at other times, peers would inform teachers when they identified a friend as being in need.

14 Lesotho Ministry of Education and Training, Annual Statistical Return Secondary School Form-ER42C (2015) ET Form 6 (c) Enrolment of orphans and vulnerable children (OVC) by age, form, and sex. 
Study participants reported on the protective nature of the schools and mentioned the various ways in which the school policies and personnel mitigated some of the challenges that they faced to ensure that they continued with schooling. As one NGO worker stated: "The school becomes the second family for the girls. It is protective. The Government of Lesotho has been putting [in place] a number of policies, which include child friendly schools." The Child Friendly School model was promoted by UNICEF to ensure that schools operated within a child rights framework and in the best interest of the child. Child friendly schools were expected to be, among other factors, inclusive, safe, protective, and accessible to children at risk (UNICEF 2012).

Another participant, "Filda," a teacher from the urban school, described how her school provided an environment where child carers were able to express their emotions and received support. She stated: "So they know that when they are in school, they can always have people to cry on, a shoulder to lean on; then we talk to them to tell them not to worry about that." Others echoed these sentiments describing the school personnel and peers as caring individuals who paid attention to the needs of child carers, and helped keep the girls in school. One teacher described how children even told them about issues that may have happened at home, demonstrating the trust that child carers placed in the school staff.

One way in which schools provided protective or mitigating support was when teachers played a facilitative role by helping link the female child carers to external support and social services. Teachers identified girls in need, who they then referred to organizations providing educational scholarships and material items that would help them stay in school. Policy maker participants alluded to the Lesotho Ministry of Social Development government bursaries for orphans and other vulnerable children, while teacher participants mentioned scholarships offered by civil society organizations as possible sources of support. The government bursary program, established in 2001, provides school fees and other scholastic requirements to ensure that orphans and other vulnerable children have access to secondary education. ${ }^{15}$

15 Unpublished Ministry of Social Development notes on the OVC Bursary Programs. Obtained from MOSD on March 25, 2016. 
The study participants described how the schools helped identify these children, some of whom solely depended on the school, to solicit this help. Teacher "Tebuho," from the rural school, described how the school and a local nongovernmental organization worked together to ensure continued schooling:

World Vision played an important role because if we identified a child, we would inform World Vision, [who] would come here and interview the child and then go home to see what they need.

Seventeen-year-old child carer, "Lerato," who is a double orphan, also expressed that type of support provided by the school in the following quote: "Sometimes here at school, they would ask for orphaned children and [we] would be given things like roll-on and pads."

In addition to facilitating linkages to support services, participants also mentioned how the schools implemented various events and programs within the school whose objective was to reach vulnerable children. For example, teacher "Kojane" from the rural school described one school initiative in this manner:

Here at school, sometimes we hold sessions, like we call motivational speakers, people from outside, they come here, they talk to them. Sometimes we call our ex-students for them to talk to them and tell them. They play a big role; you see they are motivated by such things.

Another teacher, "Tebuho" described a range of programs that girl-carers participated in: "We have games, extracurricular activities, they do singing, sport, debating. Such things keep them in school."

A single orphan, "Milly," aged 18 in Form E at the urban school and caregiver of two siblings, also described how the school recreation program provided a reprieve from the worries of caregiving:

I enjoy Thursday because it is our sports day. When I am in sports, I forget about what I left behind home. I put all my focus on enjoying this, like other children. My mind forgets everything that happens at home. 
The above quotes showed how broad-based school programs, such as motivational talks and sports events, although aimed at reaching all learners, had benefits for those at-risk. The other factors that study participants reported as making the schools conducive for child carers are discussed in the sections below.

\section{An Environment of Equity Motivated School Attendance}

Study participants described how schools treated all children equally and did not discriminate against girl-carers based on family situation or vulnerability. Teacher "Filda" from the rural school described the equal treatment philosophy of the school setting:

School is a uniform environment whereby they [students] are the same. They are the same, a child carer or no child carer, an orphan or no orphan, they are the same to us, and then when they are at school at least they have that social interaction that makes them forget all the things that are at home.

Similarly, "Fiona," aged 16, a student from the urban school and caregiver of a sibling, also brought up the issue of being treated equally by the staff: "As for our principal, she treats us well and does not discriminate against us. We are all equal before her. I like her."

The preceding quotes illustrated the welcoming and nondiscriminatory learning climate of the schools, which is an important factor that may attract students to attend school.

Some teachers hailed the fact that school children in Lesotho had to wear a school uniform, suggesting that it contributed to an egalitarian school culture. As teacher "Tebuho" stated: "There is something about the uniformity of everyone, everyone is the same. When the kids are [in] uniform..."

School authorities also used the condition of the uniform as an indicator of vulnerability that helped them identify who to target for support. School staff made personal contributions to purchase uniforms for those that could not afford them, and were not on scholarship. A school administrator, "Kakoma," explained 
how school staff tried to create an environment of equity by meeting the needs of those that were considered vulnerable:

There are also other teachers who are helping me to identify such kids; you find that she would identify a girl who does not have a uniform at all. [We] will make sure that we do whatever we can to help such a child. Even teachers are helping almost all the time; you find that they are buying uniforms for these kids.

\section{School Feeding Program Motivated School Attendance}

The Government of Lesotho, in partnership with the World Food Program, implements a National School Feeding Scheme that provides school lunches to about 400,000 learners in primary and secondary schools (Matope, 2015). Of the two sampled schools, only the rural school served free lunch for the students. I did not find out why the urban school did not have a feeding scheme. Participants highlighted how the feeding program was a motivating factor for child carers to attend school. They explained that the food provided at the school kitchen was the only meal that some of the child carers would have in a day. Teacher "Tebuho" from the rural school stated the following:

School is, for most of them, their only source of food. They eat once a day, at school, so it is very useful for them to come to school, because lunch time is a good time for them.

A government policy maker also acknowledged the role that school feeding played in motivating children to attend school.

One other thing that motivates them is that in other schools, for some of these vulnerable children who don't have anything to eat at home, they can get at least one meal though the school feeding program.

Assuring a meal a day to the children was, however, also noted as a source of concern for children who still worried about their care beneficiaries left at home with no food. "Palesa," aged 17, a single orphan and carer of five family members, described the situation she was in and expressed her mixed sentiments about the 
school lunch. Although she considered herself better off since she was able to have a meal, she still worried about the family members that she cared for:

There are times when we have nothing at all to eat, nothing at all. I am better because I will have lunch at school. When I think about the ones at home who have had nothing to eat, it really worries me a lot. So I keep thinking that they have nothing to eat.

The child carer participants seemed to underscore the value they attached to the school meal because, when probed about the one thing they would change about their school, most of the child carer participants at the rural school pointed at improving the quality of the food served in the kitchen. A few, such as "Trisha," a double orphan in Form $\mathrm{C}$ and caregiver of three family members, were happy with the food that the school offered.

I really enjoy it because [at home] we don't eat some of the food we eat at school. We always eat papa and vegetables at home but, here at school, we also have peas, samp ${ }^{16}$ and really enjoy the food we eat on Wednesdays because of the samp.

Although the school feeding program was meant to cater to children while they were in school, teachers made special arrangements to sometimes pack leftover food as a take-home for vulnerable children. Doing so demonstrated how the school supported the child carers beyond the precinct of the school. When there were leftovers from the school lunch, school personnel offered a second meal to vulnerable children before they went home. Teacher "Mapula" explained it in the quote below:

So, when food remains, these who always stay over to study, we always call them, especially the needy ones, hey wena! [Hey you] come and eat; because we know that will be their last meal.

A policy maker stated the following to explain how providing such support was an incentive for child carers to attend school:

${ }^{16}$ Crushed maize kernels. 
Mostly, such children become motivated in schools where there is a feeding program because when teachers realize that this particular child is more vulnerable, they arrange with the school kitchen to make her a package she can take home and share with her family.

Teachers at both schools described how the teachers endeavored to ensure that hunger was not a barrier to attending school. This was demonstrated at the urban school, which did not have a feeding scheme, where the teachers used personal resources to find a way to offer food to some of the vulnerable children. Teacher respondents, for example, described how school personnel brought extra food from their homes. Teacher "Gillian" explained how this gesture motivated children to attend school:

We give them food; sometimes we even pack two lunch boxes because we know that some of them will need that food. That, in itself, encourages them and makes them want to keep coming to school.

Fourteen-year-old "Bridget," a single orphan at the same urban school and caregiver of a sibling, expressed how food motivated her to go to school:

I like coming to school and if I happen to leave home without food, I know that when I come back I will be feeling very different; I would be happy.

\section{Flexibility with School Policies Benefits Girl-Carers}

Respondents described how school authorities were flexible in implementing some of their policies in order to mitigate barriers to school attendance that may have affected vulnerable children. Girl-carers benefitted from this flexibility: The findings showed that schools waivered portions of the compulsory fees, gave an extended grace period for payment of school fees, waivered the need for a complete school uniform, and reinstated children despite long periods of absenteeism. As one teacher, "Tebuho," stated, "We look at these kids in a special way."

An interview with a policy maker revealed that the Ministry of Education and Training had negotiated with the schools for children who were receiving government bursaries to be exempt from paying other fees outside of tuition. 
Schools normally requested families to make contributions towards school projects, an expense that the government scholarship did not cover. The policy maker stated the following:

They do not even ask for other compulsory fees like building, water, halls and school trips, since we do not pay for those; we still work together in harmony with schools and understand one another on behalf of those children.

Other participants described how school authorities accepted late payment of school fees. A single orphan, "Kathy," aged 18, who was a caregiver of a sibling and attended school in Form E, expressed why the school administrator was her favorite person in the school:

If I tell [the principal] my problems, she seems to understand, and sometimes if my school fees have been delayed, she understands.

This flexibility in applying policies was also extended to how schools handled issues of absenteeism involving vulnerable children. "Tebuho," a teacher, stated how the rural school was more lenient in the way they treated those in adversity:

The school is very, very flexible when it comes to such kids because, under normal circumstances, a kid staying away for three weeks, we just write [them] off, but kids like these ones, they [...] come back after one year and then we readmit them.

Teacher "Gillian" expressed a similar sentiment of the urban school when she described how her school took special discretion in dealing with disciplinary issues:

They [girl-carers] are included, for instance, because there are no parents to monitor their behavior, one may end up pregnant, the school would not expel such a child so, to me, this is great support and inclusion. They also do not get expelled if they do not have a full uniform. 
Study participants reported that the school administration at both schools offered compulsory study one day of the weekend as a way of providing space for all children to do their schoolwork. Teacher "Kakoma" from the urban school had this to say:

We decided to do that because we realized that, at home, they do not read. Like, in these cases, where they are staying with their relatives or guardians, you find that they are not able to read, they are doing house chores at home [...]. That is why we decided that they should come to school to study.

Almost all child carer respondents indicated that they used this opportunity after completing their household chores and going to church. Some child carers also mentioned how, during the week, they arrived early at school in order to do their homework before class started. The importance of this arrangement ensured that children whose home environments were not conducive for studying were able to use the school premises when needed. For example, "Trisha," aged 16, in Form C at the rural school, described in the following quote how she used the school premises during the weekend for studying: "On Sundays, I only cook and clean then go to school to study. When I come back from school, I clean if I have not done that. I fetch water and prepare my uniform for Monday."

\section{School as a Place for Psychosocial Support}

For some children, going to school provided them with a space where they were involved in activities that helped them escape from worrying about the demands and responsibilities of caregiving. For example, "Jessy," aged 18, a single orphan and caregiver of a sibling, explained why she attended school on a regular basis in the following quote: "When I am home, I think really hard about things that bother me, about the troubles that we have. So, when I am at school and playing with other children, I feel much better because I forget all these things."

Teachers also recognized the value of the female child carers interacting with other children within the school setting, and how this psychosocial support was a motivating factor to keep them attending school. Teacher "Filda" expressed this sentiment in the quote below: 
One of the things that keeps them [girl-carers] in school [is] when they are away from home they are in a different environment, they meet other children with different upbringings and different experiences.

The above quotes demonstrated how schools provided the setting for child carers to socialize with other children, something they looked forward to; ultimately, many of these girl-carers went to school for that purpose. I have called this setting "a caring school environment." Interacting with other children away from the home environment, albeit for a short time, had unintended psychosocial benefits for the child carers, and ultimately may have motivated them to attend school.

\subsubsection{Teachers as a Source of Support to Child Carers}

Child carers singled out the teachers as the most important persons in the school. Both male and female teachers seemed to play a significant role in motivating the children's school attendance. When asked who the most important person in the school was, most child carer respondents pointed to a particular teacher, either by name or subject they taught. "Mpho," a single orphan in Form E at the rural school and caregiver of a sibling, described one teacher in her school as follows:

Well, I can say that the most important person to me is my teacher [...] who teaches me economics. He has been a pillar of strength to me and supported me like a parent.

The choice of a special person was, in most cases, linked to the support a teacher provided, such as encouragement, listening to girl-carers when they had a problem, and financial assistance. "Trisha," aged 16 in Form $C$ and caregiver of three young relatives, had this to say in explaining why she considered one teacher as the most important person in the school:

Because she supports me and sometimes if we need to pay some money here at school. Every first Friday [of the month] we go to church and we have to pay M2. She would ask me if I have the money. If I have it, I would tell her, but if I don't have it, she would give it to me. She also approaches me when she realizes that my performance is going down, and she would advise me and encourage me to work harder. 
Teacher participants acknowledged that some girls in their school were at risk of dropping out of school due to caregiving responsibilities, and explained how the school staff provided support to reduce this risk. Teacher interviewees explained that they first identified child carers through the government enrollment form for orphans and most vulnerable children. Teachers then used the data generated from these forms as a basis for them to follow up to determine the level of adversity. At times, the way a child presented herself would be an indicator of vulnerability that would prompt the school personnel to understand the child's situation. Teacher "Kojane" from the rural school described this process as follows, showing how emotional state of mind and school performance would trigger further enquiries about the well-being of the child:

Some approach us directly, and [others], when a teacher enters the class. As a teacher, you are going to look at them all, but you are going to see some or one who will not be very happy, who will not be performing well. As a teacher, myself, I take responsibility to ask such kid, at the end of the class, "What is the problem, are you okay?"

Similarly, at the urban school, teacher "Kakoma" explained how teachers also used a child's appearance to single out children that needed help:

There are also other teachers who are helping me to identify such kids. You find that she would identify a girl who does not have a uniform at all, she will make sure that we do whatever we can to help such a child.

Teacher support was provided either by individual teachers or collectively by a group of teachers. Teacher "Muluti," a respondent from the rural school, described how they had contributed money to establish an informal support structure towards a fund that would be used to provide material support to children who needed help:

Even the teachers, female teachers, we have tried [...] to organize ourselves so that we put something in our bags so that in August this year we are going to give to those [children] who really need our support. 


\section{Teachers Provided Financial and Material Support}

In addition to the facilitating role that the school and teachers made to link child carers to external resources and support, study participants identified teachers as a source of financial and material support that child carers received to help them continue attending school. Teachers from both schools in the study mentioned paying school fees for children whom they had identified as vulnerable. They used their own resources to individually sponsor child carers, or by pooling money as a group. Respondents spoke about teachers seeking out children who needed support. Teacher "Mapula" from the rural school explained how teachers and the school administrator provided financial support:

There are a lot of teachers who do that within this very staff room, in this very school, even the principal herself. The principal would say, "Please give me at least one girl whom I can pay school fees for." The teachers do that.

In the same way, at the urban school another teacher, "Gillian," showed how teachers helped with paying school fees and how this kept child carers in school. She said:

One [child] would be in need of school uniform, so one teacher would voluntarily buy it and that [in] itself encourages them and makes them want to keep on coming to school.

Another area in which respondents identified teachers as the source of support was paying for other miscellaneous costs associated with schooling. For example, "Trisha," aged 16, a double orphan who cared for three family members, described the support she received from the teacher whom she considered a special person in the school:

[She is my favorite person] because she supports me, and sometimes if we need to pay some money here at school, for example, every first Friday we go to church and we have to pay two Maloti [14 US cents], she would ask me if I have the money. 
Teacher participants mentioned how teachers offered girl-carers opportunities to earn money, or supported their income generating activities. Teacher "Filda," for example, gave the following quote to explain this:

In our school year when it's a Saturday, weekends, or long school vacations, we normally call them to do small piece-jobs in our homes because at school there is nothing they can do. Weekends, I give them transport [money] and they come to do my washing, do my dishes.

The above findings demonstrated the critical role that teachers played in providing finances that directly covered school expenses, or met the child carers' home needs. Teachers meeting school needs directly or indirectly had a bearing on mitigating the risk of dropping out and kept children attending school.

\section{Teachers Provided Material Support to Child Carers}

As discussed above under the section on school environment, having a school uniform which was in a good condition was essential to ensure that no child felt discriminated against on the basis of their vulnerability. Not having a uniform was also seen as a barrier to attending school, something that teachers tried to mitigate through their own initiatives. Teacher respondents from both schools in the sample described how they joined efforts to provide a uniform to those in need. For example, "Kakoma," a school administrator at the urban school, talked about stocking school uniform in anticipation of a request for assistance.

Normally I have a shirt in my drawer [and] there I have a skirt, because sometimes you find a uniform is in tatters [...] and then I know I have something hidden somewhere so that I can help. Even shoes, I always collect. Even teachers know that in my drawer there is somewhere where I keep such things so I can help.

Teacher "Muluti," at the rural school, also made a similar statement highlighting the role teachers played in ensuring child carers had a uniform. The quote below also highlights the fact that, when possible, teachers made connections to other sources of support for the child carers. 
In some cases you find that we teachers need to intervene. We may need to even buy some shoes for them, or we can even ask people we know somewhere to buy them some things.

\section{Teachers Helped Child Carers with their Caregiving Responsibilities}

Support from teachers was said to have gone beyond help at school. Participants from both schools described how teachers got to hear about the predicaments that the child carers faced at home and often offered help in the form of food, money, material items, and transport to access medical services. The following quote by teacher "Tseliso" described how school personnel used their own initiative and resources to provide material support to help child carers at home:

We just talk among ourselves as female teachers. Sometimes we bring even our own [items] that we no longer use or no longer need. We will be told by one class teacher that one girl [said] that they are staying alone and they do not have blankets, they do not have mattresses, they do not have anything, so can we help one another and then decide whatever we can bring for such students.

Teacher "Mapula" from the rural school explained how she helped a child carer's mother access medical care: "I took the mother to the clinic, it's just near us here [...]. She was referred to a hospital. I just gave the mother 100 Rand so that she can buy some medicine and everything."

The fact that child carers were able to receive this type of support was seen as a motivation for them to keep going to the place where people who could support them were.

\section{Teachers Provided Psychosocial Support}

Study participants cited teachers as providing motivation to child carers to continue attending school, perform well, aspire for a better future, and emulate positive role models. Teachers and policy makers recognized the difficulties that female child carers faced in combining care with schooling. Teacher participants reported how they related with child carers in a way that was different from how they related with other students, and placed higher expectations on them. Teacher "Tebuho" explained this and said: "We talk to them differently from others; we 
make them see the need to work harder than everyone else." Another teacher, "Kojane," also expressed how teachers made special notice of the child carers and paid particular attention to them. "We try to motivate them although they are in difficult circumstances, but we try by all means to be close to them."

The female child carer respondents spoke fondly of their teachers as some of the most important persons in the school and described such teachers as compassionate and understanding. The children also labeled teachers as special if they spared time to listen, understood the issues they were going through, and recognized a child facing problems and talked with them. Such teachers were looked up to as substitute guardians or mentors as they provided guidance, advice, and encouragement that motivated the child carers to work hard and stay in school. "Mpho," in Form E at the rural school, described how one teacher motivated her to attend school: "I remember one other time when [my teacher] saw that my performance was going down, he came to me and he said [...] You must work hard in your school work so that you can proceed to other classes and brighten your future."

"Lerato," a double orphan in Form D and caregiver of a sibling described one teacher in this way: "[The teacher] understands me and feels compassionate; every time I tell her the reasons why I missed school, she understands. She's also one of the people who encourages me to keep on attending school." A policy maker respondent in echoing the child carers' sentiments described teachers who provided motivation: "There are some teachers who are more than teachers, who are parents instead of being teachers."

Study participants described how teachers acknowledged the difficult circumstances the child carers faced and mentored them to aspire for a better future. Staying in school and a good performance were seen as a pathway to that brighter future. For example, "Linda," a single orphan aged 14 and caregiver of her grandmother and sibling, had this to say about a teacher motivating her to keep attending school: "She always tells me to keep on coming to school because if I stay at home, my problems will seem to be too big for me, so it's best if I came to school and got educated so that I can help my siblings."

Another child carer, "Mpho," also a single orphan taking care of a sibling, had a similar view about the role teachers played in giving them hope for a better future: "[Teachers] motivate us and encourage us to work hard so that we do not live the 
kind of life that we are living now or so that our children may not live like how we are living right now."

Teacher participants also highlighted how teachers used religious belief as a way of motivating the girl-carers to stay in school and aspire for a better future. Teacher "Mapula" described this in the quote below:

We always tell them [...] that there is nothing like prayer. You pray, God provides, because God gives you even things you haven't asked for [...]. I think that's one of the things that keeps them [coming to school]. It's even in our mission statement; we have to help them even spiritually. They [girl-carers], they always tell me, "Madam, after praying we have strength."

\section{When Teachers Failed to Help}

Some teacher respondents lamented feeling overburdened by the magnitude of the need, explaining that they could not always cope with the requests for support. Teacher "Kabelo," for example, described this in the following quote: "Sometimes we voluntarily give anything that they may need. For instance, we give them money if need be, but it is not always the case because they are many and sometimes we don't have it." Another respondent, teacher "Kakoma," also mentioned that when she was not able to assist, she did not give up, but sought support from elsewhere. She said, "Sometimes I would have to refer to the principal because I would not have anything to offer. If ever I have something to offer myself, I would offer something."

\subsubsection{Peers as a Source of Support to Keep Child Carers in School}

Study participants highlighted the role that other school children played in supporting child carers as a factor that helped keep them in school. The study findings showed that peers were willing to help mitigate the risks of dropping out by sharing food; providing scholastic materials; donating school uniforms, shoes, and clothes; and providing emotional support. They were also said to have helped child carers with catching up on schoolwork that they had missed when they had been absent from school. In situations where peers could not assist, participants reported that they approached school authorities to alert them on the situation 
facing the child carers. There were two ways in which students became familiar with the plight of child carers and other vulnerable children. One way was through teachers soliciting help by making class announcements, and the other was when the girl-carers reached out to their peers for help.

Peer support groups are found in various schools in the country. These groups are formed as part of in-school activities to provide vulnerable children with a forum where they can receive life skills and psychosocial support. Although both the rural and the urban schools did not have a peer support group, the female child carers still considered the material and emotional support from friends as a driving force to keep them attending school. Friends who provided this support were either in a similar situation as the caregivers, or were said to have been somewhat better off than the child carers.

\section{Peers Shared Food with Child Carers}

Seventeen $(60 \%)$ of the girl carer interviewees described how their friends shared food and other items with them, but also talked about how this was reciprocal depending on who had enough to share on a particular day. The concept of a special person also applied to peers, as the child carers were able to identify a particular friend with whom they had this type of relationship. Most child carers mentioned sharing food as the one thing that the special friend did for them. They reported how peers went to the extent of packing extra food for lunch to be able to share with the child carers while at school. Surprisingly enough, a few (six) child carers from the rural school, which offered school lunch, and still reported that their peers shared food with them that they brought from home. Some participants also described how their peers provided more substantial food items, such as maize meal or vegetables for the child carers' home consumption. "Lisa," a double orphan in Form B at the urban school and caregiver of a sibling, explained how a friend provided food for both school and home. "I have one friend [who] if we do not have vegetables I tell her and [she] would give me [vegetables], or she would make a big lunch pack so that we can eat together with my sister at lunch time." Similarly, "Lerato," a double orphan in Form D at the rural school and caregiver of a sibling, described how a friend shared food with her: "I have one friend who usually comes in the morning and asks me if I have eaten at home, and sometimes she packs something for me or asks me to go and get some 'fat cakes' from the school vendor." The preceding quotes showed how the peers were not only 
concerned about the child carer's well-being while at school, but also tried to support them to meet their home needs.

Although child carers indicated having appreciated the help they got from their peers while at school, they also reported worrying about their care recipients at home when they did not have food. In the quote below, 16-year-old "Joan," a single orphan in Form D at the urban school, had this to say in describing her concerns: "It is stressful because sometimes I would have left my brother with no food and when I think about that or when my friends offer me food, I just feel bad because I don't know how he is doing or whether he has eaten or not."

\section{Peers Provided Material Support}

Study respondents reported how other students helped provide material support that the child carers could use at home or at school. They mentioned peers donating scholastic materials such as schoolbooks, pens, and schoolbags as a way of mitigating this as a barrier to staying in school. Peers were also said to donate uniforms, shoes, and old clothes that vulnerable children within the school could have. Seventeen-year-old "Tina," a Form B child carer at the rural school, described the extent to which her friend went in order to support her stay in school. She said: "She is the only one who helps me. If we are told to buy a certain book, she would go home and lie to her parents and buys me the book."

Policy maker respondents shared how those who received government bursaries tried to help other students. Peer support was seen at play when some graduating students, who had been beneficiaries of scholarships, handed down their uniforms to other vulnerable children for them to continue going to school. Scholarship recipients were also reported to have played a facilitating role by referring, or even accompanying, other children in need to government offices for them to apply for bursaries. A policy maker responsible for bursaries had this to say about the help from peers:

Some Form E students decided to give their uniforms to other children who remained behind since they were in their final year of schooling. I think, as children, they do realize when one is needy, so they have that compassion of helping one another. 
"Gillian," a schoolteacher at the urban school, also described how peers donated items to the vulnerable children: "Their classmates do support them because some of the things that we give to them are from their classmates who willingly bring things like T-shirts if they have extra, some bring their shoes, anything that becomes useful."

\section{Peers as a Source of Emotional Support}

Study participants reported that friends at school provided psychosocial support that motivated the child carers to continue attending school. Going to school to play and interact with friends was cited as an important part of school life that helped children forget about the problems they were facing as caregivers, and was also mentioned as the thing they liked most about attending school. For example, "Dawn," a double orphan aged 15 and caregiver of two young relatives, explained in the quote below how interacting with friends played a role in her attending school: "Even though my mind would still be at home, I try to forget and chat with my friends, focus on my studies and walk home with other children."

Similar to the traits valued in teachers, the female child respondents also singled out friends who took time to talk and listen to them as being special friends. The child carers mentioned how their peers helped them deal with various problems by being there to provide advice when needed, talking to them about their problems, and encouraging them to stay in school. One child carer, "Mpho," aged 18 , illustrates in the quote below how her friend, who was facing similar problems, was able to provide emotional support by talking about her own problems: "She sometimes shares her problems with me and advises me by encouraging me to accept things the way they are [...] saying you have to work harder and keep on going to school, no matter what."

"Jessy," a single orphan in Form C at the rural school, had this to say about why she considered her friend to be the most special person in the school: "Because she is the only person with whom I can share things with, and she also encourages me to keep on going to school."

The above quotes demonstrate how child carers valued having someone with whom they felt comfortable enough to discuss their problems. The school environment provided this opportunity and the space to meet and talk with such 
friends. The ability to have this kind of interaction became another pull factor that kept the child carers attending school.

\section{Peers Provided Support with Schoolwork}

Another area of support that study respondents reported on was how school peers helped child carers with schoolwork. This was important as it helped the child carers catch up with any schoolwork they could have missed during days when they were absent from school. The peers who offered this help were identified either as a special friend or anyone else who was willing to help. For example, "Trisha," a double orphan aged 16 in Form C at the rural school and caregiver of three young relatives, reported it as follows: "We discuss if there are things that I would have missed in class, [my classmates] are always willing to help me understand."

\subsection{Interaction amongst School Factors}

My study findings showed interactions among various stakeholders who provided support to child carers within the school. School staff and students collaborated in helping the at-risk girls in a manner that mitigated their risk of dropping out of school. This collaboration happened in order to raise awareness of the child carers' situation, and also to solicit support from other parties when needed. The quote below from teacher "Gillian" from the urban school, for example, demonstrated this interaction between the teachers and students, where teachers sought the support of other students to help vulnerable children:

A teacher will make an announcement in the class if there is a need from one of these children, without telling the name. The announcement is made in different classes, not necessarily in that class, and those that have what you requested will bring it to you and you distribute accordingly.

Another quote from teacher "Tseliso" showed how students approached teachers to solicit support for their peers. "You find that they come to us as teachers because many a time we do something, whenever they tell us, we do something about it." In addition to the quotes demonstrating how teachers and students worked together to ensure that the child carers received necessary support to keep attending school, they also emphasize the presence of a school environment that 
permits this type of interaction. What was also clear from the study was the determination that both teachers and peers had to ensure that child carers' needs were met. This was evidenced by the efforts made to solicit help when one party was not able to sufficiently meet the needs of the child carers.

\subsection{Interaction with other Socioecological Domains}

The findings primarily showed interaction between school and individual factors, and between the school and the community. There was, however, little mention of linkages between the school and family.

Study participants described how teachers helped build skills within a child carer that motivated them to stay in school. Some child carers looked up to teachers as individuals whom they aspired to emulate as role models for future career choices. Some teacher interviewees described how teachers helped to enhance skills of child carers to point them towards people they could look up to as role models, in order to bolster their hopes for a brighter future. As discussed in detail in Chapter 5, on individual factors, the children's aspirations for a better future inspired them to stay in school because schooling was seen as a stepping stone towards achieving their goals.

The interaction between the school and community was described to have happened when community members reported the plight of the vulnerable child as a way of soliciting help from the school. A quote from teacher "Mapula" explained the relationship in this manner: "Actually, we are linked like this [clasping hands to show unity] with the community. In fact, anybody from the village would come and warn us about the situation [of] such and such a kid." Another teacher, "Kojane," made a similar comment when explaining the relationship between community members and the school. "[Community members] would come to school because sometimes they report the [issues] that are happening at home that may be affecting the children." The quotes showed how the school and community linkages happened in order to find a way to ensure that the child carers continued to attend school. 
The study findings support and extend resiliency literature that showed that a conducive and positive school environment influenced female child carers' continued school attendance. Schools were said to have provided a positive experience for the at-risk students, something that played as a pull factor for them to attend school, excel in class, and aspire to a brighter future. Personal initiatives by school personnel and students, as well as structured school programs such as the school feeding scheme, weekend compulsory study time, recreation activities, and special assemblies, were said to have contributed to making the schools conducive for female child carers to strive to stay in school despite their challenges. The findings of the study showed how the school system was able to draw on the various forms of capital resources to keep female child carers attending school. These findings build on the Community Cultural Wealth Model developed by Tara Yosso (2005) who argued that communities might foster their cultural wealth through at least six forms of capital "aspirational, navigational, social, linguistic, familial, and resistant capital" (p. 77). The author's suggestion that aspirational capital cuts across the other forms of capital was confirmed in my study, which demonstrated the school environment as social capital, as well as aspirational capital which nurtured the hopes of child carers for a brighter future.

It is worth noting that in both schools, no specific support was aimed at children as carers; however, they were reached through interventions that targeted vulnerable children in general. Another significant finding was that although most school programs were implemented to reach all students, these were considered to have had unintended positive outcomes for at-risk female child carers. The school feeding scheme is a case in point, as it was designed to provide a meal to all students while at school; however, it had the unintended benefit of girl-carers being able to take leftovers home to their care recipients.

The findings showed that the school programs helped mitigate some of the challenges that girl-carers experienced and that could have been a barrier to attending school. Being able to provide a meal a day at school, designating space and time for weekend study, and getting child carers to participate in extracurricular activities provided an atmosphere of care and support within the school. This parallels the many scholars such as Benard (1991), Zimmerman and Arunkumar (1994), Christiansen et al. (1997), and Waxman et al. (2003) who 
advanced the notion that schools that were a source of support implemented activities to buffer against risks, which influenced positive outcomes of at-risk children. However, a dissenting view was presented in another study, which concluded that participation in extracurricular activities was not related to resilience (Finn \& Rock, 1997).

My study also highlighted the facilitative role that schools played in fostering linkages with service providers outside the school setting. These networks provided child carers with both school requirements, to keep them attending school, and home needs to meet their caregiving requirements. The benefit of receiving external support through the school may have been a motivating factor for child carers to stay engaged with the school. This parallels the findings of Waxman et al. (2003), who also suggested that schools could help facilitate referrals to other organizations for social services, and as well as Ferreira and Ebersohn's (2011) study, which reported how schools collaborated with external stakeholders for support. Similar findings were reported in a Lesotho study (Nyabanyaba, 2009). My findings further aligned with Yosso's (2005) Community Cultural Wealth Model, which argued that another form of capital that people could draw on was social capital. Social capital includes "networks of people and other community resources" that can provide material and psychosocial support to help people circumnavigate through institutions (p. 79). Similarly, the study findings also showed a parallel with Yosso's (2003) argument that communities may draw on navigational capital as another form of capital, which entails having the skills to maneuver through social institutions (p. 80).

As Christiansen et al. (1997) suggested, schools that made children feel welcome and provided a sense of security facilitated effective participation and encouraged at-risk children to believe in themselves. My study found that an egalitarian school environment which the school authorities and peers created promoted equity within the school, where every child was made to feel that they belonged to a caring community. This was demonstrated, for example, by the way school staff and students made efforts to provide a school uniform to those at-risk child carers who could not afford it. Cassen et al. (2009) also presented the concept of egalitarian schools, with a focus on academic success and school progression for all pupils. The authors suggested conducting individual assessments of each child's 
potential and encouraging them to aspire to reach it, in which is congruent with the current study's findings.

The school feeding scheme appeared to be a critical school program that influenced school attendance for female child carers as it assured them of a meal, which, for some, could be the only meal of the day. The World Food Program has used school feeding as an incentive to get children to school and improve attendance, while also helping the children focus on their schoolwork (World Food Programme, 2015). The link between school feeding and attendance was also established in a randomized controlled study conducted on school breakfast in rural schools in Jamaica (Powell et al., 1998), and an evaluation of the school feeding program in Bangladesh (Ahmed, 2004), which showed that school meals slightly benefited school attendance. A randomized controlled trial conducted in an agricultural community in Burkina Faso reported a counterintuitive finding, where children exposed to the school feeding intervention actually had lower attendance (Kazianga et al., 2008). The authors argued that this could be attributed to an inactive labor market in the area, resulting in children complementing adult labor and therefore missing school.

As mentioned above, my findings showed that the school feeding program also had unintended consequences for female child carers, which could have been an added incentive for them to attend school. The school feeding program was not designed with a provision for a take-home ration, but teachers, through their own initiative, packed leftovers for at-risk students to share with their families. Robert K. Merton advanced the idea of unintended consequences as the result of an unorganized or formally organized action that was not expected by an actor (Merton, 1936). He argued that although a result may not have been anticipated, it does not imply that it would necessarily be undesirable.

\section{Flexibility with School Policies Benefits Girl-Carers}

The study established that the schools' flexibility in implementing some of the policies helped mitigate barriers to school attendance. School personnel gave atrisk students waivers on certain school fees and often extended deadlines for paying school fees. School authorities did this because they were aware of the challenges that the child carers faced, knowing that the children could have potentially dropped out of school had they implemented the policies as per 
regulations. What my study found seems to be in line with Michael Lipsky's view on public service employees, such as teachers, whose work puts them in close contact with citizens (Lipsky, 2010). The author argued that the workers, whom he termed "street-level bureaucrats," make discretionary and relatively autonomous decisions in implementing policy and providing access to services. He further argued that these individually focused and personal decisions may have an effect on beneficiaries' life chances.

\section{Teachers Played a Pivotal Role in Keeping Child Carers in School}

The study findings confirmed literature which advanced the view that school personnel, including teachers and administrative staff, play a critical role in supporting child carers to continue attending school (Bhana et al., 2006; Christiansen et al., 1997; McMillan \& Reed, 1994; Sandin-Esteban \& Sanchez-Marti, 2015).

Study participants saw their teachers as special people who provided particular attention to the girl-carers. The issue of human relations and interactions between the child carers and their teachers seemed to be of paramount importance, as participants considered those teachers that paid attention to their needs by taking time to focus on them as special. Having an adult who listened to, spoke with, advised, and encouraged girl-carers seemed particularly important. Participants described such teachers as "pillars of strength" or equated them to parents. The school was therefore seen as playing a role of parental and family substitute, something that the girl-carers would have desired as a temporary reprieve from their primary caregiver role. Being in such a space could have been a motivating factor for the child carers to continue attending school. This finding reinforces the literature that advanced the concept of a special individual having a key role in promoting resiliency among at-risk children in the school setting (Christiansen et al., 1997; Condly, 2006; Cooklin, 2009; Katz, 1997; Sandin-Esteban \& Sanchez-Marti, 2015).

Help for girl-carers in the form of financial, material, emotional, and motivational support had either a direct or indirect effect on child carers attending school. Covering a child's school fees and buying their school uniform, for instance, addressed these barriers directly. A study on the challenges of migrant students and their consequences on education had similar findings indicating that teachers 
used their own resources to buy supplies and shoes for students (Free et al., 2014). The other support that teachers extended beyond the school setting helped mitigate the caregiving challenges that children faced at home, and this had an indirect effect on their school attendance. Children went to school knowing they had a source of support through the teachers. The counseling and motivational talks at school focused on aspirations for a better future. Good performance and school attendance were therefore seen as one way that the children would get out of their current situation, corroborating the findings by Johnson (1997) that academic success can help build an individual's self-esteem and confidence attributes necessary for at-risk students to work towards achieving a better future.

The caring nature of the school personnel and students extended beyond providing for school needs, and went as far as supporting them to meet their caregiving needs at home as well. For example, teachers and peers sometimes provided food for the girl-carers to take home to share with their families. A similar finding was made in Ferreira and Ebersohn's (2011) study where teachers used a "family-centered" approach to providing social support by conducting home visits to families.

It is worth noting that the support that teachers and other school personnel provided to child carers was mostly on a voluntary basis and using their own resources. The teachers went out of their way to cater for the girl-carers' needs at school, and to some extent, at home. Some teachers expressed concern about how they were emotionally overwhelmed and financially overstretched by the magnitude of the problems the child carers faced. A study conducted in South Africa on the role of teachers in providing care work to their learners, also showed how teachers extended their support by taking up responsibilities that would otherwise be provided by the family (Bhana et al., 2006).

My study had mixed findings with regard to school being a place for temporary reprieve from the challenges of caregiving. While some girl carer participants mentioned how getting involved in school programs took their minds away from the troubles they faced, others still worried about the well-being of those they had left at home, especially when there was no food at home or when a care recipient was sick. The mixed findings are reflective of what has been established in prior research which showed school as a place of refuge from caregiving responsibilities 
(Cluver et al., 2012), while Thomas et al. (2003) found that child carers continued to worry about the well-being of their family members despite being at school.

\section{School Peers Supporting Child Carers to Stay in School}

The findings showed that school peers also played a key role in supporting child carers to continue attending school. The concept of the one special person advanced by resiliency literature (Benard, 1991; Waxman et al., 2003) applied in the case of peers, as well as with girl-carers citing a school friend as the person who supported them the most and helped them stay in school. Peers provided food, material, and emotional supports to those at risk of dropping out of school. These findings are congruent with those of Masten and Coatsworth (1998), who argued that peers may provide psychosocial support; like in the case of teachers, support from peers also extended beyond the school setting to include helping them with their home needs. In situations where they were not able to assist, the school peers solicited help from teachers. This collaboration showed the interaction between various support structures within the school setting.

Also critical to keeping the child carers motivated was how peers helped them catch up on schoolwork, which they missed when they were absent from school. In Gandara (1995), study participants mentioned how peers were supportive with academic work. Having this type of support may have reduced the risk of the child carers dropping out of school as a result of poor performance which could ultimately drive a student to dropping out. As Christiansen et al. (1997) argued, low academic achievement may result in school failure.

The study showed that although material support was considered important, child carers also valued the intangible psychosocial support of having someone pay special attention to them by spending time talking to them and listening to their challenges. This confirmed the findings of resiliency scholars who identified having a caring and supportive relationship that provided necessary attention as a predictor of resiliency (Benard, 1991; Katz, 1997).

School factors interacted with individual and community factors in influencing girl-carers' school attendance. The teacher was cited most often as someone who influenced the individual girl carer's vision and academic performance, and was seen as her role model. This linkage highlighted the significance of the teacher and 
girl carer relationship. Girl-carers considered teachers to be their role models who also influenced their vision for a brighter future and academic performance. The findings also showed how teachers played a role in influencing the child carer's religious belief by providing individual counseling or through school organized events, such as assemblies. Similar findings were presented in the Ferreira and Ebersohn (2011) study, which reported teachers as having offered spiritual support and prayer. Various scholars are of the view that being part of a religious grouping may have influence on resiliency (Katz, 1997; Skovdal et al., 2013). As discussed in Chapter 5, in regards to individual factors, my study also found that child carers' religious beliefs gave them hope for a brighter future, with a conviction that their goals would be achieved.

Studies have associated parental or family involvement in school with an increased chance of success for at-risk children (Gutman \& Midgley, 2000; Johnson, 1997). In my study, the at-risk child carers reported being motivated to attend school and succeed despite little interaction between the school and family members. Although Gutman and Midgley (2000) argued for the support of teachers and schools to ensure parental involvement, most child carers in my study were in a unique situation of being heads of households, with no adult present. In such a situation, family representation may not occur as needed.

\section{Conclusion and Policy Recommendations}

Based on the findings, the study showed that school environment, school personnel, and peers played a key role in ensuring that child carers continued to attend school. Teachers and students were aware of the plight of the child carers and recognized how their challenges could be a barrier to attending school. The extent to which they went above and beyond, including sharing their own resources to ensure that these barriers were mitigated, showed how much they desired the child carers to stay in school. This support could have been a strong motivating factor for the girls to continue attending school and working hard to achieve a better future. The study also showed that the support provided did not entirely eliminate the barriers to attending school, but only helped to minimize the challenges.

The fact that the girl-carers continued worrying about their care recipients, even while at school, calls for a more comprehensive response that also addresses the 
challenges faced by the children at home. Within the school setting, the school feeding scheme that provided at least one meal a day seemed to motivate girlcarers to attend school. Government and school administration should continue to provide school lunches; however, this needs to be extended to include a take-home ration for child carers.

The data showed that caregiving responsibilities took a toll on girl-carers and their effective participation in school. Stakeholders at all levels should recognize the unique challenges that child carers face as a result of their caregiving role and work to implement mitigation and protection programs.

The study findings point at the critical role that both teachers and students played in providing psychosocial support to girl-carers. While it seemed that the school system and support network helps identify at-risk child carers, it is critical that government and nongovernmental organizations enhance teachers' skills in providing specialized psychosocial care. The data show that teachers were using their own resources to meet the financial and material needs of child carers, an indication that existing bursary schemes are not reaching some vulnerable children, such as child carers. Government and nongovernmental scholarship funds should also revisit the targeting criteria in order to make it more inclusive. In the absence of a systematic or structured way in which teachers would be supported, the teachers from both schools used a peer-based approach to support each other in pulling together resources to help the at-risk children.

The data showed that peers, mostly friends, provided critical psychosocial and material support to child carers. Schools should make this support more structured by revamping peer-support groups with trained psychosocial support facilitators. 


\section{CHAPTER 7}

\section{THE ROLE OF FAMILY AND COMMUNITY IN FACILITATING}

\section{CHILD CARERS' SCHOOL ATTENDANCE}

"Mindy" is 16-years old and a single orphan taking care of her elderly grandmother, two younger half-brothers, and another family member. Her mother left her when she was 1 year old. Her father and stepmother, who brought her up, are now both deceased. Mindy is the one who takes care of the family by performing household chores. She described her caregiving responsibilities by saying: "I make sure I wash [everyone's] clothes, I cook and if we don't have vegetables, I try to [find] what we can eat."

She mainly depends on her grandmother's pension funds for school fees and other needs, although her uncle who lives in South Africa helps out sometimes. They have, once in a while, asked neighbors for help, especially when they run out of money.

The school she attends in Form B is a two-hour walk away from home. She therefore has to leave early to make it in time for the 07:00 a.m. school start. Living so far away from school creates a challenge for her. She stated, "I don't have enough time to study because I usually get home late and have to clean and do other chores like washing dishes and cooking." Despite these challenges, she is determined to stay in school so that she can be a teacher in the future.

\subsection{Introduction}

This chapter is presented in two parts. The first section discusses the perceptions of the study participants, who comprised in-school female child carers, teachers, policymakers, civil society organizations, and community volunteers, of how family influenced the female child carers' school attendance, despite the difficulties of combining schooling with caregiving responsibilities. The second section discusses the role that community factors played in keeping female child carers in school. My study showed that family members helped the child carers stay in school by providing financial and material support to meet their home and school needs, as well as motivation to stay in school. Further, the data showed that at the 
community level, individuals such as neighbors, chiefs, and community-based organization $(\mathrm{CBO})$ volunteers also played a role in influencing girl-carers' school attendance by supporting or soliciting support for child carers' school and home needs.

Both family and community factors are nested within Urie Bronfenbrenner's socioecological model (Bronfenbrenner, 1994), the framework this study employed to explain how various factors interconnected to influence educational resiliency (Condly, 2006; Embrace the Future, 2005; Fredricks et al., 2004). Educational resilience is defined as succeeding "in school despite the presence of adverse conditions" (Waxman et al., 2003, p. 1).

The chapter starts with a description of prior literature on family and community factors as they relate to resiliency. I then present the findings with a discussion on how family and communities provided protective support to keep girl-carers attending secondary school. The final section will be a discussion and conclusion.

\subsection{Prior Literature}

Research literature has indicated that family plays a key role in building resilience among children facing adversities (Benzies \& Mychasiuk, 2009; Condly, 2006; Perez et al., 2009; Robson et al., 2006). In the sub-Saharan African context, studies such as Foster et al. (1996) and Nyamukapa and Gregson (2005) also underscored the influence of family in providing support to children in need. Further, studies reported that traditionally, in the African setting, the extended family was expected to be the prime source of assistance to children when the family was experiencing adversity (Robson, 2006; Tanga, 2013). This traditional safety net was, however, stretched by the unprecedented increase in the number of orphans and vulnerable children due to HIV and AIDS. Although research still showed that the extended family system provides care, the level and quality of care and support had diminished (de la Porte, 2008; Foster et al., 1996; Robson et al., 2006; Tanga, 2013).

The qualities of a supportive family include being able to provide protection and help a child cope with adversities by being a source of emotional and material support (Benzies \& Mychasiuk, 2009; Condly, 2006; Perez et al., 2009). The 
importance of such support was highlighted in a study on academic success in an at-risk Chicano population, where participants reported how scholarships and other forms of support from family members may have contributed to their academic achievement (Gandara, 1995). Further, literature points to the critical role of parents in building resilience among at-risk children. For example, Benzie and Mychasiuk (2009) identified a supportive parent-child relationship as a critical attribute for a child to overcome adversities. McMillan and Reed (1994) also supported this view and argued that children in adversity were motivated to aim towards school success when their parents had high expectations of them (McMillan \& Reed, 1994). Both authors, however, posited that support can also come from any member of the family, including siblings, grandparents, or aunts, with whom a child can create a close attachment (McMillan \& Reed, 1994, p. 138), and that what was paramount was for families to function as a close unit in facing challenges and helping at-risk children to cope (Benzie \& Mychasiuk, 2009).

The role of communities has also been highlighted in developing individual attributes, such as having hope for the future, social skills, and problem-solving skills, which are the characteristics of a resilient child (Benard, 1991). A supportive community is described as one whose structures and networks can help mitigate risks and provide a protective, caring, and supportive environment and whose members have high expectations of at-risk populations (Katz, 1997). According to Grant (2011), how society treats families will influence both the positive or negative outcomes of the family members, including young carers.

Scholars such as Benard (1991), Johnson (1997), and Benzies and Mychasiuk (2009) suggested that the most effective protection would be to ensure that those at risk participate in community-based programs and have access to resources and basic services. The core of this support is, according to Johnson (1997), supportive human relationships for at-risk individuals and families. Community members can also provide mentorship to enhance resiliency amongst those at risk (Benzies \& Mychasiuk, 2009). These human relationships may be fostered though social networks that will ultimately link vulnerable individuals to mitigating services (Benard, 1991). Studies on the care and support of orphans in sub-Saharan Africa have highlighted the role of communities, suggesting that, traditionally, the child was considered to belong to the community and could be disciplined and cared for by the community (Tanga, 2013, p. 180). Community groups were, therefore, best 
suited to identify those most at risk; provide social, emotional, and material support to families; and monitor their progress over time (Foster et al., 1996).

\subsection{Research Findings: Family Factors}

The study showed that family members provided salient support that had a direct bearing on the child carers' school attendance, or supported them in a way that helped mitigate the risk of dropping out. Study participants, however, presented mixed views on the role of family members in facilitating child carers' schooling. Most child carer participants gave a positive view about the support from immediate and extended family members, and described how these relatives were concerned about their general well-being, provided for their school and household needs, helped with caregiving responsibilities, and motivated them to stay in school. While some teachers also highlighted positive views about family members' support, others, however, gave contrasting perceptions by either expressing no knowledge of family support, or spoke about relatives who did not support child carers to stay in school. The study further showed that family members who were living with the child carers as their care recipients also supported them by either helping with household chores, or for those living with grandparents, paying school fees. The following quote by teacher "Muluti" summarized the general perception that, despite being in the situation where the children were primary caregivers, they still had family members that were concerned about their well-being:

I think they have [family] who really do care about them. Some of them, even if they are just here by themselves, they still have caregivers somewhere who give them a push. They can be the relatives somewhere [...] but like you see, many of them are just by themselves alone, I cannot say they do have much of the family support as such, but somewhere you find that there are still people who are still responsible for them, people you look for when you need parents to be here [at school].

\subsubsection{Family Members Nurturing Future Aspirations for Child Carers}

Both immediate and extended family members seemed to influence child carers' determination to continue attending school. Study participants reported how relatives instilled the child carers' aspirations for a better future by giving them 
advice that motivated them to stay in school. Child carers also reported how relatives used their own successes or failures as lessons for the children to stay in school and thrive. Accounts from close to half of the child carer participants linked school attendance to family members encouraging them to stay in school. For example, "June," aged 19 and attending Form A at the urban school, had this to say: "My father lives in [another town] and is a builder; he supports me really and always tells me not to be discouraged by the fact that I look after my sister, and that I should not miss school for any reason, not even because of my sister."

Another child carer, "Jackie," aged 15, whose parents were living in South Africa and who was left to take care of three siblings, had this to say about how her family motivated her to stay in school: "[I come to school] because my parents are not educated, so they always tell me to attend school so that my life does not become like theirs. They did not attend school, their parents did not care about their education; I want to be different." This quote from "Jackie" illustrates how family members used their own predicament as a lesson that inspired child carers to stay in school. Parents and other relatives were said to desire the child carers to excel and be better than them. Child carers also spoke about being encouraged by family members who were doing well and whom they looked up to as positive role models. An account from "Kathy," aged 18, also a single orphan who was attending Form $\mathrm{E}$ at the urban school, had this to say about a relative who inspired her: "I have my aunt who was struggling just like I do but persevered; she is the one who motivates me and encourages me to work even harder. She is now a teacher."

Another child carer, "Mpho," explained in the quote below how her mother's motivation and psychological support has made her aspire for a better future:

When I am with her...I am free to speak my mind and everything when I am with her. She shares her problems with me and we go as far as discussing our family issues and trying to figure out possible solutions to our problems together [...] She does not have material things [to] support me but encourages me a lot and I know that she believes that one day I will change my life. 


\subsubsection{Financial Support from Families}

The findings showed that most child carers received financial support from family members who made efforts to provide for their school and home needs. Most child carers reported that family members were sending remittances mainly from South Africa, although some participants also spoke about relatives who were working in other towns within Lesotho. Those with grandparents as care-recipients reported using the grandparents' pension to cover school-related costs. This support was in the form of school fees for the girls who were not on scholarship, school uniforms, and money to run the home. Material support included food supplies, washing soap for their uniforms, and toiletries. Figure 7.1 below depicts how most child carer participants mentioned family financial and material support as factors that assisted them to stay in school.

Most child carer participants indicated that the source of finances for school and home needs was remittances from relatives who were living in South Africa. As discussed in Chapter 3, one reason that was advanced as having led to the girls being child carers was the fact that most adults who could have been taking care of the households had migrated to South Africa or were living in the city, in search of work. Study participants pointed out how these funds enabled families to pay for child carers' school fees and other scholastic requirements, therefore linking remittances to child carers' ability to continue attending school. For example, "Joan," whose mother lived in South Africa, had this to say: "She pays my schools fees and other school needs [...] She sends money every month end so that we can buy food and other things that we may need."

The findings suggested that family members shared the financial responsibilities of supporting child carers to stay in school. Several child carer interviewees identified more than one family member who paid school fees and provided for other scholastic and home needs. "Bertha," a single orphan in Form B at the urban school and caregiver of a sibling, described this shared responsibility between family members as follows: “My grandmother, my mother's sister [helps us when] my brother is not able to send us money or when he does not have any, we tell her and she would help us." Another child carer, "Bridget," a 17-year-old single orphan in Form B and caregiver of a sibling, expressed a similar sentiment describing this joint support as follows: "Sometimes it's my step mother, sometimes it's my mother. It only depends on who has the money." In the same vein, "Palesa," aged 
17, a single orphan caring for five family members, also described the joint financial support she received from her family as follows: "My aunts also help me by buying me clothes and other school needs when I need them and [when] my father is unable to provide."

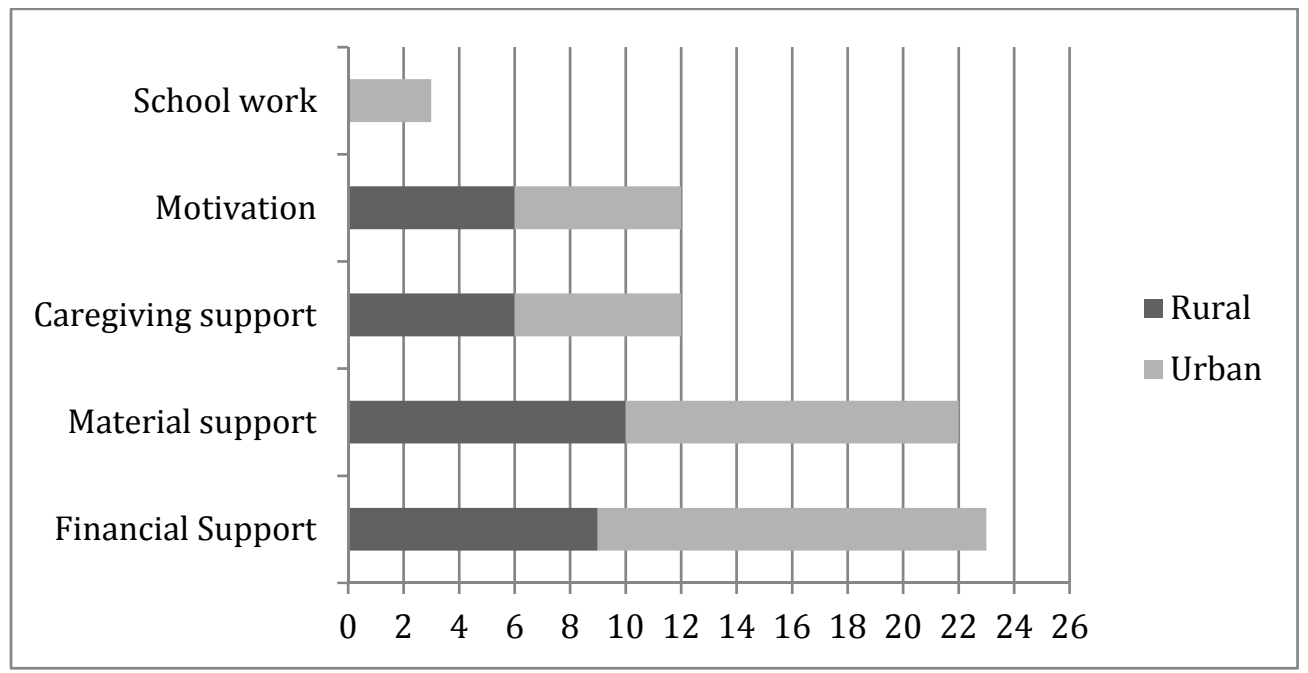

Figure 7.1. Child carer perspectives on family members' support. Source: Author's compilation based on interviews.

From the quotes above, it seems apparent that one relative was the primary source of support, but, when this failed, another family member helped out. There was a clear indication that the relatives were struggling financially and were not always able to fulfill their responsibilities to provide for the child carers. Furthermore, the quotes demonstrated that despite the challenges, the relatives were determined to find ways of keeping the child carers in school. Taking turns at providing for the children could have been a strategy that they employed to actualize this. Study participants were able to link financial and material support provided by family to the child carers' ability to attend school.

For some child carers, however, relatives were said to have either provided financial support in an ad hoc manner, or they simply did not help at all. For example, "Jessy," a single orphan aged 18, in Form C at the rural school, talked about the once-off support from her aunt as follows: "She paid my school fees when I was in Form A, she paid for the first quarter." Another child carer, "Mpho," 
aged 18 in Form E at the rural school, had this to say: "I never get any support from my relatives. My mother tried and [asked for] their support but they did not help us. They told her that they also had their problems and therefore could not help us." The girl-carers attributed this inconsistency to poverty, lack of employment, or the fact that some relatives were not interested in helping them. 14-year-old "Lisa," a double orphan in Form B at the urban school and caregiver of a sister, described how she depended on her brothers for support:

The other twin brother is married but struggles to get piece work. However, he is the one who helps us most of the time. The other twin owns a mini mart where he sells snacks and fruit and he also does help us. The eldest is a drunkard, but sometimes he [will] get a job and buys us food.

According to one policy maker participant, financial support from family members supplemented government bursaries, as expressed in the following quote: "One other thing in the bursary unit is that if you fail, you forfeit sponsorship so you will find that if such children fail, then care givers or relatives help them to repeat by paying for them, and thereafter they are reinstated into the sponsorship." This reference illustrated the extent to which relatives were prepared to go to ensure that child carers stayed in school.

\section{Financial Support from Grandparents}

The Government of Lesotho has been implementing a universal old-age pension scheme, which targets all individuals over the age of 70 to receive approximately US\$40 per month (Westphal, 2016). Some of the child carers who were living in households with grandparents indicated that their grandparents' old-age pension funds paid for their school and other needs. In expressing how family members helped her to continue attending school, 17-year-old double orphan, "Maria," who attends Form B at the rural school and is the caregiver of her grandparents, stated: "[My grandparents] get money from the old-age pension fund. They buy me a uniform." Child carers also mentioned other grandparents who were not living in the same households as people who supported them when necessary, but did not specify the source of their funds. However, it is most likely that grandparents living in other households could have used some of their pension funds to support 
child carers. Also, a teacher participant "Kojane" linked the old-age pension to child carers' school attendance in the quote below:

For these ones who stay with grandparents, I think the grandparents play a big role because the grandparents cannot bear to stay with a child who does not come to school when they know that they have paid for these kids. Grandparents here earn a monthly salary [pension] so the grandparents always tell the kids that had it not been because of you, my money would be coming to me so that makes them to come [to school].

From the above reference, it may also be likely that pressure from grandparents could have also motivated the children to continue attending school. Because the grandparents were using their pension money to cover school costs, child carers could also have been motivated by a sense of indebtedness.

\section{When Families Failed to Help}

Although most interviewees acknowledged the role of family in facilitating child carers' school attendance, others had a different view, stating how family had either not been supportive or had been inconsistent. Teacher "Kakoma" described the difficulties school authorities experienced in trying to get help from relatives in the following quote:

Actually you find that the families are not good at all, I am sorry to say, because you find that at times there is a certain pupil who needs to be helped and we need certain documents for this kid to get sponsorship, and they will refuse to give you the documents. Normally we are struggling to get help for them because their family will refuse to give them their documents, so we don't find them supportive.

Teacher "Kabelo" from the urban school explained the inconsistency of family support in the quote below:

They don't always get support because their relatives are either poor, unwilling to help them or [are] very far away. Those who still have parents, most of them have mothers who are in South Africa; they send them money once in a while or come home during Easter and Christmas 
holidays; but then you cannot say they get sufficient support from their families. It's [as if] they don't have families.

\subsubsection{Family Meeting Other School and Household Needs}

Family members were said to have provided material support such as school uniforms, shoes, and supplies for the home, including food, washing soap, and other basic needs. As mentioned in previous chapters, it is a requirement in Lesotho that students wear a uniform to school. It was therefore not surprising that study participants mentioned uniforms and school shoes as the items that family members bought for the child carers to keep them attending school. From the list of other supplies that relatives provided to child carers, soap seemed to stand out prominently. For example, "Lerato" said, "I get support from my aunts [who] help us with things like washing soap for our uniforms and [I] go to school clean. They also help me with maize meal so that we have food before going to sleep." A policy maker participant had similar views about family support for uniform and cleanliness, and had this to say:

The kind of support that they get, especially those who do not have means like Public Assistance, the extended family still provides basic needs, a uniform, making sure that the child goes to school clean and having eaten like any other child. They really give their support on such things which we seldom provide.

Other than school requirements, study participants also highlighted how family members provided food and other household supplies to the child carers. The quotes also demonstrated that when the children ran out of supplies, the child carers reached out and sought help from the family members. 17-year-old "Tina," who is in Form B and the caregiver of a sibling, explained the family support as follows: "When we don't have vegetables, we tell [my aunt] and then she buys us vegetables, and sometimes when she is around, she gives us money so that we can buy food." 


\subsubsection{Caregiving Support}

The data showed that the children sampled seemed to have been getting little help with daily caregiving responsibilities. Participants cited extended family members as having provided the material, financial, and motivational support more so than actual help with household responsibilities. The few child carers that indicated that family members helped them with their caregiving responsibilities cited help with carrying out household chores and taking care of the younger members of the household.

Although it is generally expected that most household members would be involved in the day-to-day activities of running the house, the child carer participants saw this as their responsibility, and considered another person's involvement as assisting them. This was highlighted in the following references where child carers spoke about being "helped." "Fiona," aged 16 in Form D, described the support she received from her grandmother as follows: "If one of the children is sick, I take them to the clinic. Sometimes my grandmother would help me and take the child to the clinic." Another child carer, "Gina," aged 17, a single orphan in Form D at the urban school and caregiver of three relatives, also had this to say about the help she received from her ailing grandmother: "[My grandmother] helps me a lot because she sometimes cleans the house if she feels better [... She would sometimes tell me that she has back pains, sometimes she is fine."

Older siblings under caregivers' care were reported to help with basic household chores, such as washing their own clothes. One respondent mentioned occasional assistance from her uncles who helped with taking care of a young relative. The link to school attendance could be that any type of help with caregiving may have freed the child carer from her caregiving responsibilities, thus enabling her to focus on her schoolwork.

\subsection{Research Findings: Community Factors}

This section presents the findings on how community members, either individually or as a collective, influenced female child carers' secondary school attendance. The findings established that neighbors, community-based 
organizations (CBOs), religious groups, and community leaders played a key role in providing support that directly or indirectly helped keep female child carers in school. The majority of child carer respondents most frequently cited neighbors as the ones who provided support to them, while most teachers mentioned community leaders and CBOs.

The findings demonstrated that neighbors often assumed the role of substitute family to the child carers, and they were usually the first point of contact when the children needed protective and mitigation support. Chiefs, as community leaders, were said to mobilize community resources to support child carers, and put in place protection measures to ensure the safety and security of at-risk children. The Lesotho National Policy on Orphans and Vulnerable Children (Government of Lesotho, 2006) recognizes the role that individuals and community-based organizations can play in protecting vulnerable children, including children heading households (pp. 16-17). The National Strategic Plan on Vulnerable Children (Government of Lesotho, 2012) further prescribed the role of community leaders as being that of providing oversight to "ensure that vulnerable children are protected, cared for, attend school and have access to other basic services." (p. 10).

\subsubsection{Neighbors as an Alternative Family for Child Carers}

For the purpose of the study, I defined neighbors as those individuals who lived in the same community, or village, as the child carers and were not related to them. The findings showed that study participants' perceptions of neighbors as playing a key role in supporting child carers to attend school varied. Figure 7.1 shows that most child carer interviewees cited neighbors more than they cited other community stakeholders when they mentioned individuals who provided support. In contrast, Figure 7.2 shows that the least number of teachers and policy makers cited neighbors as the source of support.

According to most child carer participants, neighbors seemed to be the first point of contact when they were in distress and offered food, financial, and material support. Furthermore, participants mentioned that neighbors also helped with caregiving responsibilities by taking care of family members. 


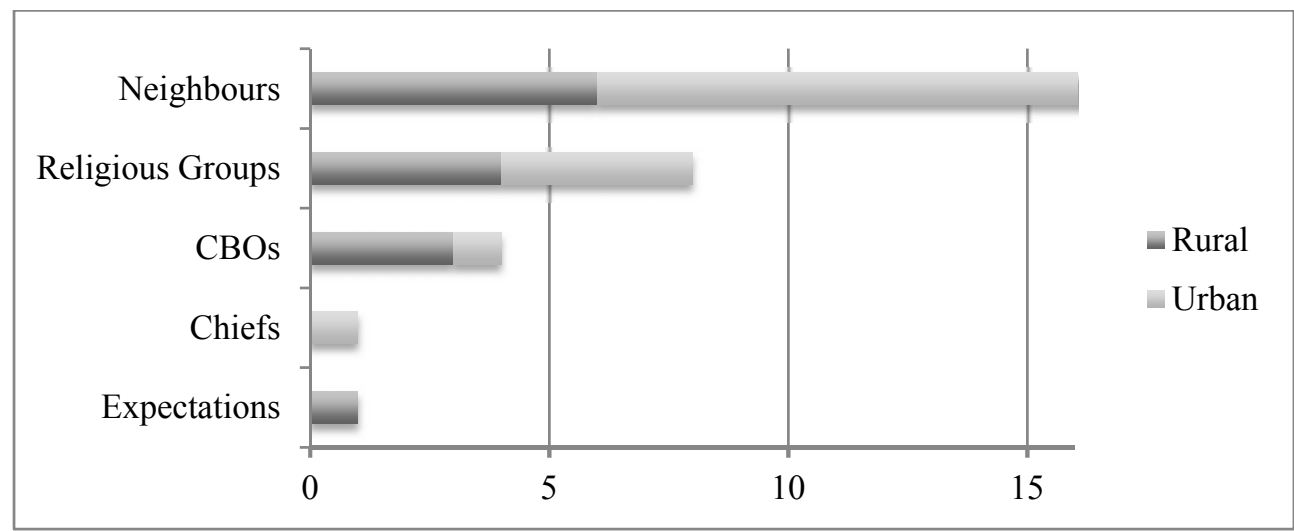

Figure 7.2. Child carer perspectives on community members' support. Source: Author's compilation based on interviews.

Child carer interviewees also considered neighbors to be people in the community who were concerned about their general well-being. As "Bridget," aged 14, a single orphan in Form A at the urban school and caregiver of a sibling, stated: "My neighbor just checks on us to find out how we are doing." Another child carer, "Kathy," had this to say: "[My neighbors] also make sure what we are safe because if there is a commotion around, they would come and check on us." I will discuss the specific nature of support that neighbors provided in the sections that follow.

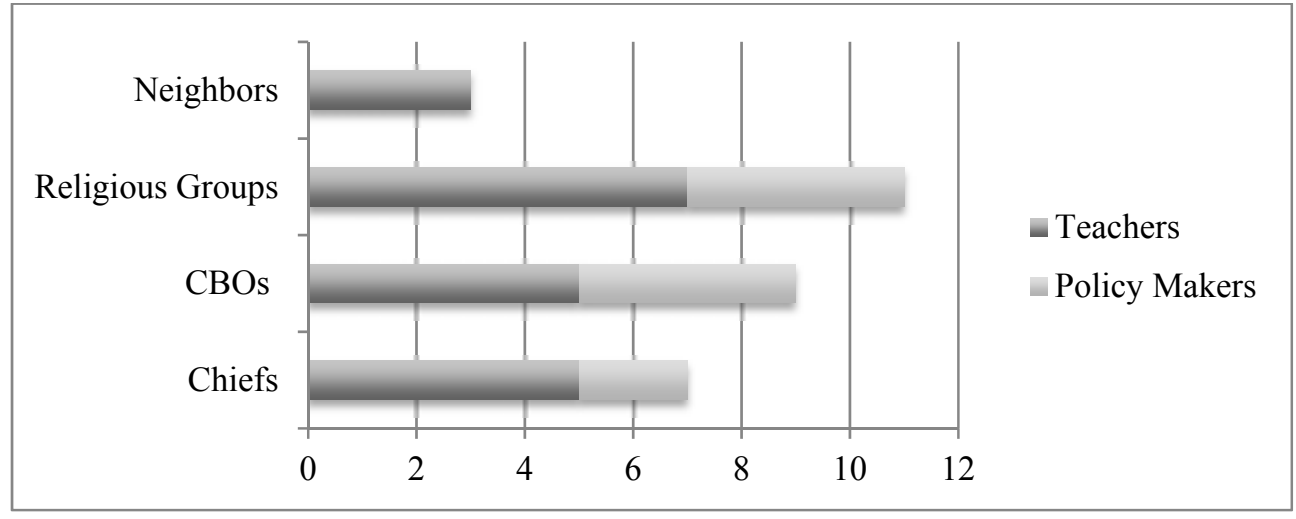

Figure 7.3. Teacher and policy maker perspectives on community support. Source: Author's compilation based on interviews. 


\section{Neighbors as a Source of Food Support}

Study participants mentioned food support from neighbors more frequently than other kinds of support. A neighbor seemed to be the first person the child carer went to when they ran out of food. The following quotes highlighted the nature of support that neighbors provided. Fourteen-year-old "Linda," a single orphan in Form B at the rural school and caregiver of her grandmother and three siblings, had this to say: "Our neighbors help us with food, when my mother does not send money." Another child carer, "Tina," aged 17, attending Form B also at the rural school, expressed similar sentiments when she said: "If we don't have vegetables, we go and ask [the neighbors], then they help us. We also ask for things like cooking oil and maize-meal. They always give us." From the urban school, "Kathy," aged 18, a single orphan attending Form E and looking after a sibling, had this to say about the food support she received from her neighbor: "We always have supper because my neighbor helps us. They try all they can to make sure that we have food." Echoing these views was teacher "Kabelo" from the urban school, who said: "Those [girl-carers] that I manage to talk to say they get help from their neighbors once in a while with things like food."

In some instances, child carers also reported how neighbors offered food as in-kind payment for work done. Seventeen-year-old "Palesa," a single orphan in Form E and caregiver of five relatives, explained this in the following quote: "Someone will call me to go and work in the fields or to go and clean and they give me food to take home." It is clear from the quote above that neighbors seemed aware of the difficult situation that child carers were in; not only were they willing to respond positively to requests for food, but they also seemed to intentionally look out for child carers to offer support.

\section{Neighbors Provided Financial Support}

Child carer interviewees reported that neighbors provided financial assistance to them to meet their school and home needs. For example, "Linda," a caregiver, in discussing how community members helped her stay in school, described the nature of financial support from her neighbor as follows:

I get help from my neighbor because sometimes at school we would be asked to pay for trips. She would ask me if I am going and I tell her that I am not because I don't have money, then she would pay. And sometimes 
if I need books, because I am studying Business Education and I need to buy a ledger or a journal, then I would ask her to help me out. If she has money, she would buy one for me.

Interviewees also cited neighbors as a source of finances for child carers to meet their home needs. Child carers were able to borrow money from their neighbors, as described by "Kathy" in the following quote: "We may run out of things before month's end, so [my neighbors] help us if we ask; [they lend me] money which I pay [back] when we get ours."

Another way that neighbors helped financially was by offering the girl-carers work that they would be paid for in cash. "Mpho," an 18-year-old single orphan, who is in Form E and a caregiver of a sibling, stated this in the following quote: "There is a lady next door whom I relate with very well. I sometimes help her do house chores, after which she would give me some money."

Financial support may have influenced school attendance directly or indirectly. Finances that helped procure scholastic materials and also covered other schoolrelated costs may have had a direct influence on school attendance, as this enabled the child carer to participate in school activities. Monetary support for home needs could have been a mitigating factor in reducing the risk of dropping out of school to earn an income to take care of the family.

\section{Neighbors as a Source of Material Support}

Study participants described how neighbors took care of the material needs of the child carers. Some of the support, such as providing a school uniform, had a direct link to school attendance, while other forms of support mitigated against the risk of dropping out of school. For example, "Dawn," aged 15, a double orphan and caregiver of two young relatives, had this to say about the neighbor's assistance: "[My neighbor] helps me with other things like school uniform. Her children have completed high school, so she sometimes gives me their uniform and shoes." Another caregiver, "Mamea," aged 17, a caregiver of two family members, reported how her neighbor provided her with material items: "Many times they help us with food, but they also give us shoe polish, washing powder and soap." The significance of shoe polish and washing powder is related to the discussion in Chapter 5, which highlighted how a clean uniform, in good condition, was an 
essential element of attending school, thus making these items necessary to have in the home.

\section{Neighbors Assisted with Caregiving Responsibilities}

A few child participants related how neighbors assisted them with their caregiving responsibilities. Caregivers of younger relatives especially pointed out this fact. For example, "Dawn," a double orphan aged 15, in Form A at the urban school and caregiver of two young relatives, had this to say when asked who took care of the children when she was at school: "We have a neighbor who is unemployed, so they [children] go there until other children arrive from their schools, then they would go and play with them." Another girl carer, "June," also in Form A, had similar sentiments about her neighbor who helped with caregiving responsibilities. She said, "If I have to go somewhere, they [neighbors] babysit my sister."

\subsubsection{Chiefs Spearheaded Provision of Care and Protection}

The Government of Lesotho has mandated chiefs to oversee matters affecting vulnerable children in their villages (Government of Lesotho, 2012). While only one child participant mentioned community leaders as playing a role in keeping child carers attending school, more than half of the teacher, civil society, and policy participants acknowledged the role of chiefs, and described how the community leaders collaborated with the schools, and helped mobilize communities to meet the needs of child carers, including ensuring their safety and protection. Teacher "Muluti" from the rural school explained the relationship between schools and the chiefs as follows: "The community is still playing a part [...] because when we have problems, we still go to the chief." Another teacher, "Kakoma" from the urban school, further explained in the quote below how the chief vouched for child carers when there was no one else to provide documentation necessary to access services:

[The chief supports by] writing letters saying he can prove that this child is vulnerable, so that [the school] can get anything that is needed like a birth certificate because if there is no one who can prove that, it will be the chief. If the chief cannot prove [it], we do not get anything. What helps us most is the chief's cooperation here [..] he always cooperates and helps us, especially [concerning] these kids. 
To show proof that a child is an orphan, documentation such as a death certificate or a passport of a deceased parent must be submitted in order for a student to be eligible for government bursaries. As discussed in Chapter 3, some children reported that they were unable to access scholarships due to a lack of necessary documents. Teachers, therefore, sought the help of chiefs to try and overcome this problem.

Study participants pointed at chiefs as being responsible for raising awareness among community members of the plight of vulnerable children under their jurisdiction in order to mobilize support to meet their needs. A policy maker from the ministry of social development had this to say:

The local chief had initiated a scheme for all villagers. Each family contributed M20.00 [\$US2] on a monthly basis. This money was used to pay school fees for children who were under the sponsorship of MOET, so that when they fail, they could be covered by the scheme so that they could carry on with their studies.

A focus group discussion participant also explained the community mobilization role of the chief by stating the following:

If we have such children within the community, the chief always knows about them, their problems and what happened to their parents. Therefore, when he addresses the community, he always appoints other people who will provide counseling to these children. These children are given some guidance and advice on what to do and how to behave, so they decide to leave all other things and focus on education.

A number of participants spoke about the chief putting in place measures that provided protection and safety to child carers. For example, "Mwaka," aged 14, a caregiver of three who is in Form A at the urban school, had this to say: "After someone knocked on the door at night, I informed our neighbor;[our neighbor] reported to the chief and a public gathering was organized even though I did not know what was being discussed there." 
A policy maker interviewee also related how chiefs played a role in protecting girls and ensured that cases of abuse were reported:

Village chiefs help our children, especially these ones who are 16 and 18, because they are prone to rape. So, you will realize that chiefs protect them, push and make sure that sexual offences cases are promptly reported.

\subsubsection{Community Groups and Faith-based Organizations}

Lesotho policy documents recognized the role of community-based organizations (CBOs) in responding to the plight of vulnerable children. The National Policy on Orphans and Vulnerable Children (Government of Lesotho, 2006) stated that the government would collaborate with $\mathrm{CBOs}$ to strengthen capacity of families and would support reintegration of vulnerable children into households with a caring adult (p. 8). This study found that community-based organizations identified atrisk children in need of assistance, mobilized resources to meet their needs, and liaised with schools for child carers to access services. These roles were summed up in the following quote by a policy maker who said: "Support groups are important in that they play a role of identifying these children in villages; being able to see those who do not have parents and are therefore helped [to] get assistance."

\section{Community Groups Provided Financial Support and School Materials}

Study participants stated that CBOs influenced child carers' school attendance by paying school fees and providing school materials for those who were at risk of dropping out. Teacher participants from both schools expressed knowledge of child carers that were beneficiaries of CBO support. Teacher "Muluti" from the rural school described in the quote below how CBOs engaged with the school in supporting the child carers:

[The $\mathrm{CBO}$ ] is paying for many of them here [...] some have already left the school. One of them that you have just interviewed is being [sponsored] by the support group. They just send us the names of the people [they] want to pay for, we don't ask them, they are able to identify them in the village, they just identify that these children are needy so we need to support them. 
The quote above showing that CBOs interacted directly with the school in their efforts to cover scholastic costs could imply that child carers may have not been aware of this assistance that went through the school and could explain the fact that only one child carer participant made reference to support provided by CBOs. In her quote, "Kathy," a single orphan attending Form E at the urban school, cited a $\mathrm{CBO}$ as a community structure that covered her school fees, and said: "The church sometimes pays our school fees."

From the urban school, teacher "Gillian" also pointed to a community-based organization as a source of support for child carers, and had this to say: "There was [a] support group which helped most of the children who were students here. [They were supported with] things like school fees, uniforms, and food."

A few study participants highlighted how community groups provided psychosocial support to child carers. Faith-based organizations were mentioned mainly in relation to providing emotional support. Female child carer participants from the rural area mentioned prayer and motivation as the only types of support they received from the church. The urban area interviewees had mixed responses, including child carers who reported that they received financial and material support from the church. For example, "Angela," aged 17, a single orphan and caregiver of two, had this to say about her participation in church activities: "To me, going to church is a sort of counseling. We are advised on how we can overcome problems." A policy maker interviewee also described, in the quote below, the importance of psychosocial support that CBOs provided to child carers:

I think they [CBOs] support in terms of emotional support maybe even financial support, but emotional support plays a big role because you can have all the finances but, if emotionally you are not healed, you are not going to achieve your goals. The emotional support that they get from the support groups for those who are a child head of households and for those who stay with sickly grandparents.

Some participants mentioned that CBOs provided material support to meet the household needs of child carers. The few child carers who pointed out this type of support indicated that it was done in an irregular manner. For example, 15-yearold "Dawn," a double orphan attending Form A at the urban school, described the 
support from her church as follows: "We sometimes receive money and food. Some people would also take clothes to the pastor's office which [would] be distributed amongst us." Policy maker respondents' perceptions regarding CBOs providing material support were, however, different from those of the child carers. A policy maker made the following statement that indicated how community groups provided stopgap measures to supplement government support:

Many times, [one] will find that churches usually help out at community level before the ministry could take over with public assistance. They offer packages when they see a child who is more vulnerable than others, giving them food and other things.

Another policy maker also described how $\mathrm{CBO}$ volunteers helped girl-carers:

Volunteers also help out. There are volunteers who work hard in making sure that they help these children; others can go as far as staying with these children, especially those from child headed households, while others would leave them in their family home but provide care and support by making sure that they have food [and] toiletries.

The support from the community came with high expectations of the child carers to succeed in school. As teacher "Kabelo" explained, some of the sponsorships came with conditions: "There is a lot of support from these organizations [..]. They tell you that if you fail, we will not sponsor you." Teacher "Tebuhho" from the rural school had similar views about community expectations of the child carers that they supported and gave the following quote:

I think even the community, we have got what we call Community-Based Organizations-These are Support Groups, normally made of women, they join together and they contribute money and identify kids [...] and then they send them to school. It's very difficult for a child to disappoint such a group because they are like their parents. If she doesn't appear at school, anyone can ask her why is it that you are at home when we are paying school fees. 
Female child carer participants from the rural area only mentioned prayer and motivation as the types of support they received from the church. The urban area participants expressed mixed responses, with some reporting financial and material support from the church, and others indicating only spiritual and motivational support.

\subsection{Discussion and Conclusion}

In this chapter, I set out to study the perceptions of child carers, and other stakeholders, and how family members and communities influenced child carers' school attendance. I started by first discussing the findings related to family factors.

The study showed that both immediate and extended family members provided support that may have had a direct, or an indirect, influence on the child carers' school attendance. This was congruent with other studies (Benzies \& Mychasiuk, 2009; Condly, 2006; Perez et al., 2009) that identified families as a source of emotional, financial and material support. The most obvious ways in which families influenced school attendance directly was when they were said to have covered the costs of schooling, such as paying school fees and supplying school uniform.

Corroborating other literature, such as Condly (2006), Robson et al. (2006), Benzies and Mychasiuk (2009), and Perez et al. (2009), my study also found that the psychosocial support provided by family members helped build child carers' individual resiliency traits. In the same vein, knowing that parents and other family members had high expectations of them, child carers seemed to have been motivated to aspire for a better future. This finding confirms other studies, such as McMillan and Reed (1994) and Benzie and Mychasiuk (2009). As discussed in Chapter 4, traits such as having positive aspirations for the future may influence positive behavioral outcomes among at-risk children.

Resilience studies have linked the interpersonal relationship with one special person in the life of a child as a factor that helped with overcoming adversity (Benard, 1991; Katz, 1997). This special person can be an individual or a network of special relationships, such as a close-knit family (Katz, 1997) or a person who was able to listen to them and share their problems. Close-knit families can also be a 
collective of relatives from the extended family, as in the case of the girls in the study who spoke about "mother's cousins" and "father's brothers" providing emotional support. The child carers described how family members provided emotional support that gave them the impetus to focus on school, despite the challenges they were facing. The knowledge that there were relatives who had high hopes for them, loved them, and wanted the best for their future could have been a motivating factor for the child carers to stay in school.

Considering that poverty seemed to have been the underlying factor that may have put most of the child carers in their situation, it was expected that families would be struggling economically. The study, however, demonstrated how family members cooperated by pooling resources to take care of the school and home needs of the child carers. This strategy was also identified in Nyamukapa and Gregson's (2005) Zimbabwe study that showed how families shared responsibilities between paternal and maternal sides of the families. The use of a grandparent's pension to cover school fees was also reported in an evaluation of the impact of the old-age pension scheme in Lesotho (Bello et al., 2008).

Regarding community factors, my study findings demonstrated that community stakeholders such as neighbors, community leaders, and community-based organizations rallied around supporting the child carers in various ways that could have facilitated school attendance. This corroborates the studies that highlighted the protective nature of caring and supportive communities as playing a role in nurturing resilience among at-risk children (Benard, 1991; Charles, 2011; Katz, 1997). My study went further to elucidate the nature of support that each community network provided. This analysis was identified as a gap in the previous resilience literature that I reviewed. The key finding was that from the child carers' perspective, neighbors seemed to play the major role in supporting child carers' school attendance and could be considered to be the substitute family or parents to child carers. Neighbors were said to be the first point of contact for child carers when they felt unsafe, and they also provided food, financial, material, and caregiving support. This finding points to the concept of a special individual providing positive supportive human interactions and relationships that may protect or compensate for children's adversities (Christiansen et al., 1997) by providing guidance, safety, protection, and support (Cooklin, 2009; Gandara, 1995; Katz, 1997). The study demonstrated that child carers were able to solicit support 
from community networks, a finding that converges with the study by Skovdal et al. (2009), whose findings showed that children who were coping depended on their ability to negotiate support from community members. This ability to maneuver through social institutions applies to what Yosso (2005) termed "navigational capital." Community members being able to rally together to support child carers also aligns with Pierre Bourdieu's social capital theory, which explains how relationships or linkages between individuals or groups may benefit individuals (Bourdieu, 2011; OECD, 2016).

Community support, which did not have a direct link to attending school, could still have influenced school attendance in various ways. First, support to the child carers may have mitigated the risk of them dropping out of school to manage their caregiving responsibilities. Having a sense of indebtedness to the community members who provided support could have been a motivating factor for child carers to keep attending school. This would also be compounded by the community networks' high expectations of the child carers to succeed. This parallels Benard's (1991) view that an environment that established a high expectation for at-risk children influenced their positive outcomes.

The findings highlighted the fact that not all girls experienced the same level of support as support may come from family and not the community, or vice versa. Some girls reported support from both family and community, where one filled in in the absence of another. What this demonstrated was that there was no "one size fits all" approach that seems to be responsible for child carers staying in school, but a combination of factors.

\section{Conclusion and Policy Considerations}

Based on the findings, the study showed that family members endeavored to support the child carers to keep attending school and, even while confronted by poverty, used strategies such as pooling resources together, or taking turns at providing support to keep the child carers in school. The unintended benefit of old-age pension as a source of financial support for caregivers of grandparents is worth noting. The government should therefore consider extending the social grant to child carers living in such households. This is in line with the recommendation by Bello et al. (2008), who suggested introducing a support grant that targeted vulnerable children who were dependent on the old-age pension grant, as a way of minimizing the strain on the pension funds. 
Within the community setting, the study findings point to the critical role that neighbors played as a substitute parent or family. The neighbors were said to be the first point of call when the child carers were in distress and seemed to find means of providing them with financial, material, and emotional support. In order to maximize and enhance this resource, government and nongovernmental programs designed to support families should therefore include community members, who appear to play this role. Government and nongovernmental programs, such as household economic strengthening, should also target those community members that are in a position to help. Such individuals should also be provided with psychosocial and parenting skills needed to engage with children in adversity. 


\section{CHAPTER 8}

\section{DISCUSSION AND POLICY CONSIDERATIONS}

\subsection{Introduction}

The aim of this dissertation was to examine the perceptions of female child carers and other stakeholders of the conditions under which female child carers are able to regularly attend secondary school despite experiencing adversity. Prior academic literature showed that caregiving responsibilities do affect regular school attendance (Lewin \& Little, 2011; Nyabanyaba, 2009; Stearns \& Glennie, 2006; UNFPA, 2012), especially among girls who would more likely be the ones staying at home to care for their siblings and other younger children (Wells, 2009).

Despite facing adverse circumstances, some child carers will still attend school regularly (Cluver et al., 2012). Children who thrive in such situations are considered resilient (Condly, 2006; Katz, 1997). I set out to answer the research question and subquestions listed below:

Why and how do some girl child carers regularly attend secondary school, despite adverse situations?

- What is the care-work provided by the girl-carers?

- What are the challenges faced by the girl-carers, and how do these pose a potential risk to school attendance?

- What individual-level factors facilitated secondary school attendance?

- What family-level factors facilitated secondary school attendance?

- What school-level factors facilitated secondary school attendance?

- What community factors facilitated secondary school attendance?

- What interaction occurs amongst individual, family, school and community factors to facilitate secondary school attendance?

The findings showed that individual factors, family factors, school factors, and community factors all played a role in influencing child carers' school attendance. The study also confirmed literature that advanced the view that the factors within 
each domain needed to interact with each other for positive outcomes. The study reported how stakeholders from each domain collaborated to find ways of supporting child carers' schooling by providing financial, material, or psychosocial help.

\subsection{How Child Caring Causes Educational Risk: Missing School and Psychological Stress}

In Chapter 4, I examined the participants' perceptions of the challenges that female caregivers face, and how these may have posed a potential risk to their schooling. The findings showed that child carers experienced challenges related to caregiving responsibilities, both at home and at school. My study established that caregiving goes beyond providing care in the home. A significant finding was that child carers were expected to fulfill the parenting responsibility in other spheres beyond the home, and were therefore presented with a situation where they had to make a choice between meeting some of their parenting obligations, such as attending parent-teacher meetings, and going to school. The challenges of parenting and providing intimate care to their family members highlighted the internal conflict that child carers experienced when having to deal with the expectation of playing the adult role, while still recognizing that they were children. This finding is important in that it identifies a gap in the definitions of child carers (Dearden \& Becker, 2002; Thomas et al., 2003) that only focus on domestic tasks provided in the home.

The key point to note from my study is that even though child carers devised coping strategies to ensure that they were able to attend school, the pressure of caring weighed heavily on their minds even while at school. As Moore (2005b) correctly asserted, this anxiety may pose a risk to school attendance and ultimately have an impact on their school success. Attending school alone is therefore not sufficient when the quality of learning is being compromised as a result of anxiety and stress outside of school. This finding is critical information for countries when they decide to implement aspects of the Incheon Declaration: Education 2030, which recommends provision of 12 years of free education and advocates quality, inclusive, and equitable education (Declaration, 2015). 
Although prior literature (Cluver et al., 2012; Nyabanyaba 2009) reported that child carers were able to combine schooling with caregiving, despite facing adversities, my study contributed to this discourse by articulating the factors that helped them do so. My dissertation suggests that child carers, families, schools, and communities had to go to great lengths in order to keep the child carers in school. The child carers also reported situations, such as illness of a relative, when they unintentionally had to miss school. Participants reported that missing school affected their schoolwork, which was therefore a potential barrier to achieving their vision for the future. These findings align with the suggestion by Cluver et al. (2012) that the decision to miss school was usually presented as a forced choice.

Study participants showed how time limitations were a factor, both for caring responsibilities and schoolwork. The child carers constantly tried to find ways to fit in both, but sometimes, however, one thing had to suffer. When children prioritized their caregiving responsibilities over school, then their schoolwork was affected, and vice versa. Prior literature showed that young carers gave primary importance to their caring responsibilities over the amount of time allocated for schoolwork (Moore, 2005b) and therefore had to find ways of catching up with missed work (Thomas et al., 2003). My study demonstrated that the type of caregiving task at hand influenced the caregivers' decisions. For example, when a care recipient was ill, then the child carer prioritized caregiving responsibilities over school. Otherwise, my data showed that they tried to accomplish their duties so that they could get back to class at some point in the day.

\subsection{A Child Carer's Vision for a Brighter Future Influenced School}

\section{Attendance}

The second empirical chapter aimed at answering the subquestion pertaining to which individual-level factors facilitated secondary school attendance. The study showed that the female child carers exhibited individual traits of resiliency. Having a vision for a better life in future was perceived to be the most prominent factor that motivated the child carers to beat the odds. The child carers perceived having an education as a conduit to achieving a future they envisioned. What was unique about the child carers' vision of a better future was that it evolved around future caregiving responsibilities. They still saw themselves as caregivers in the future, and aspired to provide better care for their current and future care 
recipients. They also had plans to reciprocate care by looking after family members who were supporting them. Another factor that influenced their vision was the desire to have a "normal" family life; the child carers hoped to normalize their family structure and mentioned plans to bring back parents and other relatives that had migrated.

Role models and other individuals who took a special interest in the child carers to motivate them also influenced the vision attribute. This ability to notice and be inspired by information that contributes to reaching one's aspirations of success is a characteristic found in optimistic or promotion-focused individuals (Lockwood et al., 2002). Religion also played a role in providing hope for the future; the role of religious background contributed to the extent that child carers' belief that God would help them through their difficult situation gave them hope for a better future, and therefore influenced their setting of future goals. Faith on its own did not directly influence school attendance.

\subsection{External Factors Family, School, and Community Influenced School}

\section{Attendance}

Two of the empirical chapters, 6 and 7, aimed to answer three subquestions that looked at how family, school, and community influenced child carers' school attendance. The study findings showed that the social networks of family, school, and community which the child carers were part of had their best interests at heart and made an effort within their means to keep them in school. For example, family members coshared financial responsibilities, school authorities applied flexibility in their policies to favor the vulnerable children, and neighbors and communitybased organizations provided school materials and food. This is line with Yosso's (2005) Community Cultural Wealth Model, which argued that another form of capital that people could draw on was social capital. Social capital includes "networks of people and other community resources" that can provide material and psychosocial support to help people circumnavigate through institutions and achieve success (Yosso, 2005, p. 79).

The study presented some commonalities in the type of support provided to child carers from family, school, and community stakeholders. Each of these groups in one way or another provided financial and material support for school and home 
needs, and also motivated child carers. Within the school setting, teachers, either individually or collectively, paid school fees for children who were not able to do so. The schools also established linkages with other service providers who would offer scholarships and provide school items. In the midst of household economic problems, family members cooperated by pooling resources to address the school and home needs of the child carers. This strategy was also identified in Nyamukapa and Gregson's (2005) Zimbabwe study.

The dissertation casts light on the importance of providing psychosocial support to child carers. Although material support was considered important, child carers also valued the psychosocial support of having someone pay special attention to them by spending time to talk and listen to their challenges. This confirmed the findings of resiliency scholars who identified having a caring and supportive relationship, one that provided necessary attention, as a predictor of resiliency (Benard, 1991; Katz, 1997). Supportive human relations and interactions between the child carers and other individuals stood out as an important factor that facilitated child carers' school attendance and was identified as a common trait in all of the external domains - family, school, and community. Specific mention was made of some teachers, neighbors, and peers as special individuals who listened to, spoke with, advised, and encouraged girl-carers.

\section{A Supportive and Structured School Environment Kept Child Carers in School}

The study findings support and extend resiliency literature that demonstrated that a conducive and positive school environment influenced successful school outcomes. Personal initiatives by school personnel and students, as well as structured school programs such as the school feeding scheme, weekend compulsory study time, recreational activities, and special assemblies, were said to have contributed to making the schools conducive for girl child carers to strive to stay in school despite their challenges. The findings of the study showed how the school system was able to draw on the various forms of capital resources (Yosso, 2005) to keep girl child carers attending school. In both schools, no specific support was aimed at child carers; however, they were reached through interventions that targeted vulnerable children in general.

A key finding was that although most school programs were implemented to reach all students, the programs were reported to have had unintended positive 
outcomes for at-risk child carers. Robert K. Merton advanced the concept of unintended consequences as unexpected results of an unorganized, or formally organized, action (Merton, 1936), and went on to argue that the result, although not anticipated, does not imply that it would necessarily be undesirable. The structured school programs are examples of such unintended positive consequences I found in my research.

Within the school setting, teachers seemed to have been viewed as having played a significant role in influencing child carers' school attendance. The teachers were seen as a substitute family or parents, as they went beyond the call of duty, and, in most cases, used their own resources to support child carers in meeting their schooling and home needs. Equally important to the child carers were teachers who took the time to provide emotional support and motivated them to stay in school.

My study also highlighted the facilitative role that schools played in fostering linkages with service providers to support child carers' schooling and home needs. The benefit of receiving external support through the school may have been a motivating factor for child carers to stay engaged with the school congruent with other studies (Ferreira \& Ebersohn, 2011; Nyabanyaba, 2009; Waxman et al., 2003). These findings also aligned with Yosso's (2005) Community Cultural Wealth Model, which argued that another form of capital that people could draw on was social capital. When schools made children feel welcome and provided a sense of security, this facilitated effective participation (Christiansen et al., 1997).

\section{Families and Community Social Networks Supported Child Carers to Stay in School}

In analyzing the role that family played in keeping child carers in school, the study showed that most child carer participants indicated that family members were interested in their educational success and endeavored to cover financial costs of schooling. Even when facing economic hardships, family members employed strategies, such as pooling money together or taking turns at providing support, to keep the child carers in school. Although it may appear as if by migrating to South Africa, parents and other relatives had abandoned the child carers, the data showed that they actually sent remittances to cover school fees and other needs. Migrating to find work seemed to have been in the interest of the child. Because 
remittances were not regular or always sufficient, it was incumbent on the child carer to find other means of support, such as asking neighbors for financial help. The study highlighted that not all child carers experienced the same level of support from family members. This was dependent on family members' willingness and ability to help.

Another important finding was the reciprocity of support between grandparents, as care recipients, and child carers. Children who were taking care of grandparents benefited from their pension, which was used to pay school fees. The use of grandparents' pension to benefit children in the household was reported in an evaluation of the impact of the old-age pension scheme in Lesotho (Bello et al., 2008). My study presents another piece of evidence of the unintended consequences of a social program.

At the community level, community-based structures were experienced as providing school fees through links with the school. My study went further to elucidate the nature of support that various community structures provided. Prior literature on resilience discusses the community as a singular entity without highlighting the roles of different community stakeholders. The key finding of my study was that from the child carers' perspective, neighbors seemed to play the major role in supporting child carers' school attendance and could be considered to be the substitute family or parents to child carers. Neighbors were said to be the first point of contact for child carers when they felt unsafe, and they also provided food, financial, material help, and caregiving support. This finding points to the concept of a special individual providing positive supportive human interactions and relationships that may protect or compensate for children's adversities (Christiansen et al., 1997) by providing guidance, safety, protection, and support (Cooklin, 2009; Gandara, 1995; Katz, 1997). Other community structures reported were chiefs and community-based organizations, but the data suggest that their role was not as pivotal as that of neighbors.

\subsection{Policy Considerations}

The results of this research may be used to further understand the phenomenon of child carers in the education, child protection, social protection, and resilience areas of research and work. My study leads to the following considerations for policy, to better improve the chances of effective quality schooling for child carers: 
free secondary schooling, teacher training to provide psychological support, more inclusive school bursaries, in-school peer-support programs, and community programs supporting those that help vulnerable groups. I further discuss these recommendations in this section.

This study was conducted at an opportune time when the global community has formulated the new sustainable development goals (SDGs) and the subsequent Education 2030 Incheon Declaration and Framework for Action (Declaration, 2015). The Incheon Declaration is committed to ensuring the "provision of 12 years of free, publicly funded, equitable quality primary and secondary education" (Declaration, 2015, p. iv). Advocating for free secondary education is therefore not far-fetched, as it aligns with the global agenda. I recommend free secondary education because the data demonstrate that providing school fees was one area of support that families, schools, and communities put efforts in covering. Participants described the extent to which the stakeholders went in order to dedicate effort, time, and resources to secure money to pay child carers' school fees. Child carers also mentioned migration to find jobs to cover school fees as one of the reasons they were in their situation. Making secondary schooling free would ease the financial burden on the families, and ultimately minimize the need for single parents to migrate. Undeniably, free education is a venture that needs to be well thought through to ensure that quality is not compromised. To implement a well-designed free secondary school program, countries can learn from the successes and challenges of Education For All movement (UNESCO, 2016) that advocated free primary education for all.

As noted in Chapter 6, both teachers and students played a critical role in providing psychosocial support to girl-carers. While it seemed that the school system and support network helped identify at-risk child carers, it is critical that government and nongovernmental organizations enhance teachers' skills in providing specialized psychosocial care. Teachers seem to be playing a big role beyond what they are required to do. Both preservice and in-service teacher training should include a component of specialized counseling to focus on the psychological wellbeing of the child. The Bhana et al., (2006) South Africa study made a similar recommendation to provide training and counseling workshops for teachers. This however should go beyond counseling in the context of HIV 
prevention as stipulated in the Lesotho Education Sector Strategic Plan (Government of Lesotho MOET, 2005).

As presented in Chapters 4,6 and 7, insufficient finances to cover school costs was cited as a challenge that teachers, family members, and communities went to great lengths to address. Chapter 4 also highlighted some bottlenecks to accessing the government bursary. This was an indication that existing bursary schemes may not be reaching some vulnerable children, such as child carers. My recommendation for policy consideration is that government and nongovernmental scholarship funds should revisit the targeting criteria in order to make it more inclusive.

The fact that the girl-carers continued worrying about their care recipients even while at school calls for a more comprehensive community-based response that addresses the challenges faced by the children at home. To mitigate this issue, government and civil society organizations should implement a household-based approach in supporting child-carers. This entails assessing the needs of the household members and providing support based on the identified gaps. To provide quality support in school, there is a need for teachers to be given adequate preservice and in-service training so that they may better respond to psychosocial concerns of child carers.

Within the school setting, the school feeding scheme, which provided at least one meal a day, seemed to motivate girl-carers to attend school. School personnel packed leftover food for the child carers to take home. This was an unplanned consequence which highlighted the need for food support at home. Government and school administrations should continue to provide school lunches; however, this needs to be extended to include a formalized take-home ration for child carers. Programs to support child carers should, therefore, examine these unintended outcomes and develop activities to provide children with the necessary supports, such as additional food rations.

My study also highlighted how school peers provided critical psychosocial and material support to child carers. Schools should make this support more structured by revamping peer-support groups with trained psychosocial support facilitators. 
The unintended benefit of old-age pensions as a source of financial support for caregivers of grandparents is worth noting. The government should, therefore, consider extending the social grant to child carers living in such households. This is in line with the recommendation by Bello and Letete (2008), who recommended introducing a support grant that targeted vulnerable children who were dependent on the old-age pension grant as a way of minimizing the strain on the pension funds.

Within the community setting, the study findings point to the critical role that neighbors played as a substitute parent or family. Their neighbors were said to be the first point of call when the child carers were in distress; they seemed to find means of providing child carers with financial, material, and emotional support. In order to maximize and enhance this resource and help the helpers, the government and NGO community-based programs should also target such community members that are already assisting vulnerable populations. These individuals may not necessarily meet the vulnerability criteria, but could still be valuable for household economic strengthening interventions and psychosocial support and parenting skills needed to engage with children in adversity.

\subsection{Academic Contribution and Recommendations for Future Research}

Academic literature on child carers in sub-Saharan Africa is, according to Becker (2007), still emerging. The findings of this research will therefore contribute to the discourse on child carers in the education, child protection, social protection, and resilience disciplines. By trying to examine why child carers experiencing adversity stayed in school, my study focused on understanding what works, rather than the risk. This tendency of focusing on resiliency versus risk is a recent shift among researchers and policy makers (Rutter, 2012). My study, therefore, adds value to this area of research as it relates to child carers in sub-Saharan Africa.

The literature on child carers in sub-Saharan Africa is considered to be emerging (Becker, 2007) and is therefore an area that is open for further research. My recommendations are based on some of the gaps that I identified in the course of my dissertation. 
My research focused on school attendance as an indicator of school success. The data showed that, although child carers were attending school regularly, they also reported worrying about their caregiving responsibilities and their families left at home. This emotional distress may affect quality of learning (Moore, 2005b). Further, data on child carers in sub-Saharan Africa are limited. A quantitative study on the extent of care, and other indicators such as school enrolment and drop out, is necessary to further spotlight this "hidden" population and provide statistical baseline knowledge about their experiences. In addition, comprehensive (country-wide) longitudinal data collection that looks at the academic outcomes, including school progression, of these children, would give a better picture of the impact of caregiving on educational outcomes.

One limitation of my dissertation is that I did not sample child carers who had dropped out of school. A follow-up retrospective research with the aim of examining the perspectives of out-of-school female child carers regarding their experience with schooling would provide the comparison that this study lacked. I suggest a retrospective study because some caregivers would have been out of school for a number of years, and their situation would have changed. Gandara (1995) used such an approach in her research on the educational success of lowincome Chicanos. My study also highlighted the fact there was no systematic way of tracking child carers who had dropped out of school. Future research should collaborate with the government to develop a database that captures the status of out-of-school child carers.

Finally, the study was on vulnerable children, an area of focus that I have devoted most of professional career on. It therefore follows that my position as a subject matter specialist may have had an effect on reflexivity. According to Roni Berger (2015), social standing, past experience or professional exposure may have an impact on reflexivity of the researcher. While my professional position as someone working for a donor agency may have facilitated access to some of my study participants such as the policy makers, this relationship could have influenced the information that the participants shared. My professional knowledge and expertise may present a risk of bias for the study. 


\section{REFERENCES}

Ahmed, A. U. (2004). Impact of feeding children in school: Evidence from Bangladesh. Washington, DC: International Food Policy Research Institute.

Aldridge, J., \& Becker, S. (1993). Children who care: Inside the world of young carers. Leicestershire: Loughborough University.

Ardington, C., \& Leibbrandt, M. (2010). Orphanhood and schooling in South Africa: Trends in the vulnerability of orphans between 1993 and 2005. Economic Development and Cultural Change, 58(3), 507-536.

Barnett, T. W., \& Alan. (2006). AIDS in the twenty-first century, disease and globalization. Hampshire and New York: Palgrave Macmillan.

Barriball, K. L., \& While, A. (1994). Collecting data using a semi-structured interview: A discussion paper. Journal of Advanced Nursing 19(2), 328-335.

Bhana, D., Morrell, R., Epstein, D., \& Moletsane, R. (2006). The hidden work of caring: teachers and the maturing AIDS epidemic in diverse secondary schools in Durban. Journal of Education, 38, 5-23.

Becker, G. S. (1993). Human capital: A theoretical and empirical analaysis with special reference to education. Chicago and London: The University of Chicago Press.

Becker, S. (2007). Global perspectives on children's unpaid caregiving in the family: Research and policy on "young carers" in the UK, Australia, the USA and SubSaharan Africa. Global Social Policy, 7(1), 23-50.

Bello, H. M., Letete, E. M., Rapapa, M. T., \& Chokobane, L. L. (2008). An evaluation of the poverty reduction impact of the non-contributory old age pension scheme in Lesotho: The case of Manonyane. Review of Southern African Studies, 12(1), 76-106.

Benard, B. (1991). Fostering resiliency in kids: Protective factors in the family, school and community. Minneapolis, MN: National Resilience Resource Center, University of Minnesota.

Benzies, K., \& Mychasiuk, R. (2009). Fostering family resiliency: A review of the key protective factors. Child \& Family Social Work, 14(1), 103-114. 
Berger, R. (2015). Now I see it, now I don't: Researcher's position and reflexivity in qualitative research. Qualitative Research, 15(2), 219-23

Blumberg, B., \& Cooper, D., \& Schindler, S. (2011). Business research methods. Berkshire: McGraw-Hill Education.

Bourdieu, P. (2011). The forms of capital. (1986).

Bray, R. (2009). A literature review on child carers in Angola, Nigeria, Uganda, and Zimbabwe. Save the Children UK.

Bronfenbrenner, U. (1994). Ecological models of human development. International Encyclopedia of Education, 3, 1643-1647.

Cassen, R., Feinstein, L., \& Graham, P. (2009). Educational outcomes: adversity and resilience. Social Policy and Society, 8(1), 73-85.

Centers for Disease Control and Prevention (CDC). (2013). The socio-ecological model: A framework for prevention.

Charles, G. (2011). Bringing young carers out of the shadows. Reclaiming Journal, 20(3), 26-30.

Christiansen, J.., Christiansen, J. L., \& Howard, M. (1997). Using protective factors to enhance resilience and school success for at-risk students. 33(2), 86-89.

Classbase. (2012). Education system in Lesotho. Retrieved March 26, 2016 from http://www.classbase.com/Countries/Lesotho/Education-System.

Cluver, L., Kganakga, M., Lane, T., \& Operario, D. (2012). I can't go to school and leave her in so much pain: Educational shortfalls among adolescent young carers in the South African AIDS epidemic. Journal of Adolescent Research, 27(5), 581-605.

Cluver, L., Operario, D., \& Gardner, F. (2009). Parental illness, caregiving factors and psychological distress among children orphaned by acquired immune deficiency syndrome (AIDS) in South Africa. Vulnerable Children and Youth Studies, 4(3), 185-198.

Condly, S. J. (2006). Resilience in children: A review of literature with implications for education. Urban Education, 41(3), 211-236. 
Connell, J. P., Spencer, M. B., \& Aber, J. L. (1994). Educational risk and resilience in African-American youth: Context, self, action and outcomes in school. Child Development, 65(2 Spec No), 493-506.

Cooklin, A. (2009). Children as carers of parents with mental illness. Psychiatry 8(1), 17-20.

Creswell, J. W. (2003). Research design: Qualitative, quantitative, and mixed methods approaches. California, Sage Publications.

de la Porte, S. (2008). Redefining childcare in the context of AIDS: The extended family revisited. In Agenda 1.1 (Sexual and reproductive rights: HIV and AIDS trilogy; pp. 129-140).

Dearden, C., \& Becker, S. (2002). Young carers and education. London: Loughborough University, Carers UK.

Dearden, C., \& Becker, S. (2004). Young carers in the UK: The 2004 report.

Declaration, I. (2015). Education 2030: Towards inclusive and equitable quality education and lifelong learning for all. World Education Forum.

Donald, D., \& Clacherty, G. (2005). Developmental vulnerabilities and strengths of children living in child-headed households: A comparison with children in adultheaded households in equivalent impoverished communities. African Journal of AIDS Research, 4(1), 21.

Elder, J. P., Lytle, L., Sallis, J. F., Young, D. R., Steckler, A., Simons-Morton, D.,...Ribis, K. (2006). A description of the social-ecological framework used in the trial of activity for adolescent girls (TAAG). Oxford Journals.

Embrace the Future. (2005). The resiliency model. Retrieved April 13, 2014 from http://www.embracethefuture.org.au/resiliency/index.htm.

Evans, R. M. (2005). Social networks, migration, and care in Tanzania: caregivers' and children's resilience to coping with HIV/AIDS. Journal of Children and Poverty, 11(2), 111-129.

Evans, R. (2010). Children's caring roles and responsibilities within the family in Africa. Geography Compass, 4(10), 1477-1496. 
Ferreira, R., \& Ebersohn, L. (2011). Formative evaluation of the STAR intervention: Improving teachers' ability to provide psychosocial support for vulnerable individuals in the school community. African Journal of AIDS Research 10(1), 63-72.

Finn, J. D., \& Rock, D. A. (1997). Academic success among students at risk for school failure. Journal of Applied Psychology, 82(2), 231-234.

Foster, G., Makufa, C., Drew, R., Kambeu, S., \& Saurembe, K. (1996). Supporting children in need through a community-based orphan visiting programme. AIDS care. AIDS Care, 8(4), 389-404.

Foster, G., Makufa, C., Drew, R., \& Kralovec, E. (1997). Factors leading to the establishment of childheaded households: The case of Zimbabwe. Health Transition Review 155-168.

Fredricks, J. A., Blumenfeld, P. C., \& Paris, A. H. (2004). School engagement: Potential of the concept, state of the evidence. American Educational Research Association 74, 59-109.

Free, J. L., Kriz, K., \& Konecnik, J. (2014). Harvestng hardships: Educators' views on the challenges of migrant students and their consequences on education. Elsevier, 187-197.

Gandara, P. C. (1995). Over the ivy walls: The educational mobility of low-income Chicanos. Albany: SUNY Press.

Garmezy, N. (1991). Resilience in children's adaptation to negative life events. Pediatric Annals, 459-460, 463-456.

Government of Lesotho. (2006). National policy on orphans and vulnerable children. D. o. S. Welfare. Lesotho, Ministry of Health and Social Welfare,.

Government of Lesotho (2012). National strategic plan on vulnerable children: April 2012-March 2017. M. o. S. Development. Lesotho.

Government of Lesotho. (2011). Situation analysis of orphans and other vulnerable children in Lesotho 2011. M. o. S. Development. Maseru, Lesotho, Government of Lesotho.

Government of Lesotho MOET. (2005). Kingdom of Lesotho education sector strategic plan 2005-2015. Lesotho. 
Grant, M. J., Lloyd, C. B., \& Mensch, B. S. (2013). Menstruation and school absenteeism: Evidence from Rural Malawi. Comparative Education Review, 57(2), 260-284.

Guo, Y., Li, X., \& Sherr, L. (2012). The impact of HIV/AIDS on children's educational outcome: A critical review of global literature. AIDS Care 24(8), 9931012.

Gutman, L. M., \& Midgley, C. (2000). The role of protective factors in supporting the academic achievement of poor African American students during the middle school transition. Journal of Youth and Adolescence, 29(2), 223-248.

International Labour Organization. (2017, 2012). What is child labour? Retrieved January 13, 2017 from http://www.ilo.org/ipec/facts/lang--en/index.htm.

Jensen, P., \& Nielsen, H. S. (1997). Child labour or school attendance? Evidence from Zambia. Journal of Population Economics, 10(4), 407-424.

Johnson, G. M. (1997). Resilient at-risk students in the inner city. McGill Journal of Education, 32(1), 35-49.

Katz, M. (1997). Overcoming childhood adversities: Lessons learned from those who have "beat the odds." EBSCOhost 32(4), 205-206.

Kazianga, H., de Walque, D., \& Alderman H. (2008). Educational and health impact of two school feeding schemes: Evidence from a randomized trial in Burkina Faso." Retrieved from

http://www1.worldbank.org/prem/poverty/ie/dime_papers/840.pdf

Kelly, M. J. (2000). Planning for education in the context of HIV/AIDS. Paris: United Nations Education, Scientific and Cultural Organization.

Kirk, J., \& Sommer, M.. (2006). Menstruation and body awareness: Linking girls' health with girls' education. Retrieved October 30, 2016 from

http://www.susana.org/_resources/documents/default/2-1200-kirk-2006menstruation-kit-paper.pdf.

Knowledge Sharing Management. (2014). Participatory rural appraisal. Retrieved April 29, 2014 from

http://www.kstoolkit.org/Participatory+Rural+Appraisal+(PRA). 
Kvale, S., \& Brinkmann, S. (2009). Interviews: Learning the craft of qualitative research interviewing. California: Sage Publications.

Kvale, S., \& Brinkmann, S. (2009). Interviews: Learning the craft of qualitative research interviewing. Oslo: Gyldendal Akademisk.

Lacey, A. L. D. (2007). Qualitative research analysis. East Midlands/Yorkshire and the Humber.

Lesotho Bureau of Statistics. (2015). 2014 educational statistics report. Lesotho: Bureau of Statistics.

Lesotho Ministry of Health. (2015). Global AIDS response progress report 2015: Follow up to the 2011 political declaration on HIVIAIDS. Intensifying efforts to eliminate HIVIAIDS. Lesotho: Ministry of Health.

Lesotho Ministry of Health and Social Welfare. (2010). Lesotho demographic and health survey 2009. Lesotho.

Lewin, K. M., \& Akyeampong, K. (2009). Education in sub-Saharan Africa: Researching access, transitions and equity. Comparative Education, 45(2), 143-150.

Lewin, K. M., \& Little, A. W. (2011). Access to education revisited: Equity, drop out and transitions to secondary school in South Asia and Sub-Saharan Africa. International Journal of Educational Development, 31(4), 333-337.

Lipsky, M. (2010). Street-level bureaucracy: Dilemmas of the individual in public services. New York: Russel Sage Foundation.

Lockwood, P., Jordan, C. H., \& Kunda, Z. (2002). Motivation by positive or negative role models: Regulatory focus determines who will best inspire us. Journal of Personality and Social Psychology, 83(4), 854-864.

Mampane, R., \& Bouwer C. (2011). The influence of township schools on the resilience of their learners. South African Journal of Education, 31(1), 114-126.

Masten, A. S., \& Coatsworth J. D. (1998). The development of competence in favorable and unfavorable environments: Lessons from research on successful children. American Psychologist, 53(2), 205-220. 
Matope, T. (2015). A new dawn for school meals in Lesotho. Retrieved June 7, 2015 from https://http://www.wfp.org/stories/new-dawn-school-feeding-lesotho-0.

May, T. (2001). Social research: Issues, methods and process. Open University Press. McMillan, J. H., \& Reed, D. F. (1994). At-risk students and resiliency: Factors contributing to academic success. Taylor $\mathcal{E}$ Francis, 67(3), 137-140.

Merton, R. K. (1936). The unanticipated consequences of purposive social action. American Sociological Review, 1(6), 894-904.

Ministry of Health [Lesotho] and ICF International (2014). Lesotho demographic and health survey. Maseru, Lesotho.

Moore, T. (2005b). Reading between the lines: Listening to children and young people about their experiences of young caring in the ACT. Lyneham: Youth Coalition of the ACT.

Moore, T., McArthur, M., \& Morrow, R. (2009). Attendance, achievement and participation: Young carers' experiences of school in Australia. Australian Journal of Education, 53(1), 5-18.

Newman, T. (2002). "Young carers" and disabled parents: Time for a change of direction? Disability E Society, 17(6), 613-625.

Noble-Carr, D. (2006). Engaging children in research on sensitive issues. Dickson ACT, Australia: Institute of Child Protection Studies, Austrialian Catholic University.

Nyabanyaba, T. (2009). Factors influencing access and retention in secondary schooling for orphaned and vulnerable children and young people: Case studies from high HIV and AIDS prevalence contexts in Lesotho. SOFIE Opening Up Access Series, 7. London: Institute of Educaiton, University of London.

Nyamukapa, C., \& Gregson, S. (2005). Extended family's and women's roles in safeguarding orphans' education in AIDS-afflicted rural Zimbabwe. Social Science $\mathcal{E}$ Medicine, 60(10), 2155-2167.

OECD. (2016). Retrieved December 4, 2016 from https://http://www.oecd.org/insights/37966934.pdf.

Olsen, R. (1996). Young carers: Challenging the facts and politics of research into children and caring. Disability $\mathcal{E}$ Society, 11(1), 41-54. 
Oster, E., \& Thornton, R. (2011). Menstruation, sanitary products, and school attendance: Evidence from a randomized evaluation. American Economic Journal: Applied Economics, 3(1), 91-100.

Perez, W., Espinoza, R., Ramos, K., Coronado, H. M., \& Cortes, R. (2009). Academic resilience among undocumented Latino students. Hispanic Journal of Behavioral Sciences, 31(2), 149.

Pocock, B., Williams, P., \& Skinner, N. (2012). Conceptualizing work, family and community: A socio-ecological systems model, taking account of power, time, space and life stage. British Journal of Industrial Relations 50(3), 391-411.

Powell, C. A., Walker, S. P., Chang, S. M., \& Grantham-McGregor, S. M. (1998). Nutrition and education: A randomized trial of the effects of breakfast in rural primary school children. The American Journal of Clinical Nutrition, 68(4), 873.

Punch, S. (2002). Research with children: The same or different from research with adults? Childhood, 9(3), 321-341.

Richter, L. M., \& Desmond, C. (2008). Targeting AIDS orphans and child-headed households? A perspective from national surveys in South Africa, 1995-2005. AIDS Care, 20(9), 1019-1028.

Robson, E. (2000). Invisible carers: Young people in Zimbabwe's home-based healthcare. Area, 32(1), 59-69.

Robson, E., Ansell, N., Huber, U. S., Gould, W. T. S., \& van Blerk, L. (2006). Young caregivers in the context of the HIV/AIDS pandemic in sub-Saharan Africa. Population, Space and Place, 12(2), 93-111.

Robson, S., \& Sylvester, K. B. (2007). Orphaned and vulnerable children in Zambia: The impact of the HIV/AIDS epidemic on basic education for children at risk. Educational Research, 49(3), 259-272.

Rose, H. D., \& Cohen, K. (2010). The experiences of young carers: A meta-synthesis of qualitative findings. Journal of Youth Studies, 13(4), 473-487.

Rutter, M. (2012). Resilience as a dynamic concept. Development and psychopathology, 24(2), 335-344. 
Sandin-Esteban, M. -P., \& Sanchez-Marti, A. (2015). Resilience and school success of young immigrants / Resilienca y exito escloar en jovenes inmigrantes, infacia y Aprendizaje. Study of Education and Development, 38(1), 175-211.

Scheier, M. F., \& Carver, C. S. (1985). Optimism, coping, and health: assessment and implications of generalized outcome expectancies. Health Psychology: Official Journal of the Division of Health Psychology, American Psychological Association, 4(3), 219-247.

Siskowski, C. (2006). Young caregivers: Effect of family health situations on school performance. The Journal of School Nursing : The Official Publication of the National Association of School Nurses, 22(3), 163-169.

Skovdal, M., Campbell, C., \& Onyango, V. (2013). Supporting "young carers" in Kenya: From policy paralysis to action. Child Care in Practice, 19(4), 318-339.

Skovdal, M., Ogutu, V. O., Aoro, C., \& Campbell, C. (2009). Young carers as social actors: Coping strategies of children caring for ailing or ageing guardians in Western Kenya. Social Science \& Medicine, 69(4), 587-595.

Smyth, C., Blaxland, M., \& Cass, B. (2011). "So that's how I found out I was a young carer and that I actually had been a carer most of my life." Identifying and supporting hidden young carers. Journal of Youth Studies, 14(2), 145-160.

Stearns, E., \& Glennie, E. J. (2006). When and why dropouts leave high school. Youth \& Society, 38(1), 29-57.

Stokes, D. (1996). Translating social-ecological theory into guidelines for community health promotion. American Journal for Health Promotion, 282-298.

Tanga, P. T. (2013). The impact of the declining extended family support system on the education of orphans in Lesotho. African Journal of AIDS Research, 12(3), 173183.

The World Bank. (2005). OVC tool kit.

Retrieved from http://info.worldbank.org/etools/docs/library/162495/index.htm.

The World Bank Group. (2016). Lesotho.

Retrieved Dec 24, 2016 from http://data.worldbank.org/country/lesotho? 
Thomas, N., Stainton, T., \& Jackson, S., Cheung, W. Y., Doubtfire, S., \& Webb, A. (2003). "Your friends don't understand": Invisibility and unmet need in the lives of "young carers." Child \& Family Social Work, 8(1), 35-46.

UNAIDS. (2013). UNAIDS report on the global AIDS epidemic 2013. Retrieved December 18, 2013 from http://www.unaids.org/en/dataanalysis.

UNAIDS. (2015). UNAIDS HIV and AIDS estimates (2015). Retrieved May 09, 2017 from http://www.unaids.org/en/regionscountries/countries/lesotho

UNAIDS. (2016). Global AIDS update 2016.

Retrieved from http://www.unaids.org/en/resources/documents/2016/GlobalAIDS-update-2016.

UNESCO. (2016). Education for all goals. Retrieved December 22, 2016 from http://www.unesco.org/new/en/education/themes/leading-the-internationalagenda/education-for-all/efa-goals/

UNESCO. (2017). Education in Africa. Retrieved January 13, 2017 from http://uis.unesco.org/en/topic/education-africa.

UNESCO and UNICEF. (2015). Fixing the broken promise of education for all: Findings from the global initiative on out-of-school children. Montreal: UNESCO Institute for Statistics.

UNFPA. (2012). Marrying too young: End child marriage. Retrieved October 19, 2013 from http://www.unfpa.org/public/home/publications/pid/12166.

UNICEF. (n.d). The convention on the rights of the child. Retrieved May 25, 2015 from http://www.unicef.org/crc/files/Guiding_Principles.pdf.

UNICEF (2006). State of the world's children 2006: Excluded and invisible.

UNICEF (2011). State of the world's children 2011: Adolescents. New York.

UNICEF. (2012). Life skills: Child friendly schools. Retrieved October 18, 2016 from http://www.unicef.org/lifeskills/index_7260.html.

UNICEF. (2015). Monitoring the situation of children and women. Retrieved March 24, 2016 from http://data.unicef.org/education/secondary.html. 
University College Cork. (2014). Research at UCC. Retrieved April 21, 2014 from http://www.ucc.ie/research/rio/ethics.html.

University of Washington. Retrieved from

http://courses.washington.edu/thesis/Manual2/6_DataCollection/Focus_Group_Dis cussion_Guide.doc.

van Nes, F., Abma, T., Jonsson, H., \& Deeg, D. (2010). Language differences in qualitative research: Is meaning lost in translation? European Journal of Ageing :

Social, Behavioural and Health Perspectives, 7(4), 313-316.

Waxman, H. C., Gray, J. P., \& Padron, Y. N. (2003). Review of research on educational resilience. Research report. University of California.

Weiss, R. S. (1995). Learning from strangers: The art and method of qualitative interview studies. New York: The Free Press.

Wells, K. (2009). Childhood in a global perspective. Cambridge: Polity Press.

Westphal, T. (2016). Universal old age pension: Lesotho. Geneva: International Labor Office.

WHO. (2002). World report on violence and health. Geneva: World Health Organization.

Williams, J. M., \& Bryan, J. (2013). Overcoming adversity: High-achieving African American youth's perspectives on educational resilience. Journal of Counseling $\mathcal{E}$ Development, 91(3), 291-300.

World Food Programme. (2015). School meals. Retrieved May 30, 2015 from http://www.wfp.org/school-meals.

Yosso, T. (2005). Whose culture has capital? Race, Ethnicity, and Education 8(1), 6991.

Zimmerman, M. A., \& Arunkumar, R. (1994). Resiliency research: Implications for schools and policy (Vol. 8, pp. 1-19). University of Michigan: Society for Research in Child Development. 
ANNEXES 


\begin{tabular}{|c|c|c|c|}
\hline No. & $\begin{array}{l}\text { Brief code } \\
\text { name }\end{array}$ & $\begin{array}{l}\text { Full description of } \\
\text { code }\end{array}$ & $\begin{array}{l}\text { When to use and when not to use the } \\
\text { code }\end{array}$ \\
\hline \multicolumn{4}{|c|}{ 1.0 Reason for Caring } \\
\hline 1 & $\begin{array}{l}\text { Reason for } \\
\text { Caring }\end{array}$ & $\begin{array}{l}\text { Participant describes } \\
\text { factors that led to } \\
\text { child carer taking up } \\
\text { caregiving } \\
\text { responsibilities. }\end{array}$ & $\begin{array}{l}\text { Use this code when participant } \\
\text { describes experiences that made her } \\
\text { start caring. This can include: } \\
\text { Death of parent or guardian, } \\
\text { relocation of parent/guardian, } \\
\text { another location and relocation of } \\
\text { child to live with care recipient. }\end{array}$ \\
\hline \multicolumn{4}{|c|}{ 2.0 Caregiving Responsibilities } \\
\hline 2 & $\begin{array}{l}\text { Househol } \\
\text { d Chores }\end{array}$ & $\begin{array}{l}\text { Participant describes } \\
\text { domestic work } \\
\text { carried out around } \\
\text { the home. }\end{array}$ & $\begin{array}{l}\text { Use this code when participant } \\
\text { describes household activities she } \\
\text { engages in to care for herself and } \\
\text { other household members. This can } \\
\text { include: } \\
\text { Sweeping the house, fetching water, } \\
\text { heating water, fetching firewood, } \\
\text { cooking, washing clothes and } \\
\text { washing dishes, working in the } \\
\text { garden or field, plastering walls. } \\
\text { Also include tasks that a girl carer } \\
\text { performs in other houses where } \\
\text { family members occupy. } \\
\text { Do not use when child carer is } \\
\text { working for other people to earn } \\
\text { income, or for food. }\end{array}$ \\
\hline 3 & $\begin{array}{l}\text { Intimate } \\
\text { Care }\end{array}$ & $\begin{array}{l}\text { Participants describe } \\
\text { situation where care }\end{array}$ & $\begin{array}{l}\text { Use this code for statements where } \\
\text { participant describes: }\end{array}$ \\
\hline
\end{tabular}




\begin{tabular}{|c|c|c|c|}
\hline No. & $\begin{array}{l}\text { Brief code } \\
\text { name }\end{array}$ & $\begin{array}{l}\text { Full description of } \\
\text { code }\end{array}$ & $\begin{array}{l}\text { When to use and when not to use the } \\
\text { code }\end{array}$ \\
\hline & & $\begin{array}{l}\text { recipient is incapable } \\
\text { of looking after } \\
\text { themselves due to } \\
\text { illness, disability or } \\
\text { age. }\end{array}$ & $\begin{array}{l}\text { - Looking after a sick individual } \\
\text { in the home. } \\
\text { - } \quad \text { Bathing or preparing; getting } \\
\text { family member in home. } \\
\text { - Taking care recipient to hospital. } \\
\text { Examples: } \\
\text { "...then I would give my younger } \\
\text { brother a bath, and the other one." } \\
\text { "After preparing porridge for my } \\
\text { grandmother [...] then I help my } \\
\text { grandmother bath." }\end{array}$ \\
\hline 4 & $\begin{array}{l}\text { Earning } \\
\text { Income to } \\
\text { Support } \\
\text { Care } \\
\text { Recipients }\end{array}$ & $\begin{array}{l}\text { Situation where child } \\
\text { carer is involved in } \\
\text { some form of work } \\
\text { outside the home for } \\
\text { pay or, in exchange } \\
\text { for food and other } \\
\text { items, to help with } \\
\text { caring } \\
\text { responsibilities. }\end{array}$ & $\begin{array}{l}\text { Use code when participant describes } \\
\text { work outside the home, such as } \\
\text { working for neighbors, working in } \\
\text { other people's fields, selling fruit, } \\
\text { food for work, plastering homes and } \\
\text { washing clothes for others. }\end{array}$ \\
\hline 5 & $\begin{array}{l}\text { Seeking } \\
\text { Help for } \\
\text { Caregivin } \\
\mathrm{g} \\
\text { Responsib } \\
\text { ilities }\end{array}$ & $\begin{array}{l}\text { Participant's } \\
\text { reference to child } \\
\text { carer asking for help } \\
\text { with caring for her } \\
\text { household members. }\end{array}$ & $\begin{array}{l}\text { Use code when participant describes } \\
\text { child carer seeking help from } \\
\text { neighbors or family members outside } \\
\text { the household with food, transport, } \\
\text { money and security. } \\
\text { Example: "if we don't have food, I go and } \\
\text { ask for help from other people, like our } \\
\text { neighbors, who sometimes give us if they } \\
\text { have." }\end{array}$ \\
\hline 6 & $\begin{array}{l}\text { Other } \\
\text { Parenting } \\
\text { Responsib } \\
\text { ilities }\end{array}$ & $\begin{array}{l}\text { Participant reference } \\
\text { to responsibilities } \\
\text { over care recipients } \\
\text { that are outside the } \\
\text { home. }\end{array}$ & $\begin{array}{l}\text { Participant reference to } \\
\text { responsibilities over care recipients } \\
\text { that are outside the home. This may } \\
\text { include: homework supervision and } \\
\text { attending PTA meetings. }\end{array}$ \\
\hline
\end{tabular}




\begin{tabular}{|c|c|c|c|}
\hline No. & $\begin{array}{l}\text { Brief code } \\
\text { name }\end{array}$ & $\begin{array}{l}\text { Full description of } \\
\text { code }\end{array}$ & $\begin{array}{l}\text { When to use and when not to use the } \\
\text { code }\end{array}$ \\
\hline \multicolumn{4}{|c|}{ 3.0 Individual Factors Influencing Girls' Regular School Attendance } \\
\hline 7 & Vision & $\begin{array}{l}\text { Participant's } \\
\text { reference to future } \\
\text { aspirations or plans, } \\
\text { either in terms of } \\
\text { education attainment, } \\
\text { career or lifestyle. } \\
\text { This also includes } \\
\text { any description of } \\
\text { what the child carer } \\
\text { does not want to } \\
\text { become. }\end{array}$ & $\begin{array}{l}\text { Use this code for statements that: } \\
\text { - } \quad \text { Provide a general description of } \\
\text { how they envision a better life in } \\
\text { the future. } \\
\text { - Articulate career plans whether } \\
\text { there is a clear pathway or an } \\
\text { indication of the type of job they } \\
\text { envision. } \\
\text { Passing exams or graduating to } \\
\text { get admitted to tertiary } \\
\text { institutions. } \\
\text { How they intend to look after } \\
\text { their own children/families in } \\
\text { future. }\end{array}$ \\
\hline 8 & $\begin{array}{l}\text { Future } \\
\text { Caring } \\
\text { Responsib } \\
\text { ilities }\end{array}$ & $\begin{array}{l}\text { The role of caregiver } \\
\text { is seen to continue in } \\
\text { future. }\end{array}$ & $\begin{array}{l}\text { Use this code where participant } \\
\text { describes: } \\
\text { - How they would like to take care } \\
\text { of their care recipients in the } \\
\text { future. } \\
\text { - Being able to improve the quality } \\
\text { of care for the people she cares } \\
\text { for now. } \\
\text { - Mentions reciprocating care. } \\
\text { E.g. "...I can have a better future in } \\
\text { order to also help people who are } \\
\text { helping me today." }\end{array}$ \\
\hline \multicolumn{4}{|c|}{ 3.3 Role Models } \\
\hline 9 & $\begin{array}{l}\text { Positive } \\
\text { Role } \\
\text { Models }\end{array}$ & $\begin{array}{l}\text { Person or persons } \\
\text { who a child caregiver } \\
\text { looks up to, and } \\
\text { aspires to be like } \\
\text { them. }\end{array}$ & $\begin{array}{l}\text { Use this code where the term role } \\
\text { model is used. } \\
\text { Also can be used when participant } \\
\text { identifies an individual or individuals } \\
\text { that they would like to emulate. } \\
\text { These can be known or unknown. } \\
\text { Role model can be a peer or older }\end{array}$ \\
\hline
\end{tabular}




\begin{tabular}{|c|c|c|c|}
\hline No. & $\begin{array}{l}\text { Brief code } \\
\text { name }\end{array}$ & $\begin{array}{l}\text { Full description of } \\
\text { code }\end{array}$ & $\begin{array}{l}\text { When to use and when not to use the } \\
\text { code }\end{array}$ \\
\hline & & & $\begin{array}{l}\text { family member or non-family } \\
\text { member. E.g. "The way I look at other } \\
\text { students and how they live. I want to get } \\
\text { educated so that I can change my life } \\
\text { because I am the one who can change the } \\
\text { whole situation." }\end{array}$ \\
\hline 10 & $\begin{array}{l}\text { Negative } \\
\text { Role } \\
\text { Models }\end{array}$ & $\begin{array}{l}\text { When a participant } \\
\text { refers to a person or } \\
\text { persons who a child } \\
\text { caregiver would not } \\
\text { like to be like or } \\
\text { emulate. }\end{array}$ & $\begin{array}{l}\text { Use this code where a participant } \\
\text { refers to an identified person or } \\
\text { persons that the caregiver would not } \\
\text { like to emulate or be like in future, eg. } \\
\text { "I come to school so that I can have a } \\
\text { good life and not be like my parents." }\end{array}$ \\
\hline 11 & $\begin{array}{l}\text { Academic } \\
\text { Performan } \\
\text { ce }\end{array}$ & $\begin{array}{l}\text { Participant refers to } \\
\text { child carers' school } \\
\text { performance as the } \\
\text { reason for attending } \\
\text { school. }\end{array}$ & $\begin{array}{l}\text { Use this code where a participant } \\
\text { refers to good school performance as } \\
\text { the motivation to keep going to } \\
\text { school. }\end{array}$ \\
\hline 12 & Faith & $\begin{array}{l}\text { Participant identifies } \\
\text { religious belief and } \\
\text { religious bodies as } \\
\text { supportive factors. }\end{array}$ & $\begin{array}{l}\text { Use this code when a respondent } \\
\text { describes how being involved in } \\
\text { religious activities motivates her. This } \\
\text { could be counseling, emotional } \\
\text { support or prayer. } \\
\text { Example: "We are told to pray to God } \\
\text { and trust in him because we will succeed } \\
\text { in life." } \\
\text { Do not use when respondent goes to } \\
\text { church but does not identify any form } \\
\text { of support. }\end{array}$ \\
\hline 13 & $\begin{array}{l}\text { Self- } \\
\text { Motivatio } \\
\mathrm{n}\end{array}$ & $\begin{array}{l}\text { Participant refers to a } \\
\text { child carer being } \\
\text { motivated by herself } \\
\text { to attend school. }\end{array}$ & $\begin{array}{l}\text { Use this code when participant refers } \\
\text { to a child carer being self-motivated } \\
\text { or has an inner drive to keep } \\
\text { attending school. }\end{array}$ \\
\hline 14 & $\begin{array}{l}\text { Seeking } \\
\text { Support }\end{array}$ & $\begin{array}{l}\text { Participant describes } \\
\text { child carer asking } \\
\text { someone for help. }\end{array}$ & $\begin{array}{l}\text { Use this code when a participant } \\
\text { mentions that the child carer is } \\
\text { seeking help from someone else. }\end{array}$ \\
\hline
\end{tabular}




\begin{tabular}{|c|c|c|c|}
\hline No. & $\begin{array}{l}\text { Brief code } \\
\text { name }\end{array}$ & $\begin{array}{l}\text { Full description of } \\
\text { code }\end{array}$ & $\begin{array}{l}\text { When to use and when not to use the } \\
\text { code }\end{array}$ \\
\hline & & & $\begin{array}{l}\text { This can be used when a child carer } \\
\text { asks for food, materials items, work } \\
\text { or help with caregiving } \\
\text { responsibilities. }\end{array}$ \\
\hline \multicolumn{4}{|c|}{$\begin{array}{l}\text { 4.0 Family Factors: Family can be Living in the Household or Away from the } \\
\text { Household. Immediate or Extended Family }\end{array}$} \\
\hline 15 & $\begin{array}{l}\text { Financial } \\
\text { Support }\end{array}$ & $\begin{array}{l}\text { Family member pays } \\
\text { school fees or gives } \\
\text { money to child } \\
\text { caregiver to pay for } \\
\text { caregiver money to } \\
\text { run the house. }\end{array}$ & $\begin{array}{l}\text { Use this code when a participant } \\
\text { mentions family member as one who } \\
\text { pays school fees, or buys school } \\
\text { uniform and other requirements. The } \\
\text { family member can be living with the } \\
\text { child e.g. grandparent, or living in } \\
\text { different area. } \\
\text { Also use this code when a participant } \\
\text { makes reference to a family member } \\
\text { sending money for use at home or } \\
\text { school. }\end{array}$ \\
\hline 16 & $\begin{array}{l}\text { Family: } \\
\text { Other } \\
\text { Material } \\
\text { Support }\end{array}$ & $\begin{array}{l}\text { When a family } \\
\text { member provides } \\
\text { tangible items such as } \\
\text { food and other } \\
\text { household items }\end{array}$ & $\begin{array}{l}\text { Use the code when participants } \\
\text { describe items they receive from } \\
\text { family members. }\end{array}$ \\
\hline 17 & $\begin{array}{l}\text { Caregivin } \\
\text { g Support }\end{array}$ & $\begin{array}{l}\text { When family } \\
\text { members help the } \\
\text { child carer with } \\
\text { household } \\
\text { responsibilities. }\end{array}$ & $\begin{array}{l}\text { Use the code when participant } \\
\text { describes how family members help } \\
\text { with household chores or looking } \\
\text { after care recipients (e.g. other } \\
\text { siblings, grandparent etc). }\end{array}$ \\
\hline 18 & $\begin{array}{l}\text { Family } \\
\text { Motivatio } \\
\mathrm{n}\end{array}$ & $\begin{array}{l}\text { Participants describe } \\
\text { family members who } \\
\text { said encouraging } \\
\text { words or gave advice } \\
\text { to child carers to stay } \\
\text { in school. }\end{array}$ & $\begin{array}{l}\text { Use this code when participants } \\
\text { mention family members who } \\
\text { encourage them to stay in school, or } \\
\text { reassures them that things will get } \\
\text { better. } \\
\text { Can also be used when a family } \\
\text { member is said to listen or discuss the }\end{array}$ \\
\hline
\end{tabular}




\begin{tabular}{|c|c|c|c|}
\hline No. & $\begin{array}{l}\text { Brief code } \\
\text { name }\end{array}$ & $\begin{array}{l}\text { Full description of } \\
\text { code }\end{array}$ & $\begin{array}{l}\text { When to use and when not to use the } \\
\text { code }\end{array}$ \\
\hline & & & $\begin{array}{l}\text { child carer's problems. } \\
\text { Example: } \\
\text { "They always motivate me, they give me } \\
\text { strength. They advise me to go to school } \\
\text { so that I can have a brighter future." }\end{array}$ \\
\hline 19 & $\begin{array}{l}\text { Help with } \\
\text { School } \\
\text { Work }\end{array}$ & $\begin{array}{l}\text { Participants describe } \\
\text { family members who } \\
\text { help the child carer } \\
\text { with school work. }\end{array}$ & $\begin{array}{l}\text { Use this code when participants } \\
\text { identify family members who help } \\
\text { the child carer with school work. }\end{array}$ \\
\hline \multicolumn{4}{|c|}{ 5.0 School Factors that contribute to child carer regular school attendance } \\
\hline 20 & $\begin{array}{l}\text { Conduciv } \\
\text { e School } \\
\text { Environm } \\
\text { ent }\end{array}$ & $\begin{array}{l}\text { Participants describe } \\
\text { school policies, } \\
\text { practices or } \\
\text { environment that } \\
\text { helps child carers } \\
\text { attend school. }\end{array}$ & $\begin{array}{l}\text { Use this code for reference when } \\
\text { school policies, practices, or } \\
\text { environment are said to keep the } \\
\text { child attending school. } \\
\text { Can be used when the participant } \\
\text { mentions flexibility of school to } \\
\text { accept children that had stayed away, } \\
\text { when there is special consideration } \\
\text { for vulnerable children. } \\
\text { Can also use the code when school is } \\
\text { mentioned as providing a place for } \\
\text { children to play, for extracurricular } \\
\text { activities. } \\
\text { Example: They come to school and forget } \\
\text { those things for at least eight hours and } \\
\text { then go back later. }\end{array}$ \\
\hline
\end{tabular}




\begin{tabular}{|c|c|c|c|}
\hline No. & $\begin{array}{l}\text { Brief code } \\
\text { name }\end{array}$ & $\begin{array}{l}\text { Full description of } \\
\text { code }\end{array}$ & $\begin{array}{l}\text { When to use and when not to use the } \\
\text { code }\end{array}$ \\
\hline 21 & $\begin{array}{l}\text { School } \\
\text { Material } \\
\text { and } \\
\text { Financial } \\
\text { Support }\end{array}$ & $\begin{array}{l}\text { Reference to how } \\
\text { school facilitates } \\
\text { material and financial } \\
\text { support to the child } \\
\text { carer. }\end{array}$ & $\begin{array}{l}\text { Use this code when the participant } \\
\text { mentions support provided by the } \\
\text { school or through the school. } \\
\text { This could include sponsorship, } \\
\text { scholarship and school uniform. } \\
\text { This could also include school } \\
\text { feeding }\end{array}$ \\
\hline \multicolumn{4}{|c|}{ 5.3 Teacher Support } \\
\hline 22 & $\begin{array}{l}\text { Teacher } \\
\text { Financial/ } \\
\text { Material } \\
\text { Support }\end{array}$ & $\begin{array}{l}\text { Participant describes } \\
\text { support from a } \\
\text { teacher which is } \\
\text { either in monetary } \\
\text { form, material items } \\
\text { or has paid for } \\
\text { services. }\end{array}$ & $\begin{array}{l}\text { Use this code when the participant } \\
\text { describes any payment a teacher } \\
\text { makes to help a child carer. This can } \\
\text { be school fees, medical fees for child } \\
\text { carer or a care-recipient and } \\
\text { transport. } \\
\text { Use the code when the participant } \\
\text { describes tangible items such as food, } \\
\text { clothes and toiletries. }\end{array}$ \\
\hline 23 & $\begin{array}{l}\text { Teacher } \\
\text { Motivatio } \\
\mathrm{n} \text { and } \\
\text { Emotional } \\
\text { Support }\end{array}$ & $\begin{array}{l}\text { Participant describes } \\
\text { teachers encouraging } \\
\text { child carer to stay in } \\
\text { school and giving } \\
\text { advice. }\end{array}$ & $\begin{array}{l}\text { Use this code when participants } \\
\text { mention a teacher who provides } \\
\text { counseling, encourages them to stay } \\
\text { in school, or reassures them of a } \\
\text { brighter future. } \\
\text { Can also be used when a teacher is } \\
\text { said to listen or discuss the child } \\
\text { carer's problems. }\end{array}$ \\
\hline \multicolumn{4}{|c|}{ 5.4 School Peers } \\
\hline 24 & $\begin{array}{l}\text { Peers } \\
\text { Material } \\
\text { support }\end{array}$ & $\begin{array}{l}\text { Participant describes } \\
\text { friends, classmates or } \\
\text { other school children } \\
\text { from within the } \\
\text { school providing } \\
\text { tangible items. }\end{array}$ & $\begin{array}{l}\text { Use code when participant describes } \\
\text { receiving tangible items such as food, } \\
\text { clothes, school stationary or toiletries } \\
\text { from another learner. }\end{array}$ \\
\hline
\end{tabular}




\begin{tabular}{|l|l|l|l|}
\hline No. & $\begin{array}{l}\text { Brief code } \\
\text { name }\end{array}$ & $\begin{array}{l}\text { Full description of } \\
\text { code }\end{array}$ & $\begin{array}{l}\text { When to use and when not to use the } \\
\text { code }\end{array}$ \\
\hline 25 & $\begin{array}{l}\text { Peers } \\
\text { Emotional } \\
\text { Support }\end{array}$ & $\begin{array}{l}\text { Participant describes } \\
\text { school peers who } \\
\text { take time to listen } \\
\text { and encourage child } \\
\text { carer to attend } \\
\text { school. }\end{array}$ & $\begin{array}{l}\text { Use this code when participants } \\
\text { mention peers who listen to their } \\
\text { problems and encourage them to stay } \\
\text { in school, or reassure them of a } \\
\text { brighter future. }\end{array}$ \\
\hline 26 & $\begin{array}{l}\text { Peer } \\
\text { Support } \\
\text { with } \\
\text { School } \\
\text { Work }\end{array}$ & $\begin{array}{l}\text { Participant describes } \\
\text { how other students } \\
\text { help the child carer } \\
\text { with academic work. }\end{array}$ & $\begin{array}{l}\text { Use this code when participant } \\
\text { mentions academic support from } \\
\text { another student. }\end{array}$ \\
\hline $\begin{array}{l}\text { S.0 Community Factors that Contribute to a Female Child Carer's Regular } \\
\text { School Attendance }\end{array}$ & $\begin{array}{l}\text { Expectation } \\
\text { from the } \\
\text { Community }\end{array}$ & $\begin{array}{l}\text { Participants } \\
\text { describe } \\
\text { community } \\
\text { members' } \\
\text { expectation of the } \\
\text { child carer to } \\
\text { attend school } \\
\text { regularly. }\end{array}$ & $\begin{array}{l}\text { Use this code when the participant } \\
\text { mentions community members' } \\
\text { expectation of child carer to attend } \\
\text { school. }\end{array}$ \\
\hline 27 & & \\
\hline
\end{tabular}




\begin{tabular}{|c|c|c|c|}
\hline No. & $\begin{array}{l}\text { Brief code } \\
\text { name }\end{array}$ & $\begin{array}{l}\text { Full description of } \\
\text { code }\end{array}$ & $\begin{array}{l}\text { When to use and when not to use the } \\
\text { code }\end{array}$ \\
\hline 28 & $\begin{array}{l}\text { Community } \\
\text { Leadership }\end{array}$ & $\begin{array}{l}\text { Participants' } \\
\text { description of } \\
\text { community or } \\
\text { village leaders } \\
\text { who support the } \\
\text { child carer. }\end{array}$ & $\begin{array}{l}\text { Use this code if there is mention of } \\
\text { village chiefs organizing support for } \\
\text { child carers. } \\
\text { This could include facilitating } \\
\text { linkages with NGOs and schools etc. } \\
\text { for access to school scholarships and } \\
\text { material support. }\end{array}$ \\
\hline 29 & $\begin{array}{l}\text { Community } \\
\text { Groups }\end{array}$ & $\begin{array}{l}\text { Participants' } \\
\text { description of } \\
\text { people, or } \\
\text { structures, within } \\
\text { the community or } \\
\text { village that } \\
\text { support or do not } \\
\text { support child } \\
\text { carers. }\end{array}$ & $\begin{array}{l}\text { Use this code when participants } \\
\text { describe community structures, such } \\
\text { as community- based organizations, } \\
\text { support groups, or non-governmental } \\
\text { organizations (NGOs) who provide } \\
\text { any form of help. } \\
\text { Do not use when there is reference to } \\
\text { support from church. }\end{array}$ \\
\hline 30 & $\begin{array}{l}\text { Religious } \\
\text { Groups }\end{array}$ & $\begin{array}{l}\text { Participants' } \\
\text { description of } \\
\text { religious bodies } \\
\text { that support child } \\
\text { carers. }\end{array}$ & $\begin{array}{l}\text { Use this code when participants } \\
\text { describe support provided by church } \\
\text { groups or individuals. This can be } \\
\text { material, emotional or financial. } \\
\text { Do not use if participant only } \\
\text { mentions church attendance, but does } \\
\text { not identify how the child benefits. }\end{array}$ \\
\hline 31 & Neighbors & $\begin{array}{l}\text { Participant } \\
\text { reference to non- } \\
\text { family members } \\
\text { living within close } \\
\text { proximity to the } \\
\text { child carers. }\end{array}$ & $\begin{array}{l}\text { Use the code when participant refers } \\
\text { to a neighbor who provides, or does } \\
\text { not provide, some form of help to the } \\
\text { child caregiver. This can be material, } \\
\text { financial or emotional support to the } \\
\text { child caregiver. }\end{array}$ \\
\hline
\end{tabular}




\begin{tabular}{|c|c|c|c|}
\hline No. & $\begin{array}{l}\text { Brief code } \\
\text { name }\end{array}$ & $\begin{array}{l}\text { Full description of } \\
\text { code }\end{array}$ & $\begin{array}{l}\text { When to use and when not to use the } \\
\text { code }\end{array}$ \\
\hline & & & $\begin{array}{l}\text { Also use when neighbors are said to } \\
\text { provide opportunities for the child } \\
\text { carer to work in their fields or home. } \\
\text { Use when there is reference to } \\
\text { neighbors who do not provide } \\
\text { support and reason for not providing } \\
\text { support. }\end{array}$ \\
\hline 32 & $\begin{array}{l}\text { Government } \\
\text { Support }\end{array}$ & $\begin{array}{l}\text { Participant } \\
\text { reference to } \\
\text { financial or } \\
\text { material support } \\
\text { received from the } \\
\text { government to } \\
\text { attend school. }\end{array}$ & $\begin{array}{l}\text { Use this code when the participant } \\
\text { mentions scholarship, bursaries or } \\
\text { cash grants. }\end{array}$ \\
\hline 33 & $\begin{array}{l}\text { External } \\
\text { Support }\end{array}$ & $\begin{array}{l}\text { Participant refers } \\
\text { to financial or } \\
\text { material support } \\
\text { given to child carer } \\
\text { by organizations } \\
\text { outside the } \\
\text { community. }\end{array}$ & $\begin{array}{l}\text { Use this code when the participant } \\
\text { refers to NGOs or donors having } \\
\text { provided scholarships, material } \\
\text { support or financial support for the } \\
\text { child carer to attend school or to } \\
\text { support the household. }\end{array}$ \\
\hline \multicolumn{4}{|c|}{ 7.0 Challenges } \\
\hline \multicolumn{4}{|c|}{ 7.1 Caregiving Challenges } \\
\hline 34 & $\begin{array}{l}\text { Providing } \\
\text { Intimate } \\
\text { Care }\end{array}$ & $\begin{array}{l}\text { Problems related to } \\
\text { providing care to the } \\
\text { sick, elderly or very } \\
\text { young children when } \\
\text { they are incapable of } \\
\text { doing so themselves. }\end{array}$ & $\begin{array}{l}\text { Use the code when participant } \\
\text { describes problems related to } \\
\text { providing hands-on care to care } \\
\text { recipient. For example, bathing, } \\
\text { feeding and dressing up. }\end{array}$ \\
\hline
\end{tabular}




\begin{tabular}{|c|c|c|c|}
\hline No. & $\begin{array}{l}\text { Brief code } \\
\text { name }\end{array}$ & $\begin{array}{l}\text { Full description of } \\
\text { code }\end{array}$ & $\begin{array}{l}\text { When to use and when not to use the } \\
\text { code }\end{array}$ \\
\hline 35 & $\begin{array}{l}\text { Managing } \\
\text { the } \\
\text { Househol } \\
\text { d }\end{array}$ & $\begin{array}{l}\text { Having to find } \\
\text { solutions to problems } \\
\text { the family is facing. }\end{array}$ & $\begin{array}{l}\text { Use the code when the participant } \\
\text { describes the problems a child carer } \\
\text { faces to manage the household in } \\
\text { general. Use when there is reference } \\
\text { to challenges in finding food, or other } \\
\text { items for the household. } \\
\text { "What challenges me the most is when I } \\
\text { have to think about how we will get } \\
\text { things that we need when we run out } \\
\text { because I struggle to think about what we } \\
\text { will eat every day." }\end{array}$ \\
\hline 36 & $\begin{array}{l}\text { Other } \\
\text { Parenting } \\
\text { Responsib } \\
\text { ilities }\end{array}$ & $\begin{array}{l}\text { Problems a child } \\
\text { carer faces with } \\
\text { taking up other } \\
\text { parenting } \\
\text { responsibilities. }\end{array}$ & $\begin{array}{l}\text { Use the code when a participant } \\
\text { describes as a problem other } \\
\text { parenting duties, such as representing } \\
\text { care recipient at school meetings, } \\
\text { having to instill, for example: } \\
\text { "The challenge that I have is that } \\
\text { sometimes my sibling would have a fight } \\
\text { with another student and she would not } \\
\text { report the case to the teachers but tell } \\
\text { me." }\end{array}$ \\
\hline 37 & $\begin{array}{l}\text { Food and } \\
\text { other } \\
\text { Material } \\
\text { Supplies }\end{array}$ & $\begin{array}{l}\text { Participants' } \\
\text { reference to a child } \\
\text { carer not having } \\
\text { food, complains of } \\
\text { hunger, lacks other } \\
\text { items needed in the } \\
\text { home and has no } \\
\text { money to run the } \\
\text { home. }\end{array}$ & $\begin{array}{l}\text { Use this code when the participant } \\
\text { refers to a child carer not having } \\
\text { sufficient food and other material } \\
\text { supplies for the household. } \\
\text { Do not use this code for school fees. }\end{array}$ \\
\hline
\end{tabular}




\begin{tabular}{|c|c|c|c|}
\hline No. & $\begin{array}{l}\text { Brief code } \\
\text { name }\end{array}$ & $\begin{array}{l}\text { Full description of } \\
\text { code }\end{array}$ & $\begin{array}{l}\text { When to use and when not to use the } \\
\text { code }\end{array}$ \\
\hline 38 & Protection & $\begin{array}{l}\text { Participant raises } \\
\text { issues of child carer's } \\
\text { safety or abuse. }\end{array}$ & $\begin{array}{l}\text { Use this code when a participant } \\
\text { mentions that a child carer's safety is } \\
\text { at risk. } \\
\text { Use this code when there is reference } \\
\text { to a child being abused, or there is } \\
\text { risk of someone breaking into the } \\
\text { child carer's house. }\end{array}$ \\
\hline \multicolumn{4}{|c|}{ 7.3 School Related Challenges } \\
\hline 39 & $\begin{array}{l}\text { Missing } \\
\text { School }\end{array}$ & $\begin{array}{l}\text { Participant identifies } \\
\text { factors that make } \\
\text { child carer miss } \\
\text { school. }\end{array}$ & $\begin{array}{l}\text { Use this code when a participant } \\
\text { describes reasons for child carer } \\
\text { missing school, eg. illness, caring for } \\
\text { household member, going to collect } \\
\text { pension etc. } \\
\text { Do not use for financial problems } \\
\text { relating to school attendance. }\end{array}$ \\
\hline 40 & $\begin{array}{l}\text { Time } \\
\text { Factor }\end{array}$ & $\begin{array}{l}\text { Participant describes } \\
\text { the difficulty of } \\
\text { combining caregiving } \\
\text { responsibilities and } \\
\text { combining school } \\
\text { work. }\end{array}$ & $\begin{array}{l}\text { Use this code when the participant } \\
\text { describes how school work is affected } \\
\text { due to caregiving responsibilities. E.g. } \\
\text { "What troubles me most is that } \\
\text { sometimes I would be given homework } \\
\text { and I don't have a chance to do it because } \\
\text { I have to cook" }\end{array}$ \\
\hline 41 & $\begin{array}{l}\text { School } \\
\text { Fees and } \\
\text { Materials }\end{array}$ & $\begin{array}{l}\text { Participant identifies } \\
\text { a lack of finances and } \\
\text { material needs as an } \\
\text { area of concern. }\end{array}$ & $\begin{array}{l}\text { Use this code to refer to any financial } \\
\text { issues identified that prevent the } \\
\text { child from attending school. } \\
\text { Also use this code when financial } \\
\text { issues affect caregiving } \\
\text { responsibilities at home. } \\
\text { Example: "There are times when the } \\
\text { principal would expel us because we } \\
\text { haven't paid school fees. I really hate that } \\
\text { because it makes me miss classes." }\end{array}$ \\
\hline
\end{tabular}




\begin{tabular}{|l|l|l|l|}
\hline No. & $\begin{array}{l}\text { Brief code } \\
\text { name }\end{array}$ & $\begin{array}{l}\text { Full description of } \\
\text { code }\end{array}$ & $\begin{array}{l}\text { When to use and when not to use the } \\
\text { code }\end{array}$ \\
\hline 42 & $\begin{array}{l}7.3 .4 \\
\text { Worrying } \\
\text { while at } \\
\text { school } \\
\text { worrying about } \\
\text { caregiving problems } \\
\text { while at school. }\end{array}$ & $\begin{array}{l}\text { Use this code when participant talks } \\
\text { about a child carer worrying about } \\
\text { care recipients or caring } \\
\text { responsibilities while at school, eg. }\end{array}$ \\
\hline 43 & $\begin{array}{l}7.4 \\
\text { Protection }\end{array}$ & $\begin{array}{l}\text { "Hey, it causes a lot of stress because, like } \\
\text { nown, I'm being in school and I know that } \\
\text { reference to problems I left home, there was no food for } \\
\text { affecting the safety of } \\
\text { child carers. }\end{array}$ & $\begin{array}{l}\text { Use this code for: } \\
\text { the child." } \\
\text { security at home. } \\
\text { - Problems related to physical or } \\
\text { emotional abuse. }\end{array}$ \\
\hline
\end{tabular}




\section{Annex 2: Ministry of Education and Training Approval}

29 October, 2014

The Principal Secretary

Ministry of Education and Training

Maseru

Lesotho

Dear Sir/Madam,

RE: Request for Approval to Conduct Academic Research in Two Secondary $\underline{\text { Schools }}$

I am a PhD student at the Maastricht Graduate School of Governance in The Netherlands in the process of collecting data for my doctoral thesis. The topic of my research is "Child Carers and Secondary Schooling: Factors that facilitate school attendance for girl child carers." I am interested in exploring the resilience factors that keep girl child carers attending school despite the adverse situation they may be experiencing. Details of the study are explained in the enclosed proposal.

In order to understand this issue, I plan to conduct interviews with 10 girl child carers attending form D or E from one urban secondary school in Maseru (XX High School) and another 10 girl child carers from one rural secondary school in Maseru (XX High School). I will in addition seek the views of school teachers on what they think are the factors that keep these girls attending school.

The information gathered from this research is purely for academic purposes and will not be used in any other way. All respondents will sign a consent form that clearly articulates that participation in this research is voluntary and the respondents have the right to stop at any time. The research is confidential and no name or identifiers will be attached to the responses.

The purpose of this letter is to seek your approval for me to conduct interviews at the two schools. Should you need further information please feel free to call me on $x x x x$ or email be on xxxx or contact my research assistant Mme Puseletso Phori on $x x x$.

Yours Sincerely, 
USAIt) Sousthem Africa

Regional HIVIAIISS Program

P.O. $13 \times 43$

Pretoria, South Africa

24) October, 2014

The Principal Secretary

Ministry of Fducation and Training

Maseru

l.esotho

Dear SiriMadam.

BE: Rsumest for Anproyal te Conduct Acudenie. Research in Two Siscojdery. Scliools

I am a PhD student at the Mastricht Graduate Schesol of Covernance in The Netheritands in the process of collecting data for my doctoral thesis. The topic of my research is "Child Curers and Secondary Selvooling: lactors that facilitate sehoot attentance for girl child carers." I am interested in exploring the resilicnce factors that keep girl child carers attcinding school despite the adversc situation the' may be experiencing. Details of the study are explained in the enclosed proposal.

In order to understand this issuc, I plan to conduet interviews with 10 girl child carers autending form $\mathrm{D}$ or $\mathrm{F}$ from one urbun secoadary schood in Masuru (e

Sehool) and another 10 girl child ceners from one rural weondary school in Masesu (C Digh School). ( will in addition seck the views of scheol teachers on what they think are the factors that kecp these giris attending sclaoul.

The information gathered from this research is purely for academic purposes and will not be used in any other way. All respondents will sign a consent form thut clearly articulates that participation in this research ts volum ary and the respondents have the right to stop at any line. "The rexearch is conifidential and no name or identifiers will be attached to the responses.

The purpose of this letier is to sech your approval fior me to conduct interviews at the two schools. Should you need further information please feel free to call me on 127

sor conail be on

Puscletso Phori on +266

or contact my research assistant Mme

Yours Sincerely,

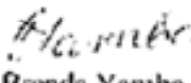

Brenda Yamba
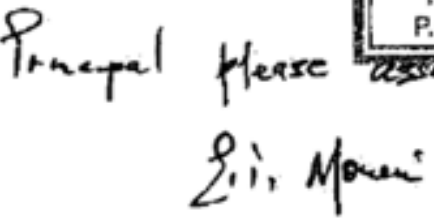

MINISTAY OF EDUCATION CENTRAL INSPECTOAATE

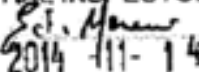

TEL.: 22322846/22313828

P.O. BOX 47, MASERU 100

assars in eveny way fosenble.

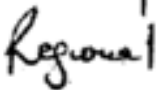

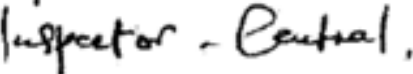




\section{Annex 3: Ministry of Social Development Approval}

USAID Southern Africa

Regional HIV/AIDS Program

P.O. Box 43, Pretoria, South Africa

29 October, 2014

The Principal Secretary

Ministry of Social Development

Maseru

Lesotho

Dear Mme Chisepo,

\section{RE: Request for Approval to Conduct Academic Research in Two Communities}

I am a PhD student at the Maastricht Graduate School of Governance in The Netherlands in the process of collecting data for my doctoral thesis. The topic of my research is "Child Carers and Secondary Schooling: Factors that facilitate school attendance for girl child carers." I am interested in exploring the resilience factors that keep girl child carers attending school despite the adverse situation they may be experiencing. Details of the study are explained in the enclosed proposal.

In order to understand this issue, I plan to conduct interviews and focus group discussions with girl child carers who are in and those out-of-school as well as some members of their households and community based organizations. Details of the interview list is attached as an annex in the proposal.

The information gathered from this research is purely for academic purposes and will not be used in any other way. All respondents will sign a consent form that clearly articulates that participation in this research is voluntary and the respondents have the right to stop at any time. The research is confidential and no name or identifiers will be attached to the responses.

The purpose of this letter is to seek your approval for me to conduct the interviews at community level. Should you need further information please feel free to call me on xxxx or email be on xxxx or my research assistant Mme Puseletso Phori on xxxx. 
USAID Southem A frica

Regina! HIV/AIDS Progrnum

P.0. Box 43

Prcieria, South Africa

290 ctober, 201.1

The Principal Secrelary

Ministry of Social Developinent

Maseni

Lesndio

Dear Mme Chisepo.

\section{Rl: Revess for Anomol is Conduct Academic Retearch in Two Comenumities}

I am a PhD student at the Mastricht Graduats School of Governance in The Nctherlands in the process of collecting data for my doctoral thesis. The lopic of my research is "Child Carers and Secundary Schonling: Factors that facilitale school attendance for gid chill carcrs." I am interested in exploting the resilicuce factors that keep girl child carers attending seheol despite the advore silaztion thes may be experiencing. Details of the stedy are explained in the enclosed proposal.

In order to understand this issue, I plan to conduct intervieus and focus group discussions with girl child carers who are $i$ and these oet-of-school as wetl as some meinbers of their huwsehold and commuaity based aryanizations. Dealails of the interview list is artached as an anuex in the proposal.

The information gathered from this reseirch is purcly for axadenic purposes and will not be used in uny cther way. All respondents will siga a conscat form that clearly antictulates that participolion in this research is voluntary and the respondents have the rigit io stop at any tiane. 'The research is onefidential and no name or identifiers will be atuached to the responses.

The perpose of this letier is to seck your approval for me to conduct the imervieus at conmunity level. Should you need further infomation please foel free to eall me $00+27$ teroment enail he on or my research nssisant Mine

Yours Sincersly,

Aleter:

Brenda Yambe

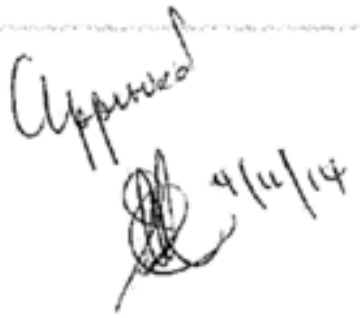




\section{Annex 4: Child Consent Form ${ }^{17}$}

\section{University of Maastricht \\ School of Policy and Governance \\ Child Consent Form}

\section{Dear (Name of Child):}

You have been invited to participate in a research study entitled "Child Carers and Secondary Schooling" conducted by Ms. Brenda Yamba who is a PhD candidate at Maastricht University in The Netherlands.

\section{Purpose and Procedures}

The purpose of this research is to understand factors that enable girls, such as you with caregiving responsibilities, to stay in secondary school. The research findings will be used for academic purposes only.

- In this study, you will be one of 40 girls who will be asked questions to help me understand what you think are the reasons for female child carers staying in school or dropping out.

- The interview will be conducted either at the school or at your house and will take up to one hour. I have a small gift for you that you can use at school.

- Your participation in this research is voluntary; you may choose not to participate. You also have the right to stop participating at any time, for any reason, and you will not be punished should you decide not to participate.

- You are free to stop the interview at any time if you feel very sad or uncomfortable. We have people who can help you when you feel that way.

\footnotetext{
Adapted from Washington, U. o. from http://courses.washington.edu/thesis/Manual\%202/6_DataCollection/Focus_Group_Discussio n_Guide.doc.
} 
- This research is confidential. Your name or other identifiers will not be attached to your answers.

\section{Consent}

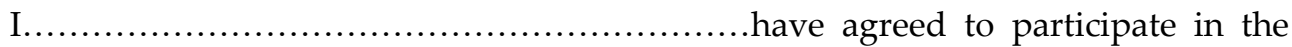
research study. The purpose and nature of the study has been explained to me and I will participate voluntarily.

- I give/do not give permission for the interview to be tape-recorded.

- I understand that I can withdraw from the study, without repercussions, at any time, whether before it starts or while participating.

- I understand that my name will not be used in the study.

Signature

Date 


\section{Annex 5: Adult Consent Form}

\section{University of Maastricht \\ School of Policy and Governance \\ Parental/Guardian/Teacher Consent Form}

\section{Dear Parent/Guardian/Teacher:}

Your child/student has been invited to participate in a research study entitled Child Carers and Secondary Schooling conducted by Ms. Brenda Yamba who is a PhD candidate at Maastricht University in The Netherlands.

\section{A. Purpose and Procedures}

- The purpose of this research is to understand factors that enable female child carers to stay in secondary school. The female child carers include those taking care of a sick, disabled, frail adult or sibling in the home, or heading a household. The research findings will be used for academic purposes only.

- In this study, your child will be one of 40 girls who will be asked questions that will help them explain what they think are the reasons for female child carers staying in school or dropping out.

- The interview will be conducted either at the school or at home and will take up to one hour. Participation in the study is voluntary and participants will be given a stipend and set of pens as a token of appreciation.

\section{B. Risks and discomforts}

There are no known risks to participating in this study. If however some questions cause psychological stress, the child will be referred to the school counselor or to the district social welfare officer for psychosocial support.

\section{Potential benefits}

There are no direct benefits to you or your child from participating in this research but the research may help us to understand factors that enable or hinder female child education. 


\section{Protection of confidentiality}

Your child's name or other identifiers will not be attached to her answers so that her confidentiality can be maintained. Her privacy will be ensured in that all data resulting from this study will be analyzed, written, and published in summary form.

\section{E. Voluntary participation}

- Your child/student's participation in this research study is voluntary; She may choose not to participate. She also has the right to stop participating at any time for any reason. She will not be penalized in any way should she decide not to participate or if she withdraws from this study.

\section{F. Consent}

give

permission

for

my

Child/student to participate in the research study.

- The purpose and nature of the study has been explained to me.

- The child will participate voluntarily.

- I give/do not give permission for the interview to be tape-recorded

- I understand that the child can withdraw from the study, without repercussions, at any time, whether before it starts or while participating.

- I understand that anonymity will be ensured in the analysis and write-up. 


\section{Annex 6: Interview Guide for Girl-Carers Who Stay in School}

\section{Introduction:}

My name is Brenda Yamba. I am a PHD candidate studying factors that facilitate school attendance for female child carers. I intend to identify and examine individual, household, school and community factors that are perceived to be facilitating secondary school attendance. Interview responses will be anonymous and strict confidentiality will be maintained. Information that will be collected will solely be used for writing my dissertation. Your participation is voluntary. This means that you can choose not to answer any questions in this study, and you can stop participating in this interview anytime.

\section{Questions}

\section{Warm-up questions}

- Tell me about yourself. What do you enjoy most about school?

- Tell me about your family. Who do you live with in your house?

- Tell me about your family members. Who takes care of them?

- What types of responsibilities do you have for caring for other members of your family? How are you involved in caring for them?

- Tell me how you spend your day during the week, and how you spend your Saturdays and Sundays.

- How would you describe the amount of work related to the responsibilities you just described?

Tell me about the work you do to help care for your family.

What are the biggest challenges for you when it comes to staying in school?

Now, let's move on to the people and things that help you stay in school.

\section{Individual Factors}

(Probing questions)

- Tell me about what has kept you in school!

- Probe for: How about your motivation or other feelings that may have kept you attending school?

- What is the help and support from others that you think has kept you going to school?

- $\quad$ Tell me what you see yourself doing in five years from now. 
- Tell me about your religion and the role, if any, it has played in keeping you in school.

2. Family Factors: (Probing questions)

a. Tell me about the support, if any, you receive from family members. Who helps you so that you can go to school?

- Where do they live?

- How do they help you? (Emotionally, financially, household chores, other?)

- What are they like?

3. School Factors: (Probing questions)

Who is the most important person, or persons, for you at school right now? Why?

- Does the school support you in staying in school? If so, how?

- Do your peers and friends help you in staying in school? If so, how?

Are there any other school-related factors that I have not mentioned that you think help you stay in school?

\section{Community Factors}

- When you think of your community, which people or organizations, if any, have helped you stay in school?

- How do they do that?

\section{Other factors}

- Are there any other factors, or individuals, apart from those discussed already, that help you stay in school?

- What would you change about school if you could?

- Do you have any comments about this interview? Is there any question that you think is important about girls staying in school that I have not asked?

\section{Information about the child}
a. Age:.....................
b. Form:
c. Location: Rural/Urban
d. Number of household members: Below 18 Above 18
e. Number of household members attending:
i. Primary school
ii. Secondary school
iii. Tertiary education 
f. Number of household members earning an income ......................

g. Number of hours a child is working outside the home

h. Number of days absent in the year

\section{Annex 7: Interview Guide For Government Policy Makers, Secondary School Teachers and NGO Staff. 18}

\section{Consent Process}

Thank you for agreeing to participate. I am very interested to hear your valuable opinion on factors that facilitate school attendance for female child carers.

- The purpose of this study is to learn why and how some female child carers regularly attend secondary school despite adverse situations. I hope to get your views on this matter as it relates to children in Maseru, Lesotho.

- The information you provide is completely confidential, and I will not associate your name with anything you say in the focus group. All responses will be assigned a pseudo name in the write up for the results so that no participant will be identified in any publications that are based on this study.

- I would like to tape the interview to make sure to capture the thoughts, opinions and ideas I hear from you. Your name will not be attached to the interview, and the tapes will be destroyed as soon as they are transcribed.

- You may refuse to answer any question or withdraw from the study at any time.

- If you have any questions now or after you have completed the interview, you can always contact me on phone XXXX

\footnotetext{
${ }^{18}$ Adapted from Washington, U. o. from http://courses.washington.edu/thesis/Manual\%202/6_DataCollection/Focus_Group_Discussio n_Guide.doc.
} 


\section{Introduction:}

1. My name is Brenda Yamba. I am a PHD candidate studying factors that facilitate school attendance for female child carers. I intend to identify and examine individual, household, school and community factors that are perceived to be facilitating secondary school attendance. Interview responses will be anonymous and strictest confidentiality will be maintained. Information that will be collected will solely be used for writing my dissertation. Your participation is voluntary.

2. Turn on Tape Recorder

3. Are there any questions before we get started?

Interview begins.

\section{Questions:}

1. Let's start the discussion by talking about female children with caregiving responsibilities. What type of care do they provide? How would you describe the amount of work related to the responsibilities you just described?

2. What has put them in this situation?

3. I would like us to talk about the female child carers who are in secondary school and are regularly attending school. Why do you think they are still able to attend school despite the caregiving roles?

4. What do you think are the individual attributes of the female child carers who attend school regularly? Probe for optimism, seeking support and religious belief.

5. What do you think are the family-related factors that facilitate female child carers' regular school attendance? Probe for support from immediate and extended family.

6. What do you think are the school-related factors that facilitate female child carers' regular school attendance? Probe for support from teaching staff, school leadership, school staff, peers and school policies.

7. What do you think are the community-related factors that facilitate female child carers' regular school attendance? Probe for existence of community-based support structures and type of support.

8. Are there any other factors that would promote girl-carers' regular school attendance? 
That concludes our interview. Thank you so much for coming and sharing your thoughts and opinions with me.

\section{Annex 8: Focus Group Interview Guide for Community-Based Organizations ${ }^{19}$}

\section{Consent Process}

Thank you for agreeing to participate. I am very interested to hear your valuable opinion on factors that facilitate school attendance for female child carers.

- The purpose of this study is to learn why, and how, some female child carers regularly attend secondary school despite adverse situations. I hope to get your views on this matter as it relates to children in Maseru, Lesotho.

- The information you provide is completely confidential, and I will not associate your name with anything you say in the focus group. All responses will be assigned a pseudo name in the write up for the results so that no participant will be identified in any publications that are based on this study.

- I would like to tape the focus groups to make sure to capture the thoughts, opinion, and ideas I hear from the group. No names will be attached to the focus groups and the tapes will be destroyed as soon as they are transcribed.

- You may refuse to answer any question or withdraw from the study at any time.

- I understand how important it is that this information is kept private and confidential, and will ask participants to respect each other's confidentiality. However, I cannot guarantee complete confidentiality for focus groups since participants may share information despite being instructed to maintain (editor suggests finishing off the sentence.)

\footnotetext{
${ }^{19}$ Adapted from Washington, U. o. from http://courses.washington.edu/thesis/Manual\%202/6_DataCollection/Focus_Group_Discussio n_Guide.doc.
} 
- If you have any questions now or after you have completed the questionnaire, you can always contact me on phone XXXX

- Please sign on the attached sheet to show you agree to participate in this focus group.

\section{Introduction:}

My name is Brenda Yamba. I am a PHD candidate studying factors that facilitate school attendance for female child carers. I intend to identify and examine individual, household, school and community factors that are perceived to be facilitating secondary school attendance. Interview responses will be anonymous and strictest confidentiality will be maintained. Information that will be collected will solely be used for writing my dissertation. Your participation is voluntary.

\section{Explanation of the Process:}

I would like to find out if anyone has participated in a focus group before. I am using the focus group as a way of learning from you to gather information on the key issues that you think facilitate school attendance for female child carers.

\section{Logistics}

- Focus group will last about one hour

- We will have a short break to stretch and have drinks

\section{Ground Rules}

Would you please suggest some ground rules to make this discussion a fruitful one, for example, everyone should be free to participate, Information provided in the focus group must be kept confidential, stay with the group and please don't have side conversations [MOST important only one person can speak at a time and the moderator will ensure everyone is given opportunities to provide their perspective on this topic]. 


\section{Turn on Tape Recorder}

- Are there any questions before we get started?

- Introductions

- Discussion begins.

\section{Questions:}

1. Let's start the discussion by talking about female children with caregiving responsibilities. What type of care do they provide? How would you describe the amount of work related to the responsibilities you just described?

2. What has put them in this situation?

3. I would like us to talk about the female child carers who are regularly attending secondary school. Why do you think they are still able to attend school despite the caregiving roles?

4. What do you think are the individual attributes of the female child carers who attend school regularly? Probe for optimism, seeking support and religious belief.

5. What do you think are the family related factors that facilitate female child carers' regular school attendance? Probe for support from immediate and extended family.

6. What do you think are the school related factors that facilitate female child carers' regular school attendance? Probe for support from teaching staff, school leadership, school staff, peers and school policies.

7. What do you think are the community related factors that facilitate female child carers' regular school attendance? Probe for existence of communitybased support structures and type of support.

8. Are there any other factors that would promote girl-carers' regular school attendance?

That concludes our focus group. Thank you so much for coming and sharing your thoughts and opinions with us. 
Annex 9: Example of a MOET Form to Capture Orphans and School Enrolment

(a) ENROLMENT OF ORPHANS BY TYPE, FORM AND SEX

\begin{tabular}{|c|c|c|c|c|c|c|c|c|c|c|c|}
\hline \multirow{2}{*}{$\begin{array}{l}\text { Type of } \\
\text { Orphan }\end{array}$} & \multicolumn{2}{|c|}{ Form A } & \multicolumn{2}{|c|}{ Form B } & \multicolumn{2}{|c|}{ Form C } & \multicolumn{2}{|c|}{ Form D } & \multicolumn{2}{|c|}{ Form E } & \multirow{2}{*}{ TOTAL } \\
\hline & $\mathbf{M}$ & $\mathbf{F}$ & $\mathbf{M}$ & $\mathbf{F}$ & $\mathbf{M}$ & F & $\mathbf{M}$ & $\mathbf{F}$ & $\mathbf{M}$ & $\mathbf{F}$ & \\
\hline \multicolumn{12}{|l|}{ Paternal } \\
\hline \multicolumn{12}{|l|}{ Maternal } \\
\hline \multicolumn{12}{|l|}{ Double } \\
\hline TOTAL & & & & & & & & & & & \\
\hline
\end{tabular}

NB. The totals in the above table (Table 6a) must be the same as the totals on the next Table $b$

Note: - Paternal Orphan is a child whose father is dead and mother is alive

- Maternal Orphan is a child whose mother is dead and father is alive

- Double Orphan is a child whose both parents are dead

(b) ENROLMENT OF ORPHANS BY AGE, FORM AND SEX

\begin{tabular}{|c|l|l|l|l|l|l|l|l|l|l|l|l|l|}
\hline \multirow{2}{*}{ Age } & \multicolumn{2}{l}{ Form A } & \multicolumn{2}{l}{ Form B } & \multicolumn{2}{l|}{ Form C } & \multicolumn{2}{l|}{ Form D } & \multicolumn{2}{l|}{ Form E } & \multicolumn{2}{l|}{ TOTAL } \\
\hline & M & F & M & F & M & F & M & F & M & F & M & F \\
\hline$<13$ & & & & & & & & & & & & \\
\hline 13 & & & & & & & & & & & & \\
\hline 14 & & & & & & & & & & & & \\
\hline 15 & & & & & & & & & & & & \\
\hline 16 & & & & & & & & & & & & \\
\hline 17 & & & & & & & & & & & & \\
\hline 18 & & & & & & & & & & & & \\
\hline 19 & & & & & & & & & & & & \\
\hline 20 & & & & & & & & & & & & \\
\hline 21 & & & & & & & & & & & & \\
\hline 22 & & & & & & & & & & & & \\
\hline 23 & & & & & & & & & & & & \\
\hline 24 & & & & & & & & & & & & \\
\hline$>24$ & & & & & & & & & & & & \\
\hline TOTAL & & & & & & & & & & & \\
\hline
\end{tabular}

Source: Reproduced from Lesotho Ministry of Education and Training Form (6), obtained from sampled schools. 


\section{Summary of the Thesis}

The PhD dissertation titled "Schooling Despite All Odds: Evidence from Lesotho on Female Child Carers who Stayed in School" aimed to examine perceptions of stakeholders, including in-school female child carers, teachers, policy makers, civil society organizations, and community volunteers, of conditions under which female children who are the primary carers in their households are still able to regularly attend secondary school. The focus of this study is Lesotho, a country based in Southern Africa, where the impact of HIV and AIDS has been greatest (UNAIDS 2016) and child carers have been identified as being vulnerable (Government of Lesotho, 2012; Tanga, 2013).

Children, from time immemorial, have contributed to the caregiving responsibilities in the home. However, when this stretches beyond the normal expectations of domestic chores (Robson et al., 2006) and becomes more substantial and significant (Becker, 2000), then this adult role denies children their childhood and deprives them of their rights as children (UNICEF, 2011).In sub-Saharan Africa, the effects of the human immunodeficiency virus (HIV) and acquired immunodeficiency syndrome (AIDS) have resulted in a change in household composition, with children increasingly taking up caregiving roles. Recently, there has been a shift in caring patterns due to parental AIDS deaths, leaving grandparents increasingly taking up this role (Ardington \& Leibbrandt, 2010) and the emergence of child-headed households (Foster et al., 1997). It is within these family structures that children may be taking up caregiving roles beyond what may be considered the norm.

Caregiving responsibilities have been cited as one of the factors affecting regular school attendance (Lewin \& Little, 2011; Nyabanyaba, 2009; Stearns \& Glennie, 2006; UNFPA, 2012). However, some children will still attend school regularly, despite facing adverse circumstances (Cluver et al., 2012). Such children who thrive despite adversities are considered resilient (Condly, 2006; Katz, 1997). Lesotho policy documents, such as the Lesotho Education Sector Strategic Plan 20152015 (Government of Lesotho MOET, 2005), the National Policy on Orphans and Vulnerable Children (Government of Lesotho, 2006), and the National Strategic Plan on Vulnerable Children 2012-2017 (Government of Lesotho, 2012), acknowledge child 
carers as part of the vulnerable children population in need of social services. Academic literature also cites the child carer phenomenon in Lesotho, with one author attributing the rise of child-headed households to the inability of the extended family safety net to take care of orphans (Tanga, 2013).

I examined the perceptions of stakeholders on how individual, family, school, and community factors influenced female child carers regularly attending secondary school. I adopted the definition of school attendance by Lewin and Little (2011) as "regular attendance of at least $80 \%$ of the time." (p. 333). Lesotho's education system has a five-year secondary school program that runs from Form A to Form E, with an official age range of between 13 and 18 years (Classbase, 2012), although older students are not excluded from attending. The main research question is: Why and how do some girl child carers regularly attend secondary school, despite adverse situations?

Using Urie Bronfenbrenner's socioecological model (Bronfenbrenner, 1994) as the guiding framework, the subquestions that I sought to answer in this research study were:

- What is the care-work provided by the female child carers?

- What are the challenges faced by the female child carers, and how do these pose a potential risk to school attendance?

- What individual-level factors facilitated secondary school attendance?

- What family-level factors facilitated secondary school attendance?

- What school-level factors facilitated secondary school attendance?

- What community factors facilitated secondary school attendance?

- What interaction occurs amongst individual, family, school, and community factors to facilitate secondary school attendance?

This dissertation employed a qualitative research approach and employed an indepth semi structured interview guide with 58 participants, comprising 28 female child carers attending secondary school, nine secondary school teachers, five policy makers, two civil society staff, and 14 members of community-based organizations. I chose this approach because it allowed me to purposefully sample my participants (Creswell, 2003), especially the child carers whom we do not know much about and who have been referred to as a "hidden" group of children 
(Becker, 2007; Moore, 2005b; Rose \& Cohen, 2010). My research sought to obtain girl-carers' views on, and experiences with, caring and schooling and stakeholders' perspectives of child carers and schooling.

I took into account ethical considerations to ensure that the rights of all the participants were protected by explaining the purpose of the study and their rights and protection (Blumberg et al., 2011). For the interviews with children, I included other ethical considerations recommended by Noble-Carr (2006), including "informed consent, privacy and confidentiality..." (p. 5). The content of the consent form was read to the child in either English or Sesotho, ensuring that the child also understood that only pseudonyms would be used in the study.

The dissertation is presented in eight chapters as follows:

Chapter 1 provides an introduction to the research.

Chapter 2 provides the theoretical framework guiding the dissertation, outlining prior literature on educational resilience using the socioecological framework. The chapter starts with a review of the prior literature on child carers, the reasons for caring, the nature of care, and how this relates to school attendance and educational resilience.

Chapter 3 outlines the methods used to conduct the research and provides the rationale for the research approach and site selection. Furthermore, the chapter describes the sample and details the data collection and data analysis processes.

Chapter 4 presents the profile of the child carers in the study, describing the factors that may have caused them to be caregivers, the nature of care they provided, and who their care-recipients were. The chapter also describes the challenges faced by the child carers and how these may pose a potential risk to school attendance.

Chapter 5 discusses study participants' views on how and why individual attributes play a role in keeping female child carers attending secondary school despite the challenges they experienced due to their caregiving roles. It also highlights the collaboration between individual factors and external factors, such as family, school, and community.

Chapter 6 is an account of the perceptions of study participants of how schoolrelated factors such as the school environment, teachers, and student peers contributed to child carers being able to regularly attend secondary school. 
Chapter 7, which contains two parts, first highlights study participants' perceptions of the roles that the immediate and extended family plays in influencing female child carers' school attendance. I further discuss the role of neighbors, community leaders, and community-based organizations in influencing school attendance.

Chapter 8 concludes the dissertation with a discussion, conclusion, and policy considerations.

The findings showed that child carers experienced challenges related to caregiving responsibilities, both at home and at school. My study established that caregiving goes beyond providing care in the home. The key point to note from my study is that even though child carers devised coping strategies to ensure that they were able to attend school, the pressure of caring weighed heavily on their minds even while at school. Attending school alone is therefore not sufficient when the quality of learning is being compromised as a result of anxiety and stress outside of school. The findings showed that a child carer's vision for a better future was the key individual attribute that kept the child in school. External support and a conducive environment within family, school and community all played a role in nurturing this resilience and providing protective and mitigating support that influenced child carers school attendance. The study however demonstrated that there was no "one size fits all" approach that seemed to be responsible for child carers' staying in school, but a combination of factors, that needed to interact with each other for positive outcomes.

My study leads to the following considerations for policy, to better improve the chances of effective quality schooling for child carers: free secondary schooling, teacher training to provide psychological support, more inclusive school bursaries, in-school peer-support programs, and community programs supporting those that help vulnerable groups. This study was conducted at an opportune time when the global community has formulated the new sustainable development goals (SDGs) and the subsequent Education 2030 Incheon Declaration and Framework for Action (Declaration, 2015). The Incheon Declaration is committed to ensuring the "provision of 12 years of free, publicly funded, equitable quality primary and secondary education" (Declaration, 2015, p. iv). Advocating for free secondary education is therefore not far-fetched, as it aligns with the global agenda. I 
recommend free secondary education because the data demonstrate that providing school fees was one area of support that families, schools, and communities put efforts in covering. It is critical that government and nongovernmental organizations enhance teachers' skills in providing specialized psychosocial care. Teachers seem to be playing a big role beyond what they are required to do. Both preservice and in-service teacher training should include a component of specialized counseling to focus on the psychological wellbeing of the child.

Insufficient finances to cover school costs was cited as a challenge that teachers, family members, and communities went to great lengths to address. Chapter 4 also highlighted some bottlenecks to accessing the government bursary. This was an indication that existing bursary schemes may not be reaching some vulnerable children, such as child carers. My recommendation for policy consideration is that government and nongovernmental scholarship funds should revisit the targeting criteria in order to make it more inclusive.

The fact that the girl-carers continued worrying about their care recipients even while at school calls for a more comprehensive community-based response that addresses the challenges faced by the children at home. To mitigate this issue, government and civil society organizations should implement a household-based approach in supporting child-carers. The unintended benefit of old-age pensions as a source of financial support for caregivers of grandparents is worth noting. The government should, therefore, consider extending the social grant to child carers living in such households. 


\section{Valorization Addendum}

In accordance with the Regulation Governing the Attainment of Doctoral Degrees at Maastricht University, this addendum discusses the valorization presented by this dissertation, presenting the non-academic value of the research. This study focuses on a group of children for whom there is little research. Studies on child or young carers have mainly concentrated on the global North (Aldridge \& Becker, 1993), with a few studies emerging from sub-Saharan Africa (Becker, 2007). Lesotho national policy documents, however, acknowledge that being a child carer presents a risk to schooling (Government of Lesotho MOET, 2005, Government of Lesotho, 2006, Government of Lesotho, 2012). Some children will still attend school regularly despite facing adverse circumstances of being caregivers. The results of this research may therefore be used to further understand the phenomenon of child carers in the education, child protection, social protection, and resilience areas of research and work. My research contributes new information regarding child carers in sub-Saharan Africa that governments, educationists, civil society organizations and other stakeholders may find valuable for designing programs that help this group of vulnerable children.

The main focus of this research aimed to examine the conditions under which atrisk female child carers were still able to regularly attend secondary schooling despite the challenges of caregiving. This dissertation presents the perspectives of female child carers, teachers, policy makers, civil society organizations and community members on how individual and external factors influenced school attendance. The research focused on what was perceived to be keeping them in school deviating from emphasizing what may cause them to drop out, an area that has been broadly documented. The socio-ecological model (Bronfenbrenner, 1994) that I used as the framework for my research helped examine how factors within the individual, family, school and community domains influence school attendance for female child carers. The research findings present an in-depth picture of dynamics at play at each level and the interactions among various stakeholders within the domains. The findings showed that individual factors, family factors, school factors, and community factors all played a role in influencing child carers' school attendance. The study findings further highlighted 
how stakeholders from each domain collaborated to find ways of supporting child carers' schooling by providing financial, material, or psychosocial help.

The dissertation presents policy and programmatic recommendations for policy makers and civil society organizations to consider for enhancing the capacity of these support structures to facilitate school attendance among child carers. Additionally, this information may be of value for designing preventative and protective interventions targeting at-risk children and their families.

My study was conducted at an opportune time when the new global sustainable development goals (SDGs) and the Education 2030 Incheon Declaration and Framework for Action were put in place. These call for governments to provide free, equitable and quality education for both primary and secondary schooling. Governments are expected to deliver on these goals. The dissertation data is enriched by quotes from in-school children and their teachers who described how responsibilities of being a child carer compromise quality of learning. These voices from the child carers may provide education practitioners with insights into what may work to enhance quality of learning.

The research findings illuminated the fact that although the child carers reported regularly attending school, they were constantly worrying about the well-being of their care recipients left at home. These concerns may have a negative psychological impact on the child carers and consequently affect quality of learning. The dissertation suggests a more comprehensive community-based response that addresses the challenges faced by the children at home and calls upon government and civil society organizations to implement a household-based approach in supporting child carers. My data further showed that within the school setting teachers played a critical role in providing psychosocial support to girl-carers. The dissertation recommends a review of the preservice and in-service teacher training curriculum to incorporate a component of specialized counseling for children going through adversities.

The data demonstrated that providing school fees was one area of support that families, schools, and communities put efforts in covering. Participants described the extent to which the stakeholders went in order to dedicate effort, time, and resources to secure money to pay child carers' school fees. Child carers also 
mentioned family members' migration to find jobs to cover school fees as one of the reasons they were in their situation. Making secondary schooling free would ease the financial burden on the families, and ultimately minimize the need for single parents to migrate. Advocates for social protection and free secondary education as well as policy makers and development practitioners may use the findings of this study to inform program design and implementation.

This dissertation would be of value to governments, NGOs and other stakeholders working within community settings. The study findings point to the critical role that neighbors played as a substitute parent or family by providing child carers with financial, material, and emotional support. The data further highlighted the role of local leaders in coordinating community responses to protect vulnerable children. The recommendations invite governments and NGO community based programs to maximize and enhance these existing resources and suggest implementation of interventions that strengthen capacity of households. These may include economic strengthening initiatives, psychosocial support and parenting skills needed to engage with children in adversity.

Results of my research may also be relevant to the work of development agencies and non-governmental organizations implementing HIV and AIDS prevention and impact mitigation interventions. Keeping girls in school has shown to have positive health benefits including decreasing the risk of contracting HIV. My study provides an in-depth understanding of how individual attributes and support structures may keep at-risk girl child carers in school despite the odds, information that implementing organizations may use to target their program activities. 


\section{CURRICULUM VITAE}

Brenda Yamba was born on December 8, 1967 in Zambia and is currently based in Pretoria, South Africa where she is working as a Senior Regional Orphans and Vulnerable Children Advisor for the United States Agency for International Development (USAID) Regional HIV/AIDS Program office. Her passion for working with children started with her first job as a teacher at Munali Secondary School in Lusaka Zambia in 1989. She later worked for various non-governmental organizations including Red Cross Society, Project Concern International, Voluntary Services Overseas and Care International Zambia. She left Zambia to work for Save the Children Federation as HIV/AIDS Advisor for Malawi (20022005) and Mozambique (2005-2008). In 2008, she joined the Save the Children Federation Regional Office in Addis Ababa, Ethiopia as the Africa Regional HIV/AIDS Advisor. Between 2010 and 2014, Brenda joined USAID Lesotho, as their Orphans and Vulnerable Children Advisor, before being promoted to her current position. Brenda holds a Bachelor of Arts Degree in Education obtained from the University of Zambia in 1989, a Masters Degree in International and Community Development from Deakin University, Australia. She started working towards her PhD with Maastricht University School of Policy and Governance, in 2013. 


\section{MGSOG DISSERTATION SERIES}

2017

Sheng Zhong

Moving towards An Energy Efficient Future:

Essays on Energy Efficiency, Technology and Development

UNU-MERIT/MGSoG Dissertation Series № 187

Julieta Marotta

Access to Justice and Legal Empowerment of Victims of Domestic Violence through Legal Organizations in the City of Buenos Aires; A Qualitative Empirical Legal Study

UNU-MERIT/MGSoG Dissertation Series, № 186

Andrea Franco-Correa

On the Measurement of Multidimensional Poverty as a Policy Tool;

Empirical Applications to Chile, Colombia, Ecuador and Peru

UNU-MERIT/MGSoG Dissertation Series, № 185

2016

Yesuf Awel

Insurance for Growth; Empirical Essays on Insurance Demand and Impacts in Africa

UNU-MERIT Dissertation Series, № 108

Tigist Mekonnen Melesse

Grow More Food using Fewer Resources;

Agricultural Technology Adoption and Innovation Practices for Inclusive and Sustainable Development

UNU-MERIT Dissertation Series, № 107

Eleni Yitbarek

Getting Ahead or left Behind?; Essays on Poverty Dynamics and Social Mobility in Africa

UNU-MERIT Dissertation Series, № 106 
Thuy Dieu Nguyen

Firm-Level Theory and Evidence of Corruption

UNU-MERIT Dissertation Series, № 105

Raquel Tsukada Lehman

Essays on Household Production with Labor-Saving Technology

UNU-MERIT Dissertation Series, № 104

Eva Barteková

Multi-Problem Challenges for a Renewable Future; Empirical Studies on Competitive Disadvantages from Electricity Price Differentials and

Mineral Supply Risk in an Open Economy

UNU-MERIT Dissertation Series, № 103

Jocelyn Olivari

Entrepreneurial Traits and Innovation; Evidence from Chile

UNU-MERIT Dissertation Series, № 102

Muhammad Shafique

Essays on the role of knowledge, $R \& D$, and Technology-based Firms in the Evolution of Socio-techno-economic System

UNU-MERIT Dissertation Series, № 101

Serdar Türkeli

Governance of Innovation Policy; Empirical Studies on Applied Political Economy by Multi-Methods Analysis

UNU-MERIT Dissertation Series, № 100

Ayokunu Adedokun

Pathways to Sustainable Peacebuilding in Divided Societies; Lessons and Experiences from Mozambique

MGSoG Dissertation Series, № 75

Luiz Rothier Bautzer

Organizing Concurrent Engineering through ICT Platforms

Blueprinting Product Lifecycle Management Platforms across Disciplinary Agencies

MGSoG Dissertation Series, № 74 


\section{Natalia Popova}

Migration in the Periphery of the European Union;

Determinants of Successful and Sustainable Labour Market Integration of

Return Migrants in Albania, Egypt, Moldova and Tunisia

MGSoG Dissertations Series, № 73

Richard A. Martina

Uncertainty and Resource Constraint in the Small Island Developing

States;

Essays in Entrepreneurial Cognition

MGSoG Dissertations Series, № 72

Cécile Cherrier

The Expansion of Basic Social Protection in Low-income Countries;

An Analysis of Foreign Aid Actors' Role in the Emergence of Social

Transfers in Sub-Saharan Africa

MGSoG Dissertations series, № 71

Paul Caldron

The Tacit Bargain in Short-Term Medical Missions; Why U.S. physicians go and what it costs

MGSoG Dissertation Series, № 70

Mahmut Kobal

Customs \& Excellence: A Comparative Approach on Administrative and Regulatory Compliance Perspectives of the EU-Turkey Customs Union MGSoG Dissertation Series, № 69

Craig Loschmann

Essays on Conflict-related Migration and Development in the Case of Afghanistan

MGSoG Dissertations Series, № 68

Andrea Milan

Rural Livelihoods, Location and Vulnerable Environments; Approaches to Migration in Mountain areas of Latin America

MGSoG Dissertation Series, № 67 
Farida Lada

On Guarding the Welfare of Clinical Trial Subjects While Promoting Novel Drug Innovation

A Game Theoretical Approach

MGSoG Dissertation Series, № 66

2015

Hibret Belete Maemir

Dissecting Aggregate Productivity; International Integration and Growth with Heterogeneous Firms

UNU-MERIT Dissertation Series, № 96

Giorgio Triulzi

Looking for the Right Path; Technology Dynamics, Inventive Strategies and Catching-up in the Semiconductor Industry

UNU-MERIT Dissertation Series, № 95

Abdul Baseer Qazi

Knowledge flows and networks in the ICT sector; The case of Pakistan UNU-MERIT Dissertation Series, № 94

Ajay Thutupalli

Technology Paradigm Shifts in Agriculture; Drivers of Sustainability and Catch up

UNU-MERIT Dissertation Series, № 93

Eduardo Urias

Improving access to HIV/AIDS treatment in Brazil; When are Compulsory Licenses effective in Price Negotiations?

UNU-MERIT Dissertation Series, № 92

Francesca Guadagno

Why have so few Countries Industrialised?

UNU-MERIT Dissertation Series, № 91

Daniel Opolot

The Evolution of Beliefs and Strategic Behaviour

UNU-MERIT Dissertation Series, № 90 
Alejandro Lavopa

Structural Transformation and Economic Development; Can Development Traps be Avoided UNU-MERIT Dissertation Series, № 89

Jinjin Zhao

Urban water management reform; The Case of China

UNU-MERIT Dissertation Series, № 88

Simona Vezzoli

Borders, Independence and Post-colonial Ties; the Role of the State in Caribbean Migration

MGSoG Dissertation Series, № 65

Silvia Consuelo Gómez Soler

Civil Conflict and Education; How Does Exposure to Civil Conflict Affect

Human Capital Accumulation? Evidence from Standardized Exit Exams in

Colombia

MGSoG Dissertation Series, № 64

Paula Nagler

Occupational Choice in the Developing World

MGSoG Dissertation Series, № 63

Jasmin Kientzel

Determinants of Professional Commitment to Environmental

Sustainability

MGSoG Dissertation Series, № 62

Mehmet Güney Celbiş

Regional Policies; Convergence, Trade, and the Allocation of Public

Capital

MGSoG Dissertation Series, № 61

Florian Henning

Living Up to Standard; Interoperability Governance and Standards Adoption in Government Information Networks

MGSoG Dissertation Series, № 60 
Niels P. Groen

The Never-Ending Project

Understanding E-Government Project Escalation

MGSoG Dissertation Series, № 59

Derek Copp

Teacher-Based Reactivity to Provincial Large-scale Assessment in Canada MGSoG Dissertation Series, № 58

Michaella Vanore

Family-Member Migration and the Psychosocial Health Outcomes of

Children in Moldova and Georgia

MGSoG Dissertation Series, № 57

Sonja Fransen

The Economic and Social Effects of Remittances and Return Migration in Conflict-Affected Areas; The Case of Burundi

MGSoG Dissertation Series, № 56

Ibrahim Khalil Conteh

The Impact of Floods on Primary School Education in Zambia

MGSoG Dissertation Series, № 55

Richard Bluhm

Growth Dynamics and Development

Essays in Applied Econometrics and Political Economy

MGSoG Dissertation Series, № 54

Nevena P. Zhelyazkova

Work-Family Reconciliation and Use of Parental Leave in Luxembourg;

Empirical Analysis of Administrative Records

MGSoG Dissertation Series, № 53

2014

Dirk Crass

The Impact of Brands on Innovation and Firm Performance; Empirical Evidence from Germany

UNU-MERIT Dissertation Series, № 87 
Samyukta Bhupatiraju

The Geographic Dimensions of Growth and Development

UNU-MERIT Dissertation Series, № 86

François Lafond

The Evolution of Knowledge Systems

UNU-MERIT Dissertation Series, № 85

Annalisa Primi

Promoting Innovation in Latin America; What Countries Have Learned (and What They Have Not) in Designing and Implementing Innovation and Intellectual Property Policies

UNU-MERIT Dissertation Series, № 84

Fatoumata Lamarana Diallo

Evaluation of Meal and Deworming Programs for Primary Schools in Rural Senegal

UNU-MERIT Dissertation Series, № 83

Sachin Kumar Badkas

Metachoice and Metadata; Innovating with Environmental Policy

Analysis in Europe

MGSoG Dissertation Series, № 52

Irina S. Burlacu

An Evaluation of Tax-Benefit Systems Impact on the Welfare of Frontier Worker;

The Case of Luxembourg and Belgium

MGSoG Dissertation Series, № 51

Özge Bilgili

Simultaneity in Transnational Migration Research; Links Between

Migrants' Host and Home Country Orientation

MGSoG Dissertation Series, № 50 
Yulia Privalova Krieger

Reshaping the Big Agenda; Transnational Politics and Domestic

Resistance

Financial crisis and social protection reform in Bosnia and Herzegovina MGSoG Dissertation Series, № 49

Marieke van Houte

Moving Back or Moving Forward? Return migration after Conflict

MGSoG Dissertation Series, № 48

Oxana Slobozhan

Global Governance in the Management of Natural Resources; The Case of the Extractive Industries Transparency Initiative (EITI)

MGSoG Dissertation Series, № 47

Luis Bernardo Mejia Guinand

The Changing Role of the Central Planning Offices in Latin America; A

Comparative Historical Analysis Perspective (1950-2013)

MGSoG Dissertation Series, № 46

Cheng Boon Ong

Ethnic Segregation in Housing, Schools and Neighbourhoods in the

Netherlands

MGSoG Dissertation Series, № 45

Luciana V. Cingolani

Bureaucracies for Development; Oxymoron or Reality? Studies on State Capacity in Challenging Governance Contexts

MGSoG Dissertation Series, № 44

Carlos Cadena Gaitán

Green Politics in Latin American Cities - Sustainable Transport Agendas MGSoG Dissertation Series, № 43

Katie Kuschminder

Female Return Migration and Reintegration Strategies in Ethiopia

MGSoG Dissertation Series, № 42 
Metka Hercog

Highly-Skilled Migration and New Destination Countries

MGSoG Dissertation Series, № 41

Margaret Agaba Rugadya

Can Remittances Influence the Tenure and Quality of Housing in Uganda? MGSoG Dissertation Series, № 40

Ilire Agimi

New Governance Under Limited Statehood; The Case of Local Government Reform in Kosovo

MGSoG Dissertation Series, № 39

2013

Anant Kamath

Information Sharing through Informal Interaction in Low-Tech Clusters UNU-MERIT Dissertation Series, № 82

Flavia Pereira de Carvalho

What we talk about when we talk about Brazilian Multinationals; An Investigation on Brazilian FDI, Economic Structure, Innovation and the Relationship between them

UNU-MERIT Dissertation Series, № 81

Jun Hou

Complementarity in Innovation and Development; A Cross-country

Comparison

UNU-MERIT Dissertation Series, № 80

Rufin Baghana

Impacts of Government Incentives to $R \& D$, Innovation and Productivity; A Micro econometric Analysis of the Québec Case

UNU-MERIT Dissertation Series, № 79

Lilia I. Stubrin

High-Tech Activities in Emerging Countries; A Network perspective on the Argentinean Biotech Activity

UNU-MERIT/MGSoG Dissertation Series, № 78 
Kristine Farla

Empirical Studies on Institutions, Policies and Economic Development MGSoG Dissertation Series, № 38

Marina Petrovic

Social Assistance and Activation in the Pursuit of Happiness; Shedding New Light on Old Policy Solutions to Social Exclusion

MGSoG Dissertation Series, № 37

Laura Torvinen

Assessing Governance Assessments; The Case of Mozambique; Governance Assessments in the Context of Aid Effectiveness Discourse

MGSoG Dissertation Series, № 36

Biniam Egu Bedasso

Institutional Change in the Long Shadow of Elite; Essays on Institutions, Human Capital and Ethnicity in Developing Countries

MGSoG Dissertation Series, № 35

Sepideh Yousefzadeh Faal Deghati

Childhoods Embargoed; Constructing and Reconstructing

Multidimensional Child Poverty in Iran 1984-2009

MGSoG Dissertation Series, № 34

Robert Bauchmüller

Investing in Early Childhood Care and Education; The Impact of Quality on Inequality

MGSoG Dissertation Series, № 33

Martin Rehm

Unified Yet Separated; Empirical Study on the Impact of Hierarchical Positions within Communities of Learning

MGSoG Dissertation Series, № 32

2012

Abdul Waheed

Innovation Determinants and Innovation as a Determinant; Evidence from Developing Countries

UNU-MERIT Dissertation Series, № 77 
Bilal Mirza

Energy Poverty and Rural Energy Markets in Pakistan

UNU-MERIT Dissertation Series, № 76

Benjamin Engelstätter

Enterprise Software and Video Games; An Empirical Analysis

UNU-MERIT Dissertation Series, № 75

Fulvia Farinelli

Natural Resources, Innovation and Export Growth; The Wine Industry in

Chili and Argentina

UNU-MERIT Dissertation Series

Rodolfo Lauterbach

Innovation in Manufacturing; From Product Variety and Labor

Productivity Growth to Economic Development in Chile

UNU-MERIT Dissertation Series

Kirsten Wiebe

Quantitative Assessment of Sustainable Development and Growth in Sub-

Saharan Africa

UNU-MERIT/MGSoG Dissertation Series, № 74

Julio Miguel Rosa

Organizational Strategies, Firms' Performance and Spatial Spillovers; The

Canadian Case in Research and Development.

UNU-MERIT Dissertation Series, № 73

Johannes Wilhelmus Marie Boels

Joseph Schumpeter, Honderd Jaar Economische Ontwikkeling; Een

Historisch-theoretische Beschouwing.

UNU-MERIT Dissertation Series

Dorcas Mbuvi

Utility Reforms and Performance of the Urban Water Sector in Africa MGSoG Dissertation Series, № 31 
Lina Salanauskaite

Distributional Impacts of Public Policies; Essays in Ex-Ante and Ex-Post Evaluation

MGSoG Dissertation Series, № 30

Esther Schüring

To Condition or not - is that the Question?

An Analysis of the Effectiveness of Ex-Ante and Ex-Post Conditionality in Social Cash Transfer Programs

MGSoG Dissertation Series, № 29

Joe Abah

Strong Organisations in Weak States; Atypical Public Sector Performance in Dysfunctional Environments

MGSoG Dissertation Series, № 28

Zina Samih Nimeh

Social Citizenship Rights; Inequality and Exclusion

MGSoG Dissertation Series, № 27

2011

Daniel Vertesy

Interrupted Innovation; Emerging Economies in the Structure of the

Global Aerospace Industry

UNU-MERIT Dissertation Series, № 72

Tina Saebi

Successfully Managing Alliance Portfolios; An Alliance Capability View UNU-MERIT Dissertation Series, № 71

Nora Engel

Tuberculosis in India; A Case of Innovation and Control

UNU-MERIT/MGSoG Dissertation Series, № 70

Evans Mupela

Connectivity and growth in Sub-Saharan Africa; The Role of

Communication Satellites

UNU-MERIT Dissertation Series, № 69 
Nantawan Kwanjai

Cross Cultural Intelligence amid Intricate Cultural Webs; A Tale of the UnDutchables in the Land of 1002 Smiles

UNU-MERIT Dissertation Series, № 68

Lina Sonne

Innovation in Finance to Finance Innovation; Supporting Pro-poor

Entrepreneur-based Innovation

UNU-MERIT Dissertation Series, № 67

Lenka Eisenhamerová

Legitimacy of 'Humanitarian Military Intervention'

MGSoG Dissertation Series, № 26

Sonila Tomini

Informal Payments for Health Care Services in Albania

MGSoG Dissertation Series, № 25

Jinjing Li

Dynamic Microsimulation in Public Policy Evaluation

MGSoG Dissertation Series, № 24

Aziz Atamanov

Rural Nonfarm Employment and International Migration as Alternatives to Agricultural Employment; The Case of Kyrgyzstan

MGSoG Dissertation Series, № 23

Frieda Vandeninden

Poverty Alleviation; Aid and Social Pensions

MGSoG Dissertation Series, № 22

Juliana Nyasha Tirivayi

The Welfare Effects of Integrating AIDS Treatment with Food Transfers;

Evidence from Zambia

MGSoG Dissertation Series, № 21

Agnieska Ewa Sowa

Who's Left Behind? Social Dimensions of Health Transition and Utilization of Medical Care in Poland

MGSoG Dissertation Series, № 20 
Emmanaouil Sfakianakis

The Role of Private Actors in the Provision of Public Goods with Applications to Infrastructure and Financial Stability

MGSoG Dissertation Series, № 19

Siu Hing Lo

White Collars Green Sleeves; An Inter-organizational Comparison of Determinants of Energy-Related Behaviors among Office Workers MGSoG Dissertation Series, № 18

Treena $\mathrm{Wu}$

Constraints to Human Capital Investment in Developing Countries;

Using the Asian Financial Crisis in Indonesia as a Natural Experiment

MGSoG Dissertation Series, № 17

Henry Espinoza Peña

Impact Evaluation of a Job-Training Programme for Disadvantaged

Youths;

The Case of Projoven

MGSoG Dissertation Series, № 16

2010

Fernando Santiago

Human Resources Management Practices and Learning for Innovation in Developing Countries; Pharmaceutical Firms in Mexico

UNU-MERIT Dissertation Series, № 66

Zakaria Babutsidze

Essays on Economies with Heterogeneous Interacting Consumers

UNU-MERIT Dissertation Series, № 65

Bertha Vallejo

Learning and Innovation Under Changing Market Conditions; The Auto

Parts Industry in Mexico

UNU-MERIT Dissertation Series, № 64 
Donatus Ayitey

Technical Change, Competitiveness and Poverty Reduction; A Study of the Ghanaian Apparel Industry

UNU-MERIT Dissertation Series, № 63

Sergey Filippov

Multinational Subsidiary Evolution; Corporate Change in New EU Member States

UNU-MERIT Dissertation Series, № 62

Asel Doranova

Technology Transfer and Learning under the Kyoto Regime; Exploring the Technological Impact of CDM Projects in Developing Countries

UNU-MERIT Dissertation Series, № 61

Florian Tomini

Between Family and Friend; Understanding the Interdependency of Private Transfers

MGSoG Dissertation Series, № 15

Michał Polalowski

The Institutional Transformation of Social Policy in East Central Europe;

Poland and Hungary in Comparative and Historical Perspective

MGSoG Dissertation Series, № 14

Maha Ahmed

Defining, Measuring and Addressing Vulnerability; The Case of Post

Conflict Environments

MGSoG Dissertation Series, № 13

Pascal Beckers

Local Space and Economic Success; The Role of Spatial Segregation of Migrants in the Netherlands

MGSoG Dissertation Series, № 12

Victor Cebotari

Conflicting Demands in Ethnically Diverse Societies; Ethno political Contention and Identity Values in Europe

MGSoG Dissertation Series, № 11 
Dennis Gyllensporre

Competing and Complementary Perspectives on the EU as a Crisis

Management Actor;

An Examination of the Common Security and Defence Policy through the Lenses of Idealism and Realism

MGSoG Dissertation Series, № 10

Judit Vall Castello

Business Cycle and Policy Effects on Labour Market Transitions of Older and Disabled Workers in Spain

MGSoG Dissertation Series, № 9

Keetie Roelen

False Positives or Hidden Dimensions; The Definition and Measurement of

Child Poverty

MGSoG Dissertation Series, № 8

Denisa Maria Sologon

Earning Dynamics in Europe

MGSoG Dissertation Series, № 7

Melissa Siegel

Money and Mobility; Migration and Remittances

MGSoG Dissertation Series, № 6

Jessica S. Hagen-Zanker

Modest Expectations; Causes and Effects of Migration on Migrant

Households in

Source Countries

MGSoG Dissertation Series, № 5

2009

Alexis Habiyaremye

From Primary Commodity Dependence to Diversification and Growth;

Absorptive Capacity and Technological Catch Up in Botswana and Mauritius.

UNU-MERIT Dissertation Series, № 60 
Yoseph Getachew

The Role of Public Capital in Economic Development

UNU-MERIT Dissertation Series, № 59

Sandra Leitner

Embodied Technological Change and Patterns of Investment in Austrian

Manufacturing

UNU-MERIT Dissertation Series, № 58

Semih Akçomak

The Impact of Social Capital on Economic and Social Outcomes

UNU-MERIT Dissertation Series, № 57

Abraham Garcia

The Role of Demand in Technical Change

UNU-MERIT Dissertation Series, № 56

Saurabh Arora

Coherence in Socio-technical Systems; A Network Perspective on the

Innovation Process

UNU-MERIT Dissertation Series, № 55

Mirtha R. Muniz Castillo

Human Development and Autonomy in Project Aid; Experiences from four bilateral projects in Nicaragua and El Salvador

MGSoG Dissertation Series, № 4

Christiane Arndt

Governance Indicators

MGSoG Dissertation Series, № 3

Britta Augsburg

Microfinance; Greater Good or Lesser Evil?

MGSoG Dissertation Series, № 2

2008

Rutger Daems

Medicines for the Developing World

UNU-MERIT Dissertation Series, № 54 
Johannes Hanel

Assessing Induced Technology; Sombart's Understanding of Technical

Change in the History of Economics

UNU-MERIT Dissertation Series, № 53

Rifka Weehuizen

Mental Capital; the Economic Significance of Mental Health

UNU-MERIT Dissertation Series, № 52

Danielle Cloodt

The Relationship between R\&D Partnership Formation, Social

Embeddedness and Innovative Performance

UNU-MERIT Dissertation Series, № 51

Sabine Fuss

Sustainable Energy Development under Uncertainty

UNU-MERIT Dissertation Series, № 50

Geranda Notten

Measuring and Managing Poverty Risks

MGSoG Dissertation Series, № 1

2007

Tobias Kronenberg

Reconciling Environmental Conservation with Economic Prosperity; The Feasibility of Double Dividends in the Short and Long Run

UNU-MERIT Dissertation Series, № 49

Viktoria Kravtsova

Assessing the Impact of Foreign Direct Investment in Transition

Economies

UNU-MERIT Dissertation Series, № 48

Suhail Sultan

The Competitive Advantage of Small and Medium Sized Enterprises; The Case of Jordan's Natural Stone Industry UNU-MERIT Dissertation Series, № 47 
Bulat Sanditov

Essays on Social Learning and Imitation

UNU-MERIT Dissertation Series, № 46

Mamata Parhi

Dynamics of New Technology Diffusion; A Study of the Indian Automotive Industry

UNU-MERIT Dissertation Series, № 45

Andreas Reinstaller

Social Structures and the Innovation Process; Their Role in the Demand of Firms and Consumers

UNU-MERIT Dissertation Series, № 44

Rose Kiggundu

Innovation systems and Development; The Journey of a Beleaguered Nile Perch Fishery in Uganda

UNU-MERIT Dissertation Series, № 43

Thomas Pogue

The Evolution of Research Collaboration in South African Gold Mining; 1886-1933

UNU-MERIT Dissertation Series, № 42

Geoffrey Gachino

Foreign Direct Investment, Spillovers and Innovation; The Case of Kenyan Manufacturing Industry

UNU-MERIT Dissertation Series, № 41

Önder Nomaler

Technological Change, International Trade and Growth; An Evolutionary, Multi-Agents-Based Modeling Approach

UNU-MERIT Dissertation Series, № 40 
Samia Satti Osman Mohamed-Nour

Change and Skill Development in the Arab Gulf Countries

UNU-MERIT Dissertation Series, № 39

Elad Harison

Intellectual Property Rights; Economics and Policy Analysis

UNU-MERIT Dissertation Series, № 38

Daniel Dalohoun

The Relationship between R\&D Partnership Formation, Social

Embeddedness and Innovative Performance; a Multi-level Approach of Social Embeddedness

UNU-MERIT Dissertation Series, № 37

Müge Ozman

Networks, Organizations and Knowledge

UNU-MERIT Dissertation Series, № 36

Bas Straathof

Product Variety and Economic Growth; The Counteracting Effects of Scale and Idiosyncrasy

UNU-MERIT Dissertation Series, № 35

Wilfred Schoenmakers

Knowledge Flows between Multinational Companies; A Patent Data Analysis

UNU-MERIT Dissertation Series, № 34

Myriam Cloodt

Mergers and Acquisitions (M and As) in High-Tech Industries; Measuring the Post-M and A Innovative Performance of Companies

UNU-MERIT Dissertation Series, № 33 
Paola Criscuolo

$R \& D$ Internationalisation and Knowledge Transfer; Impact on MNEs and their Home Countries

UNU-MERIT Dissertation Series, № 32

Maarten Verkerk

Trust and Power on the Shop Floor

UNU-MERIT Dissertation Series, № 31

Gottfried Leibbrandt

Adoption, Harmonization and Succession of Network Technologies across Countries

UNU-MERIT Dissertation Series, № 30

Mark Sanders

Skill Biased Technical change; Its Origins, the Interaction with the Labour Market and Policy Implications

UNU-MERIT Dissertation Series, № 29

2003

Nadine Roijakkers

Inter-firm Cooperation in High-tech Industries; a Study of R\&D

Partnerships in Pharmaceutical Biotechnology

UNU-MERIT Dissertation Series, № 28

Viki Sonntag

Speed, Scale and Sustainability

UNU-MERIT Dissertation Series, № 27

Masaru Yarime

From End-of-Pipe Technology to Clean Technology

UNU-MERIT Dissertation Series, № 26

Stéphane Malo

The Combinatorial Chemistry Revolution; Sustaining a Superior Performance Position through Technological Learning

UNU-MERIT Dissertation Series, № 25 
Annelies Hogenbirk

Determinants of Inward Foreign Direct Investment; the Case of the Netherlands

UNU-MERIT Dissertation Series, № 24

Bastiaan Johan ter Weel

The Computerization of the Labour Market

UNU-MERIT Dissertation Series

2001

John Adeoti

Technology Investment in Pollution Control in Sub-Saharan Africa; The Case of the Nigerian Manufacturing Industry

UNU-MERIT Dissertation Series, № 23

Edward Huizenga

Innovation Management; How Frontrunners Stay Ahead; An Empirical Study on Key Success Factors in the ICT sector

UNU-MERIT Dissertation Series, № 22

2000

Machiel van Dijk

Technological Change and the Dynamics of Industries; Theoretical Issues and Empirical evidence from Dutch Manufacturing

UNU-MERIT Dissertation Series, № 21

1999

Jan Cobbenhagen

Managing Innovation at the Company Level; A Study on Non-Sector-

Specific Success Factors

UNU-MERIT Dissertation Series, № 20

Marjolein Caniëls

Regional Growth Differentials; The Impact of Locally Bounded Knowledge Spillovers

UNU-MERIT Dissertation Series, № 19 
Aldo Geuna

Resource Allocation and Knowledge production; Studies in the Economics of University Research

UNU-MERIT Dissertation Series, № 18

1996

Reinoud Joosten

Dynamics, Equilibria, and Values

UNU-MERIT Dissertation Series, № 17

Hugo Kruiniger

Investment, $R \& D$, and the Financing Decisions of the Firm

UNU-MERIT Dissertation Series, № 16

1995

Hans van Meijl

Endogenous Technological Change; The Case of Information Technology, Theoretical Considerations and Empirical Results

UNU-MERIT Dissertation Series, № 15

René Kemp

Environmental Policy and Technical Change; A Comparison of the

Technological Impact of Policy Instruments

UNU-MERIT Dissertation Series, № 14

Rohini Acharya

The Impact of New Technologies on Economic Growth and Trade; A Case Study of Biotechnology

UNU-MERIT Dissertation Series, № 13

Geert Duysters

The Evolution of Complex Industrial Systems; The Dynamics of Major IT Sectors

UNU-MERIT Dissertation Series, № 12 


\section{Marjan Groen}

Technology, Work and Organisation; A Study of the Nursing Process in Intensive Care Units

UNU-MERIT Dissertation Series, № 11

1994

Huub Meijers

On the Diffusion of Technologies in a Vintage Framework; Theoretical Considerations and Empirical Results

UNU-MERIT Dissertation Series, № 10

Theon van Dijk

The Limits of Patent Protection; Essays on the Economics of Intellectual Property Rights

UNU-MERIT Dissertation Series, № 9

Hans Voordijk

Naar Integrale Logistiek in Bedrijfsketens; Ontwikkelingen in de Bouw UNU-MERIT Dissertation Series, № 8

1993

Paul Diederen

Technological Progress in Enterprises and Diffusion of Innovation;.

Theoretical Reflections and Empirical Evidence

UNU-MERIT Dissertation Series, № 7

Ben Dankbaar

Economic Crisis and Institutional Change; The Crisis of Fordism from the Perspective of the Automobile Industry

UNU-MERIT Dissertation Series, № 6

Hanno Roberts

Accountability and Responsibility; The Influence of Organisation Design on Management Accounting

UNU-MERIT Dissertation Series, № 5 
Bart Verspagen

Uneven Growth Between Interdependent Economies; An Evolutionary View on Technology Gaps, Trade and Growth

UNU-MERIT Dissertation Series, № 4

Sjoerd Romme

A Self-organization Perspective on Strategy Formation

UNU-MERIT Dissertation Series, № 3

1989

John Spangenberg

Economies of Scale, and Atmosphere in Research Organisations

UNU-MERIT Dissertation Series, № 2

1988

John Hagedoorn

Evolutionary and Heterodox Innovation Analysis; A Study of Industrial and Technological Development in Process Control and Information Technology

UNU-MERIT Dissertation Series, № 1 